\title{
CONCRETE ISLAND: \\ Lost Sites and Hidden Heritage
}

\author{
BY
}

ZACKARY JOHNSON

\author{
A 120-point thesis \\ submitted to the Victoria University of Wellington \\ in partial fulfilment of the requirements for the \\ degree of Master of Architecture (Professional)
}

Victoria University of Wellington

School of Architecture 


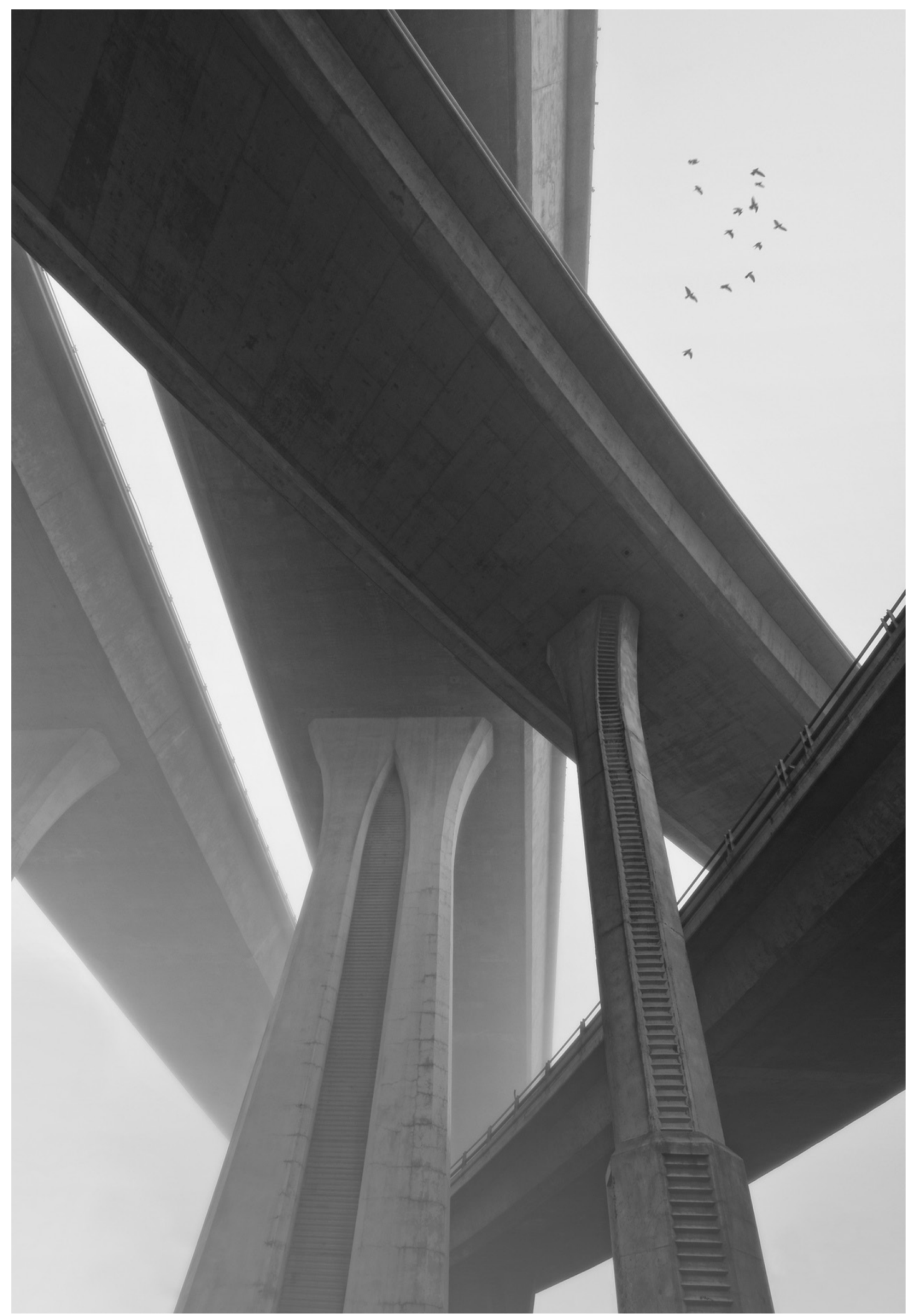

Figure 0.1: The elevated motorway typology found in many large cities. 


\section{|| Abstract}

In cities like Auckland, suburban sprawl has led to the introduction of extensive elevated motorways that create barriers and cuts across the ordering elements of the city. Urban planner Roger Trancik refers to the areas beneath and adjacent to these urban motorways as "lost sites", considered 'unbuildable' even though they occur within the central business district. This research investigation looks at how architecture can help return a sense of place identity and cultural significance to otherwise placeless zones defined by elevated urban motorways.

The central Auckland site for this designled research is the Central Motorway Junction (CMJ), commonly referred to as 'spaghetti junction' - a site physically and environmentally inappropriate for housing development, but large and high profile enough to contribute significantly to Auckland's 'cultural hub'.

The proposed programme for this investigation is a new facility to house Museum of New Zealand Te Papa Tongarewa's stored collections. Arguably New Zealand's most valuable cultural holdings, only $3 \%$ of Te Papa Tongarewa's collections are on display at any time. The rest of the museum's stored collections are completely hidden from public view within its back of house facilities and warehouse structures in Wellington.
Due to Wellington's location on major fault lines, studies are underway to permanently move the stored collections to Auckland, where they will remain removed from the public eye. This design-led research investigation proposes that once these collections are relocated to Auckland, if they are made visually accessible to the public, they could provide a vital extension of the cultural hub for the city centre.

The investigation proposes to architecturally inhabit one of Auckland's most prominent lost sites, the Central Motorway Junction, in a way that celebrates its iconic elevated motorway as a viable urban context capable of actively contributing to urban re-vitalisation and cultural consolidation.

The thesis investigation examines the city's motorway infrastructure as a framework for a new typology for architecture that actively uses the 'motorway typology' to establish architectural and place identity. Simultaneously the investigation explores how expansive elevated motorway sites can provide significant footprints for new public buildings to enhance the cultural identity of the urban centre. 
66

"In his aching head the concrete overpass and the system of motorways in which he was marooned had begun to assume an ever more threatening size. The illuminated route indicators rotated above his head, marked with meaningless destinations." The man looks for "some circuitous route through the labyrinth of motorways"

- but finds none.

He simply sees "vast, empty parking lots laid down by the planners years before any tourist would arrive to park their cars, like a city abandoned in advance of itself." Indeed, [the main character of the novel] is "alone in this forgotten world whose furthest shores were defined only by the roar of automobile engines... an alien planet abandoned by its inhabitants, a race of motorway builders who had long since vanished but had bequeathed to him this concrete wilderness."

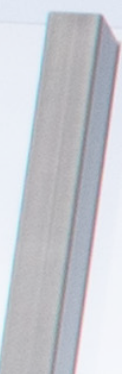




\section{|| Preface}

The title of this thesis is taken from the short novel Concrete Island (1974), the second installment of existentialist English author J. G. Ballard's Urban Disaster Trilogy. In the novel, the main character is an architect, and "concrete island" refers to an inaccessible urban site trapped between three elevated motorways, where the architect is marooned after an auto accident.

Pere Gallardo-Torrano, in his article "From Mindscapes to Landscapes: J.G. Ballard's Self-sought Utopia in Concrete Island", argues that the motorway trapped site in the novel is allegorical: "Originally meant to be a geographical reference, the island soon acquires a psychological dimension, becomes a personified element in the story, and begins to act as [the main character's] interlocutor. ... Ever since the moment of the accident, [the main character] sees his body and conscience as separate elements" (22).
According to Gallardo-Torrano, "The working hypothesis is that, as Ballard's novel seems to suggest, there is no real difference between inner and outer territories when it comes to creating a utopian landscape. As a matter of fact, as is the case with Concrete Island, both spaces tend to overlap" (16). This thesis argues that such urban motorway sites can be interpreted as heterotopias. French philosopher Michel Foucault describes heterotopias as places that are 'neither here nor there', counter-sites, sites that invert and contest what would be traditionally considered 'real place' (Foucault, 3-4).

To Gallardo-Torrano, Ballard's concrete island represents "a chance to start afresh" (20). This design-led research investigation looks at how the "concrete islands" created by Auckland's elevated motorway might also be given "a chance to start afresh". 
Figure 0.2 (previous): A concrete barrier condition in the Central Auckland motorway site. 


\section{|| Acknowledgements}

This thesis could not be completed without giving special thanks to the following people:

To Daniel K. Brown, for your dedicated supervision and the passion you have had in helping my project along. I have learnt a lot from you this year that I will carry with me into my professional career.

To Muddo for providing all the necessary distractions when I needed mental breaks from university, constantly supporting me, and helping me knuckle down when I needed to.

To my grandparents, aunties, uncles, and all the cuzzies who have both directly and indirectly helped me get to this point.

To my close friends and to my flatmates at 289a, you guys have made this year super chill and a hell of a lot of fun.

To all the archi-nerds that I have shared studios with. Our tight-nit year group with our mutual love (and at times despair) towards architecture and post-hand-in BYOs has made the last half decade more than bearable.

And most importantly to Mum, Dad and Neesh for the endless stream of care packages filled with home baked goodies and the constant and unwavering support you have provided me since 1993. None of this could have ever happened without you. 


\section{|| Table of Contents}

Abstract iii

Preface iv

Acknowledgements vii

Chapter One:

$\begin{array}{ll}\text { Introduction } & \mathbf{1} \\ \text { Problem Statement } & 3 \\ \text { Principal Research Question } & 3 \\ \text { Research Proposition } & 4 \\ \text { Research Aims } & 4 \\ \text { Research Objectives } & 5 \\ \text { Methodology and Processes } & 6 \\ \text { Research Scope } & 8 \\ \text { Thesis Structure } & 9\end{array}$

Chapter Two:

Context Analysis

11

Introduction 13

Lost Site 18

Site Dynamics 20

City Heritage 28

Site Engagement $\quad 35$

Conclusions $\quad 47$

Chapter Three:

Programme Analysis $\quad 49$

Introduction 51

Hidden Heritage 54

Curatorial Opportunities $\quad 62$

Beyond Stored Objects $\quad 74$

Conclusions
Chapter Four:

Literature + Project Review $\mathbf{8 5}$

Introduction 87

Lost Site 90

Place and Cultural Identity $\quad 91$

Embracing Heritage 93

Monumentality 100

Didactic Design 104

Heterotopia 107

Conclusions 111

Chapter Five:

\section{Conceptual +}

Preliminary Design $\quad 113$

Introduction 115

Conceptual Design $\quad 116$

Preliminary Design 134

Preliminary Design Solution 146

Critical Reflection $\quad 160$

Chapter Six:

Developed Design 163

Introduction 165

Embracing Heritage $\quad 166$

Pedestrian Access $\quad 172$

Linking Space $\quad 174$

Structure 178

Interior Space $\quad 180$

Facades 184

Developed Outcome $\quad 198$

Critical Reflection 225

Chapter Seven:

Conclusion 229

Critical Reflection 230

Limitations of the Findings $\quad 230$

Conclusions Drawn 231

Going Forward 231

Bibliography 235

Sources of Figures 240 



\section{1 | Introduction}

\section{[ Problem Statement ]}

Auckland City's defining urban infrastructure - its complex motorway system - is often regarded as a negative component of the city framework. Urban dwellers typically view an elevated urban motorway like the Auckland Central Motorway Junction (figure 1.1) as an eyesore and a detriment to the urban character. This thesis looks at how an 'architecture of the motorway' can establish these 'unbuildable' sites as exemplary of the urban context, rather than as divisive barriers in the city fabric.

This issue is not specific to Auckland alone. All across the world massive amounts of valuable inner city space are lost due to infrastructure that carves through the urban fabric, creating urban barriers and placeless sites detrimental to an integrated and uninterrupted urban fabric (see figure 1.2).

The unfortunate reality of these sites is that they create harsh environmental conditions above and adjacent to them making the possibilities for their re-use severely limited. The nature of the Auckland Motorway Junction makes it inappropriate for housing, despite the city's desperate need for housing space. This creates the unfortunate situation of having a huge amount of inner city space but limited architectural programme capable of successfully inhabiting it.
In considering a potential programme that might successfully inhabit such a site, this investigation sought important new civic structures that require very large footprints, but where no space in the central city is available. The National Museum of Te Papa Tongarewa in Wellington has an extensive archive collection that is rapidly running out of storage space. Only $3 \%$ of the collection is ever able to be displayed, the remaining $97 \%$ being stored out of public view (Dominion Post). Boxed away in warehouse facilities, this hidden national heritage has immense potential to develop New Zealanders' cultural and historic awareness if it become visible to the public.

\section{[ Principal Research Question ]}

How can a public architectural intervention be effectively integrated with an elevated inner city motorway to help provide new buildable sites for large public structures, while enhancing the motorway's permeability, reinforcing its motorway identity, and enabling the motorway to be appreciated as a positive heritage element for cities like Auckland? 


\section{[ Research Proposition ]}

This design research investigation proposes that - through architectural design - the Auckland motorway can be viewed as iconic to the city, and celebrated in that capacity through design. It proposes that architectural design can reclaim lost urban sites, such as extensive elevated inner city motorways, in ways that encourage uninterrupted urban flow, rather than acting as divisive barriers. And, it proposes that this can be achieved by incorporating large-scale public buildings onto these large motorway sites, in ways that can contribute actively to a city's identity.

The proposed programme for this investigation is the collected stores of The Museum of New Zealand Te Papa Tongarewa, which the government is currently planning to move permanently to Auckland due to Wellington's high earthquake risks (Macdonald "Te Papa taonga on the move north"). This investigation proposes that by relocating the stored collection to Auckland, New Zealand's hidden heritage artefacts can be returned to the public realm, where they can contribute productively to the city's cultural infrastructure.

\section{[ Research Aims ]}

The principal Research Aims of this thesis investigation are:

- Lost Sites: to use architectural design to reclaim lost urban sites, such as extensive elevated inner city motorways, in ways that diversify the utilitarian nature of the motorway, mitigate the barrier-like nature of the motorway, and contribute to the enhancement of the cultural identity of a city;

- Hidden Heritage: to use architectural design to reclaim lost urban heritage, such as permanently stored national archives, in ways that return them to the public realm so they can contribute productively to a city's cultural infrastructure. 


\section{[ Research Objectives ]}

The principal Research Objectives are:

\section{[ Lost Sites ]}

\section{R01:}

to diversify the utilitarian nature of the elevated inner city motorway by incorporating a suitable architectural programme capable of productively engaging with the monumentality of such a site;

\section{R02:}

to reduce the 'urban barrier' characteristics of an inner city motorway by enhancing its permeability, incorporating green space, and establishing place identity; and to utilise these elements to shift the site from dystopian to heterotopian;

\section{R03:}

to embrace and celebrate the 'motorway typology' by establishing an architectural intervention that embraces the iconic nature of the elevated motorway, rather than trying to hide it.

\section{[ Hidden Heritage ]}

R04:

to enhance engagement with stored national heritage artefacts by placing them into the public realm to encourage public engagement in diverse ways;

\section{RO5:}

to 'curate' stored national heritage artefacts in ways that maximise the didactic potential of the archive collection and increase cultural awareness about these items for the general public;

\section{R06:}

to explore the 'non-archived' elements of the city and the site's 'hidden heritage', inviting these alternative elements of heritage to also actively contribute to cultural and place identity. 


\section{[ METHODOLOGY AND PROCESSES ]}

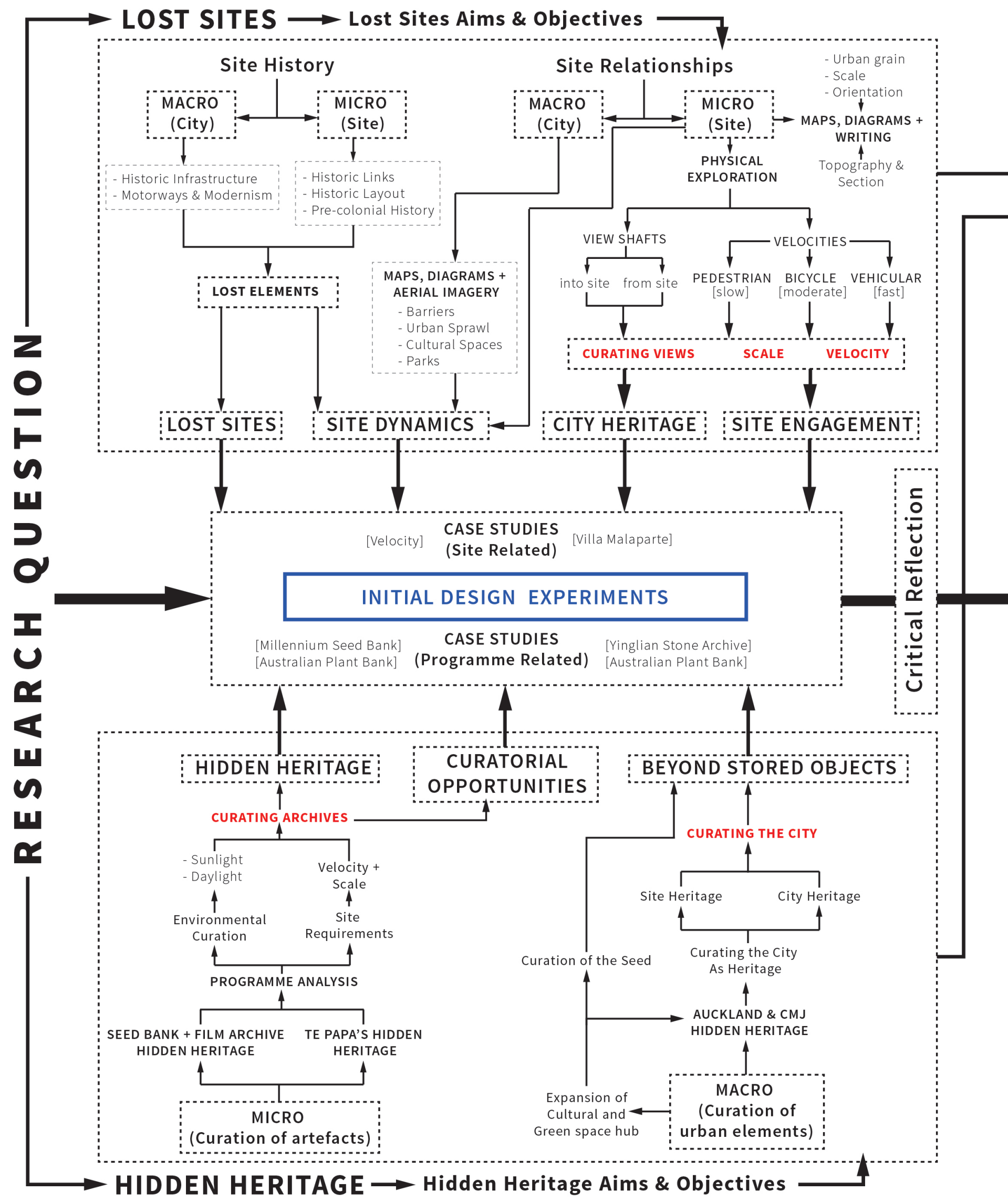




\section{LITERATURE + PROJECT REVIEW}
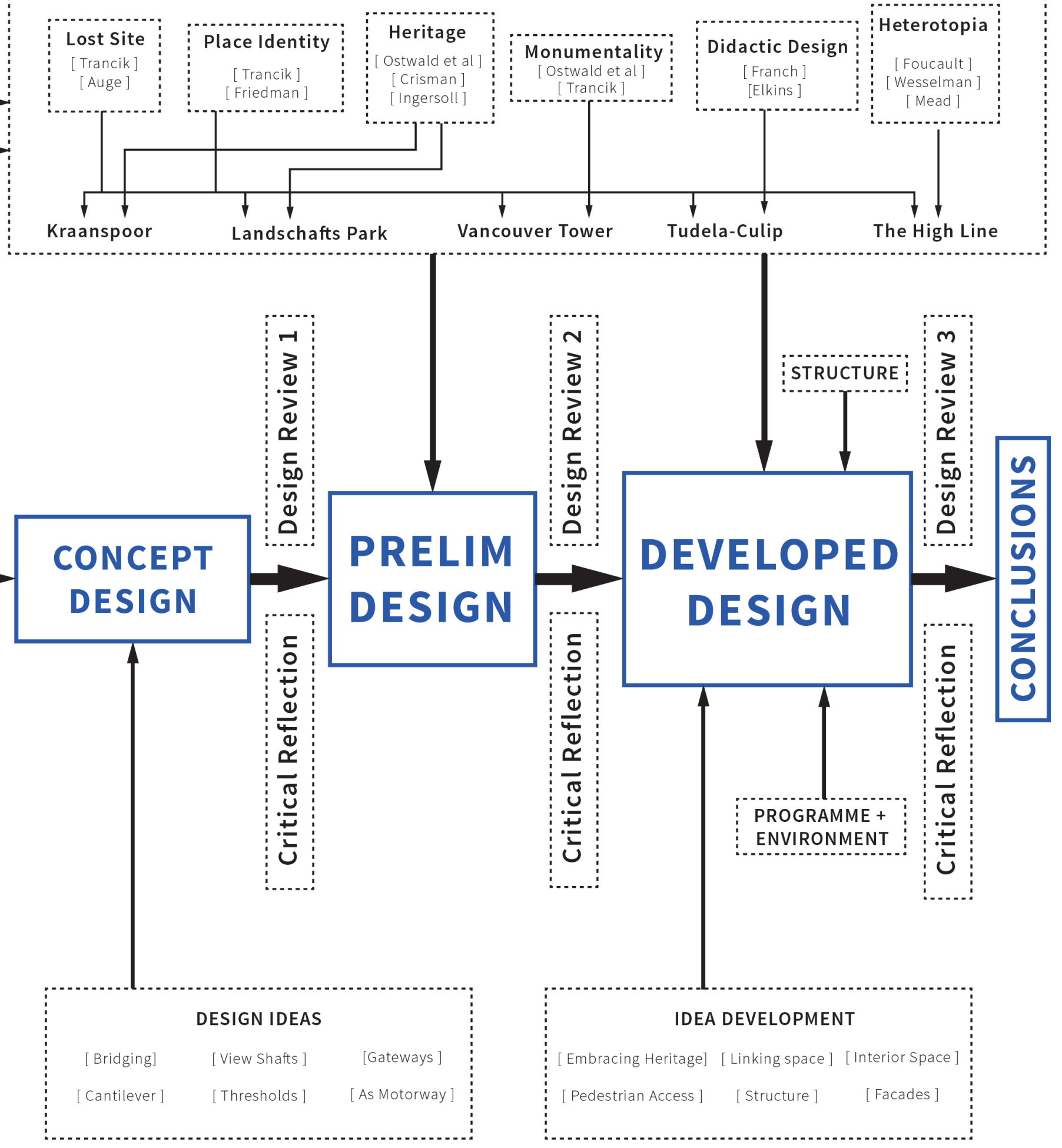

Figure 1.3: Thesis methodology diagram. 


\section{[ Methodology and Processes ]}

The overarching research question for this thesis is tackled through two related sets of aims and objectives. The first set relates to the site issues of the central motorway junction, the second to the programme issues of the Te Papa Archives.

The research methodology began by exploring issues around site and programme independent from each other to clearly establish the individual opportunities in each. As research continued, specific themes arose including elements such as history and dynamics, scale and velocity, and curation. It was at this point that research deriving from both site and programme analyses was integrated in the form of initial design sketch experiments and ideas.

Concept Design began by focusing on formal elements of the architecture and was heavily derived from relationship opportunities with the CMJ site. Preliminary design followed and was influenced by theory and project reviews with a particular focus around achieving research objectives of increasing permeability, embracing historic heritage, and incorporating motorway heritage.

Developed design explored elements of programme in greater detail with a focus on objectives around the curation of 'hidden heritage'.

At each design phase critical reflection occurred in response to the design experiments and associated critique from design reviews, with final critical reflection coming at the end of developed design.

\section{[ Research Scope ]}

A new facility in Auckland is currently being considered by the government to house the Te Papa archives. The total area requirement for this facility will be approximately 20,000 sqm. Due to the large scale of the building the research development in this thesis investigation predominantly focuses on establishing the important relationships of public and private spaces.

Detailed requirements for the more refined logistical elements such as the programme components of research and staff facilities, environmental and building systems, functional loading and movement systems are all acknowledged in the thesis design, but their detailed design is outside the scope of the investigation.

A structural engineer was consulted to ensure the overall structural concept was sound, but a detailed structural analysis is also outside the scope of the project. Costing, construction phasing, and architectural detailing also fall outside of the scope of research due to the scale of the project. 


\section{[ Thesis Structure ]}

\section{Chapter One: Introduction}

This chapter establishes the research question, proposition, the two aims relating to 'lost site' and 'hidden heritage' and their respective research objectives.

\section{Chapter Two: Context Analysis}

The context analysis chapter primarily explores research aims and objectives around the context as a 'lost site'. It looks at issues of the motorway as an urban barrier, its utilitarian nature, and current typologies of use. Context analysis also researches objectives of 'hidden heritage' through investigation of the historic heritage of the site and heritage of the surrounding city.

\section{Chapter Three: Programme Analysis}

The programme analysis chapter primarily explores research aims and objectives around the Te Papa archives programme as 'hidden heritage'. First the issues of public engagement are discussed and archives collections themselves are explored for their didactic potential. The research then continues with how the 'hidden heritage' could be better integrated into the public realm. Finally alternative elements of 'hidden heritage' are explored along with potential programmes that could contribute to cultural awareness and identity in the city.

\section{Chapter Four: Literature + Project Review}

The first section of the literature and project review explores theories relating to 'lost site' and place identity to establish the issues around the CMJ site. It follows with theorists and project reviews on topics related to 'hidden heritage' and 'lost site': embracing heritage, engaging with the monumentality of lost sites, maximising the didactic potential of architecture, and establishing heterotopia from dystopia.

\section{Chapter Five: Conceptual + Preliminary Design}

Conceptual design starts with simple moves that aim to increase permeability on site and explore some of the 'non-archived' elements of heritage. Moving into preliminary design, aspects of theory significantly influence decisions particularly around resolving objectives such as increasing permeability, engaging with monumental scale, and embracing the motorway typology. Preliminary design concludes with critique, critical reflection, and analysis before moving into the developed design phase.

\section{Chapter Six: Developed Design}

Developed design focuses in greater detail on the 'hidden heritage' research objectives whilst refining elements of the 'lost site' objectives. The final section analyses and critically reflects on the developed outcome in terms of all six principal research objectives.

\section{Chapter Seven: Conclusions}

This chapter discusses what was learned through the design-led research, conclusions that have been drawn, constraints of the research, and where further research could lead. 


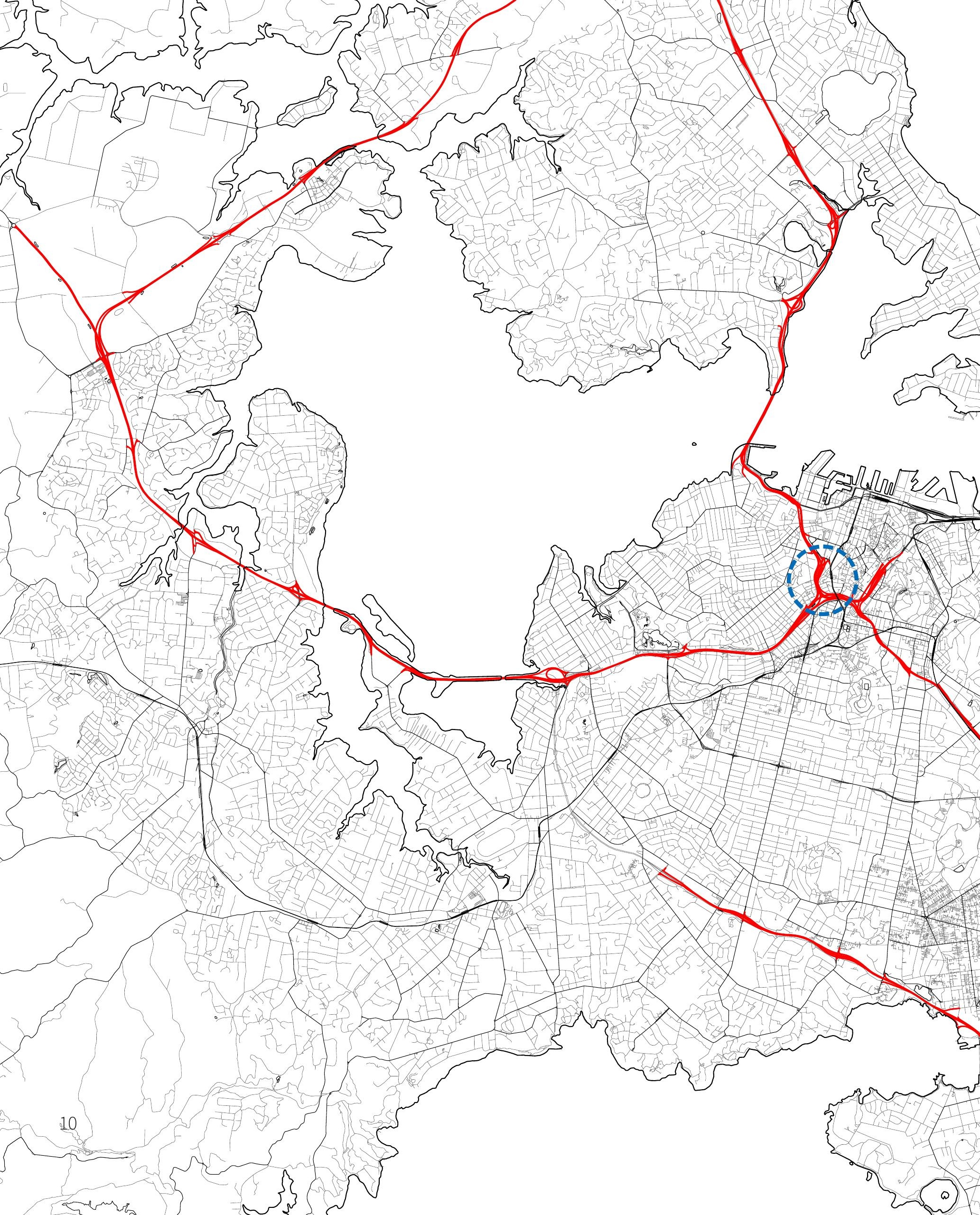



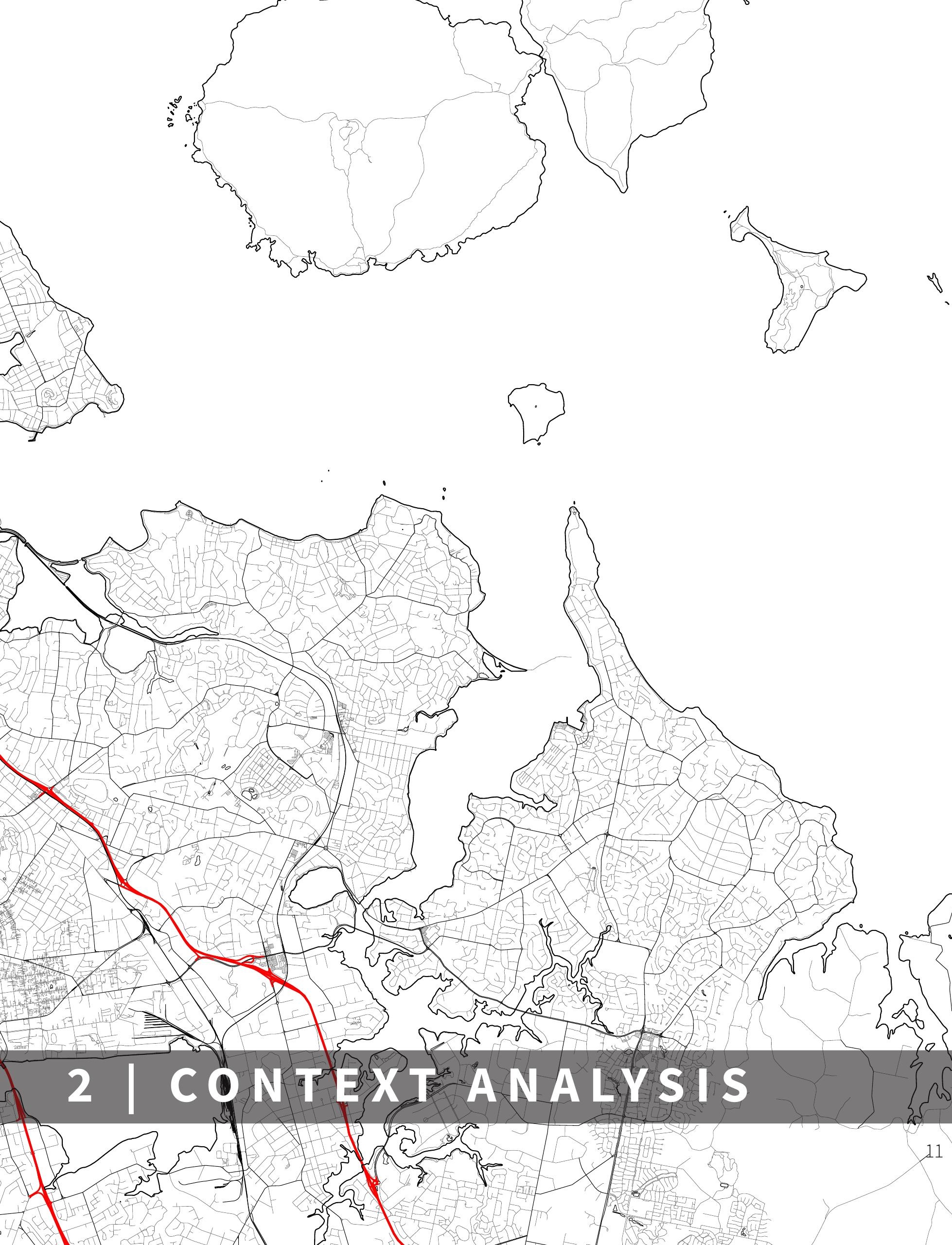


\section{6 \\ A transplanted observer might wonder about the cause, and wisdom, of so many vacant building sections and the appetite of the motorway that has eviscerated both large amounts of the lush gully and entire neighbourhoods of plain, neat, little cottages.}

- Terence Hodgson, 110

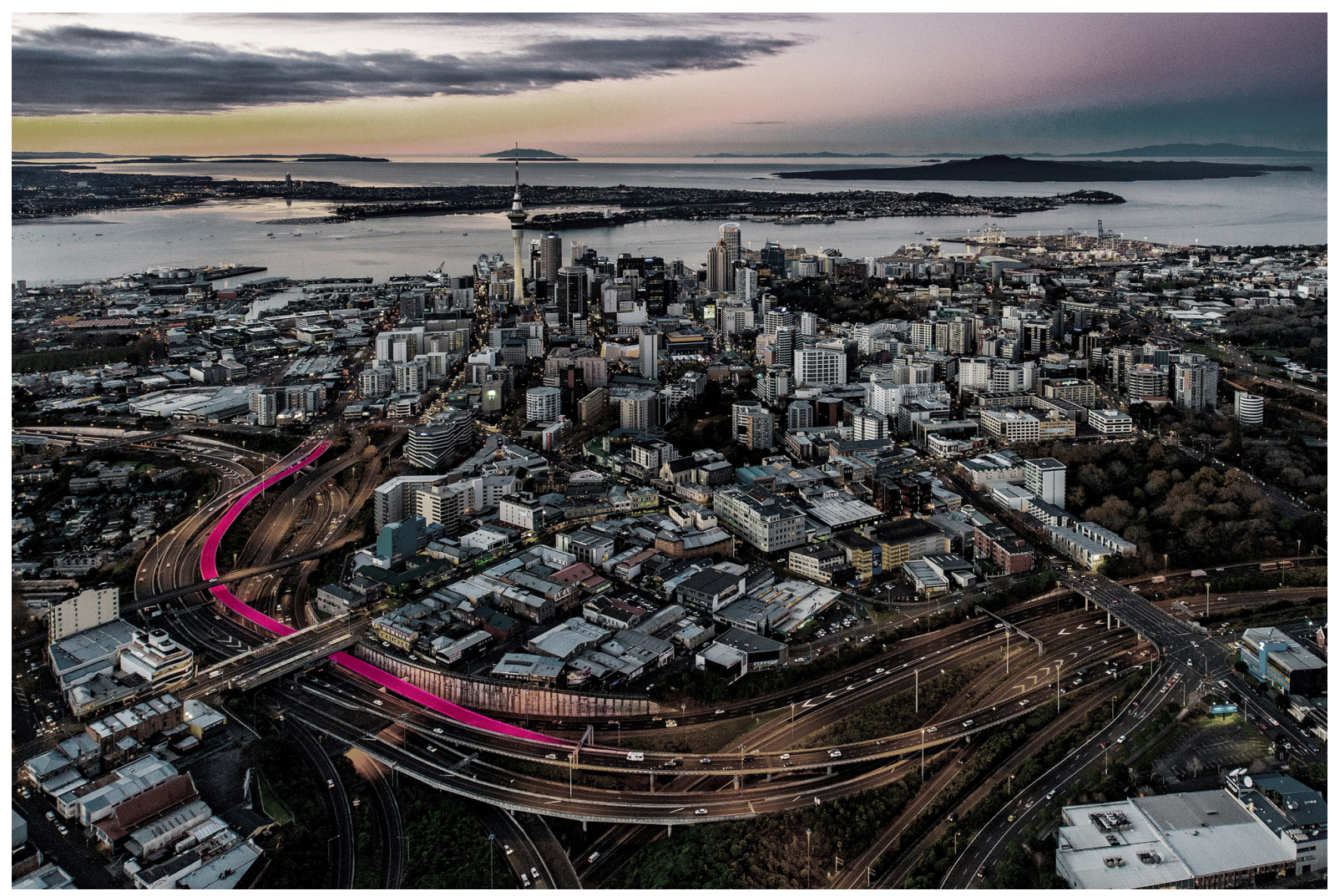

Figure 2.1 (previous): Auckland city with its motorway systems marked in red and the research site circled. Figure 2.2 (above): The central motorway junction and Auckland's pink bicycle lane wrapping around the southern end of the city CBD. 


\section{2 | Context Analysis}

This chapter primarily focuses on the research objectives pertaining to 'Lost Site' (RO1 - RO3).

The chapter also explores opportunities for addressing the 'Hidden Heritage' Research Objectives regarding the 'non-archived' elements of city and site.

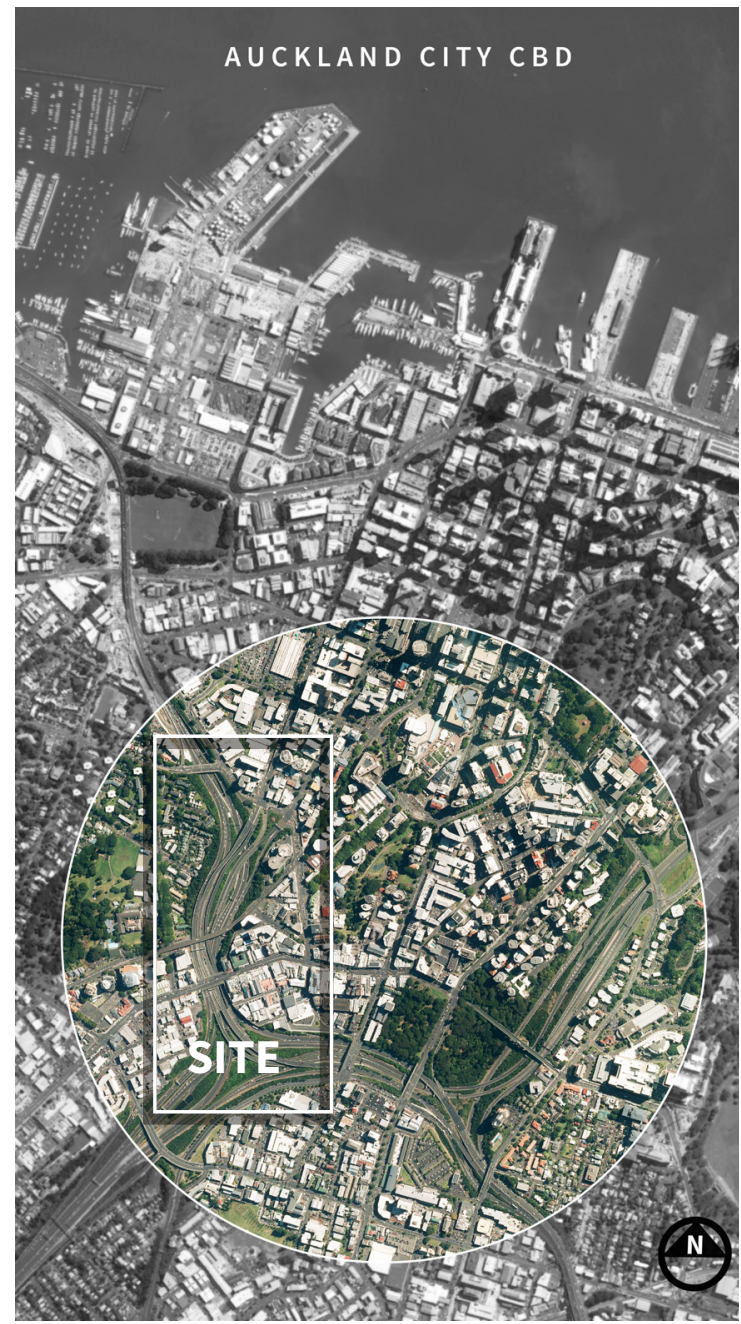

\section{\{ Lost Site ]}

The first section of the chapter explores the historic heritage of the site in combination with understanding the layout and permeability of the original gully (RO2 and $\mathrm{RO} 6$ ).

\section{[ Site Dynamics ]}

Following on from the historic layout of the CMJ, further research explores the current conditions and layout of the site, the urban dynamics of the city around it, and how the CMJ has become a barrier condition. Analysis will explore the best site available for the architecture to provide increased diversity and permeability (RO1 and RO2).

\section{[ City Heritage ]}

Once site selection has been completed the opportunities to engage with the wider elements of the city's heritage are explored (RO6).

\section{[ Site Engagement ]}

The final section of the chapter investigates the current interactions that occur through the CMJ. The typology of the motorway is explored in terms of velocity and scale as well as where opportunities may lie to diversify its utilitarian nature (RO1 and $\mathrm{RO} 2$ ).

Figure 2.3: 2011 Aerial view of the Central Motorway Junction, the CBD, and its surrounding suburbs. This part of the Auckland motorway has been selected as it is sited adjacent to a variety of diverse urban conditions: the dense CBD, suburban housing, urban park space, and low rise commercial and shopping areas. 

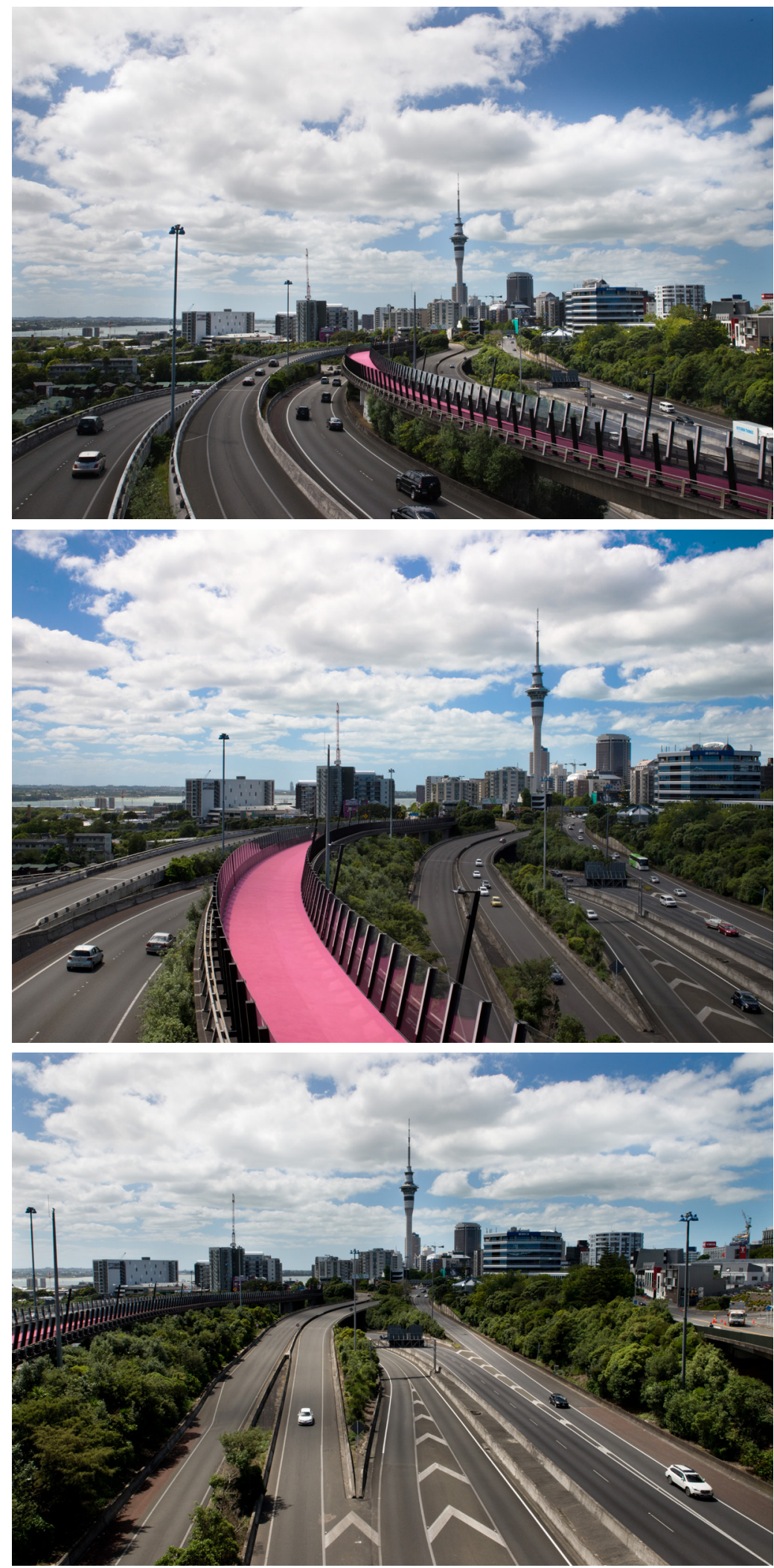

Figure 2.4: Northern views walking across the Hopetoun Bridge over Newton Gully exemplify the vast barrier the motorway creates between the western suburbs and the CBD. 



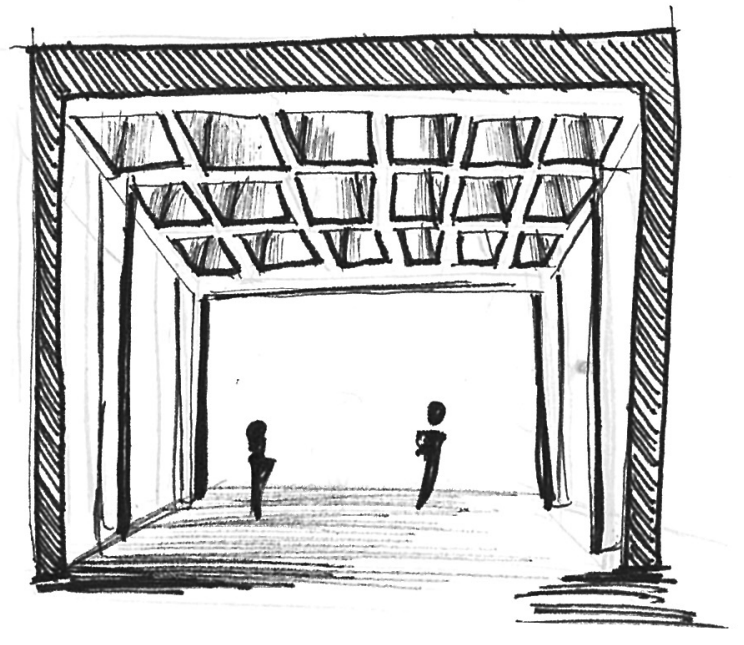

USING MOTORWAY
STRUCTURE TYPOLOMY
IN THE ARCHITECTURE? 


\section{[ LOST SITES ]}

The natural landscape of Auckland in the early mid-19th century was one of ridges and gullies. For many decades parts of the city were too steep to build housing on, so they remained as forested green pockets throughout the urban environment.

One of these green pockets was Newton Gully. Sitting between the edge of the CBD and its periphery western suburbs, the streets of Wellington, Hayden, and Beresford linked across the gully directly into the heart of the city.

The addition of the motorways and the development of the road infrastructure in the mid-20th century saw these original links either adjusted or completely eradicated.

Design Proposition: A design research intervention that can reestablish these links across the CMJ will contribute in a variety of ways to the city, not only increasing the permeability of the divisive motorway infrastructure, but also by using architectural elements to create an allegorical archive of Auckland City's historic layout before the motorway carved out the urban form as we know it today.

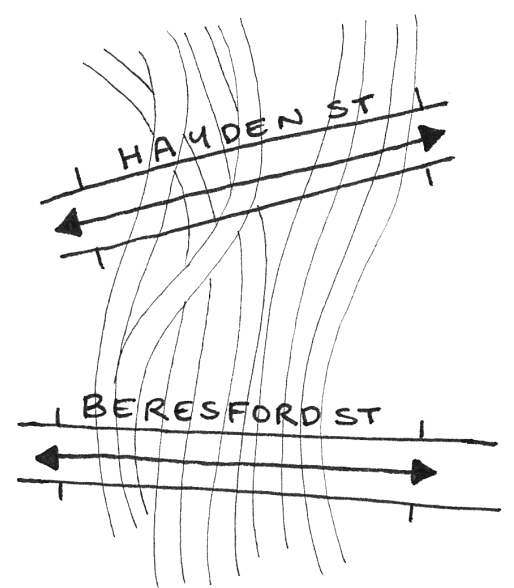

Figure 2.8: Reestablishing lost urban links through design.

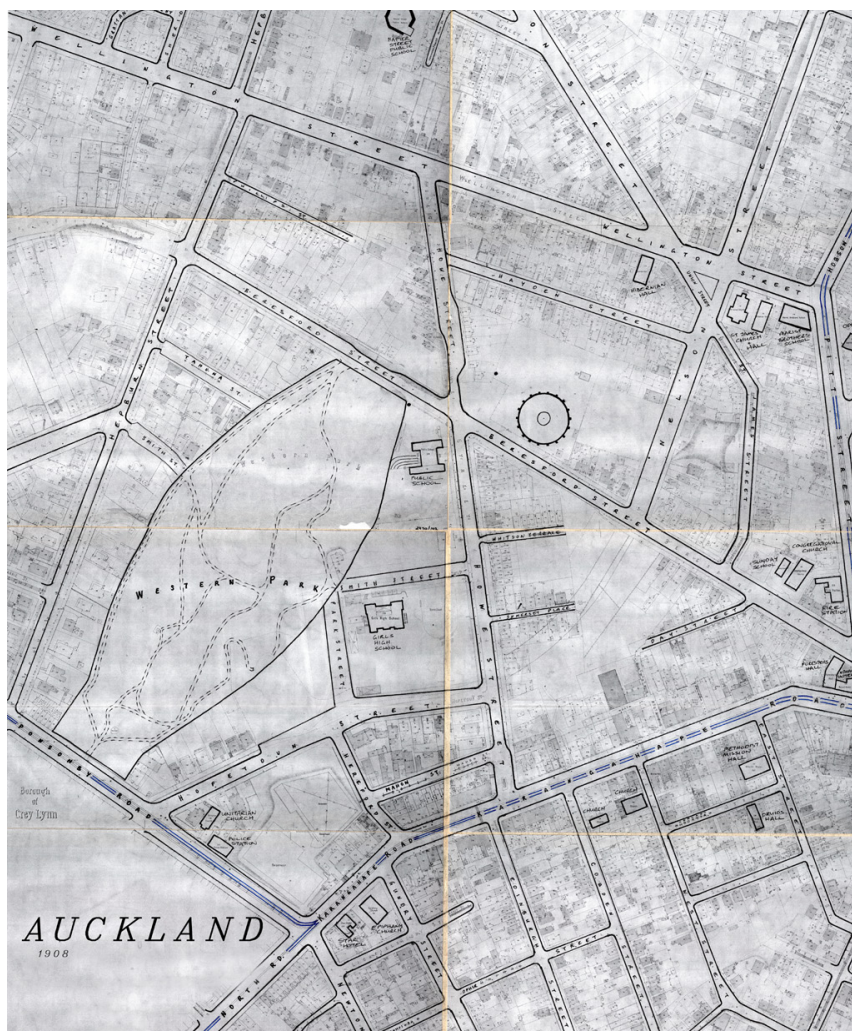

Figure 2.9: Auckland City 1908

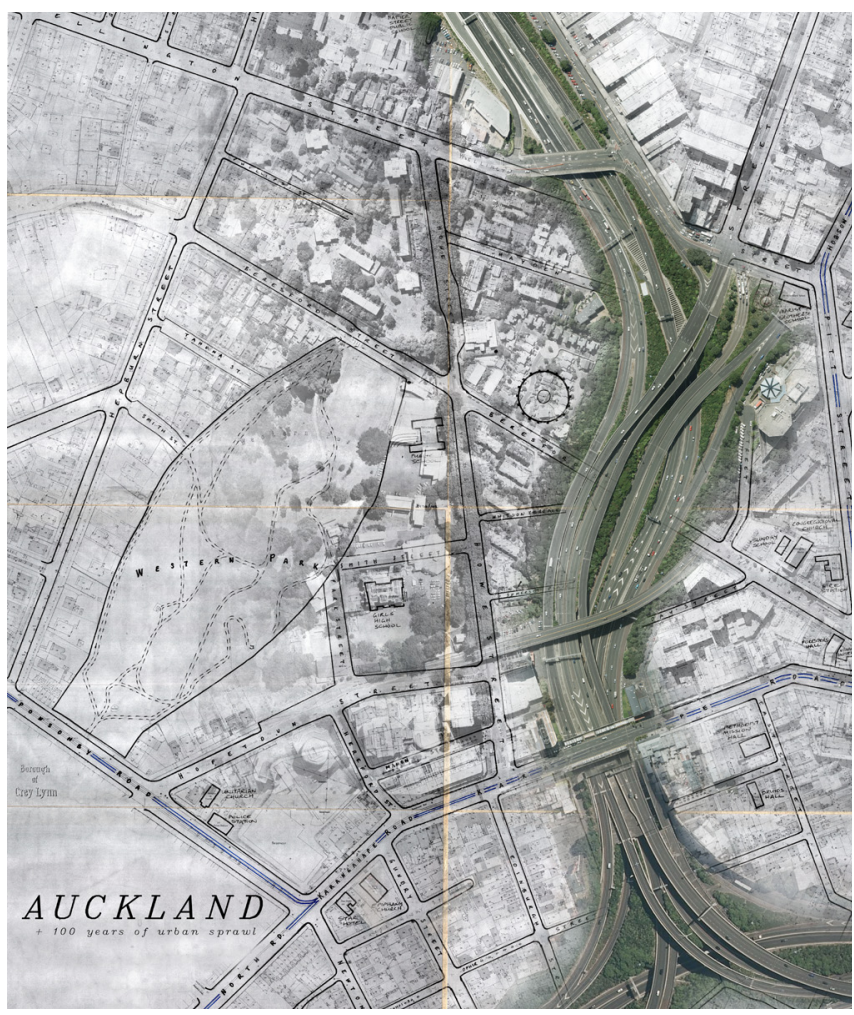

Figure 2.10: How Newton Gully has changed with $100+$ years of growth 


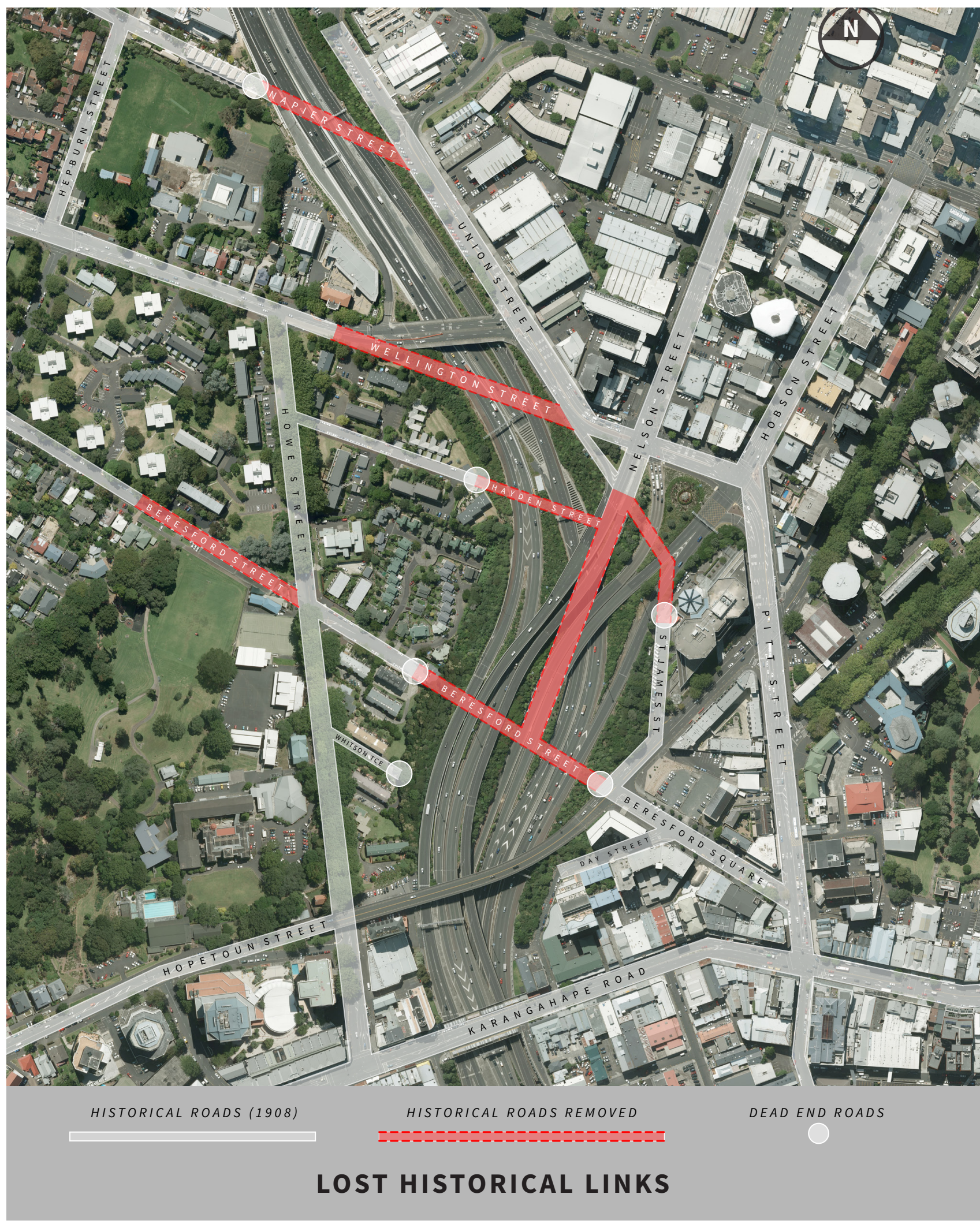

Figure 2.11: Lost historical links of the site caused by the introduction of the CMJ. 


\section{[ SITE DYNAMICS ]}

Looking at a broader urban scale, there are several defining features that have determined the layout of the CBD and its surrounds:

\section{- The Harbour}

Particularly in the northwest area of Auckland's CBD, there is a strong grid layout that is aligned perpendicular and parallel to the waterfront.

\section{- $\quad$ Ridges and Gullys + Infrastructure}

In the early years of Auckland City the CBD had a similar ' $U$ ' belt defining its boundaries. However, this belt was originally one of green space rather than concrete. The CMJ now acts as an unforgiving urban barrier for the southern part of the city.

\section{- Parks and Squares}

The ordered grid of the city breaks apart on the eastern side of the CBD. Town squares and inner city green spaces cause the logical grid infrastructure to twist and curve.

The design research intervention can use these broader site dynamics as formal drivers for how to address the CMJ site and increase its coherence and permeability in the urban environment.

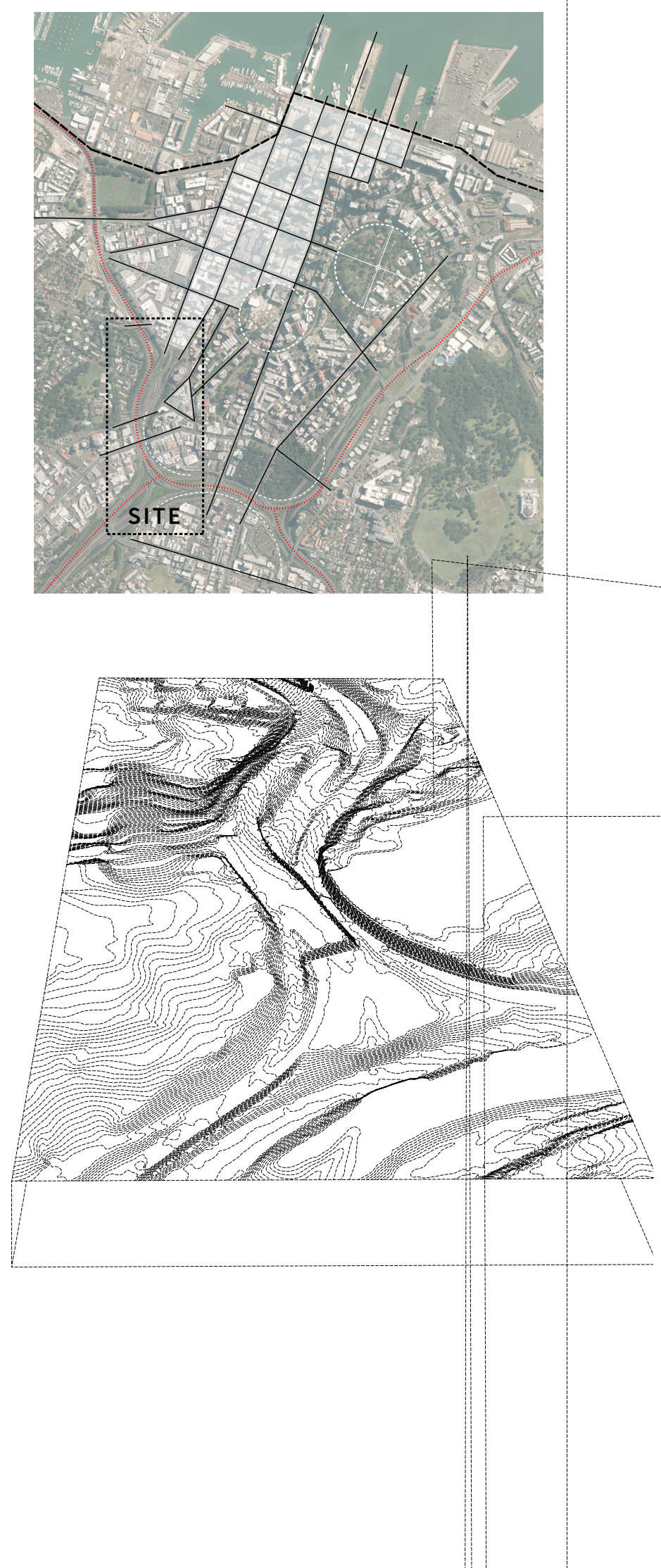


(1) waterfront + harbour (industrial \& recreational)

(2) dense CBD with orthogonal layout in relation to the waterfont

(3) triangulated shift in city layout in relation to the waterfront and gully

(4) Grafton Gully, Grafton Bridge \& the Gully Cemetery

(5) the suburb of Newton now segregated by a semi-circle of motorways
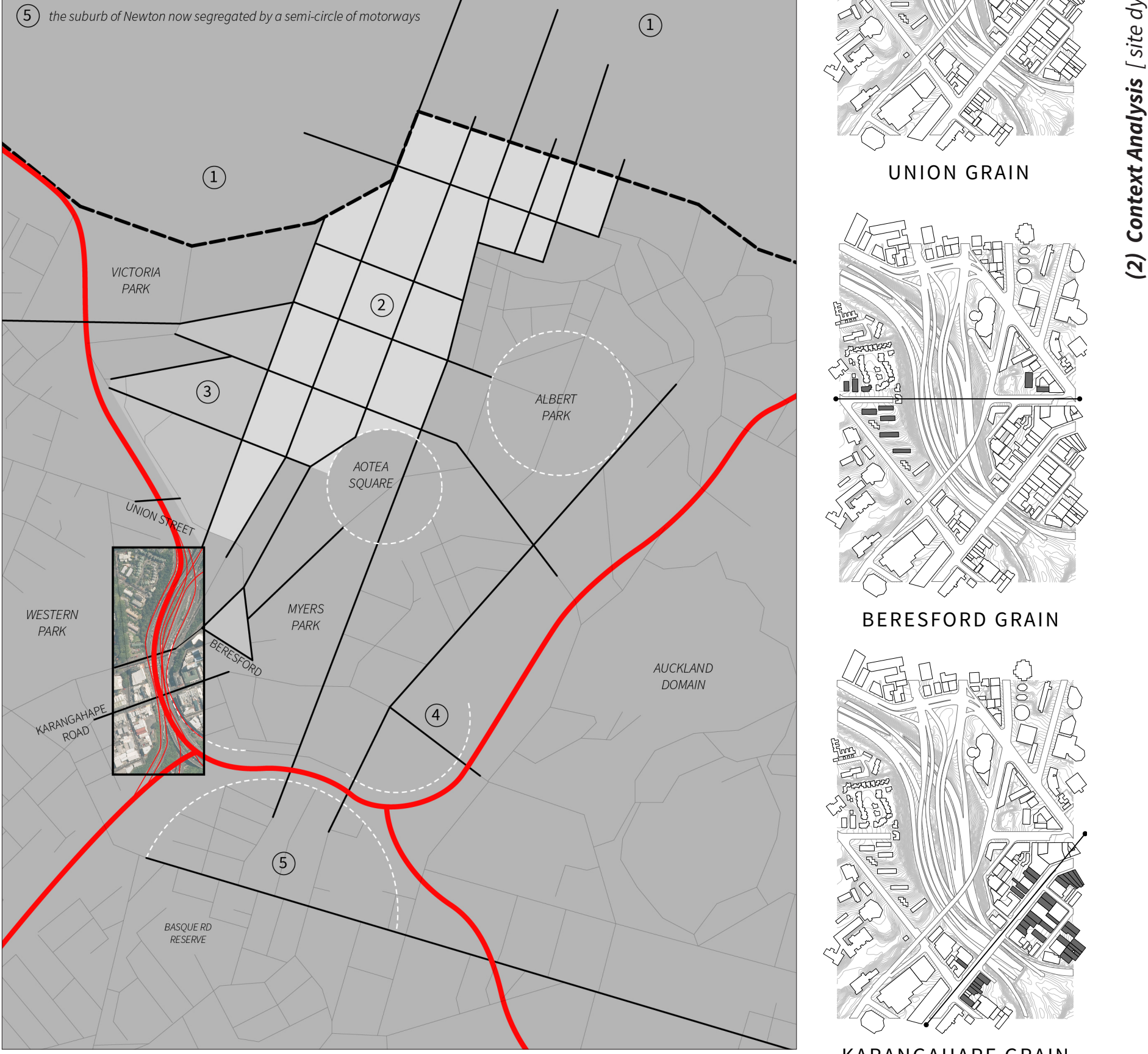

BERESFORD GRAIN

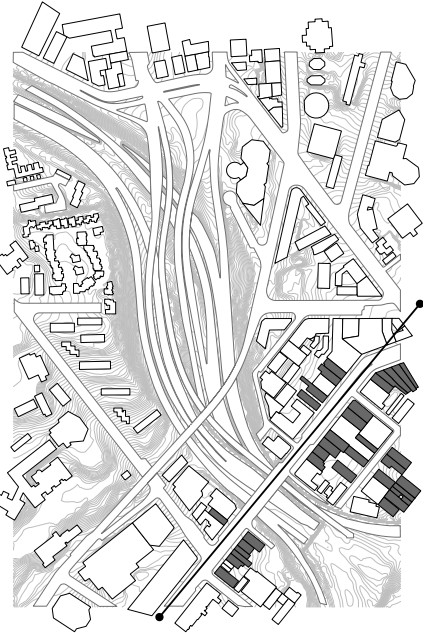

KARANGAHAPE GRAIN

Figure 2.14 (left): Looking at the site as a place where three different dynamic typologies collide - the motorway, the urban grid, and the suburban grid.

Figure 2.15 (right): Analysing the existing grains and layouts around the site. 


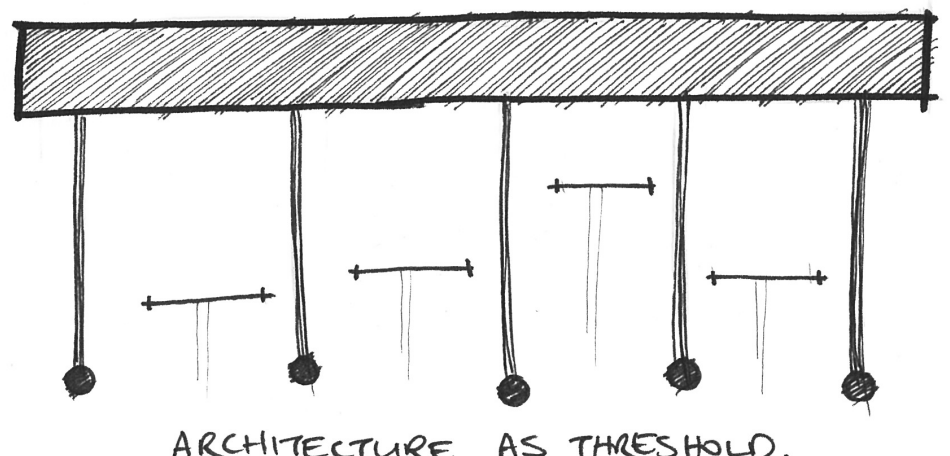

ARCHITECTURE AS THRESHOLD.

Figure 2.17 (right): Sectional analysis through motorway site, showing allegorical 'gateway' opportunities. 
章
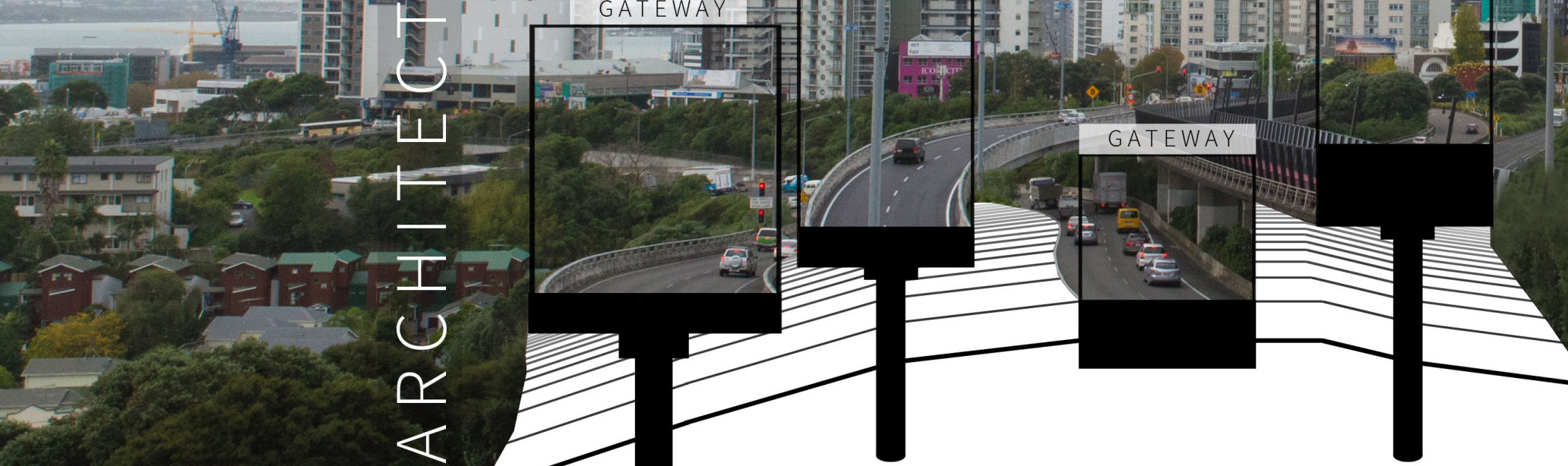


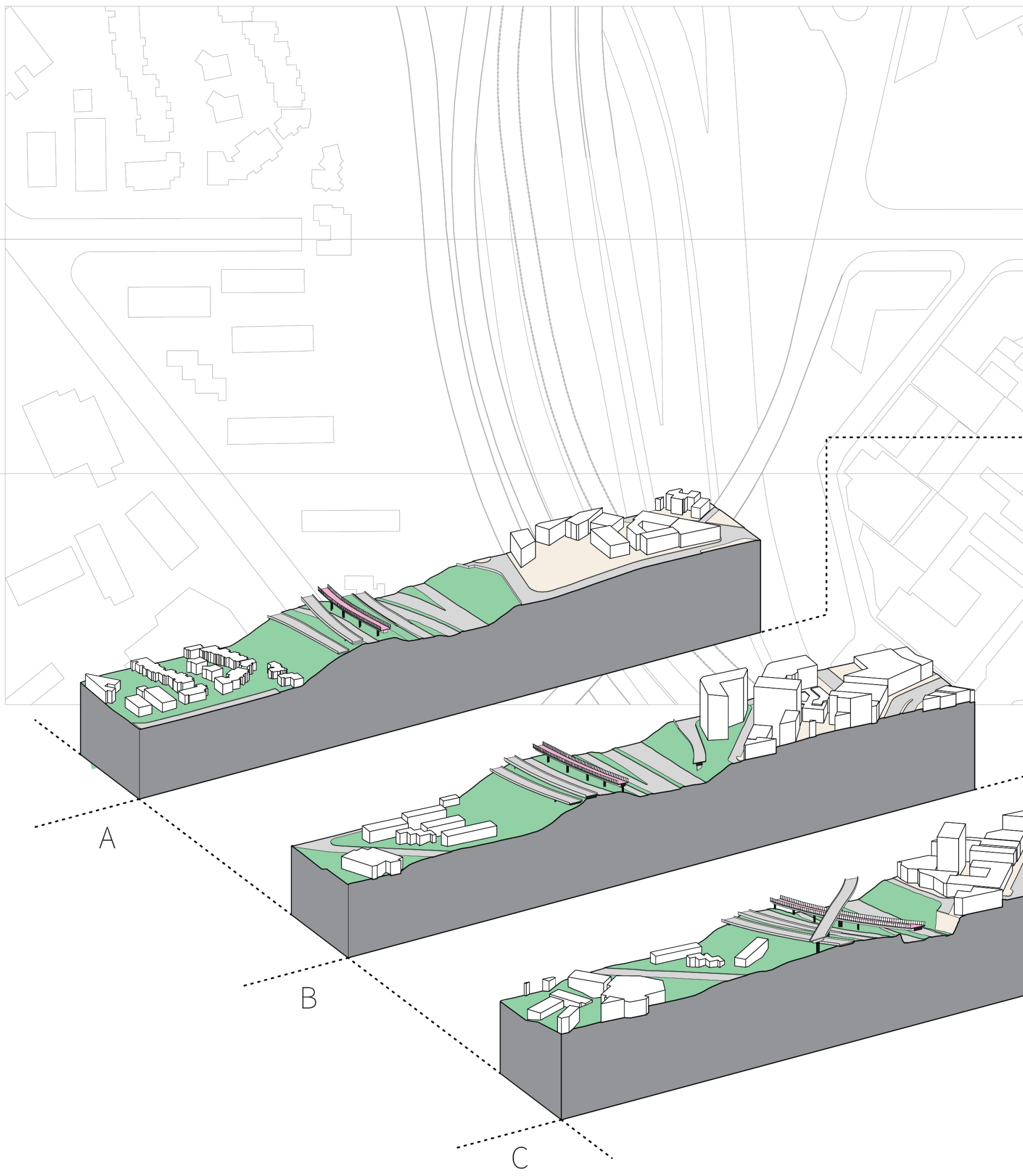

Figure 2.18: Investigating the implications of sectional site dynamics. 


\section{DYNAMICS OF SITE AND SITE SELECTION}

Preliminary sketch experiments by author to determine the most appropriate site for increasing permeability of $\mathrm{CMJ}$ and engaging with its monumental nature.
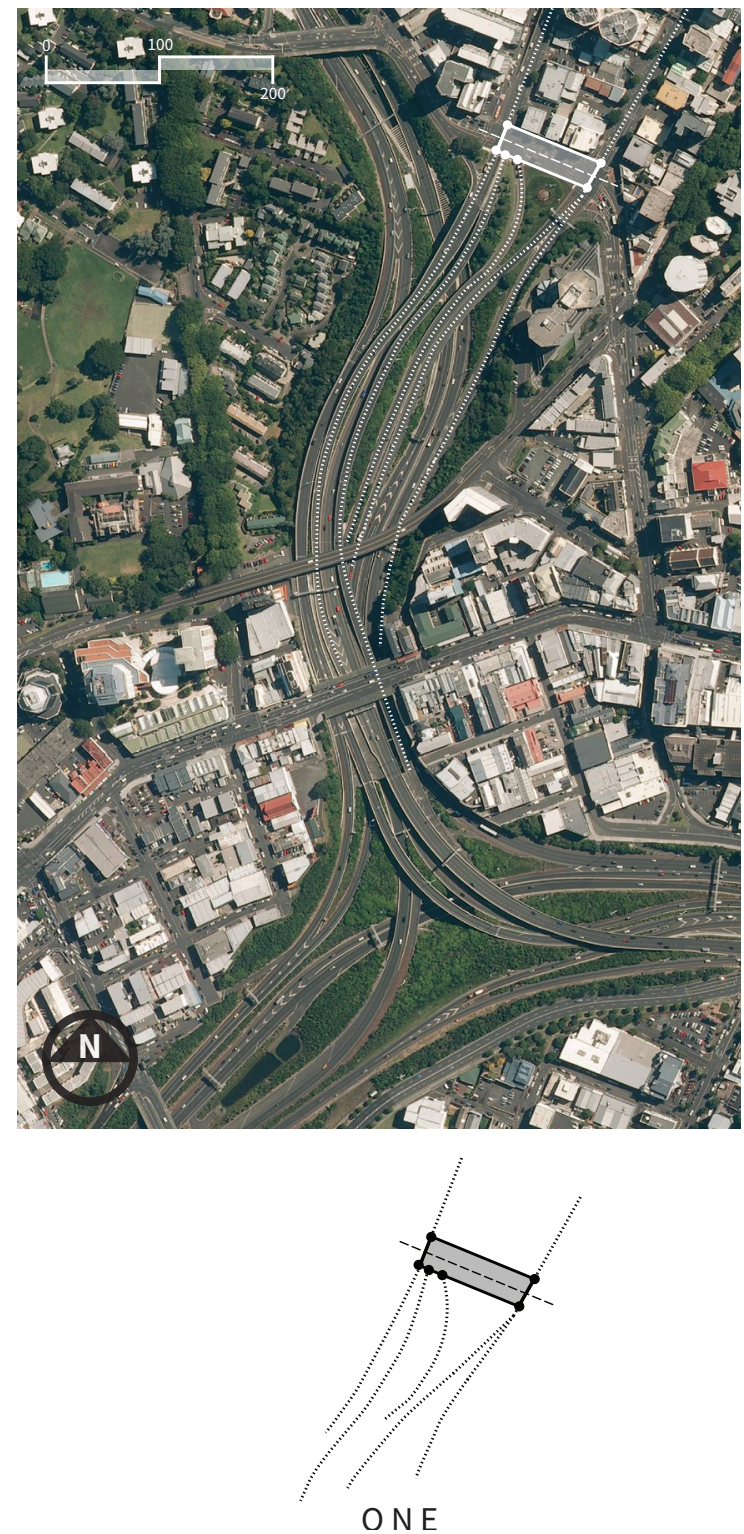

the PINCH

Experiment One looks at siting the design research intervention at one of the 'pinch' points where several of the motorways terminate or originate. This is a gateway area into the CBD for large numbers of motorists and provides opportunity for the architecture to be a major threshold.
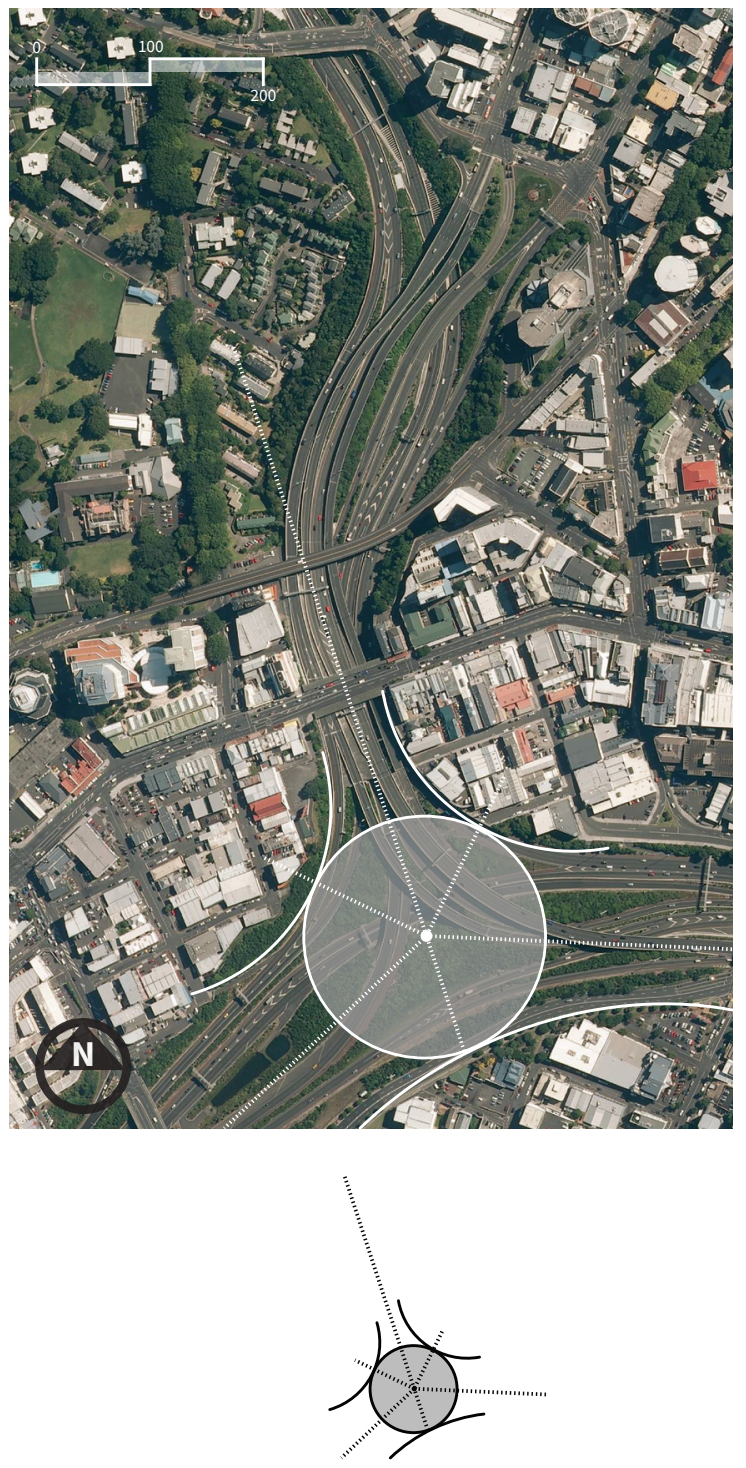

TWO

the PIVOT

Experiment Two looks at siting a new intervention in the most expansive portion of the motorway on the western side of the CMJ. An intervention here could act as a pivot between the monumental triangular division the CMJ has created. 


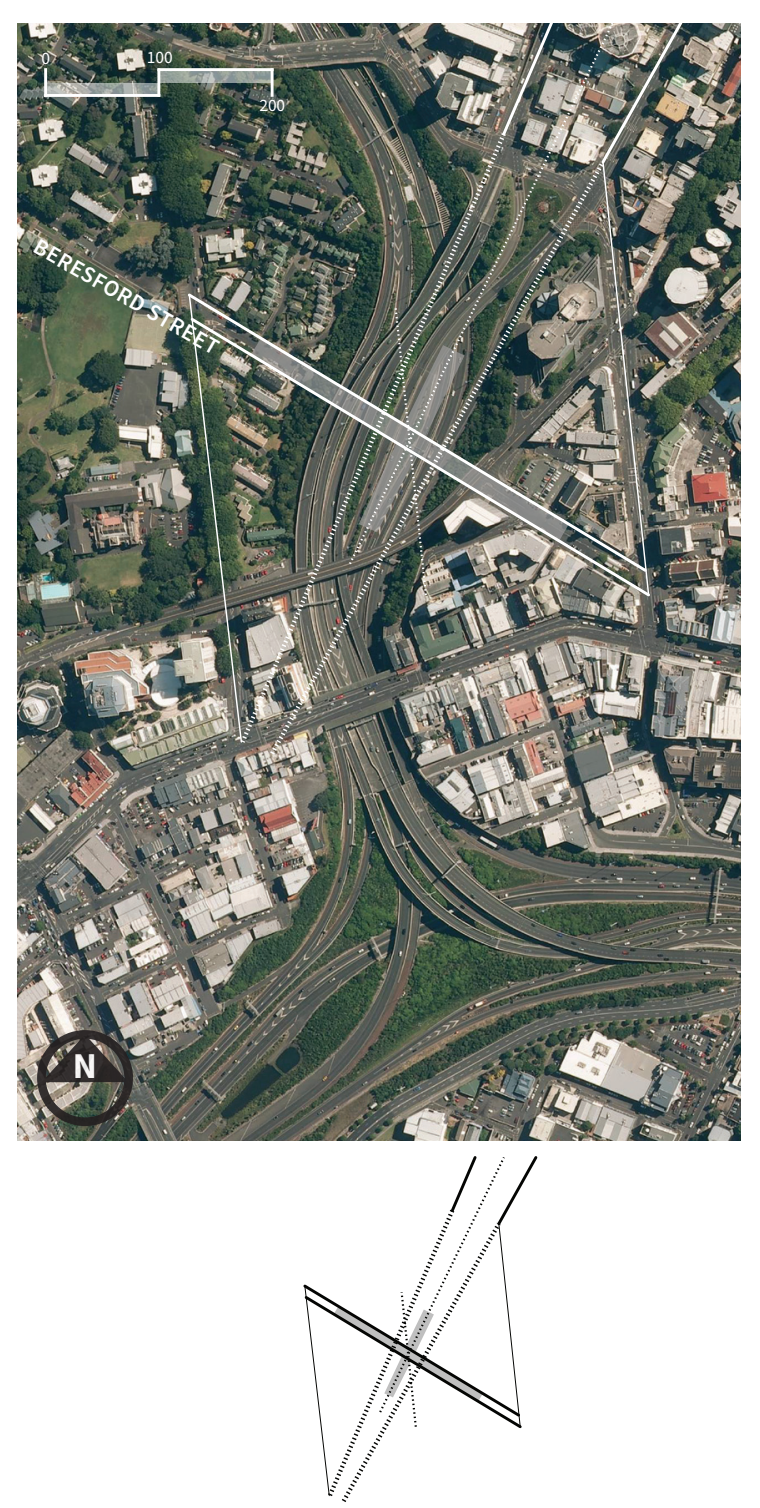

THREE

the AXIS*

Experiment Three looks at siting the design research intervention at the intersection point created by the historic Beresford Street in the W-E direction and the main axis of the CBD in the N-S direction.
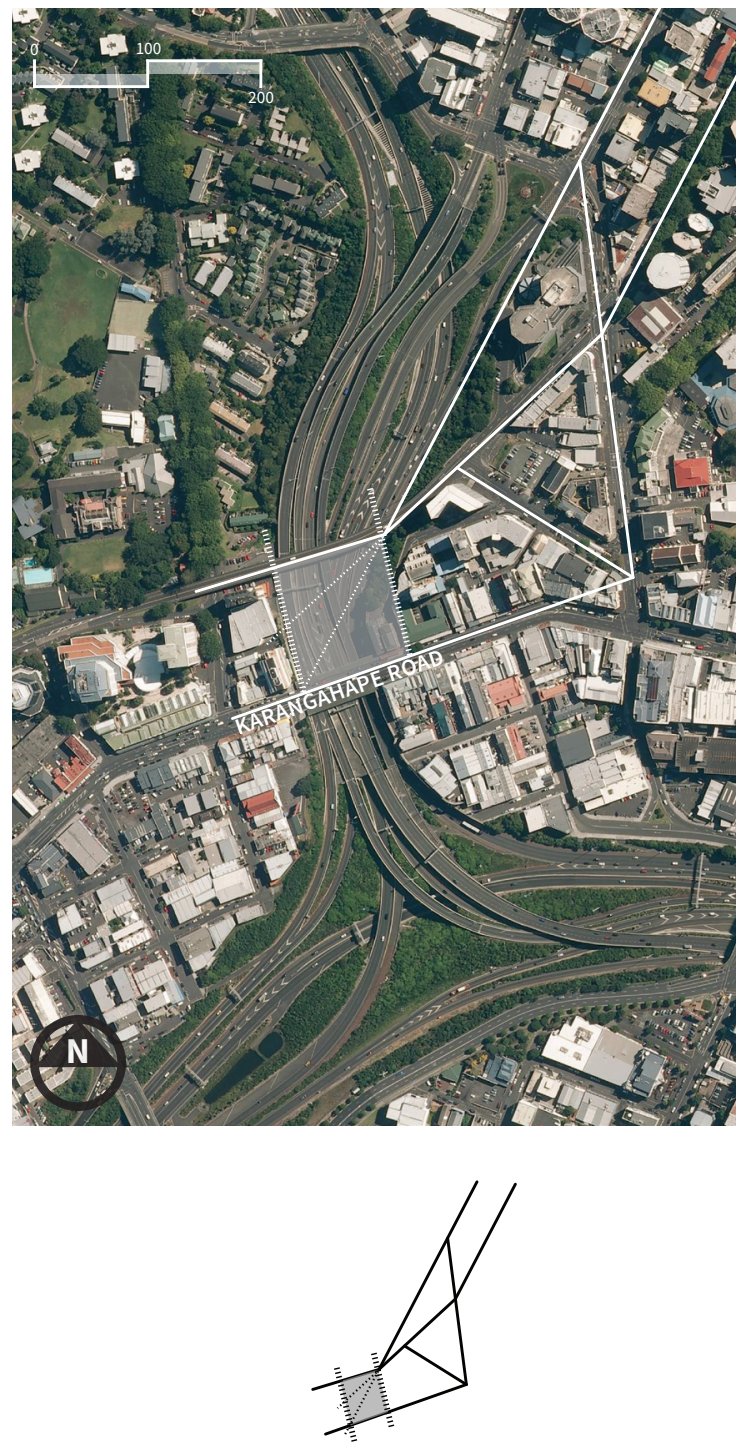

F O UR

the PATCH *

Experiment Four looks at siting the intervention in relation to non-vehicular (ie, pedestrians and cyclists) forms of transport across the CMJ. It has opportunities to respond to the layout and grain along Karangahape Road.

* A combination of the 'axis' and the 'patch' provides the best opportunity to achieve objectives regarding 


\section{[ CITY HERITAGE ]}

Research objective six explores opportunities for the 'non-archived' elements, the hidden heritage of the CMJ and the city itself, to contribute actively to cultural and place identity. An essential element of this heritage is the history of the city itself.

The figure on the right shows critical elements of urban Auckland that have defined the city. By framing these within the design, the architecture can effectively archive the heritage of the city through articulated views that subtley document its history, urban growth, and development in the years to come.

\section{6}

Framing devices become literal and metaphorical ways for the public viewer to see what surrounds him or her. It is as if the artist were giving eyeglasses to the public to help them comprehend their environment, to slow down and appreciate what already exists

- Zapatka and Miss, 26

Figure 2.20: Curating view shafts.

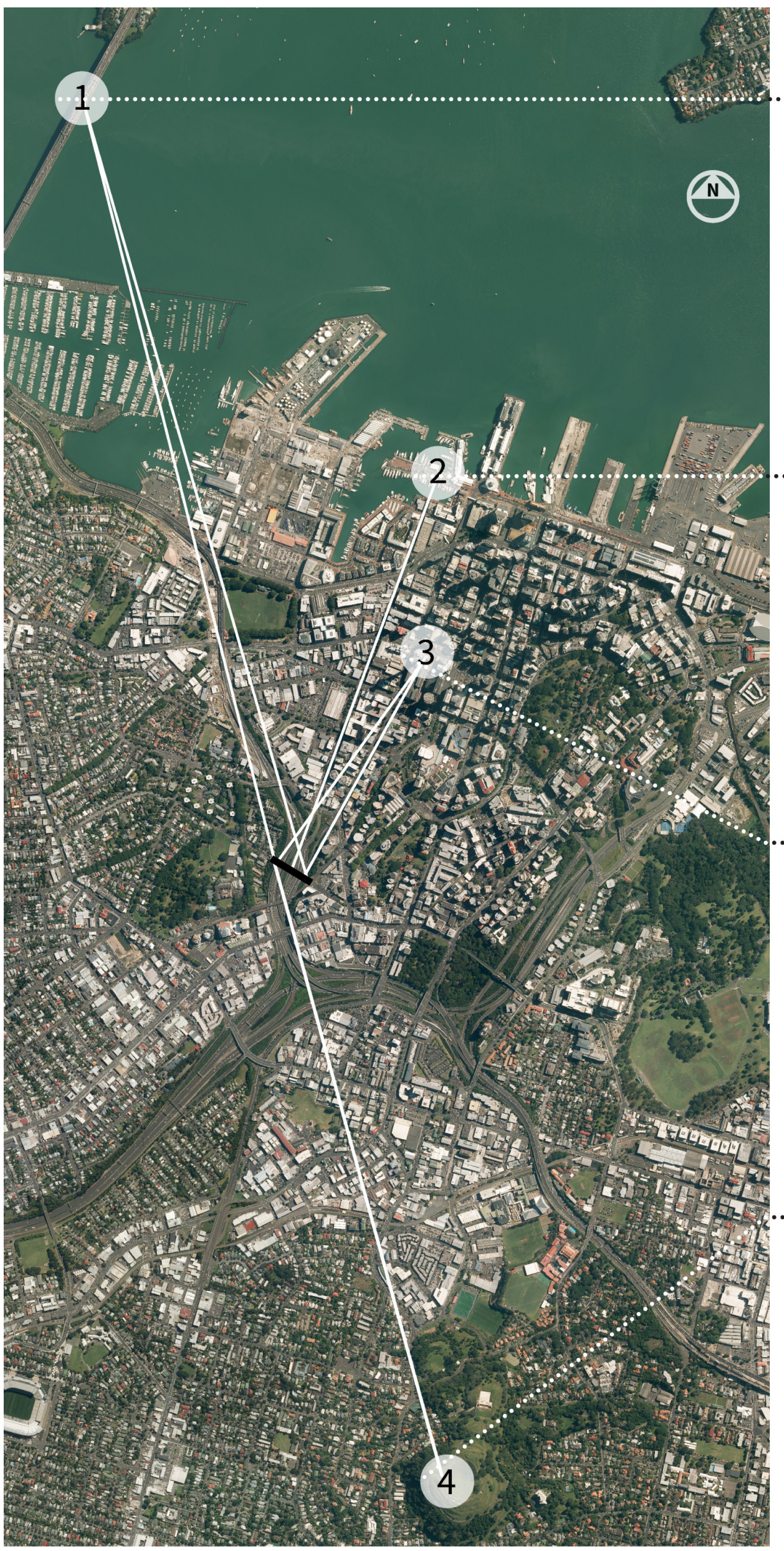


1. HABOUR + BRIDGE

\section{$3000 \mathrm{~m}$ | view range}

cultural significance

Opened in 1959 the Auckland Harbour Bridge finally provided a much needed vehicular link between Auckland Central and its northern suburbs. It is a significant marker of the city's development and its preference for the motor vehicle, with the bridge providing no walking or cycle access across its span.

\section{NELSON STREET APERTURE}

\section{$300-4500 \mathrm{~m}$ | view range} cultural significance

The street that has historically demarcated the western boundary of the Auckland CBD runs from the CMJ site directly down to the city waterfront.

3. SKY TOWER + SKYLINE

$1000 \mathrm{~m}$ | view range

cultural significance Completed in 1997 the Sky Tower instantly became the most dominating figure in the Auckland City skyline.

4. MOUNT EDEN

$2200 \mathrm{~m}$ | view range

cultural significance

The volcanic cone of Mount Eden is the most historic and culturally rich of the four. The area once was a prized stronghold for local Māori tribes.
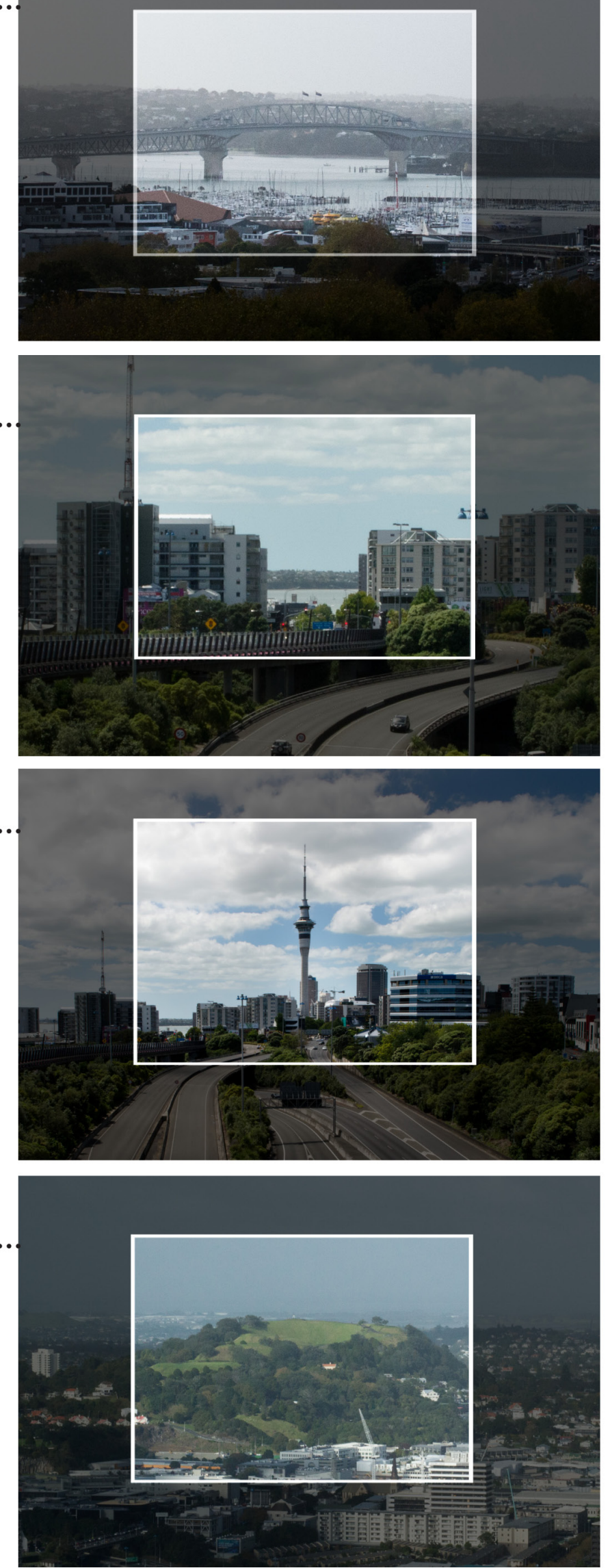

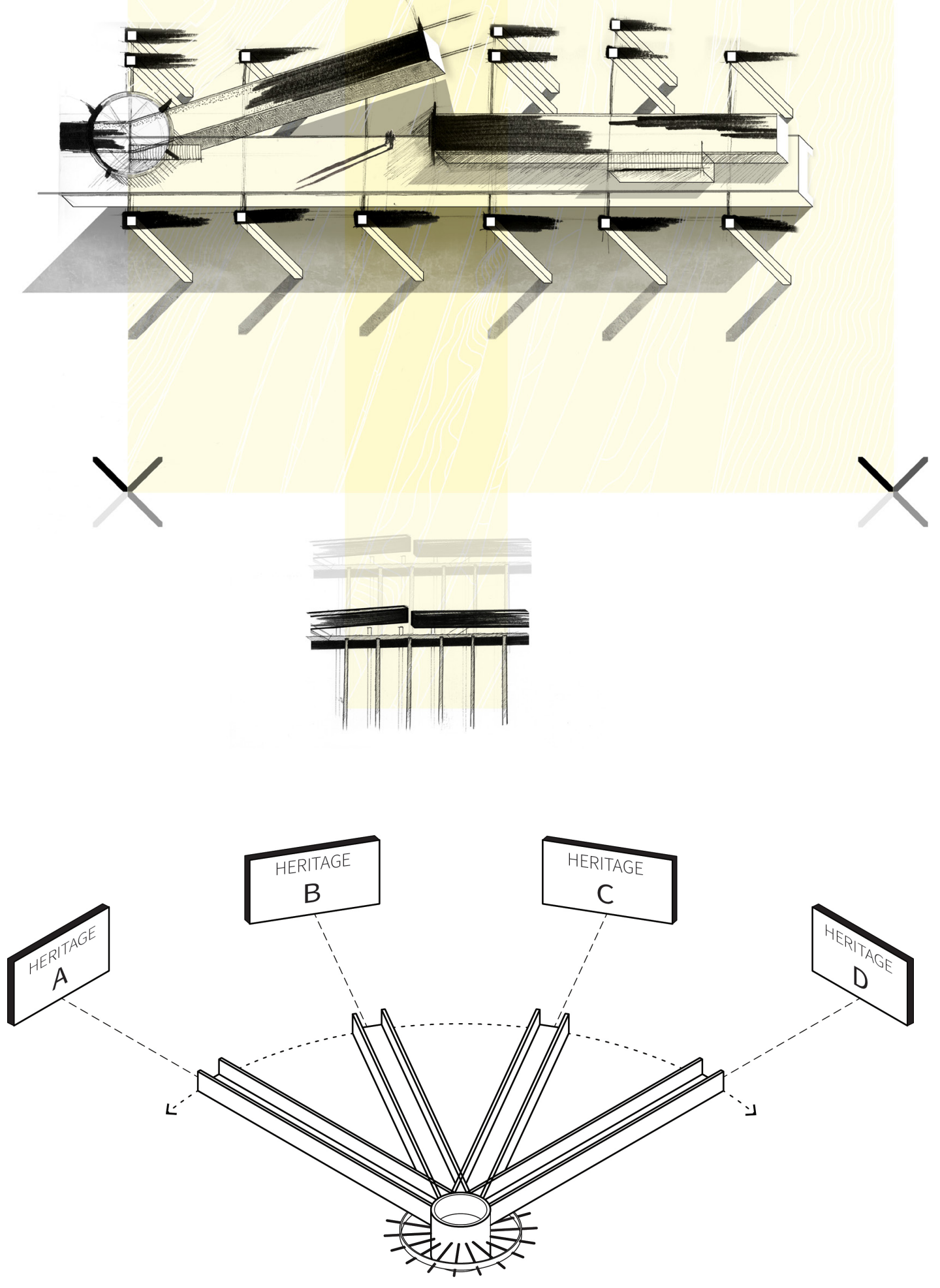

|| ehancing place identity through heritage awareness \|

Figure 2.21 (top): Early experiment investigating how architectural form could frame the heritage of the city. Figure 2.22 (bottom): Exploring some of the defining city views that could be engaged through the architecture. Figure 2.23 (right): Understanding alignments and perspectives of city elements relative to site. 


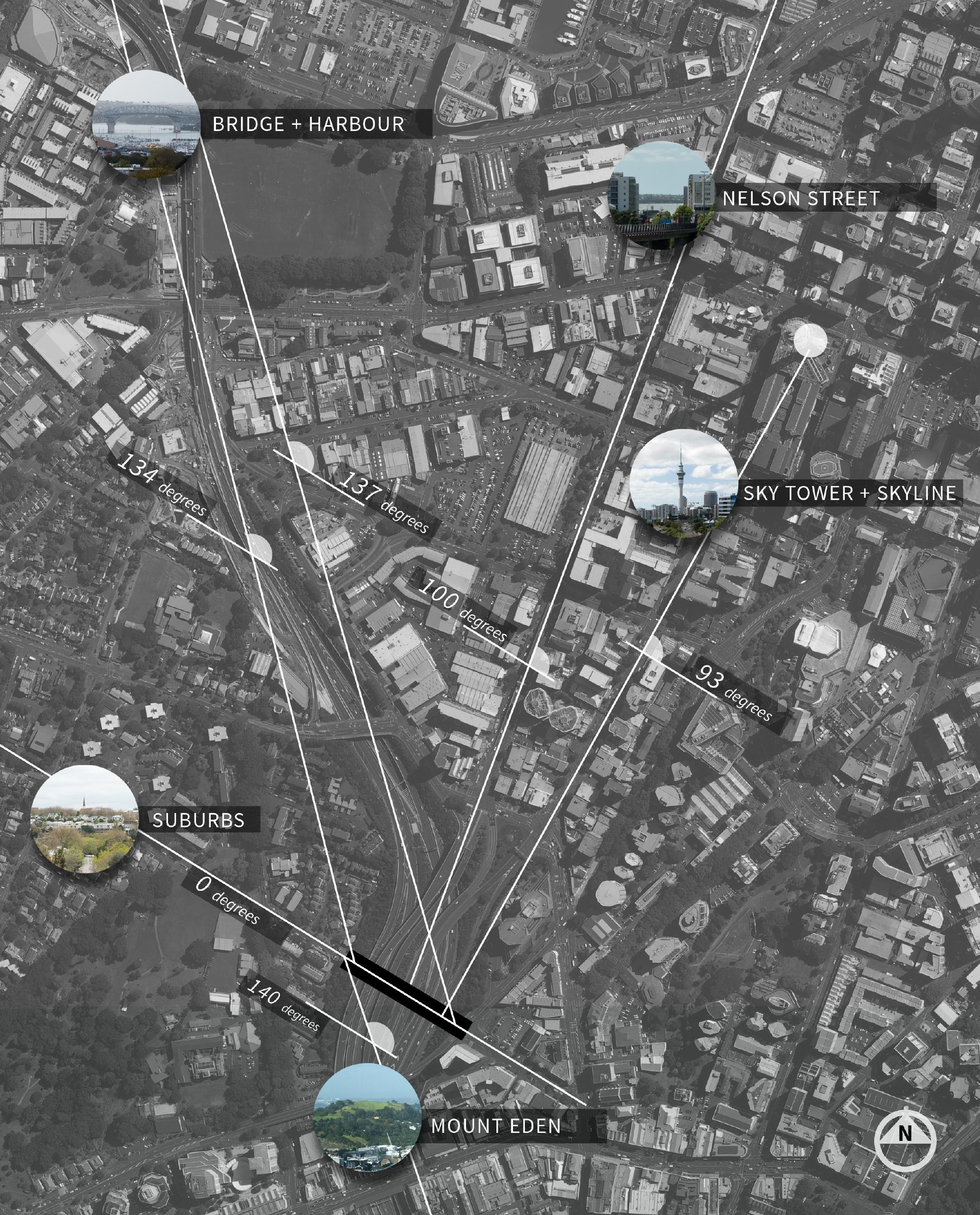


VILLA MALAPARTE (Italy)

\section{PROJECT REVIEW}

Curating the surroundings

Architect: $\quad$ Adalberto Libera

Location: Isle of Capri, Italy

Year: $\quad 1938$

Size: $\quad 450 \mathrm{sqm}$.

The project review on the Villa Malaparte offers insights on how architectural design can curate views of its surrounding environment.

Architectural apertures are carefully articulated in the design, used to frame specific pieces of the outside world to create a heightened level of awareness of the surrounding landscape. This generates opportunities for inhabitants within the architecture to reflect on their position within

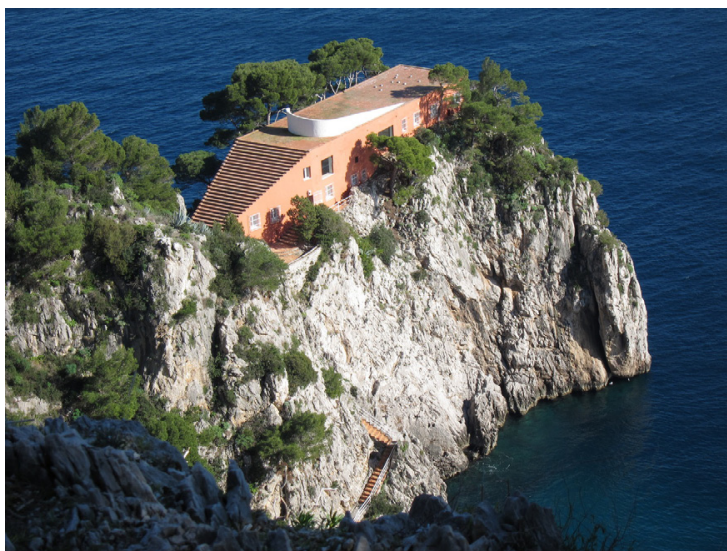

Figure 2.24 - The Villa Malaparte

These 'framed views' are simple and effective and a design typology like this could be applied to the architecture on the CMJ, curating iconic elements of the surrounding city into greater modes of appreciation. the wider environment.

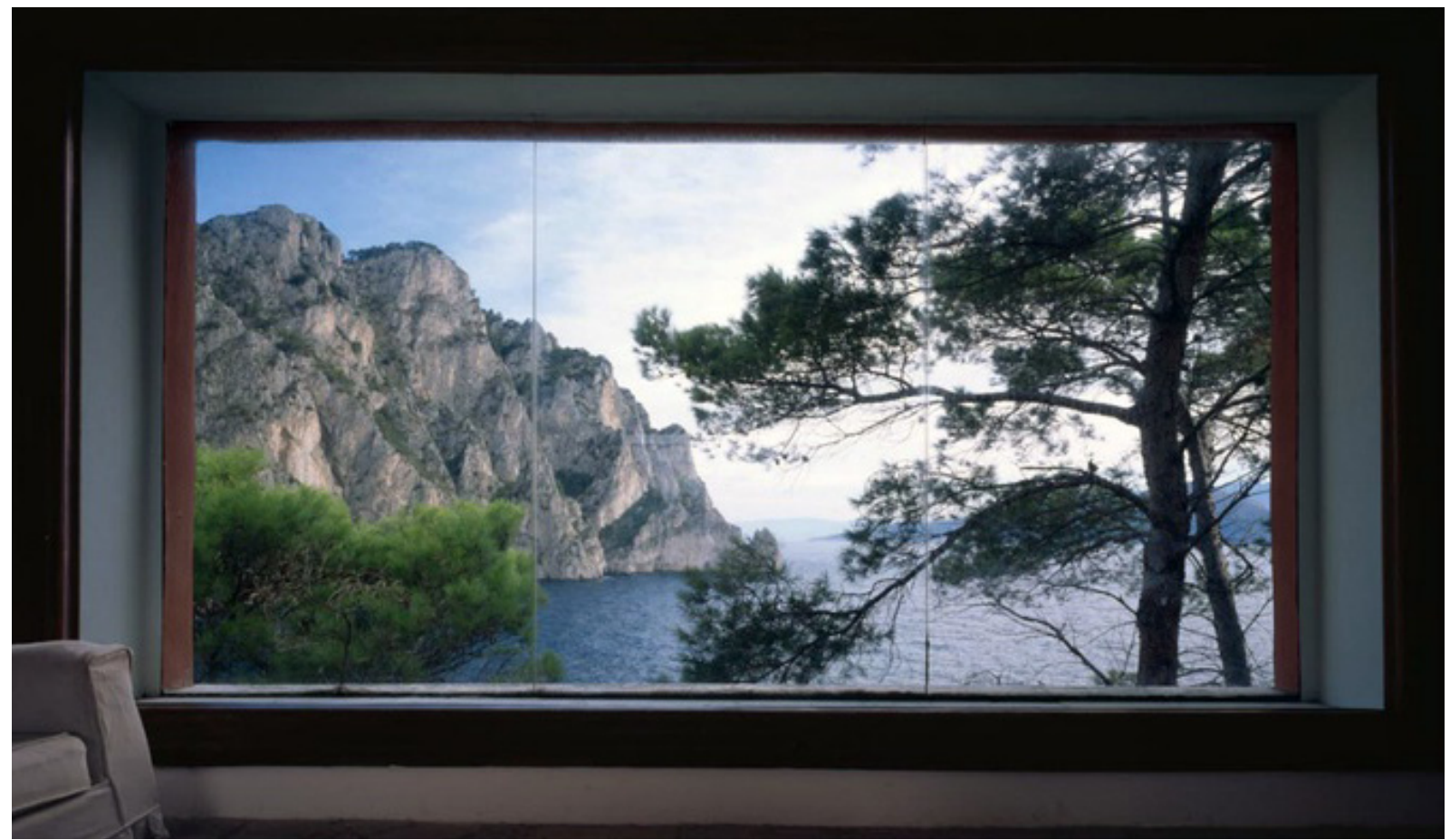

Figure 2.25 (above): The view from the Villa is both static and dynamic. Its position within this environment will never shift, but the environment itself is always subtley changing. 


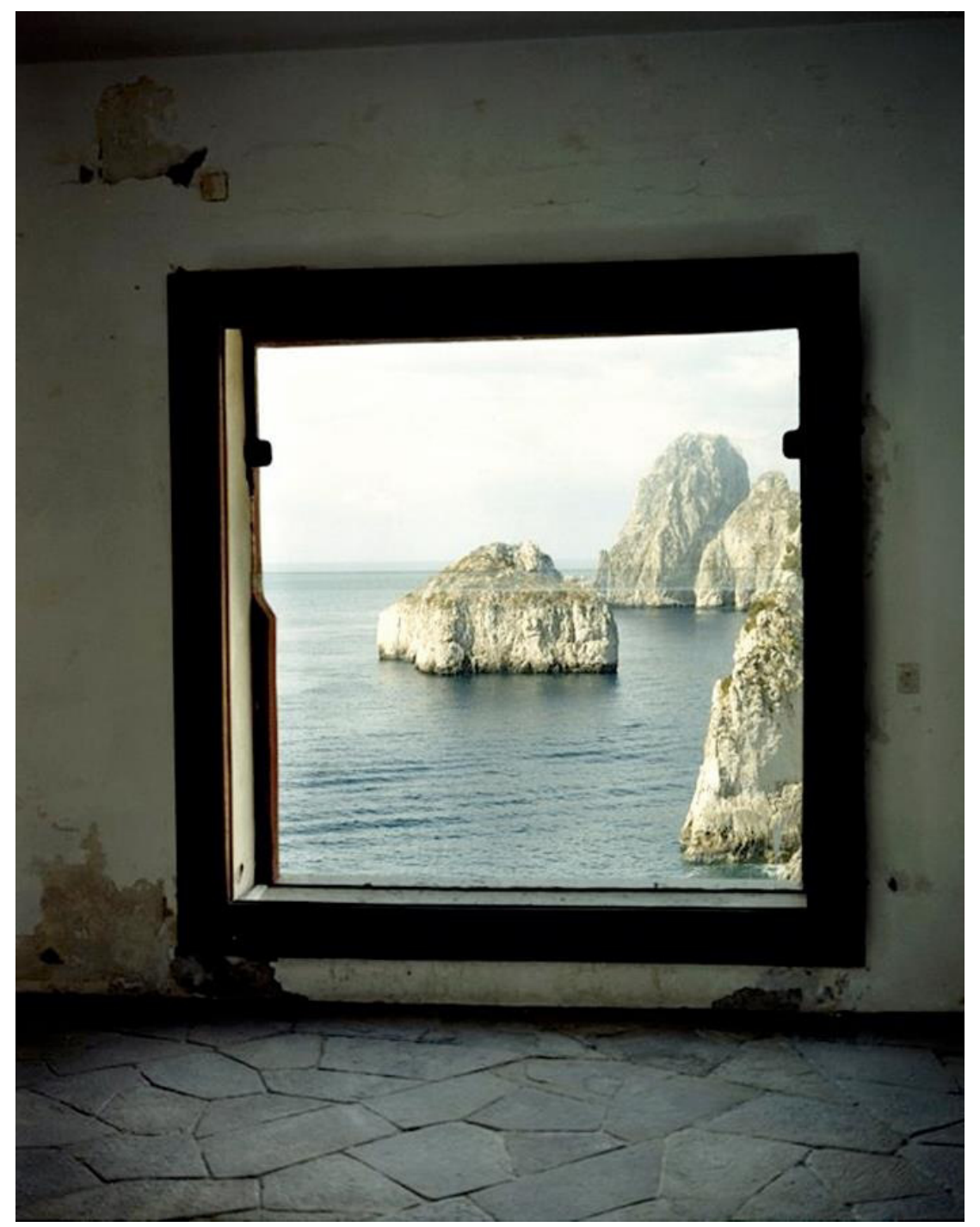

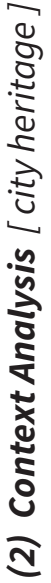

Figure 2.26 (above): The lonely rock form framed by the Villa Malaparte creates a dialogue, reflecting on the solitary nature of the viewer within this architecture on the edge of the island. 


\section{6}

The very different requirements of $5 \mathrm{~km} / \mathrm{h}$ architecture and $60 \mathrm{~km} / \mathrm{h}$ architecture must logically lead to treating the different types of space separately, or even better, collecting the activities in space that are carefully articulated, so that the small scale is used along facades and the rapid scale along lanes of motorised traffic.

- Jan Gehl, Cities for People 164

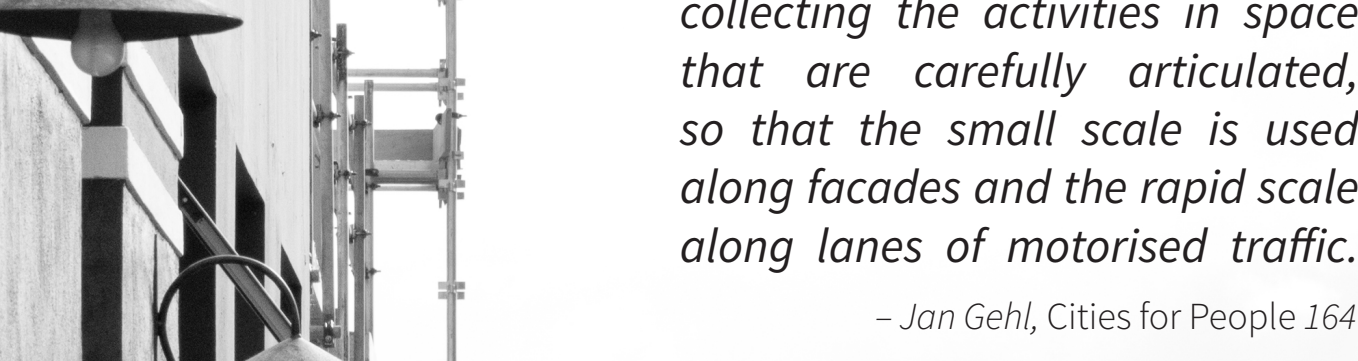




\section{[ SITE ENGAGEMENT ]}

There are three main types of engagement through the CMJ site:

[1] Slow velocity or sedentary in the form of pedestrians.

[2] Moderate velocity in the form of cyclists.

[3] Fast velocity in the form of motor vehicles.

Each user reads the architecture in a different manner. Currently the site is dominated by a rapid north - south flow of vehicular traffic and only one narrow north - south lane through the centre allowing pedestrian and cyclist engagement.

To achieve the objective of embracing the 'motorway typology' through architecture the design intervention must anticipate the engagement the vehicles have with the site in terms of velocity and direction.

Diversifying the utilitarian nature of the motorway can be partially achieved through a greater volume of slower and moderately paced users - pedestrians and cyclists engaging with the space.
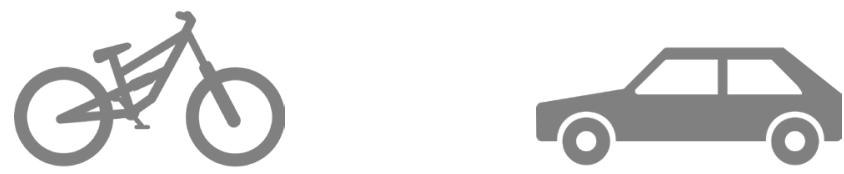


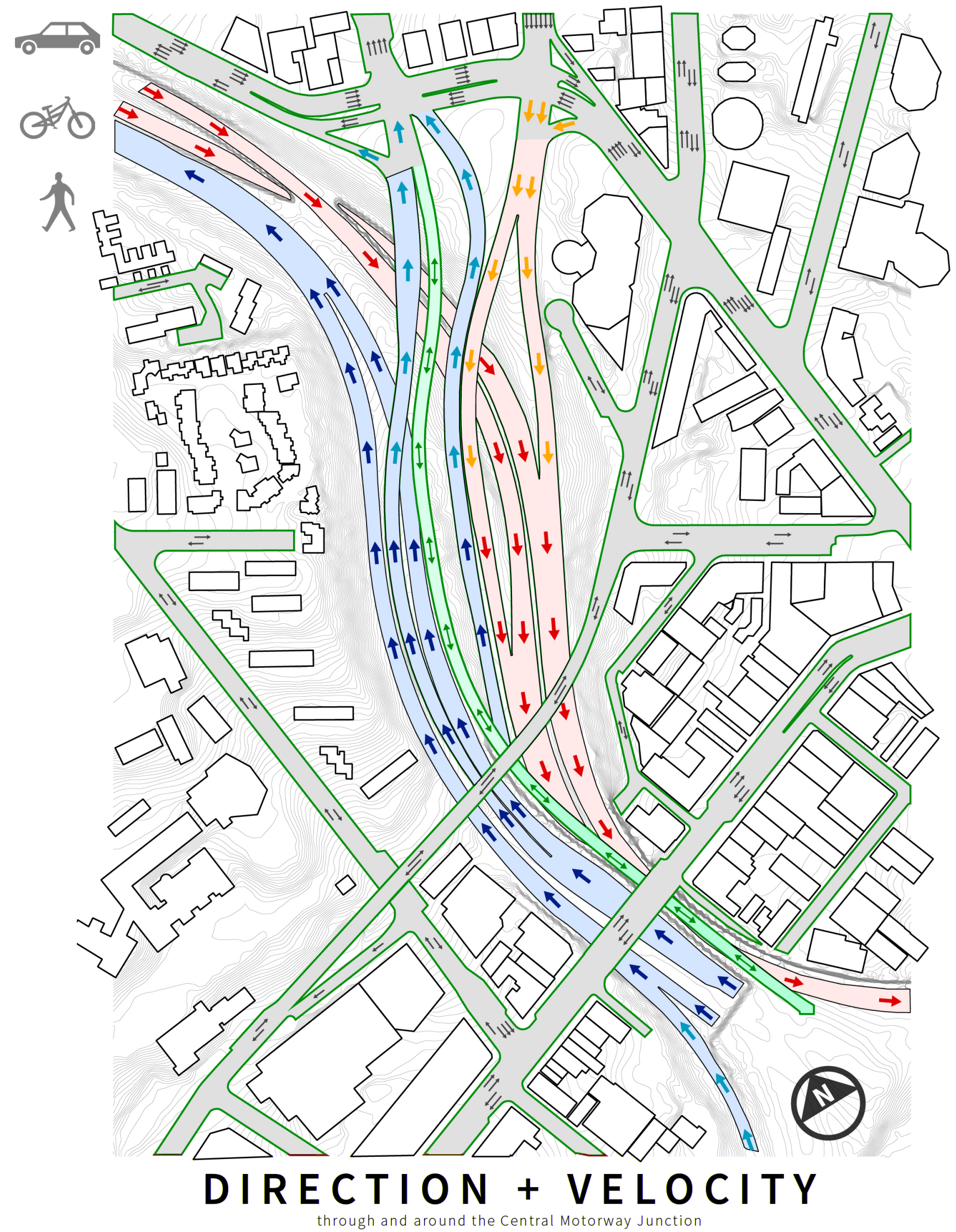




\section{SPEED | GRAIN | ENGAGEMENT}

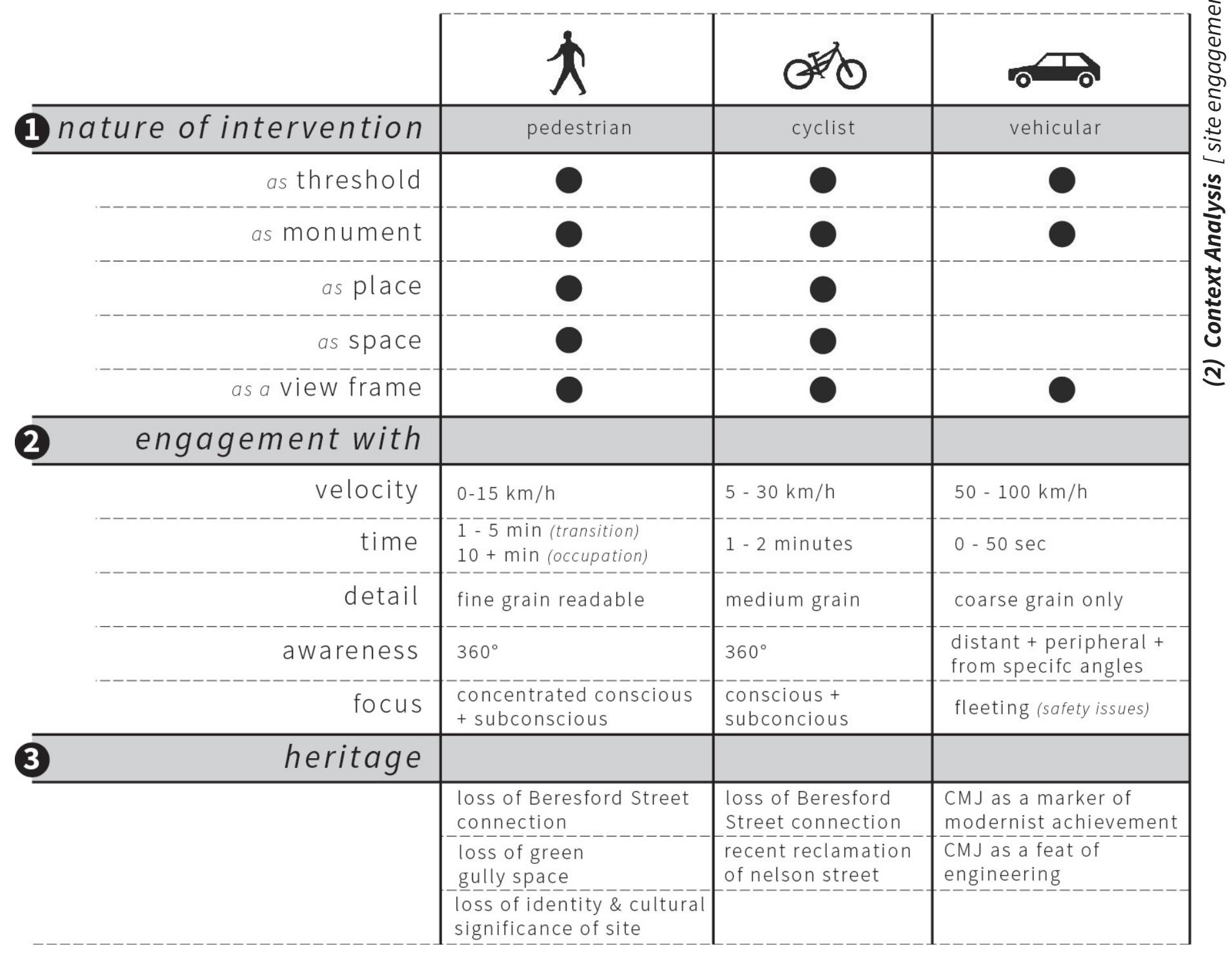

Figure 2.28 (opposite): Understanding the velocity and directions with which the site is interacted.

Figure 2.29 (above): Understanding the typology of users and how they would engage with the architecture. 


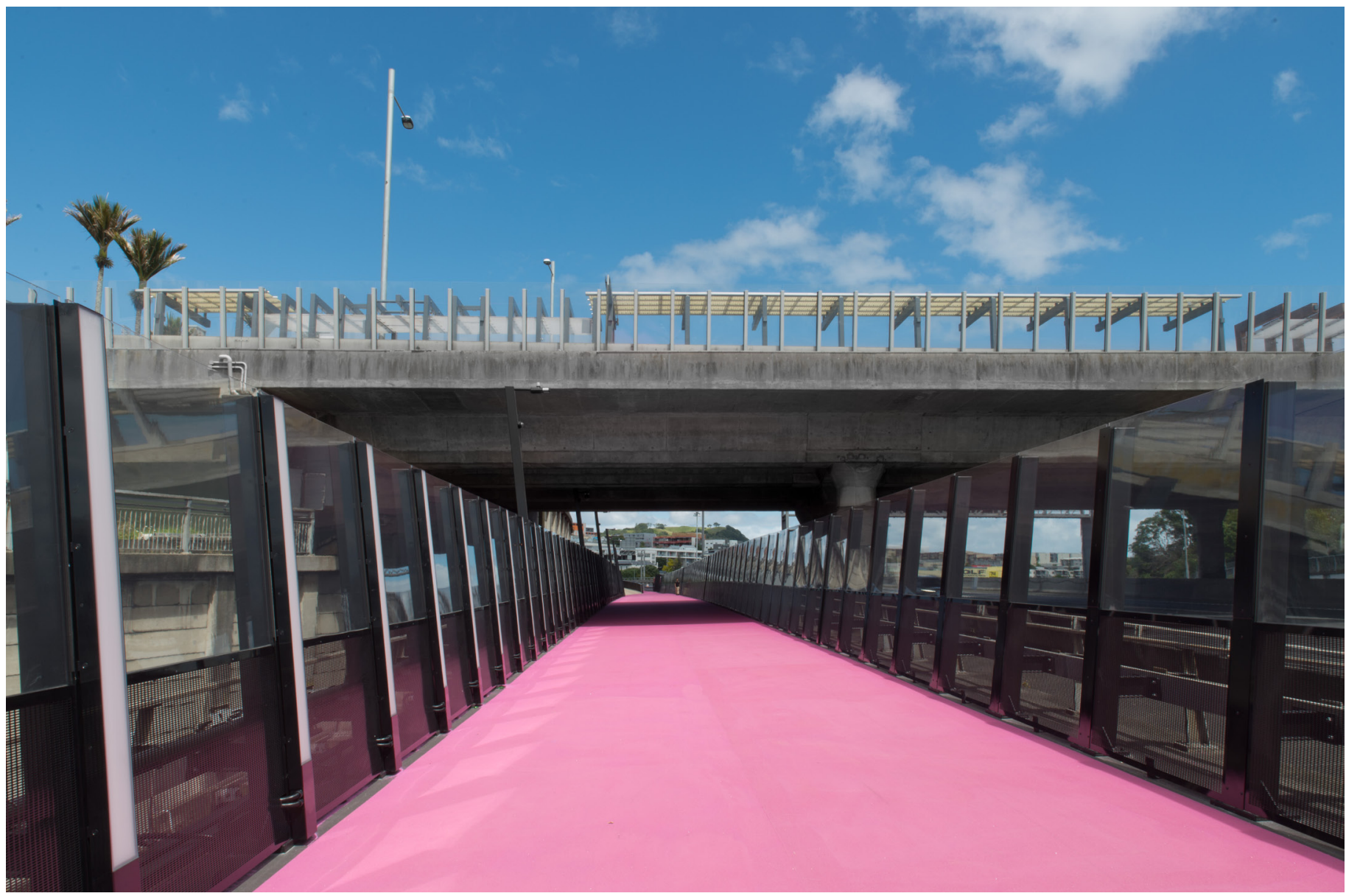

\section{NELSON STREET CYCLEWAY}

In December 2015 the bright pink Nelson Street Cycleway was opened. Designed by Monk Mackenzie, GHD, Novare and LandLAB, the intervention utilises the unused Nelson Street off ramp running through the core of the $\mathrm{CMJ}$ as a pedestrian and cyclist link.

The cycleway is an attempt to diversify the utilitarian motorway infrastructure but has a singularity of programme that restricts its urban contributions. The centrality of its location in the CMJ, however, does provide opportunity for it to be established as a cyclist and pedestrian 'spine' for further architectural intervention and permeability opportunities.

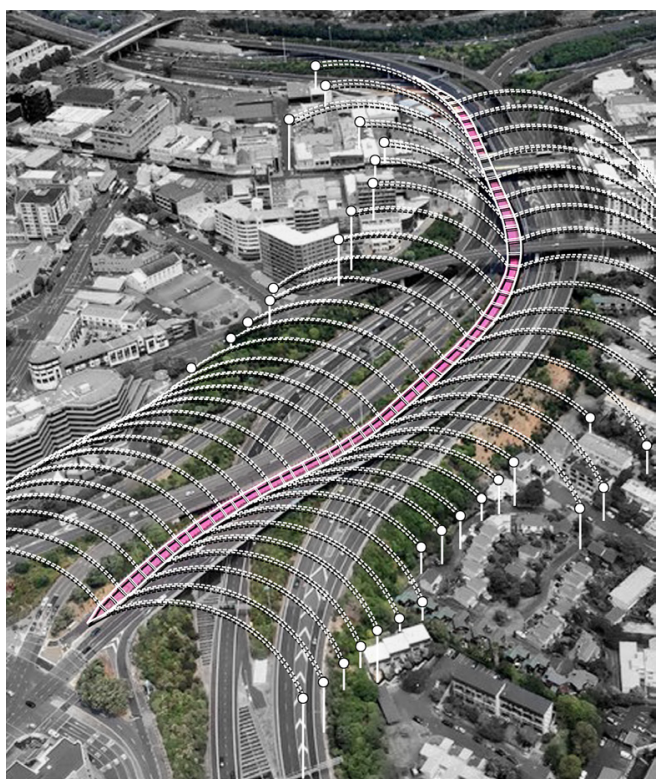

Figure 2.31 (bottom right): The potential for the cycleway to act as a circulation spine for the design research intervention. 



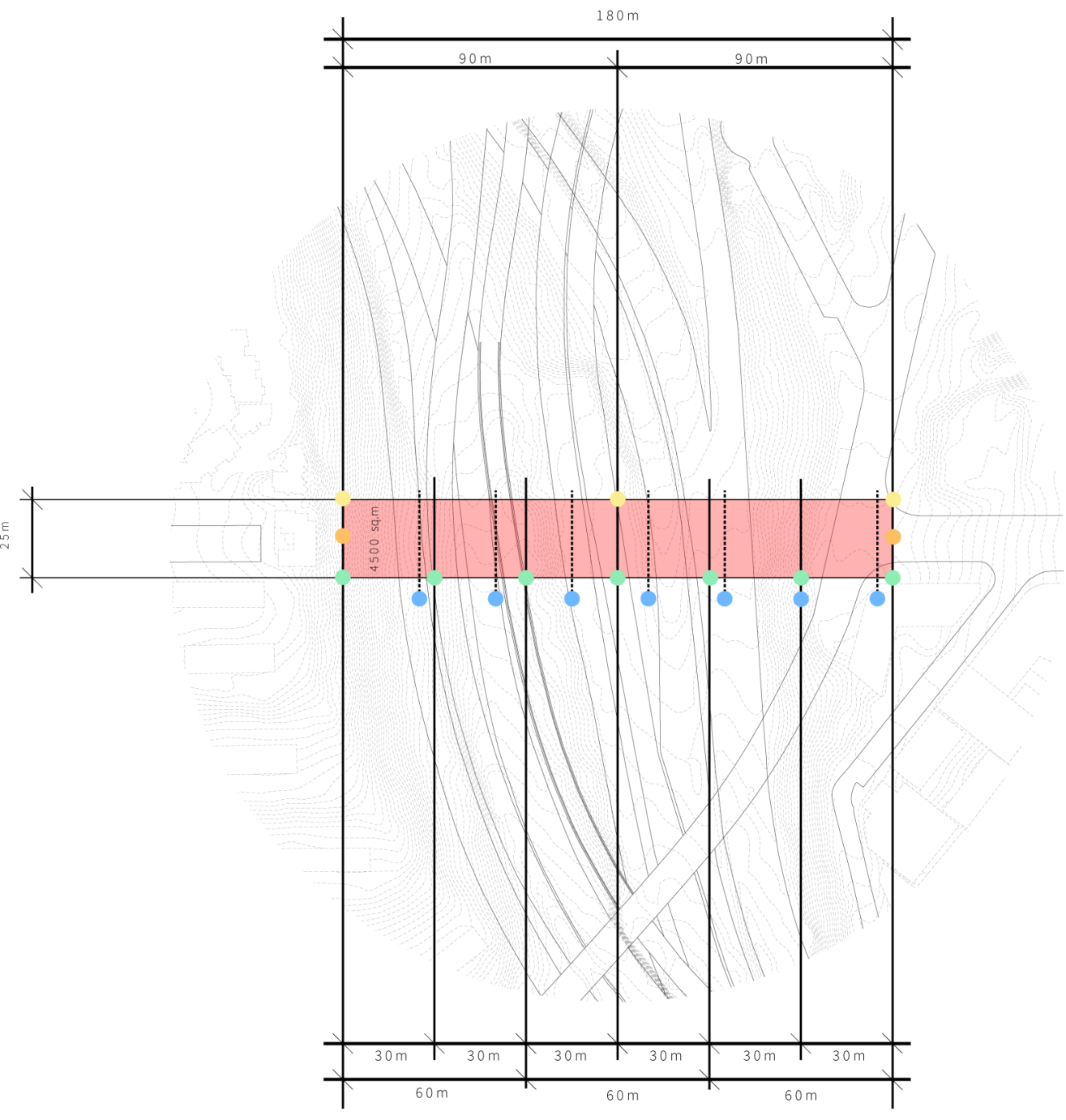

at $<100 \mathrm{~m}$ movement of people can be read (Gehl 36)

\section{THE PEDESTRIAN SCALE}

\section{readability and coherence of people at distances}

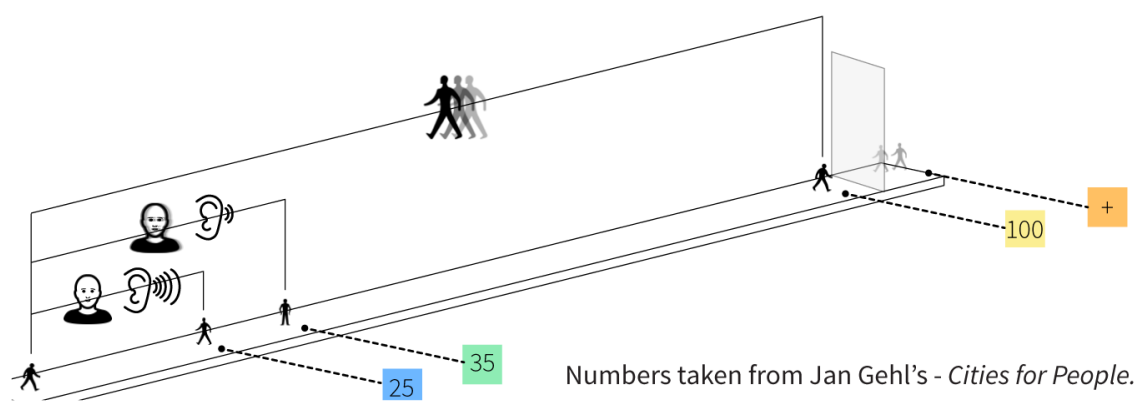

Working with the small scale is the key to ensuring better conditions for the human dimension.

- Jan Gehl, 195 scale. The figures show the site broken down into segments where key moments of human interaction are understood. 


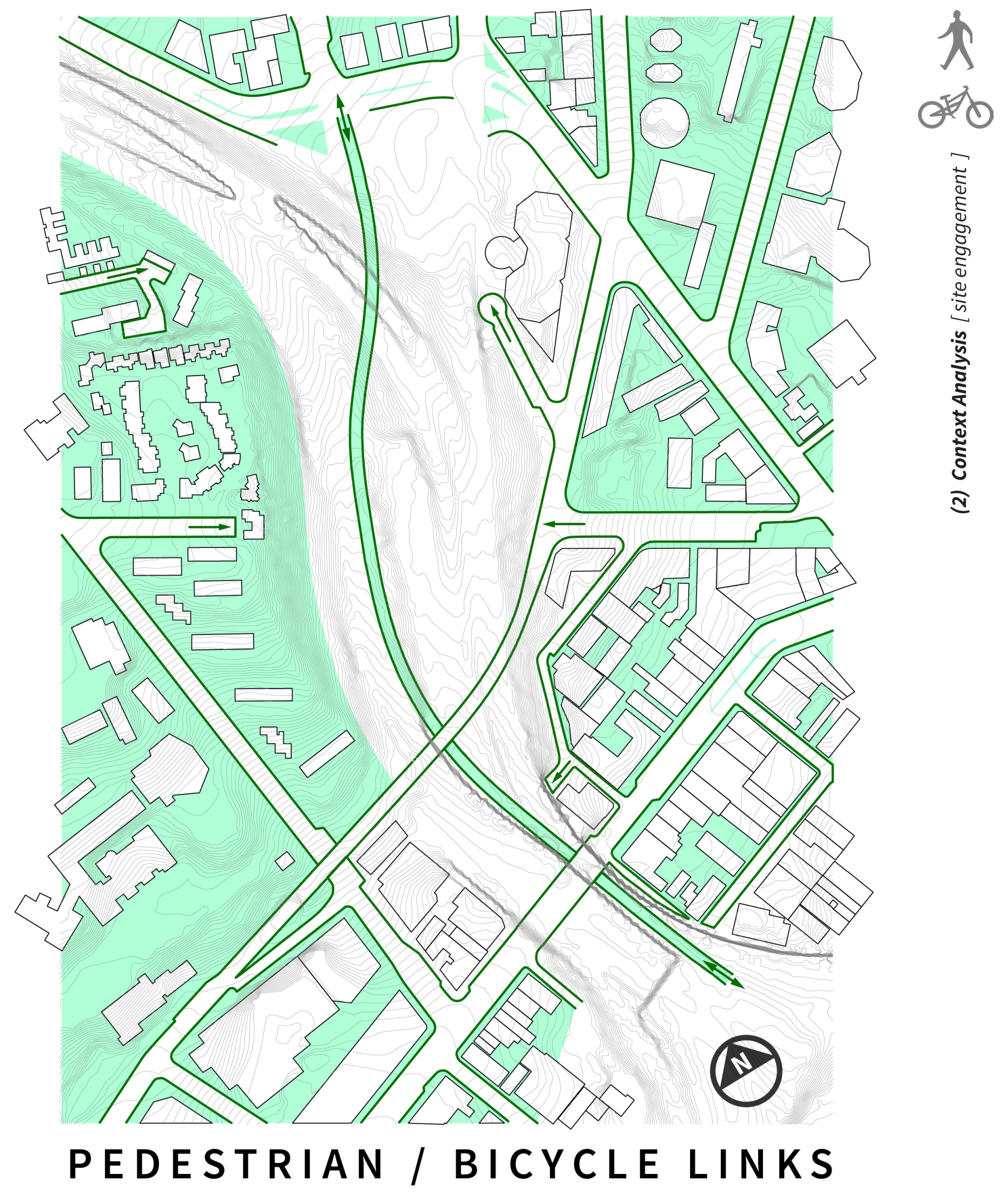

pedestrian accessible area

pedestrian / cycle path

* note extensive void space either side of the cycleway.

Figure 2.34: Understanding the existing pedestrian access points and links through the CMJ. Currently, except for the Nelson Street Cycleway the CMJ is a massive pedestrian barrier in the urban environment. 


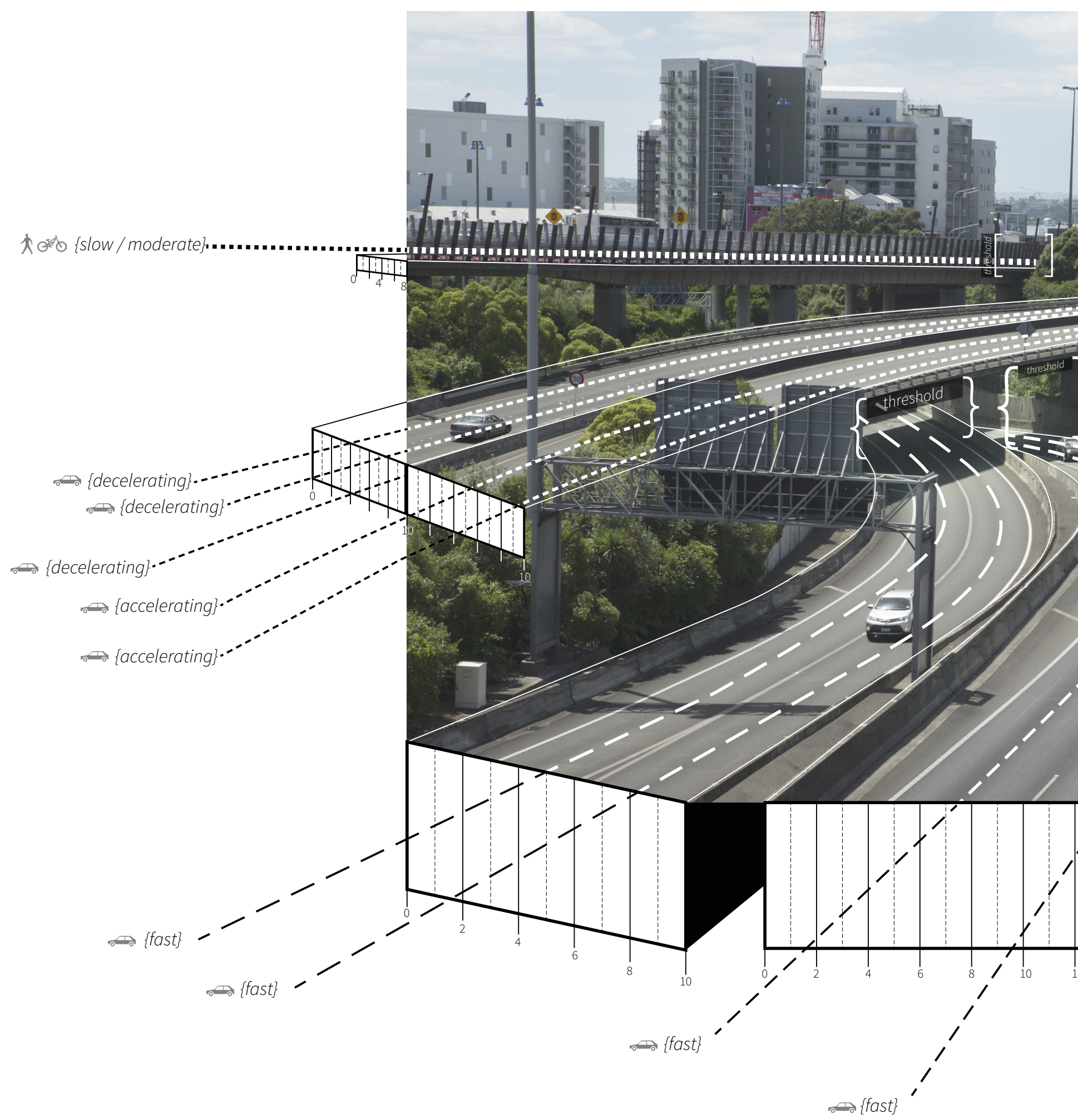

42 Figure 2.35 (Above left): Velocities and typologies of transport moving through the site.

Figure 2.36 (Above right): Understanding site scale (in metres). 

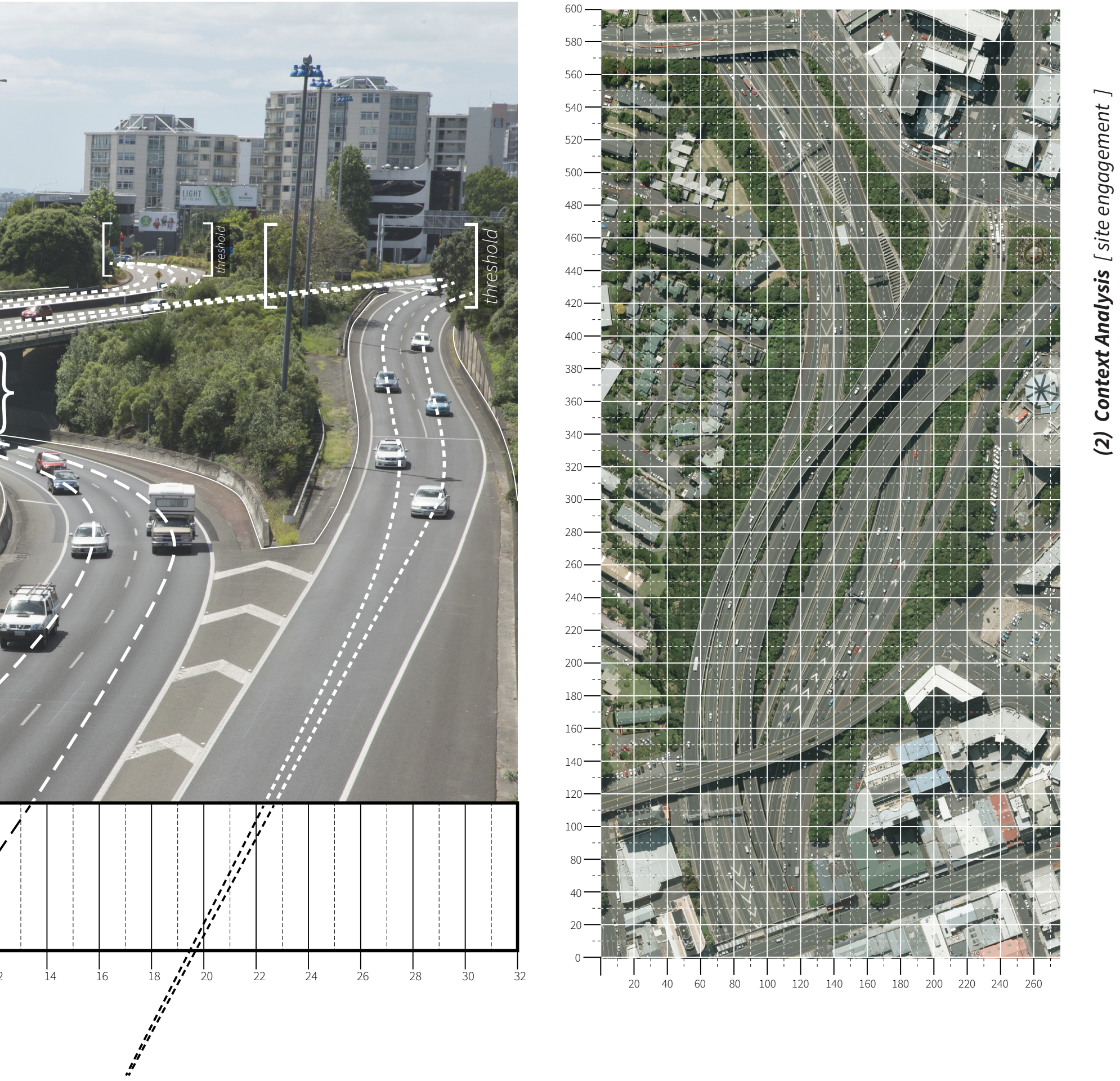

당 $\{$ fast $\}$

$\mathbf{6 6}$ The designers must ask themselves, where does the speed drop and what occurs there? How can we manipulate the speed of the transport modes and how do these different speeds register architectural input? 


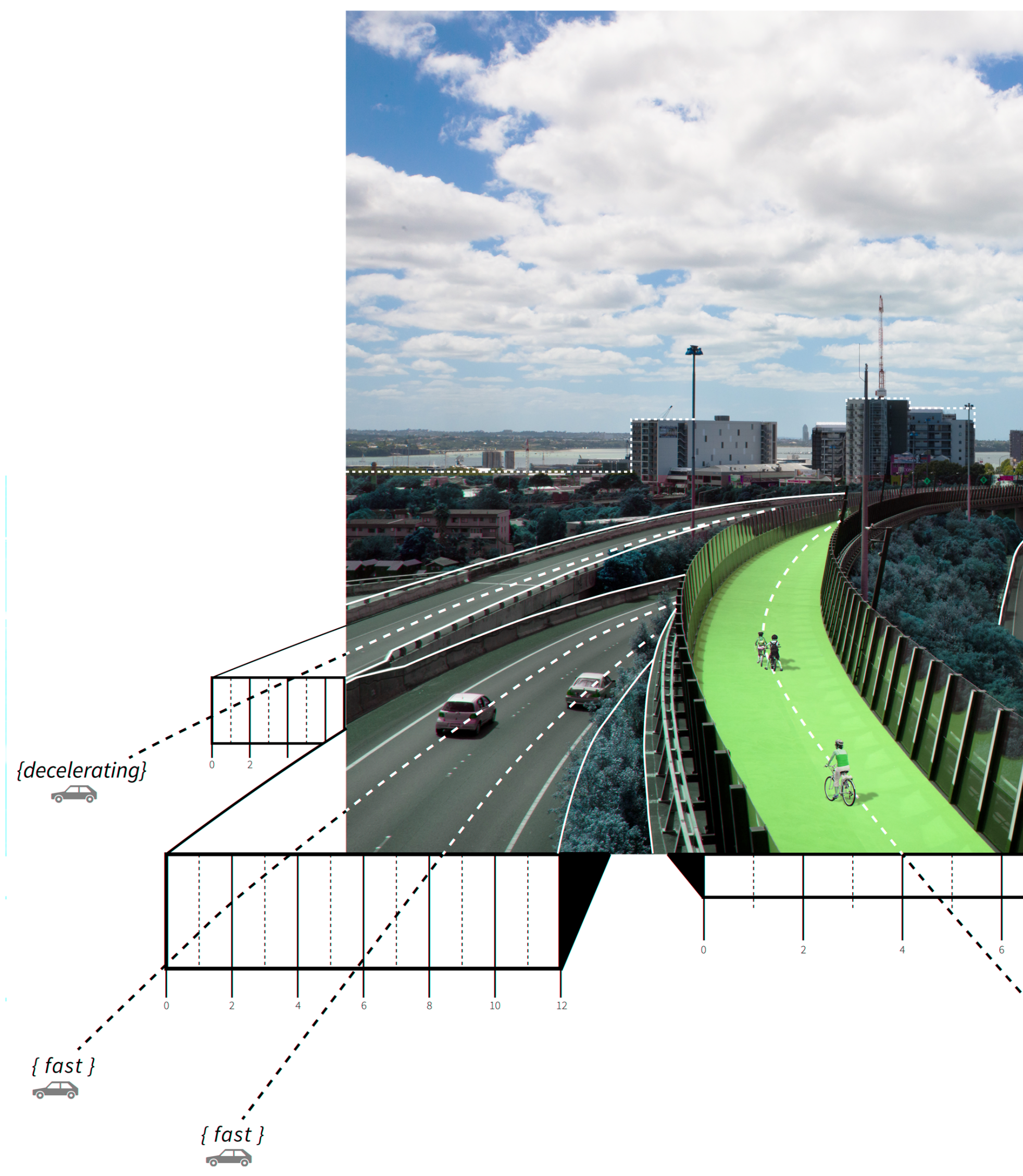




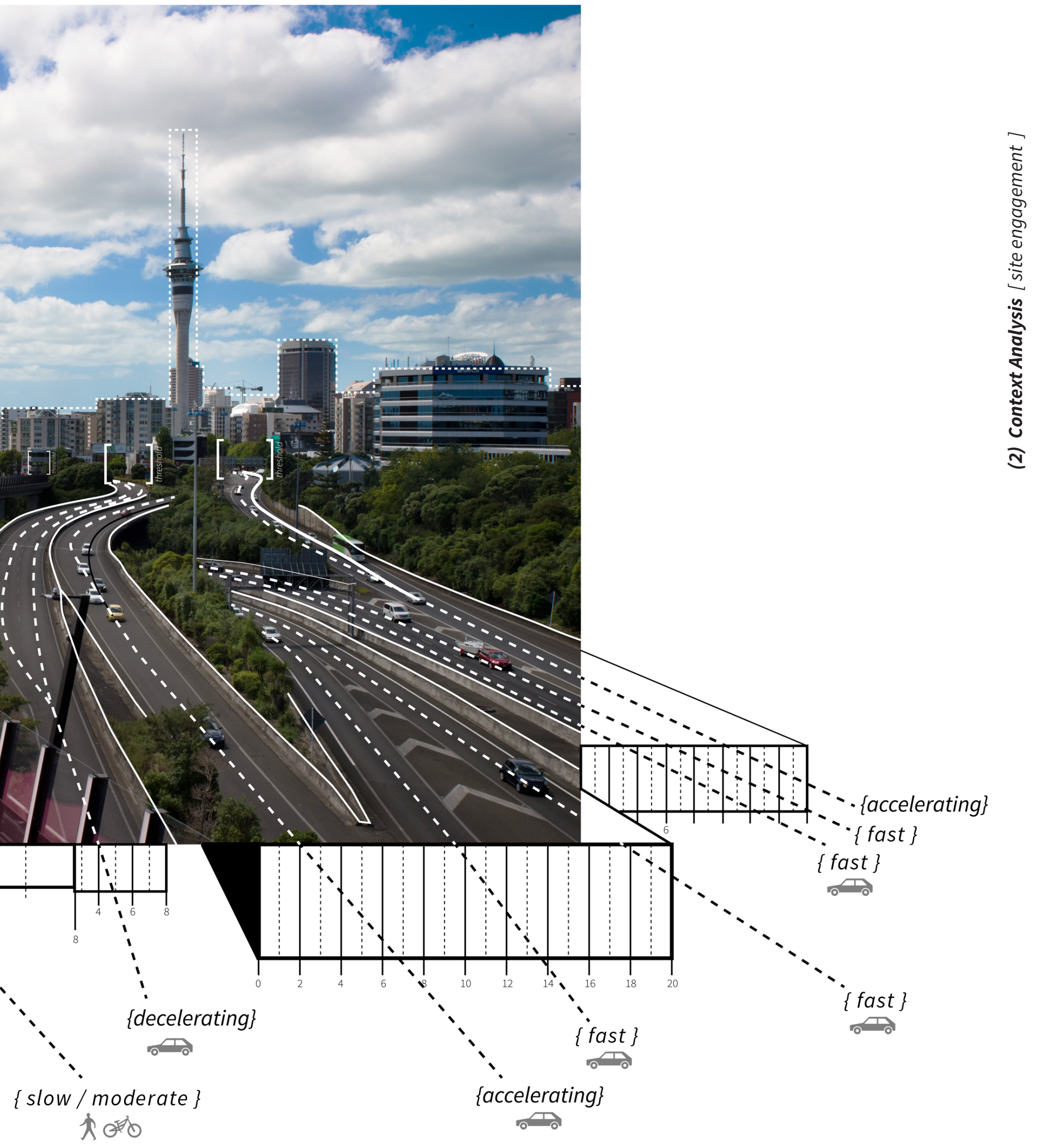

Figure 2.37: Velocity and typologies of transport moving through the site. 


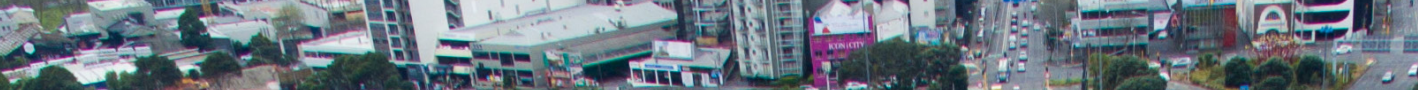

.

tit?

त.

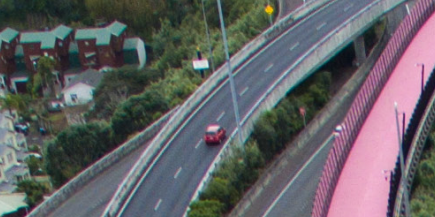

.

.
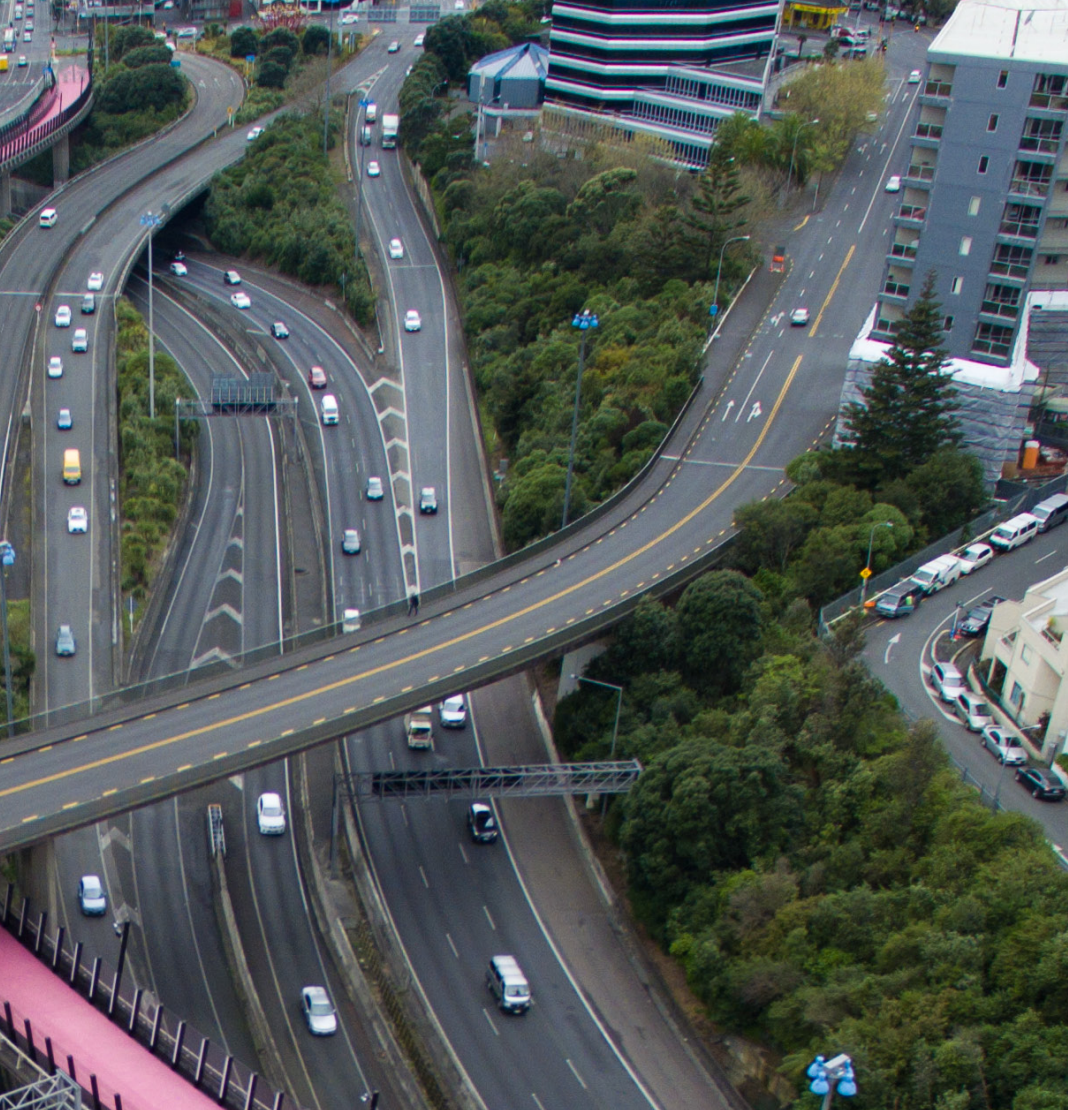

. I. $=4$

5.

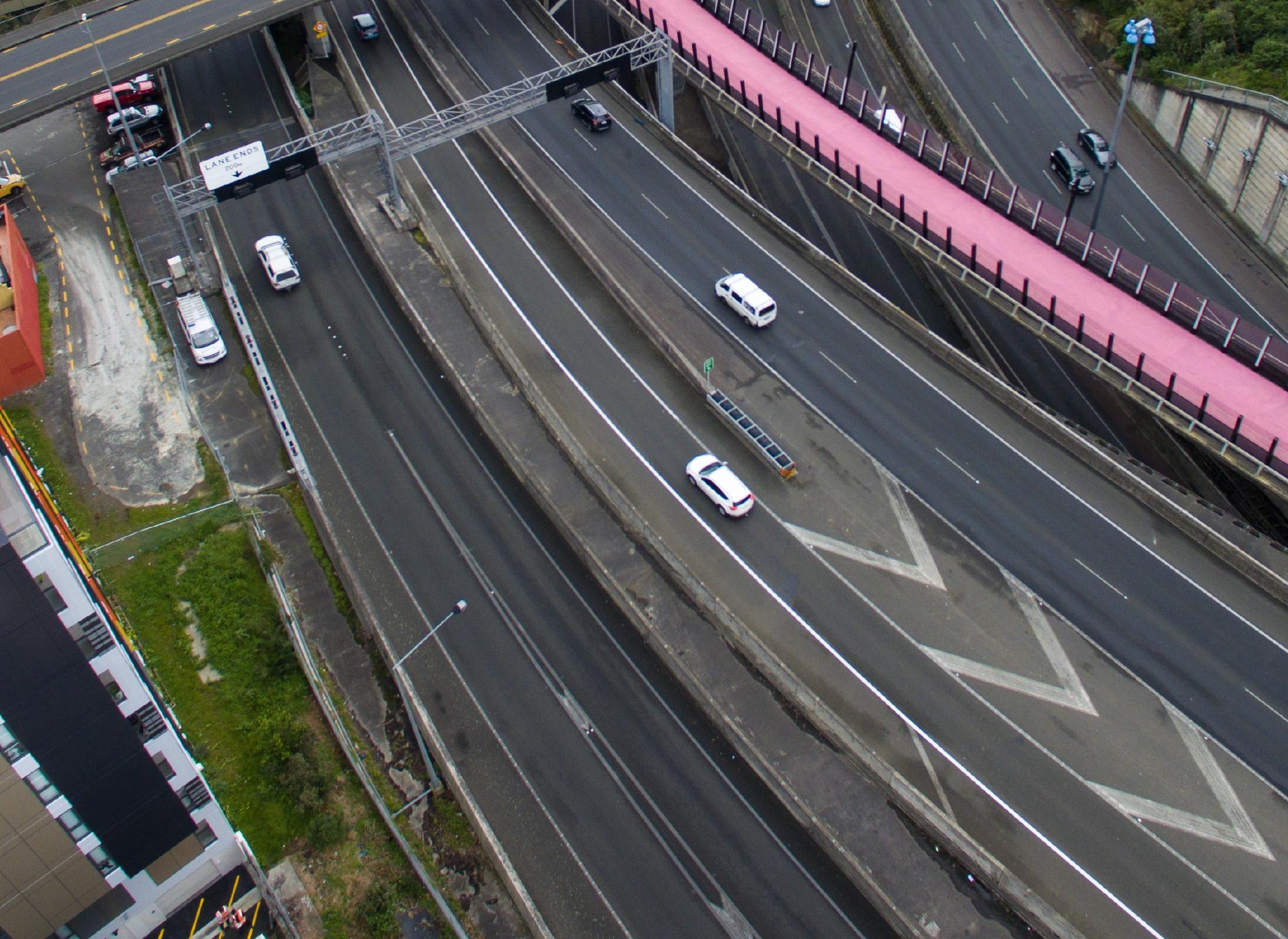




\section{[ CONCLUSIONS ]}

Context analysis of the CMJ site and its wider urban surrounds has led to the following design opportunities and implications relating to the thesis research objectives:

\section{[ Lost Sites ]}

By embracing the historic heritage of the site, two of the six principal research objectives can be engaged. Historic links can be reintroduced to create greater permeability through the barrier like CMJ (RO2), and reestablishing these historic links will reveal elements of the site's 'hidden heritage' that can contribute to its cultural and place identity (RO6).

\section{[ Site Dynamics ]}

The surrounding layout of the wider urban environment can be utilised as design reference for how to create the most coherent links across the CMJ to achieve objectives of increased diversity and permeability. This analysis has led to the selection of a site within the CMJ that best achieves these two objectives (RO1 and RO2).

\section{[ City Heritage ]}

The prominent position of the CMJ site in the city creates opportunity to investigate the research objective around the non-archived elements of 'hidden heritage'. By curating views of iconic elements of Auckland in the architecture, the 'city heritage' can be embraced in the design research intervention (RO6).

\section{[ Site Engagement ]}

Crucial to achieving the research objective of 'embracing and celebrating the motorway typology' (RO3) is understanding the nature of the interaction the vehicles have with the site and engaging with velocity and scale in the architecture. It is also clear that to diversify the utilitarian nature of the CMJ a greater range of users needs to be invited to actively engage with the site. 


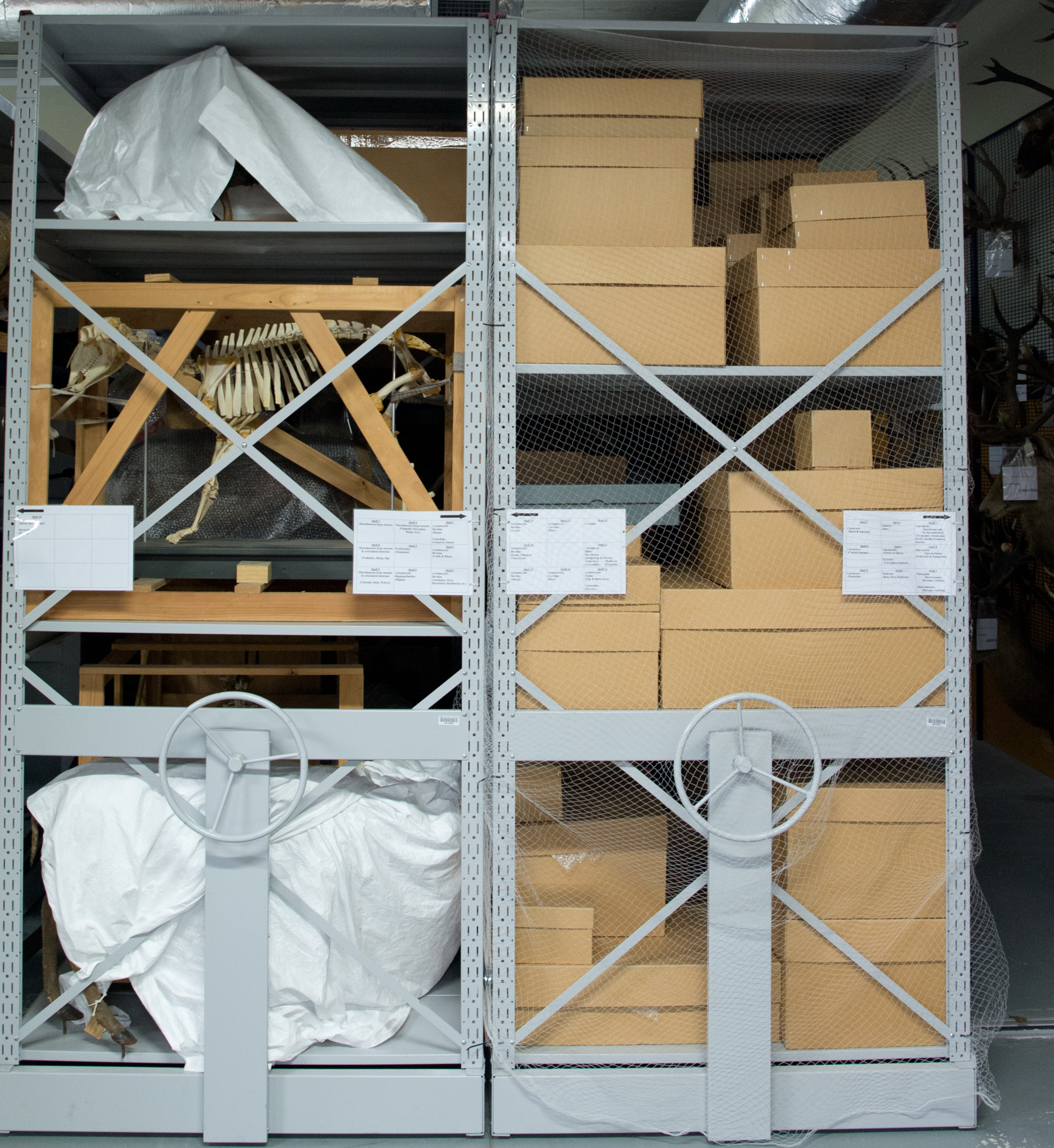

Figure 3.1 (previous): A view inside the current Te Papa archive storage on Tory Street (photo by author).

Figure 3.2 (above): Current storage typologies at the Tory Street building. 


\section{3 | Programme Analysis}

The thesis's three principal research objectives relating to 'Hidden Heritage' are:

[RO4] to enhance engagement with stored national heritage artefacts by placing them into the public realm to encourage public engagement in diverse ways;

[RO5] to 'curate' stored national heritage artefacts in ways that maximise the didactic potential of the archive collection and increase cultural awareness about these items for the general public, and

[R06] to explore the 'non-archived' elements of the city and the site's 'hidden heritage', inviting these alternative elements of heritage to also contribute to cultural and place identity.

This chapter begins by considering the appropriateness of the Te Papa stored archives as a potential programme for engaging 'Hidden Heritage' within the context of the monumental scale of the site and its harsh environmental conditions. The chapter is then divided into the following three sections.

\section{[ Hidden Heritage ]}

This section explores the current issues around the Te Papa archive collection including practical storage issues, archive safety issues in Wellington, and most concerning - the lack of engagement these significant cultural items have in the public realm.

\section{[ Curatorial Opportunities ]}

The next section examines Te Papa's existing collection and the didactic potential of this extensive range of items. At this stage elements of the CMJ site such as velocity, scale, and natural light intensity are at the forefront of the research, exploring how the implications of the motorway site and archive programme might enhance curatorial opportunities for the collections.

\section{[ Beyond Stored Objects ]}

The final section researches the potential of other programmes to contribute to the cultural identity of the city and the extension of the city's cultural hub into the CMJ site. This section focuses on elements of programme and 'hidden heritage' that are beyond the scope of the Te Papa archives such as green spaces and the heritage of the city itself. 
EXISTING PROGRAMME $+$

\section{SITE AMENITIES}

Opportunites for expanding the cultural and green space hub across the CMJ.
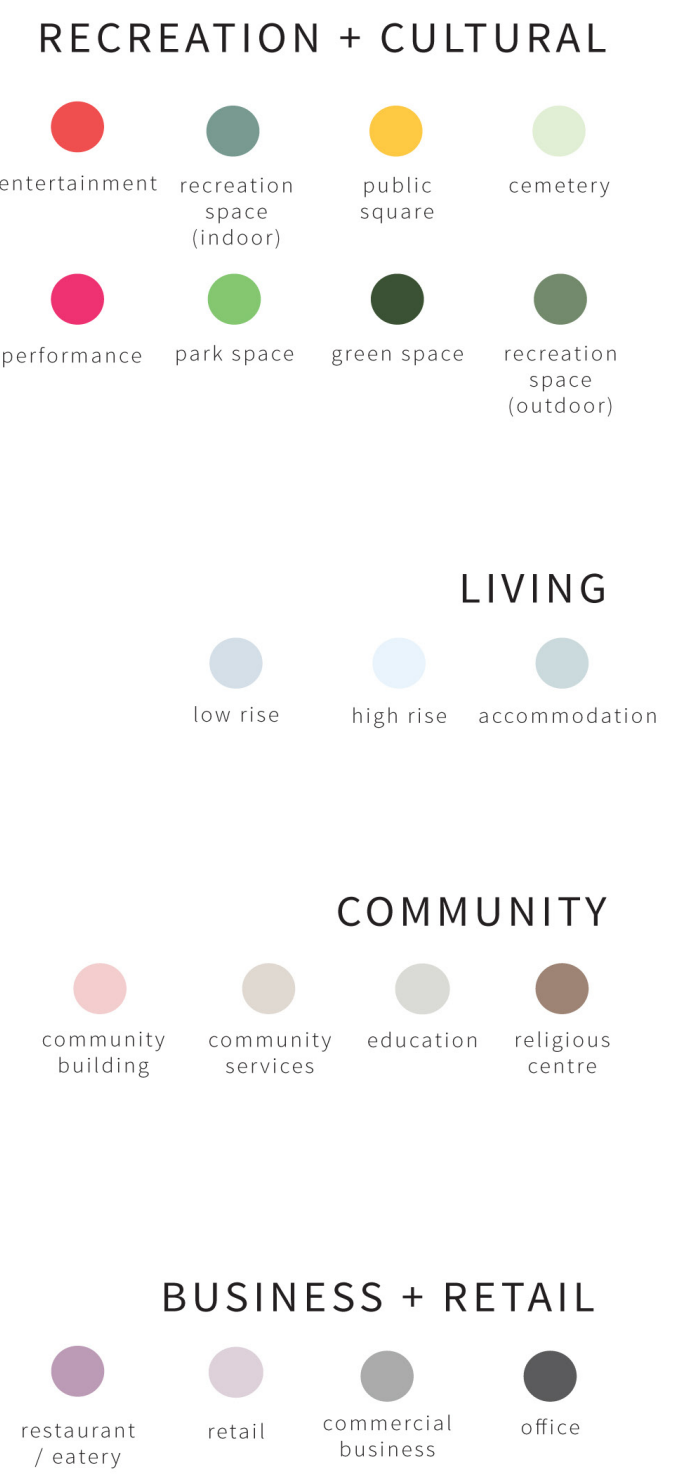

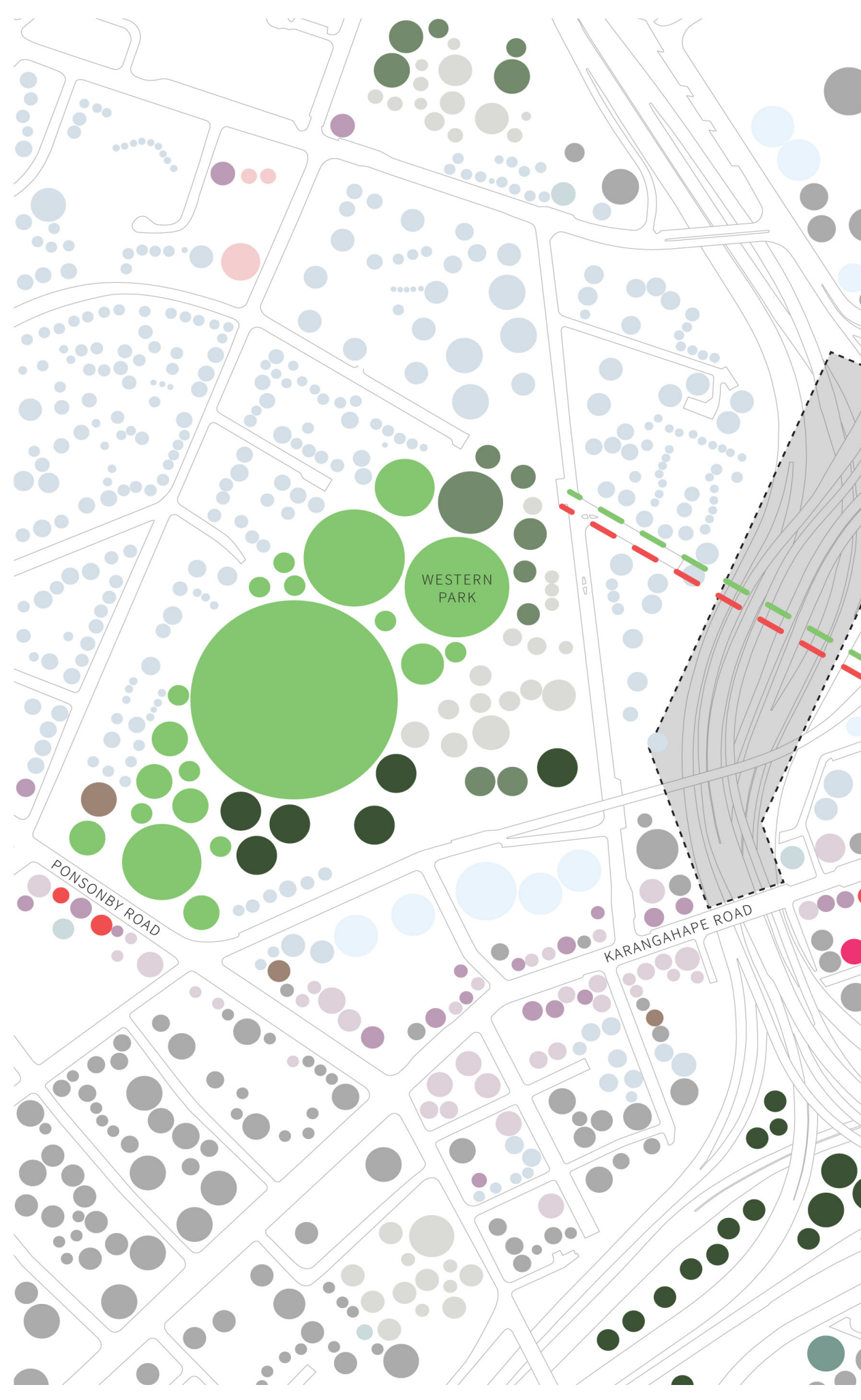




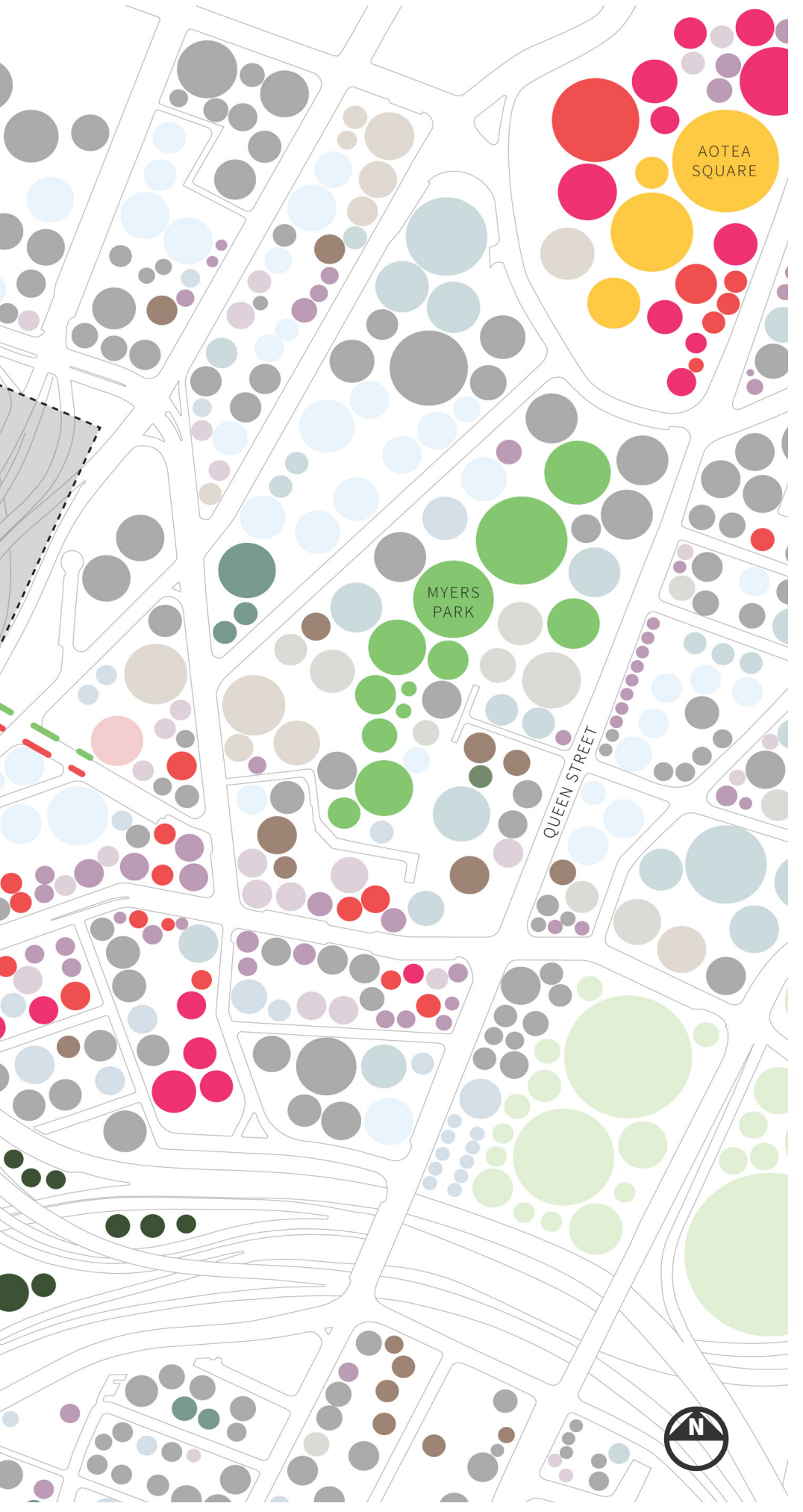

\section{PROGRAMME + SITE}

From figure 3.3 it can be seen that a cultural / green space belt is already partially established in the city. This belt travels from the CBD and Aotea Square into Meyers Park but then abruptly is cut in half as it reaches the harsh barrier condition of the CMJ. There is opportunity for the design research intervention to continue this belt across the CMJ, linking it with Western Park, hence expanding a more cohesive cultural / green space belt in the city.

The Auckland CBD has limited space available for large scale architectural infrastructure. However the available CMJ footprint seen in figure 3.3 shows an enormous area over the motorway expanse that could provide opportunity for a large CBD project. Whilst housing would be the preferable programme to densify the inner city and combat the current urban sprawl issues, the environmental conditions of the site make it unsuitable.

The design research proposes that the Te Papa archive collection which requires large amounts of internal storage space and hosts mainly inanimate objects would be a suitable programme to productively engage with this otherwise 'lost' monumental urban footprint (RO1). This would also place the archive storage right in the heart of Auckland allowing integration of the collections into the public realm to enhance the cultural awareness around these items (RO4).

Figure 3.3: Mapping existing programme in the vicinity of the CMJ site. 


\section{[ HIDDEN HERITAGE ] - The Storage Issues}

The Museum of New Zealand Te Papa Tongarewa archive collection - a wealth of items that represent a significant portion of the nation's collected memories - is currently stored between two buildings in Wellington City.

Despite the prime location of the archive stores in the city, this beautiful collection representing a lifetime of New Zealand's cultural heritage is barely known to those who walk or drive past it every day.

However, the fact that the collection is both literally and metaphorically boxed up, hidden from the general public, is only one part of another pressing issue - lack of secure storage space.
Between the main museum building on Cable Street and the warehouse on Tory Street a total of $10,500 \mathrm{sqm}$ of dense storage space is available for the archives. At least another $2,900 \mathrm{sqm}$ of space is required to safely and accessibly store the variety of items (Francis).

On top of that figure it is estimated that by the year 2030 an extra 7000 sqm will be required to host the ever-growing collection (Macdonald "Te Papa's planned Auckland offshoot is put on ice") .

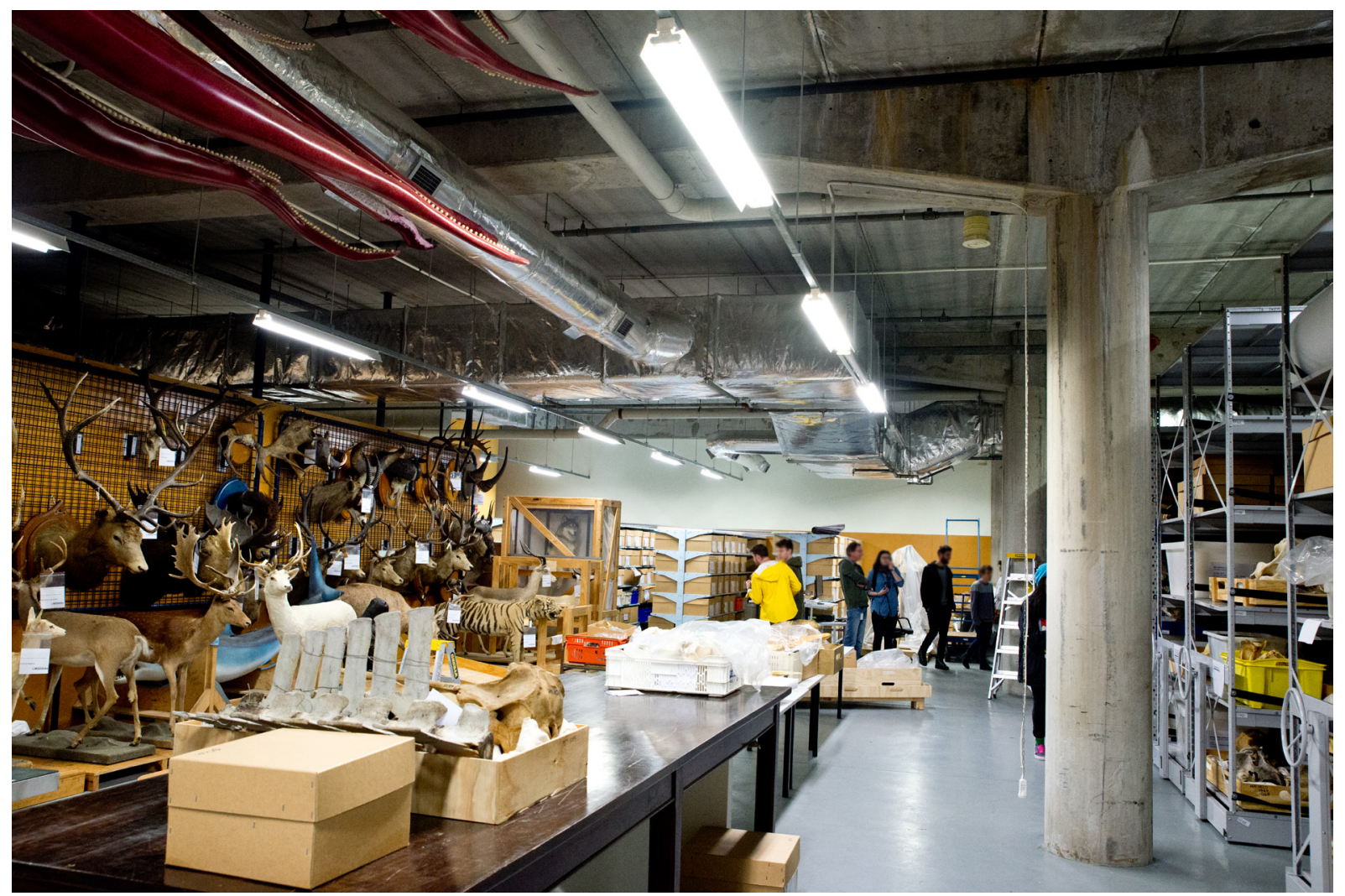

Figure 3.4: Looking at the non-curated jumble of objects inside one of the dry storage rooms at the Tory Street Building. 
In summary there are three major concerns around the current archive storage situation:

1) Only 3\% of Te Papa's stored archives are accessible for public viewing due to lack of museum space (Dominion Post).

2) The government has intentions to move the archives to Auckland due to the high earthquake risks involved in keeping them in Wellington (Macdonald "Te Papa taonga on the move north).

3) Such a national collection is by definition ongoing, needing to house artefacts significant to each period including those yet to come. The warehouse spaces are already cramped and have little or no capacity to handle expansion.

This thesis investigation proposes that by moving the archive collection to the CMJ site in Auckland the following can be achieved:

- Maximum utilisation of a 'lost site' that is inappropriate for most programme typologies and in turn addresses Te Papa's archival storage issues.

- The collections can be housed directly within the CBD, even though there is no 'apparent' site of significant footprint to accommodate them in the CBD.

- Enhanced cultural identity in the site, cultural hub of the city, and cultural awareness for the people in Auckland through an architecture that represents the collected memories of a nation.

- Expansion of the cultural and public urban band so that it links from the CBD across the motorway to suburbs and parks.

- Utilising a programme that can embrace the motorway typology as a viable site.

\section{6}

... a view into spaces that, to all intents and purposes, belong to everyone but are guarded by physical, social, and intellectual hurdles that discourage most from knocking at the door.

- Anna Marie-White 15

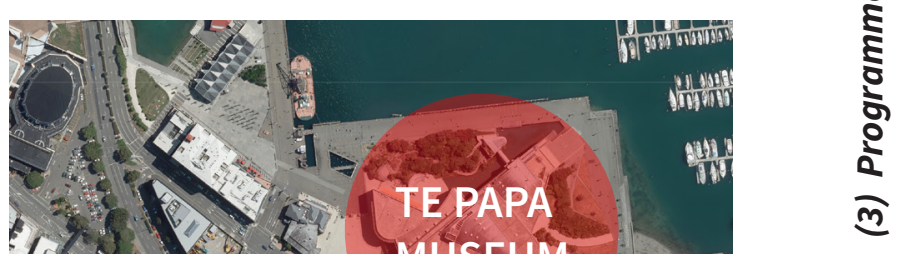

Figure 3.5: The two archive buildings currently storing collections in Wellington. 


\section{[ HIDDEN HERITAGE ] - Neil Pardington's The Vault}

Exemplifying the theme of a 'nation's hidden treasures behind closed doors', Wellington artist / photographer Neil Pardington's exhibition and subsequent book The Vault gives a behind the closed doors look into some of New Zealand's most prominent archive storage centres.

Pardington's photos capture the volume and beauty of the artefacts hidden from public consumption.

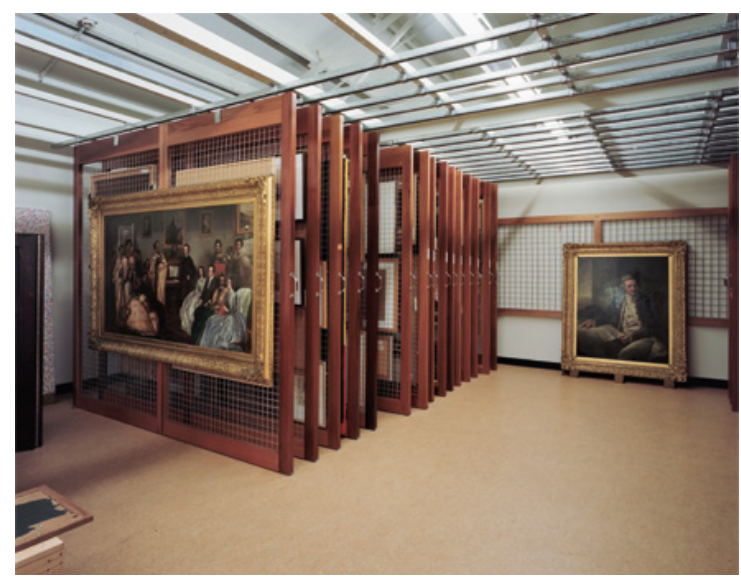

Figure 3.6

\section{6}

Although all have been sufficiently valued to be kept and stored, there seemsnopressingobligationforthese institutions to prove the usefulness of much of the amassed material - this is territory rich with artistic promise.
66

Despite the public mandate of such institutions, Pardington's photos are interior studies that depict private and guarded spaces - the treasure chest of the nation - certainly not intended for unsupervised public access.

- Anna Marie-White 15

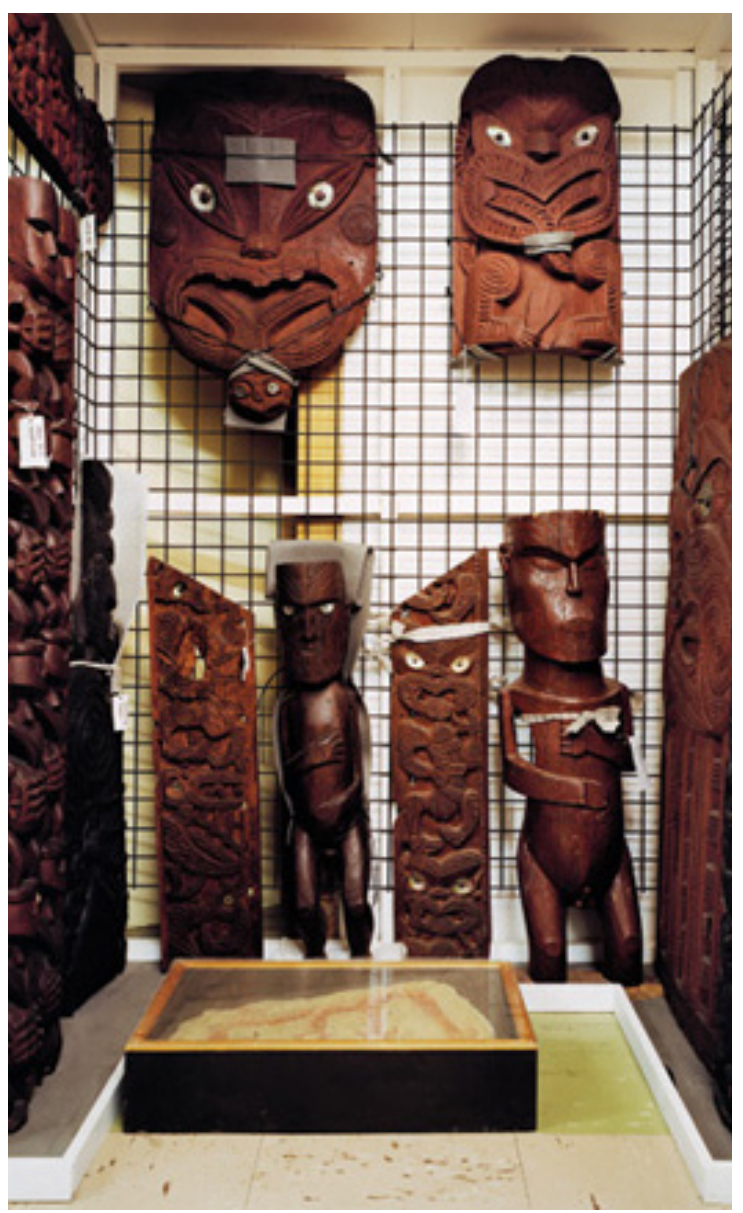

Figure 3.7 


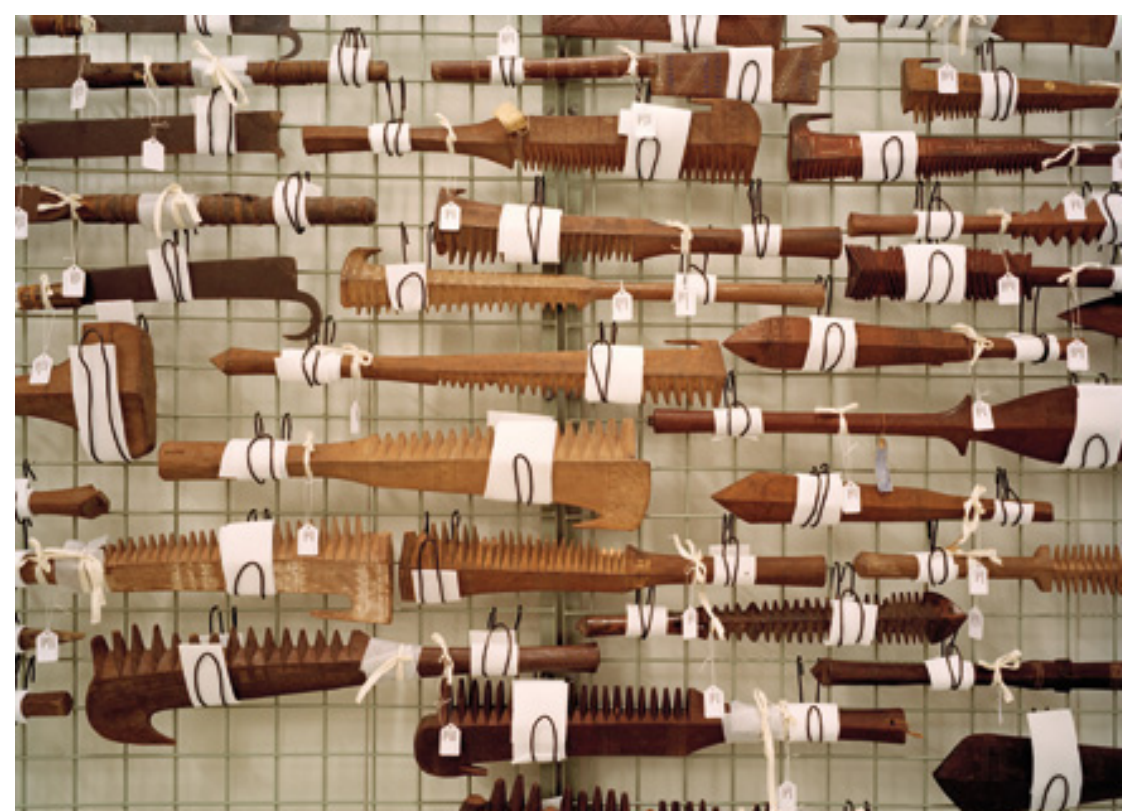

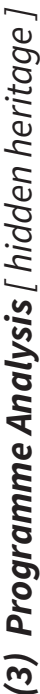

Figure 3.8

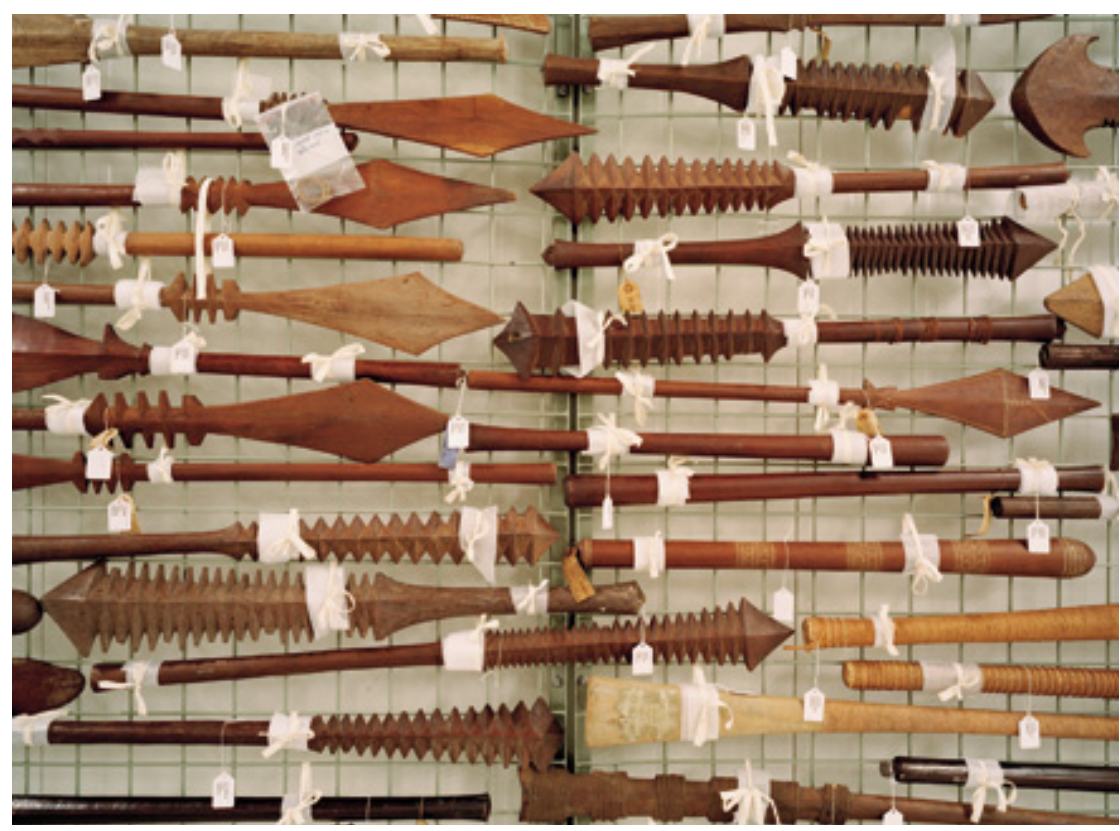

Figures 3.6 - 3.9: Neil Pardington's photos of archived national artefacts.

\section{6}

... the collected culture and history of those things we deem important enough to keep, and what they tell us about ourselves.

- Neil Pardington 19 


\section{ARCHIVE SPATIAL REQUIREMENTS}

Te Papa Tongarewa's existing storage footprints

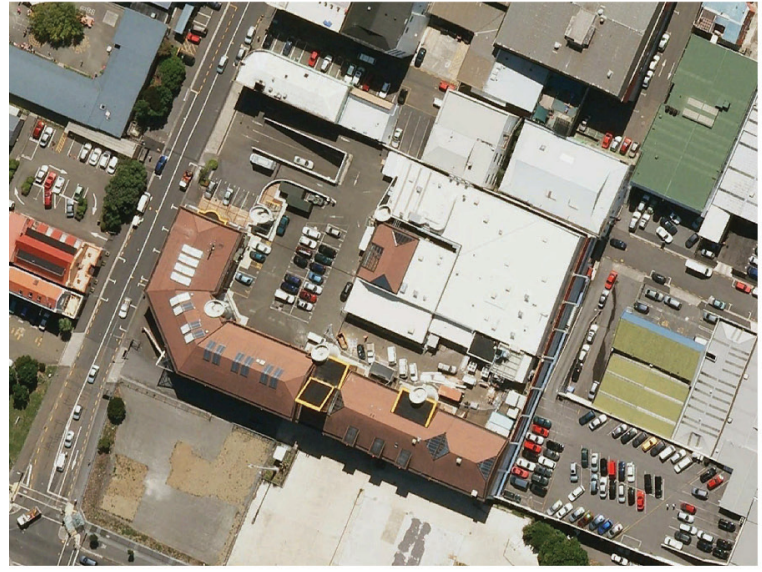

Archives at Tory Street footprint plans of archive elements
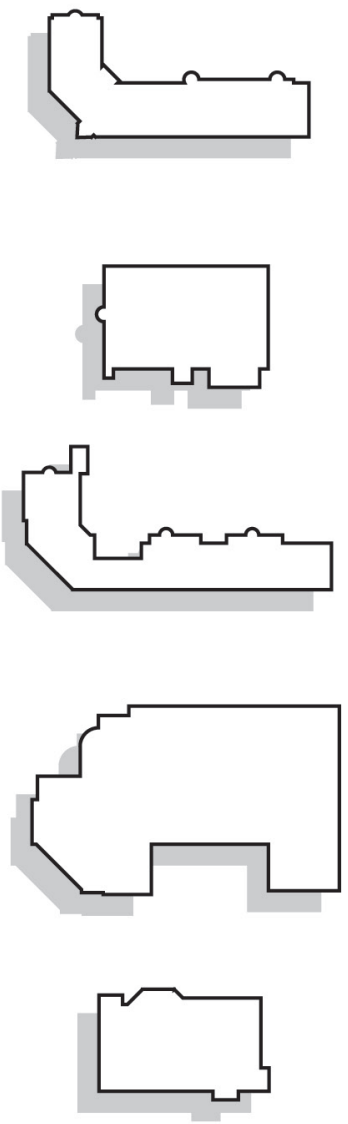

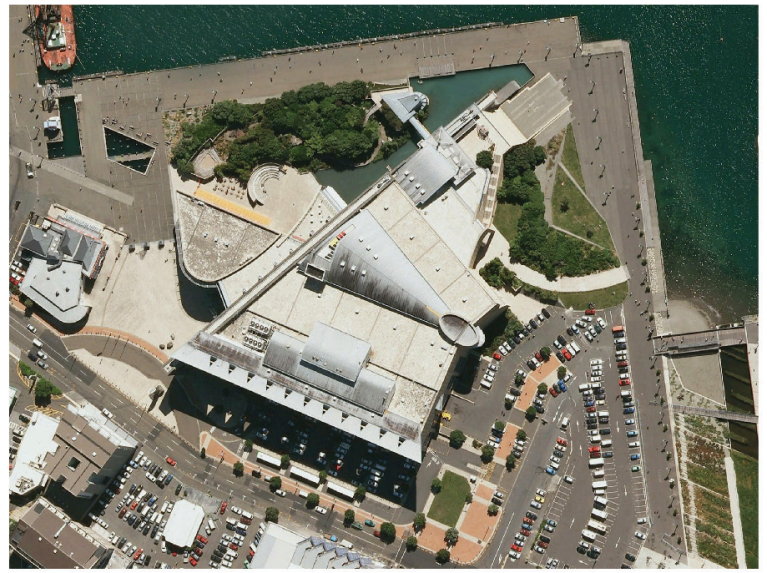

Te Papa Cable Street

footprint plans of archive elements
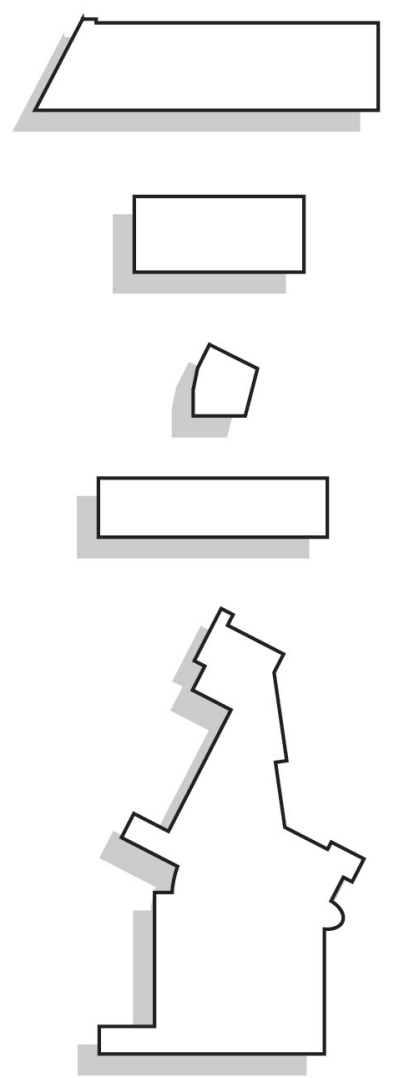

Figure 3.10a: Understanding the current storage requirements in relation to the scope of the site. 


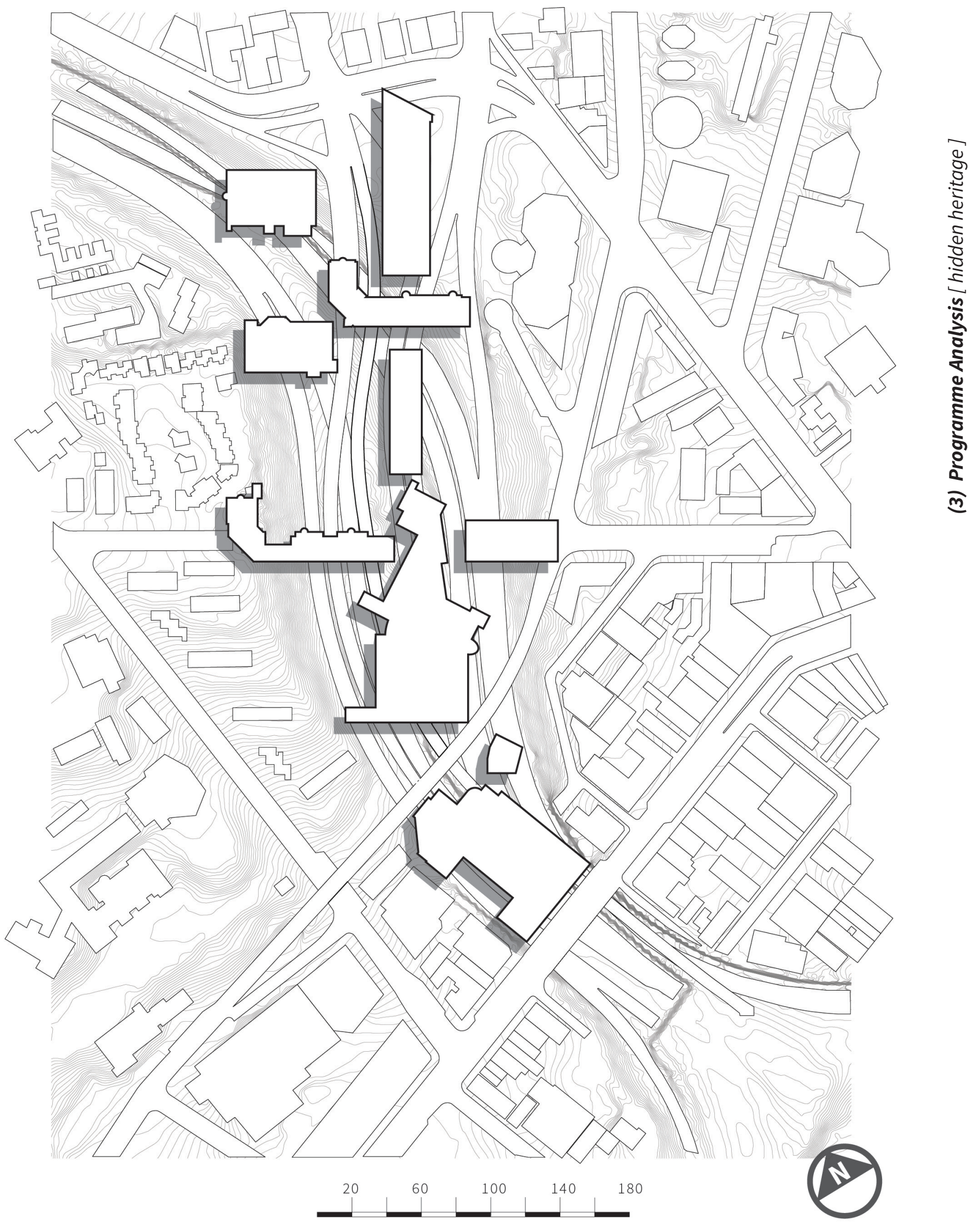

Figure 3.10b: Spatial requirments shown on the CMJ site at identical scales. 


\section{LOGISTICAL SPACES}

The following are the logistical and administration spaces that are critical to the success of an archive facility. The importance of these items of programme is noted in the thesis, however, due to the scale of the project detailed design of these elements falls outside of the research scope. The current facilities at Te Papa allow for approximately 4,865 sqm for these spaces.

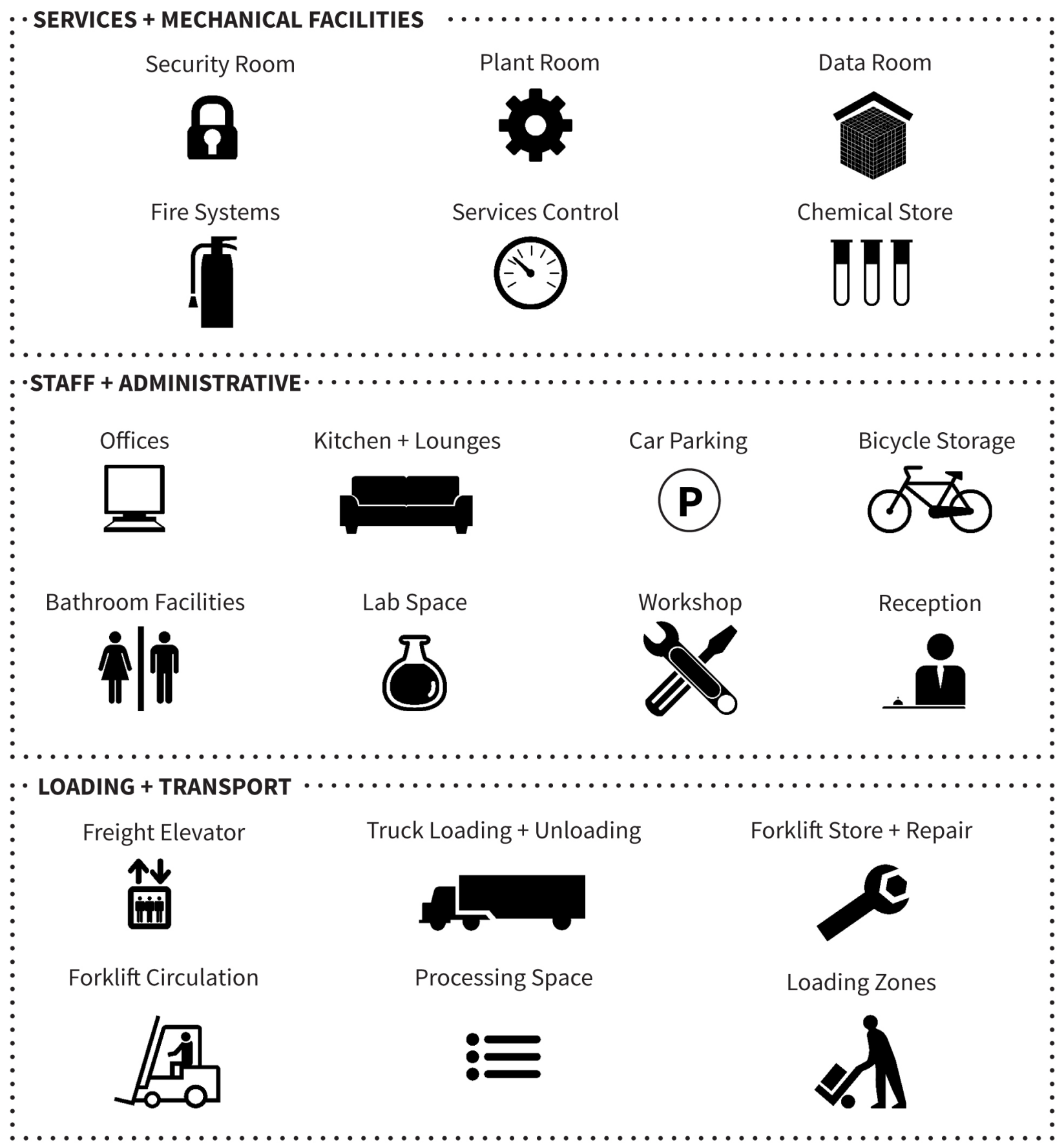




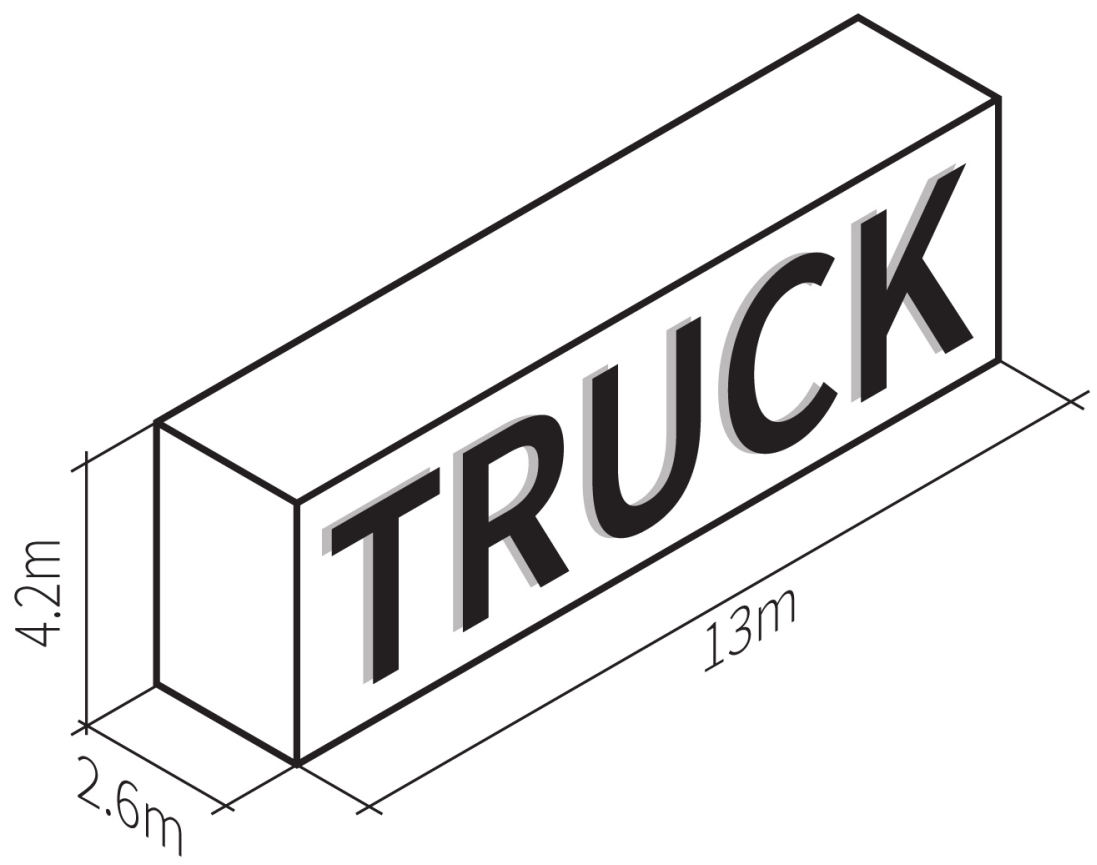

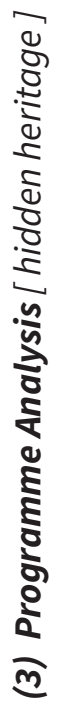
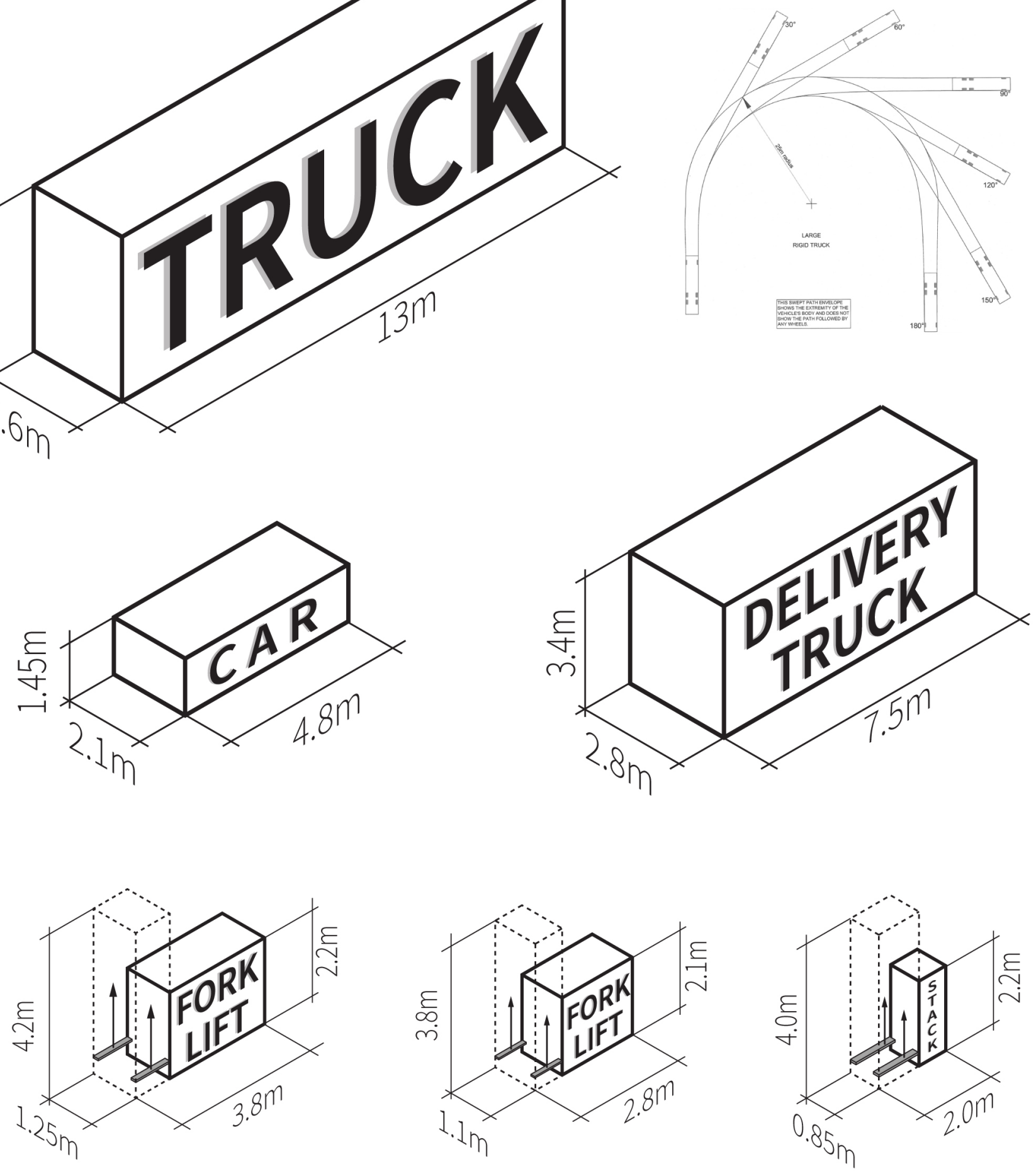

Figure 3.12: Vehicle logistics. 


\section{[ CURATORIAL OPPORTUNITIES ] - Current Collection}

To achieve R05, to 'curate' stored national heritage artefacts in ways that maximise their didactic potential and increase cultural awareness, the Te Papa stored archives were evaluated in relation to size and light sensitivity.
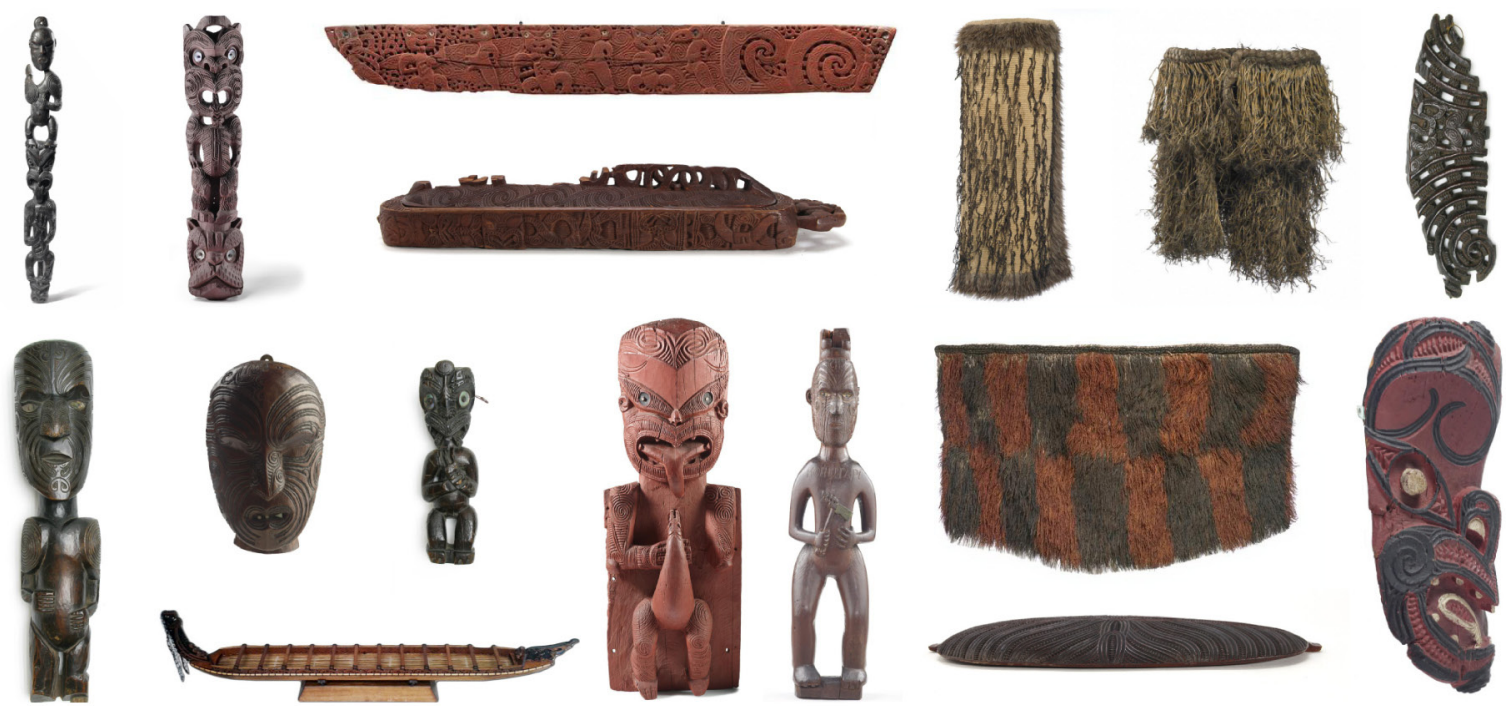

MĀORI TAONGA (DRY STORAGE) Current storage space: 1500 sqm.

Large non-light sensitive Items: Large carvings | waka | large taiaha (weapons) | large wheku Small and/or sensitive items: Kakahu (cloaks) | fabrics and items with feathers
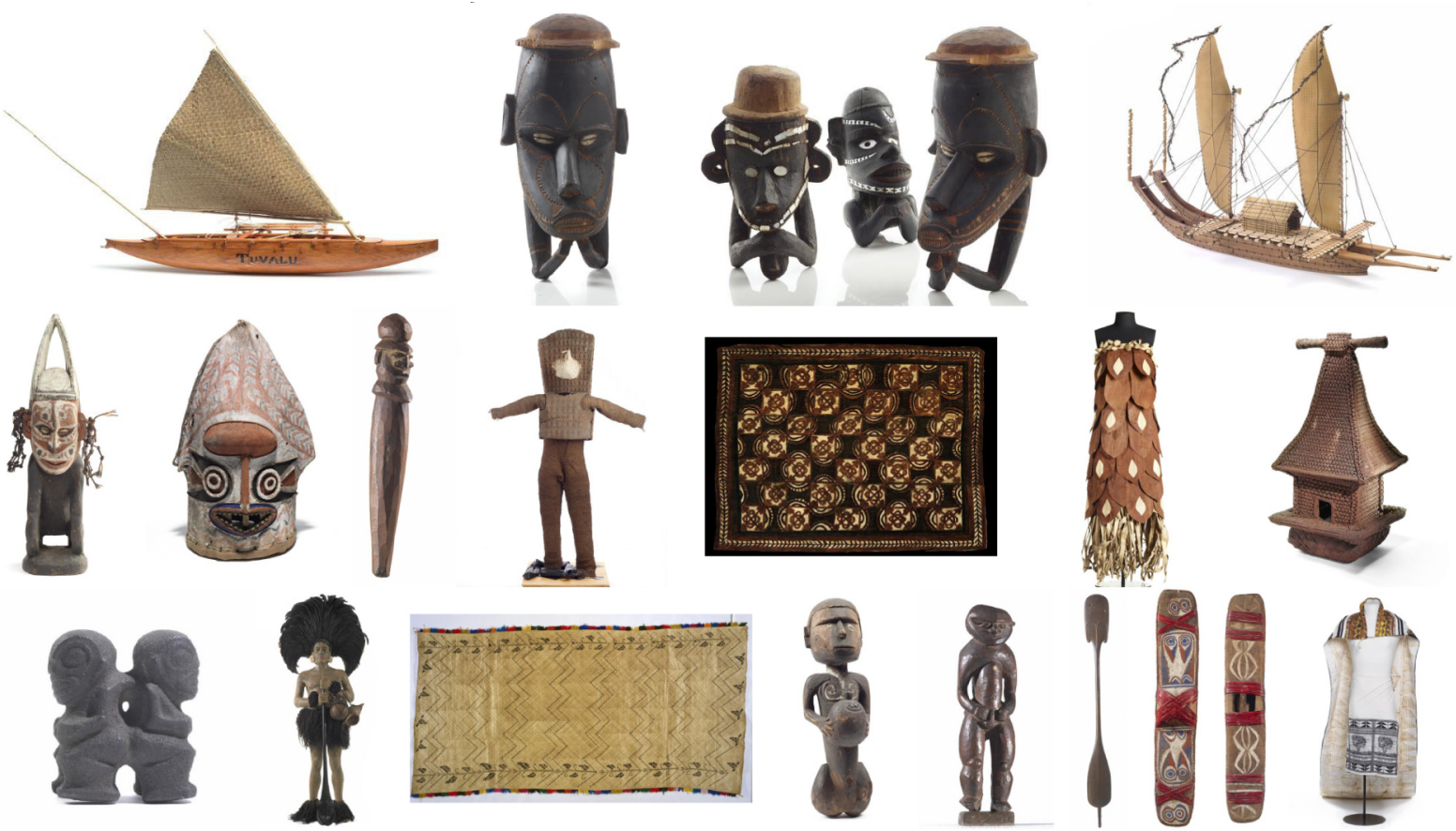

PASIFIKA ITEMS (DRY STORAGE) Current storage space: 130 sqm.

Large non-light sensitive Items: some boats | large weapons | large carvings Small and/or sensitive items: tapa (fabrics) | fish hooks | fabrics and cloaks 

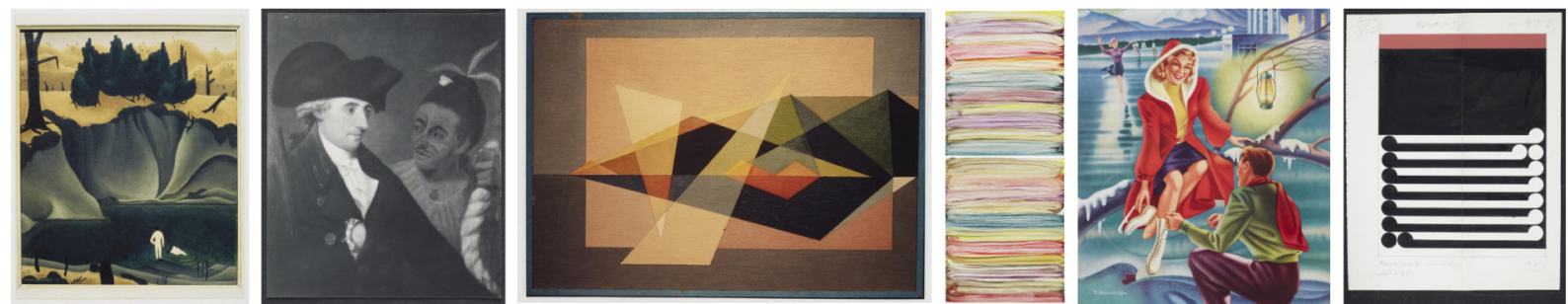

ART + PHOTOGRAPHY (DRY STORAGE) Current storage space: 2532 sqm.

Large non-light sensitive Items: large oil paintings | sculptural items | large stone \& metal artworks Small and/or sensitive items: works on paper | fabrics | stamps | photographs
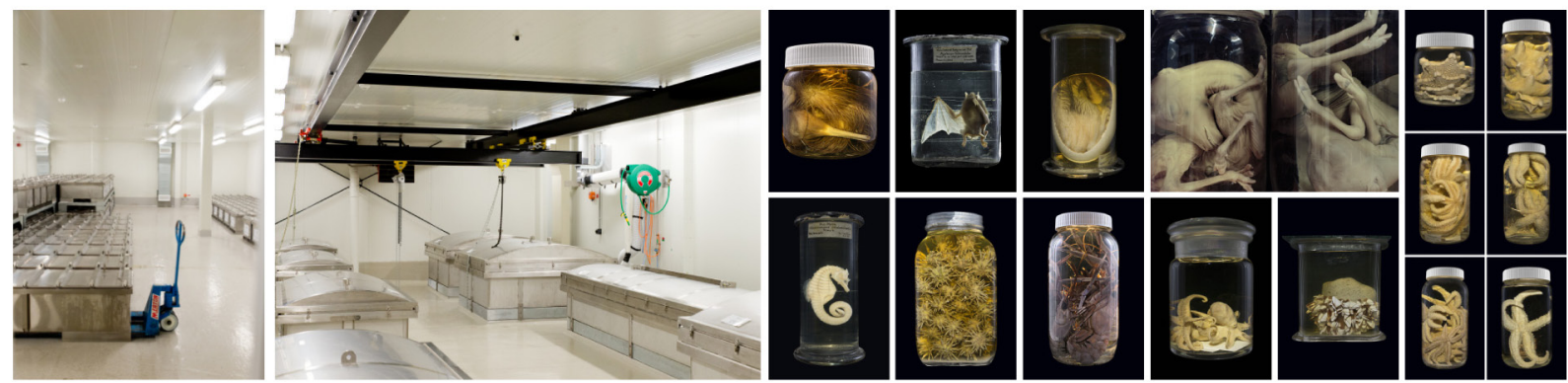

ANIMALS (ALCOHOL STORAGE) Current storage space: 1290 sqm.

Large non-light sensitive Items: none

Small and/or sensitive items: all alcohol store items are sensitive in nature
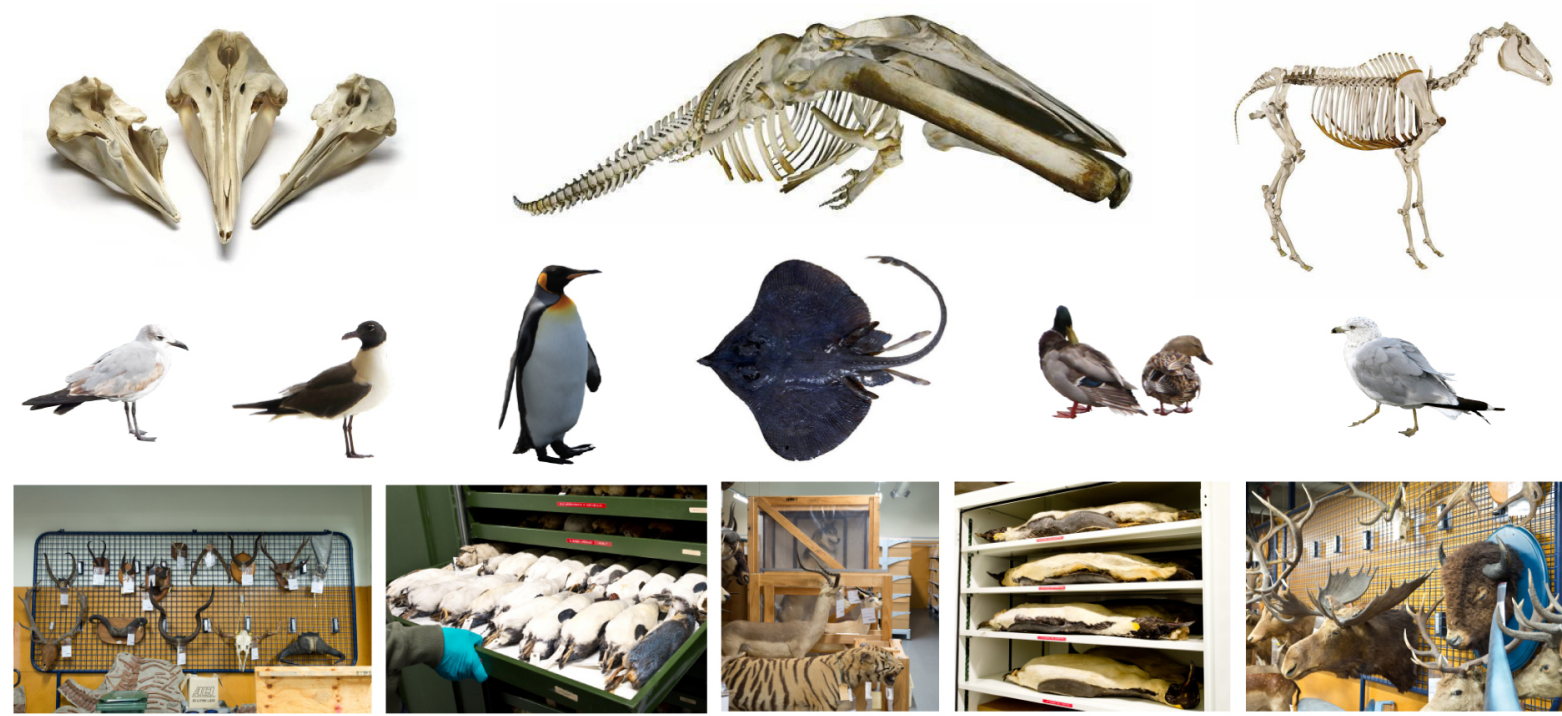

ANIMALS (DRY STORAGE) Current storage space: 2441 sqm.

Large non-light sensitive Items: animal replicas | large skeletons

Small and/or sensitive items: all organic specimens | all furs

Figure 3.15 (Top): Examples of the Art \& Photography items in the Te Papa Collection.

Figure 3.16 (Middle): Examples of the Alcohol store animals in the Te Papa Collection.

Figure 3.17 (Bottom): Examples of the Dry store animals in the Te Papa Collection. 


\section{[ CURATORIAL OPPORTUNITIES ] - Current Collection}
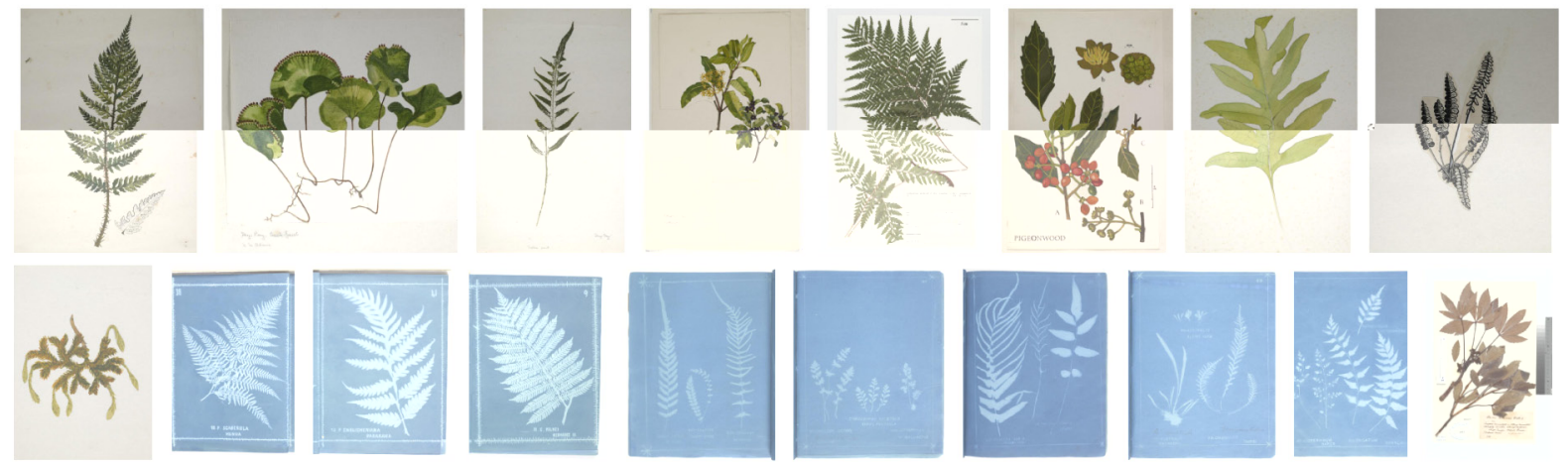

BOTANY (DRY STORAGE) Current storage space: 390 sqm.

Large non-light sensitive Items: none

Small and/or sensitive items: all dried botanic specimens are sensitive in nature
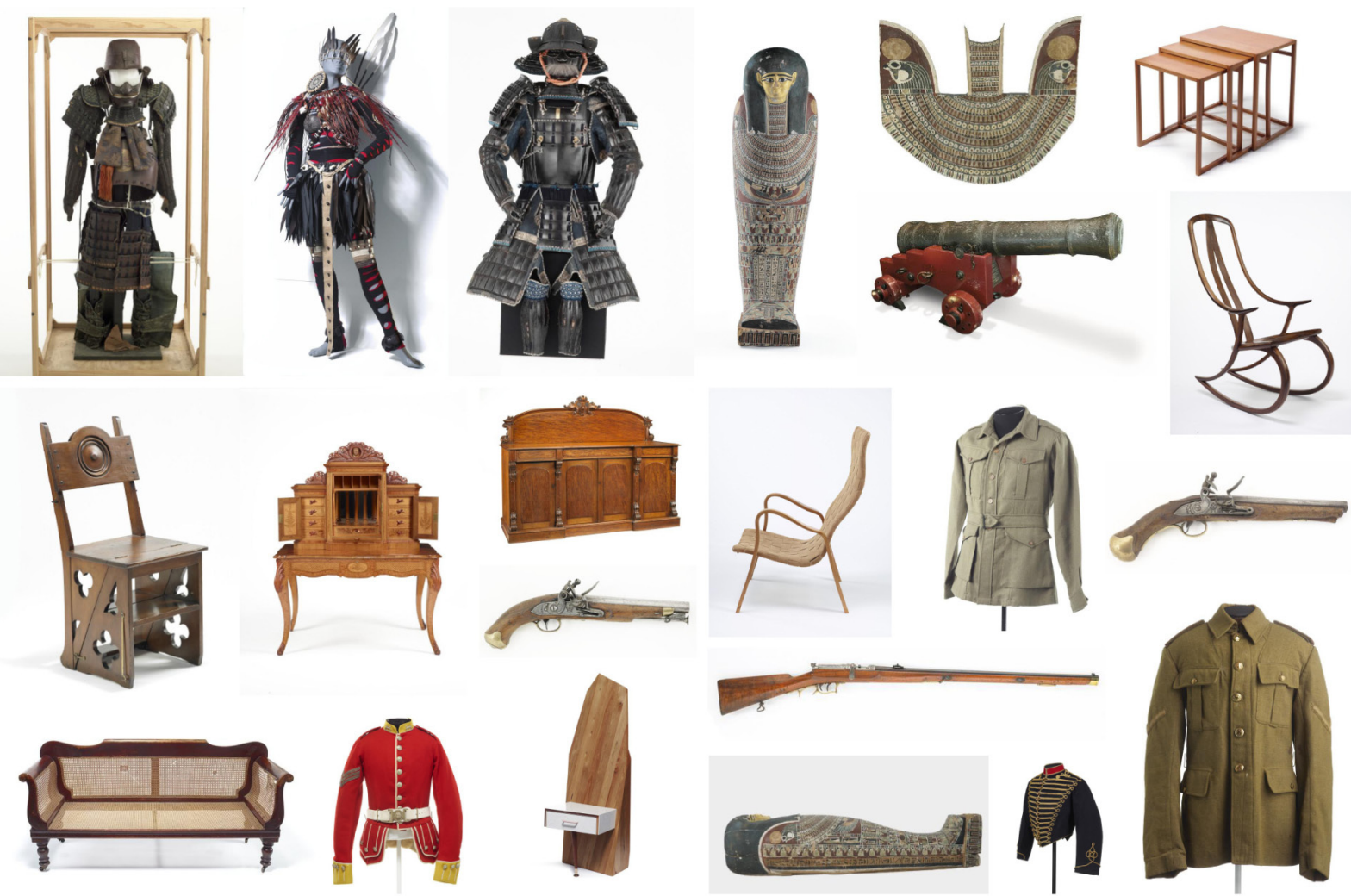

HISTORY GENERAL (DRY STORAGE) Current storage space: 2595 sqm.

Large non-light sensitive Items: metal armour | large weapons | some furniture | stone items Small and/or sensitive items: furniture with fabric | clothing items | jewellery 
TE PAPA CURRENT STORAGE

- tory street + cablestreet
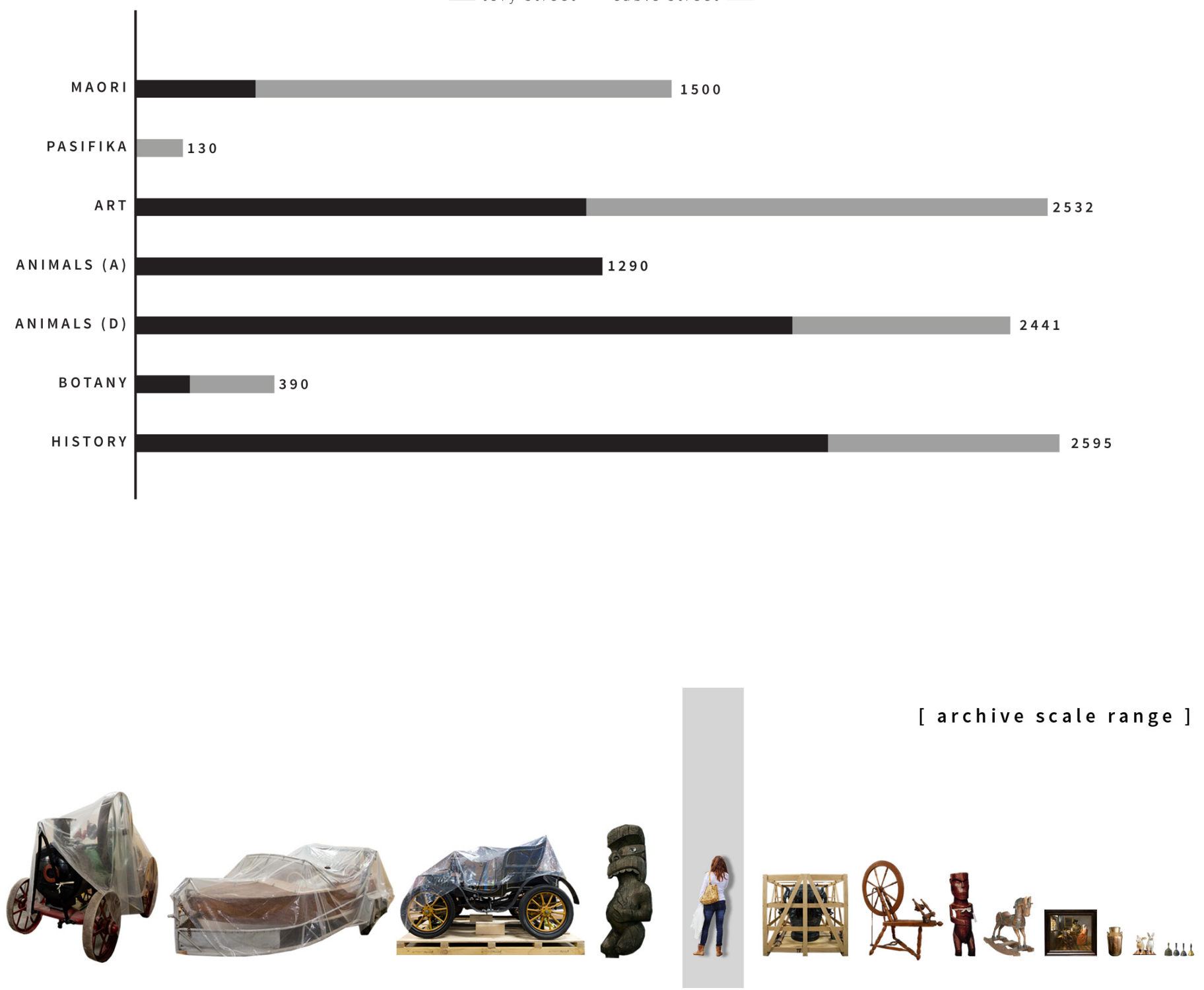

Figure 3.20 (top): A graph of the current storage space for the archives between the two buildings.

Figure 3.21 (bottom): The scale range between the archive objects means they will be engaged by the public in different 


\section{[ CURATORIAL OPPORTUNITIES ] - Velocity + Scale}

By 're-cataloguing' the collected artefacts in relation to size and light sensitivity, the research intervention can be designed to take advantage of viewing opportunities from cars travelling at high velocity, bicyclists travelling at moderate velocity, and pedestrians both inside the facility and outside walking past it.

The fast travelling cars can only engage with the larger items in the brief period that they pass by, whilst the slow moving pedestrians are able to engage with smaller archive items over a longer period of time.

This suggests opportunities for facade treatments and presentation of the archives that are strategically adjusted to suit the typology of the viewer who is passing through. 


\section{6}

How speed affects our interaction with the environment is a critical issue. Different modes of travel create different scales of perception: detail is not perceived when travelling quickly.

- Annalisa Meyboom, 79
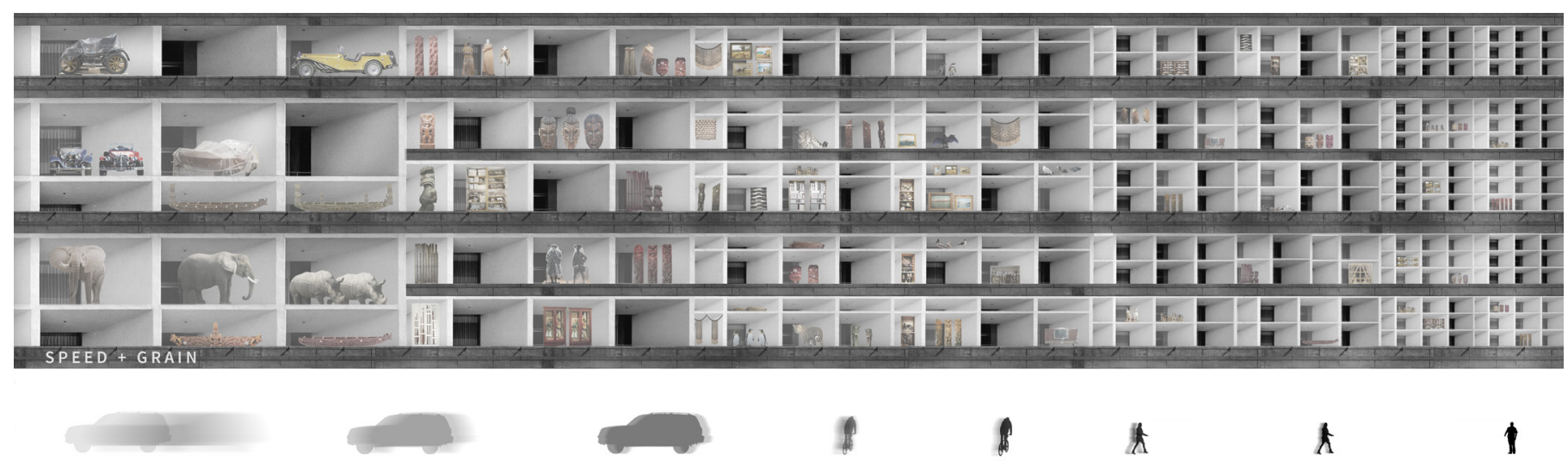


\section{[ CURATORIAL OPPORTUNITIES ] - Sunlight + Daylight}

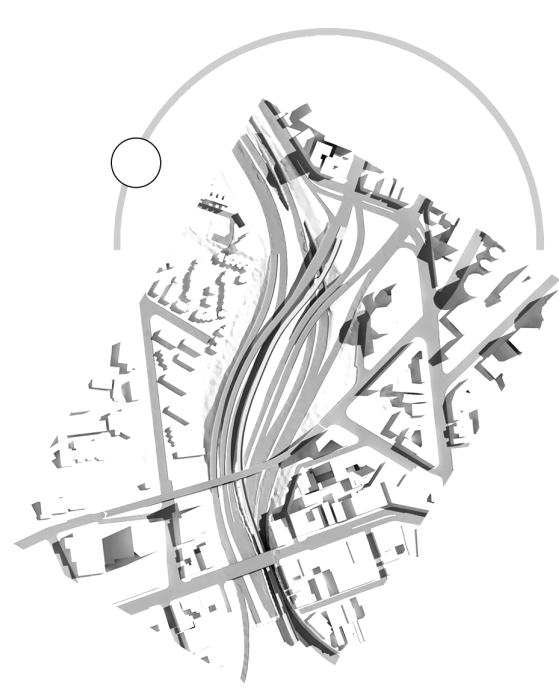

MORNING

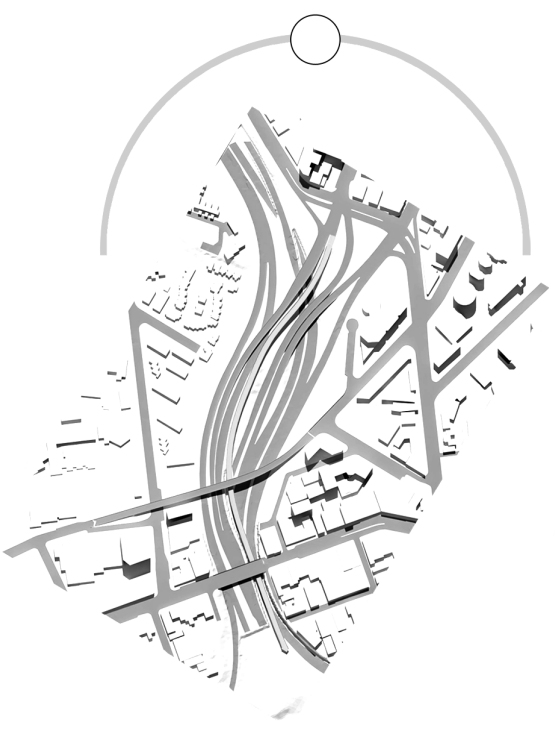

MIDDAY

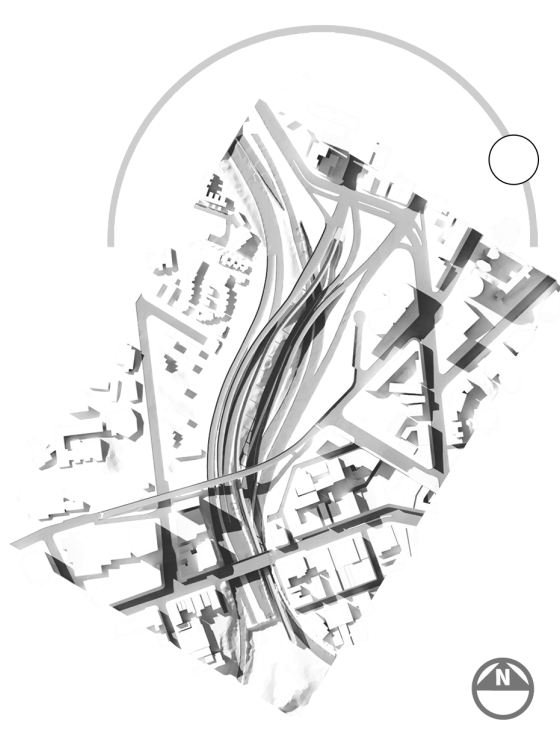

AFTERNOON

The delicate nature of some of the archive collections results in many of the items being sunlight sensitive (direct light), and many being daylight sensitive (indirect light). This means placement of the archives in the design research intervention needs to consider which elements are most suitable for facing north vs. south, or being exposed vs. enclosed. 
[PROGRAMME + SUNLIGHT / DAYLIGHT]

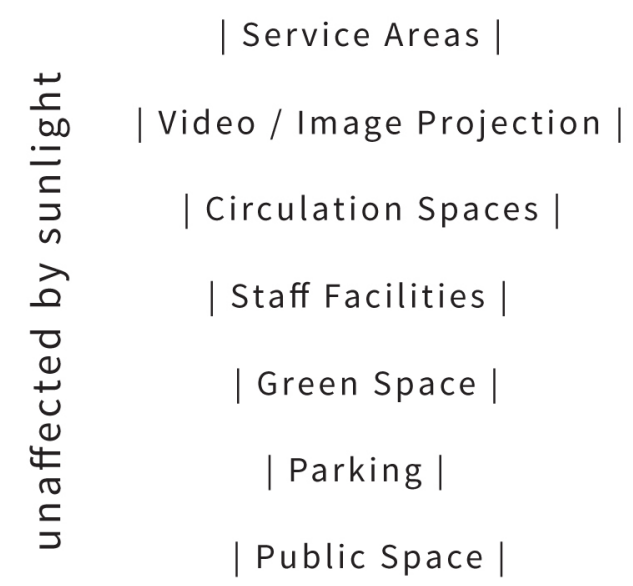

$\downarrow \frac{\text { NORTH FACING / exposed }}{\text { SOUTH FACING / enlcosed }} \downarrow$

| Some Lab Spaces |

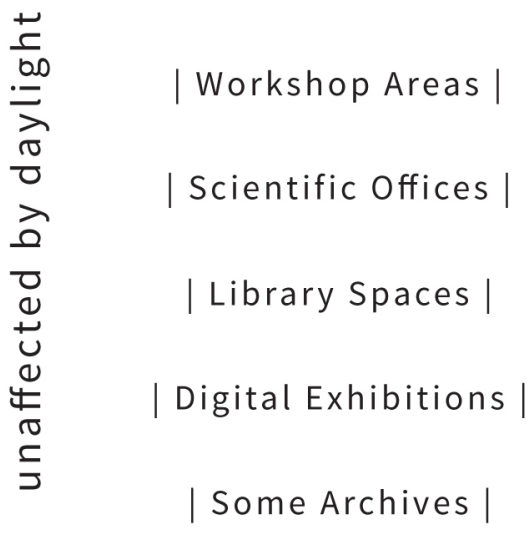

\section{[ARCHIVES + DAYLIGHT LEVELS]}

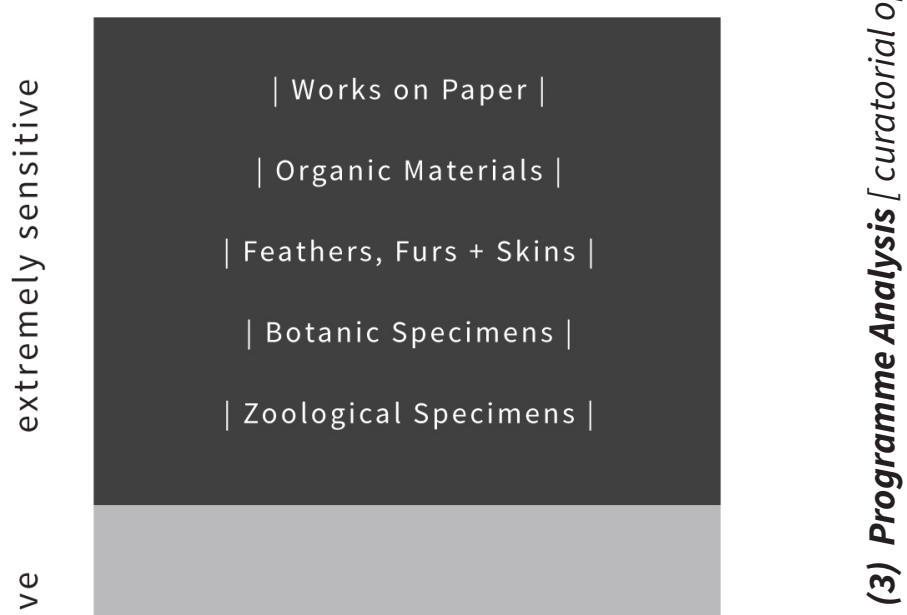

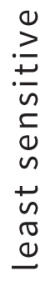

| Oils |

| Acrylics |

| Composites |

| Stone Items |

| Ceramic Items |

| Metal Items

| Glass Items | 


\section{[ CURATORIAL OPPORTUNITIES ] \\ - Categorising Archives}

This research proposes grouping the archive collections based on their scale and their sensitivity to light. This results in the creation of seven new categories for storage.

This new means of 'cataloguing' stored objects allows each of these storage typologies to be placed within the design research intervention according to opportunities for interaction with the general public. This grouping will allow large numbers of the items to enter the public realm and provide opportunities for more engagement - thereby promoting a greater cultural awareness around these collections (RO5 and RO6).

Current technology relating to digital coding of artefacts allows all objects to be readily located wherever they are stored.

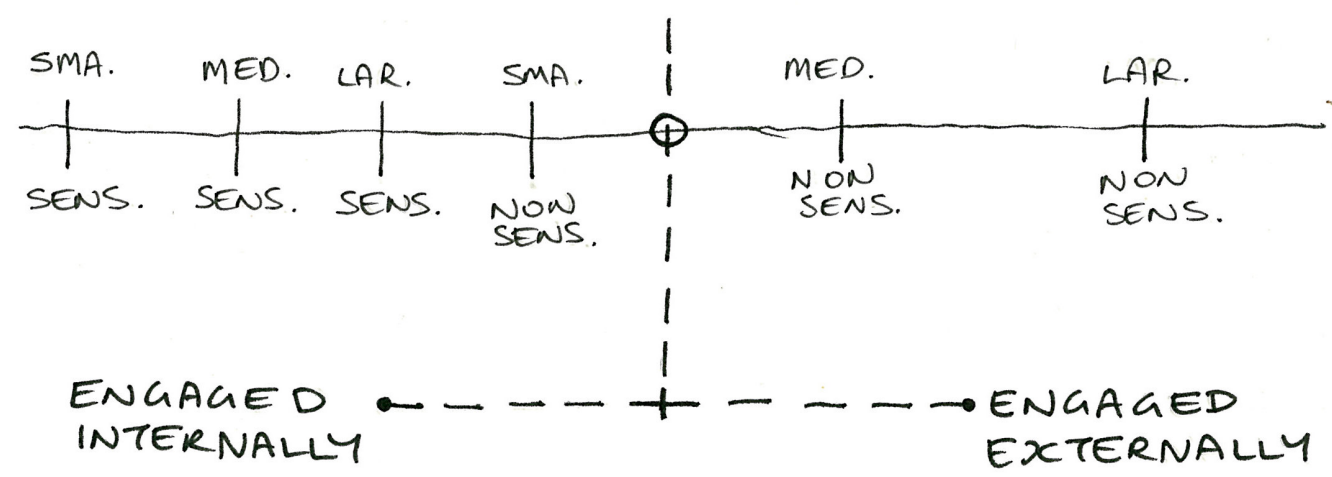




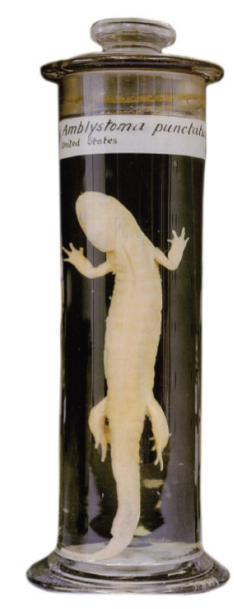

[ Categories of Storage ]

\section{[ Non-Sensitive ]}

(N)

can face north / sunlight acceptable

A vehicular - pedestrian interaction stone items / living plants + greenery / video displays

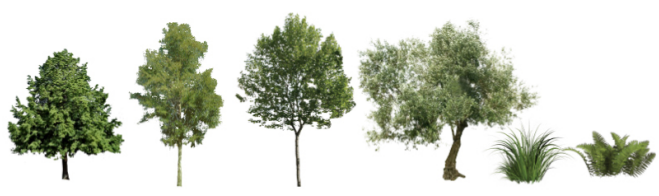

\section{[ Small Low Sensitivity ]}

(5) south facing / daylight only

$\star$ pedestrian interaction

crockery / small sculpture / colonial weapons / traditional weapons / small carvings / jewellery /

\section{VA A}

\section{[ Medium Size Low Sensitivity ]}

(3) south facing / daylight only

$\underset{0}{A}$ 太 vehicular - pedestrian interaction oil based and acrylic artworks / larger carvings / chairs and furniture / statues / metal armour / modern weapons /

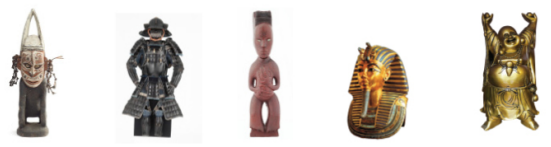

\section{[ Large Low Sensitivity ]}

(5) south facing / daylight only

vehicular interaction

vehicles / machinery / mechanical items/large furniture / transport items /

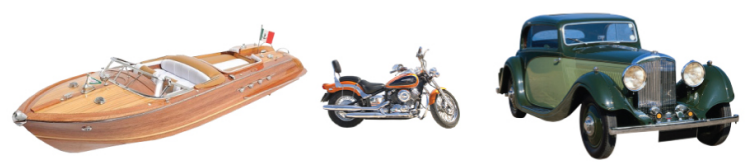

丸 pedestrian interaction

tapas and large fabric prints / large zoological specimens / alcohol stored large animals
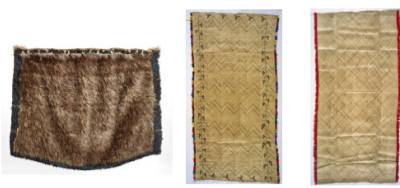

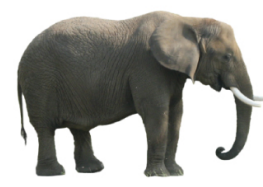




\section{[ CURATORIAL OPPORTUNITIES ] - Precedents}

\section{Yinglian Stone Archive}

This project review offers insights into how architectural design can enhance public engagement with stored collections.

Architects: Atlier Alter Location: Beijing, China Year: 2016

- Utilises permeable facades and tapered entries to draw outsiders' attention to archive items inside.

- Allows public circulation throughout the archive for more intensive engagement with the archive elements.

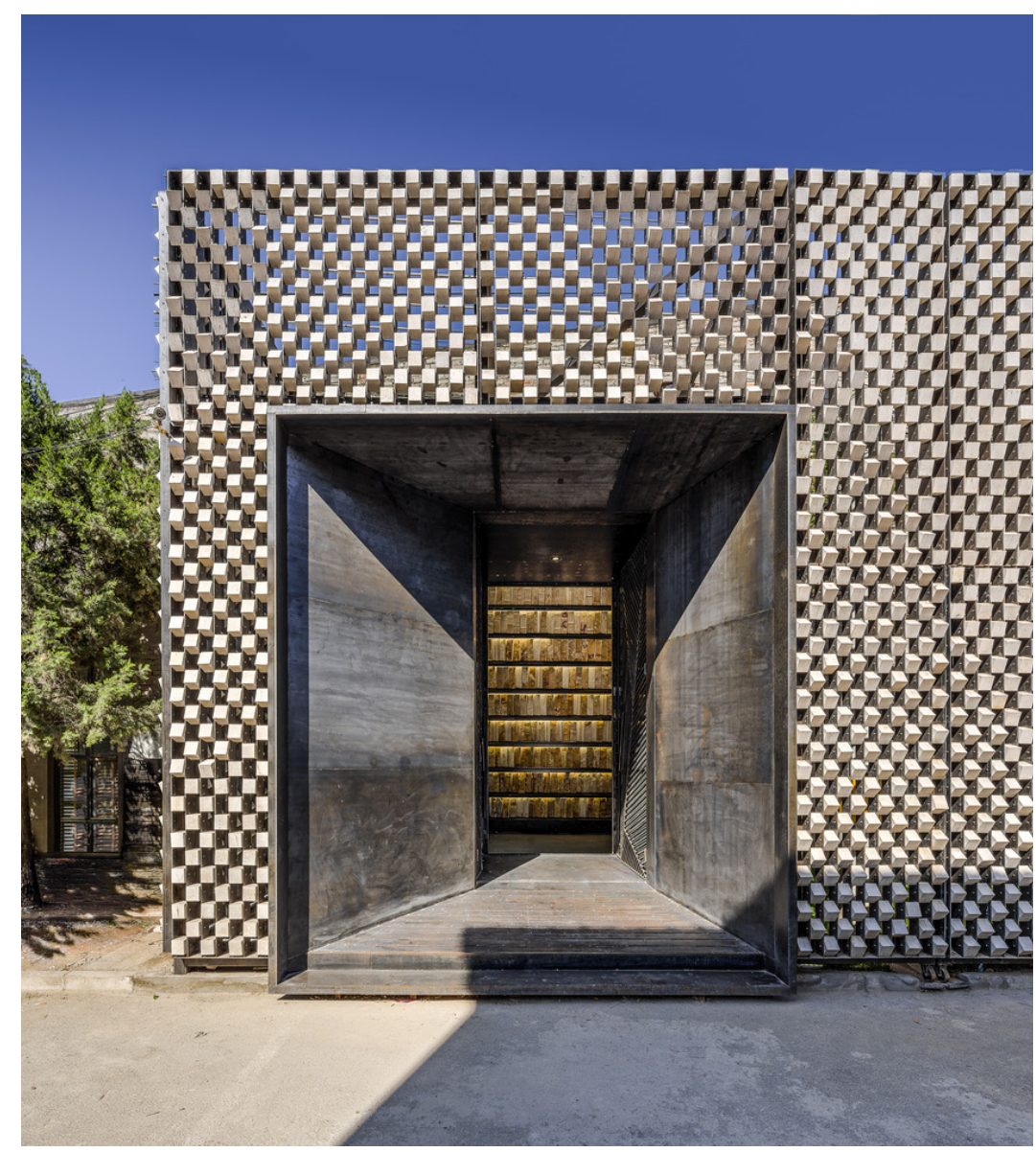

Figure 3.28: The Stone Archive.

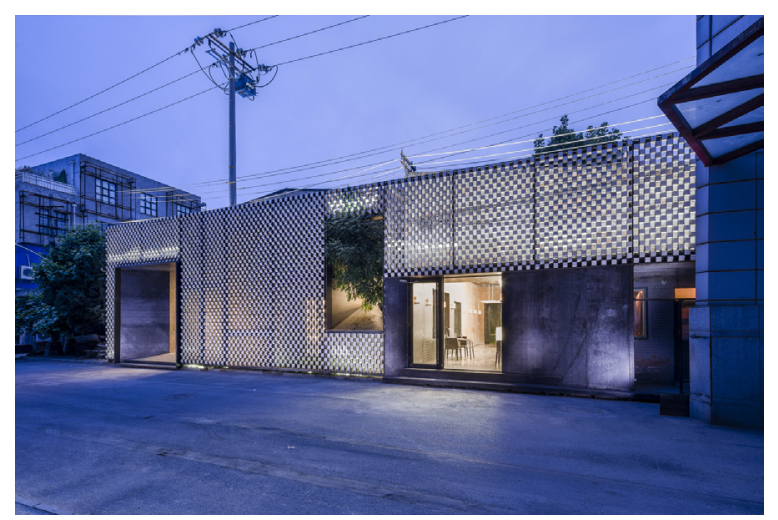

Figure 3.29: The Stone Archive.

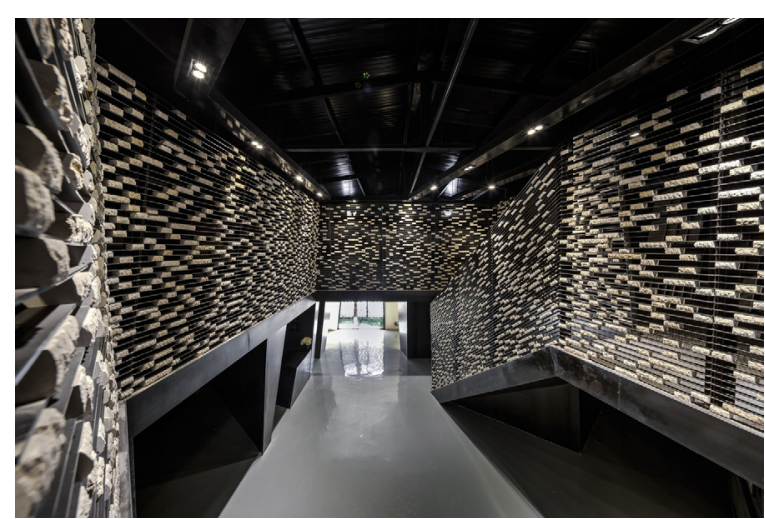

Figure 3.30: The Stone Archive. 

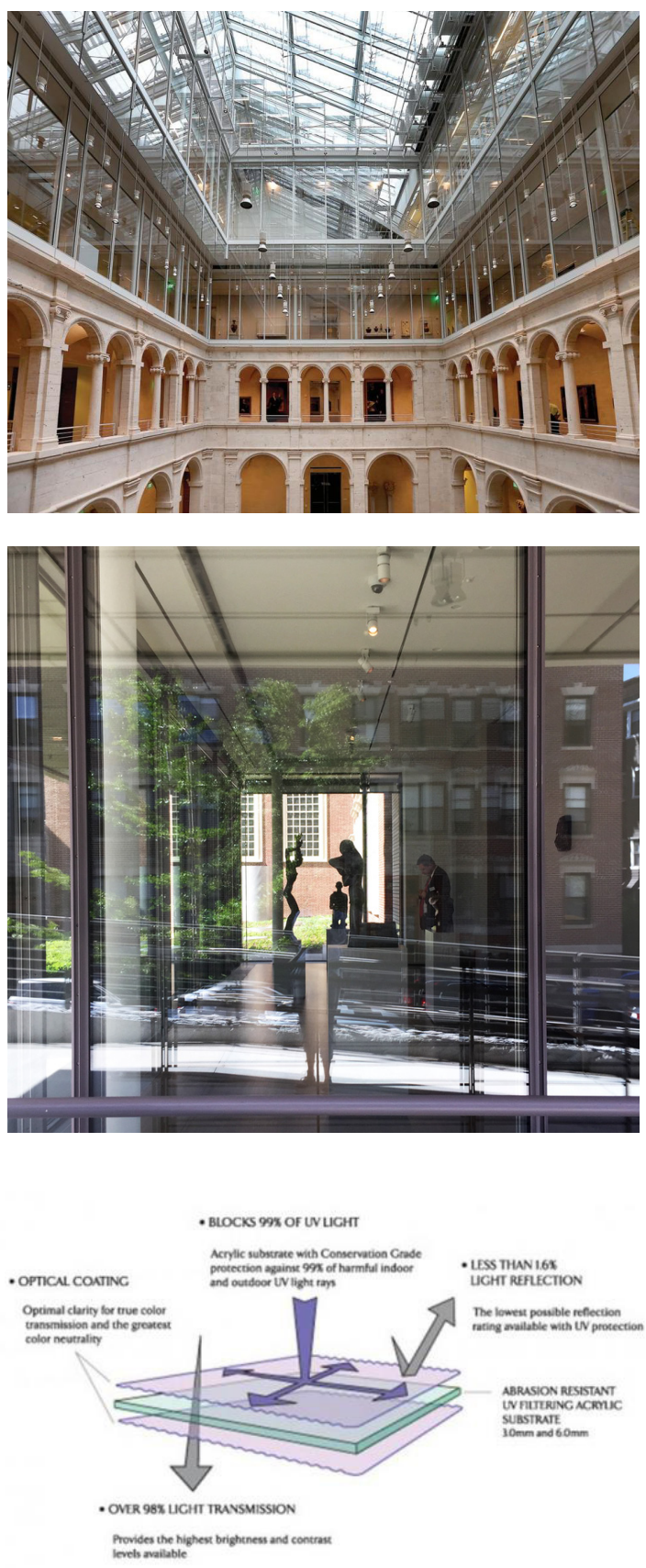

Figure 3.33: shows Art Glass AR Protect. It is one of several glazing products used in museums around the world that allows daylight into the collection spaces without damaging the items.
Figures 3.31, 3.32: Harvard Art Museum, Boston MA | Renzo Piano Building Workshop + Payette 2014.

The Harvard Art Museum utilises the UV resistant 'Art Glass' to allow daylight into its spaces without damaging the valuable items inside. The most intriguing aspect of the design can be seen in figure 3.32 where instead of the roof being glazed to allow light in, the end facade of the corridor is glazed allowing visual permeability into the space from the ground level outside and creating opportunities for outside public engagement.

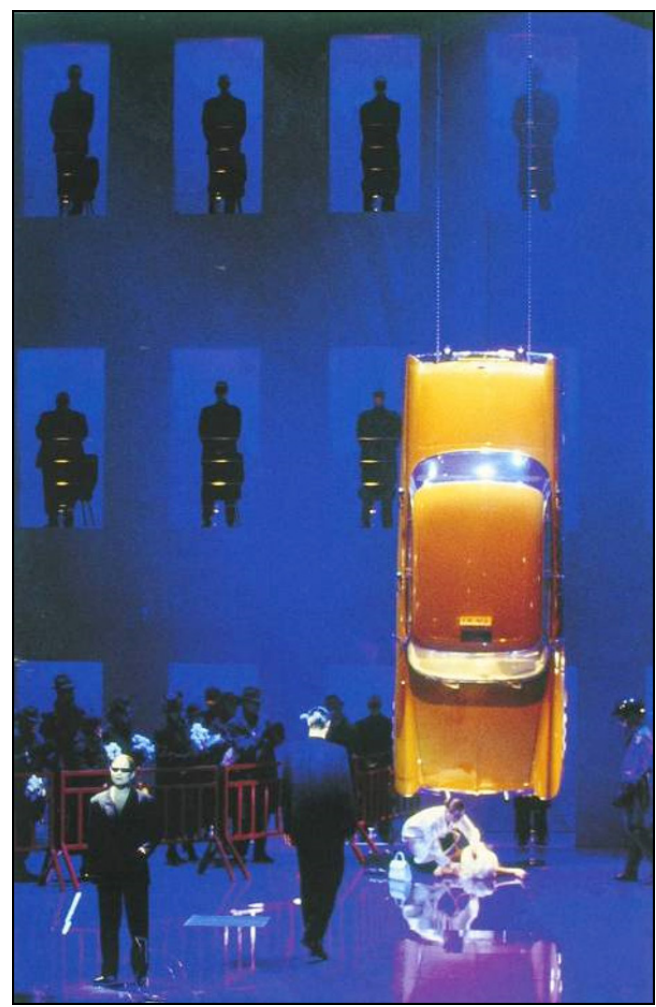

Figure 3.34: An exemplar of a unique way the design research intervention could 'curate' a heritage object in the public realm (RO5). 


\section{[ BEYOND STORED OBJECTS ] - Green Spaces}

\section{6}

Green space structures can act as organisational structures for sprawling metropolitan areas, providing space for nature development, leisure/recreation and cultural heritage.

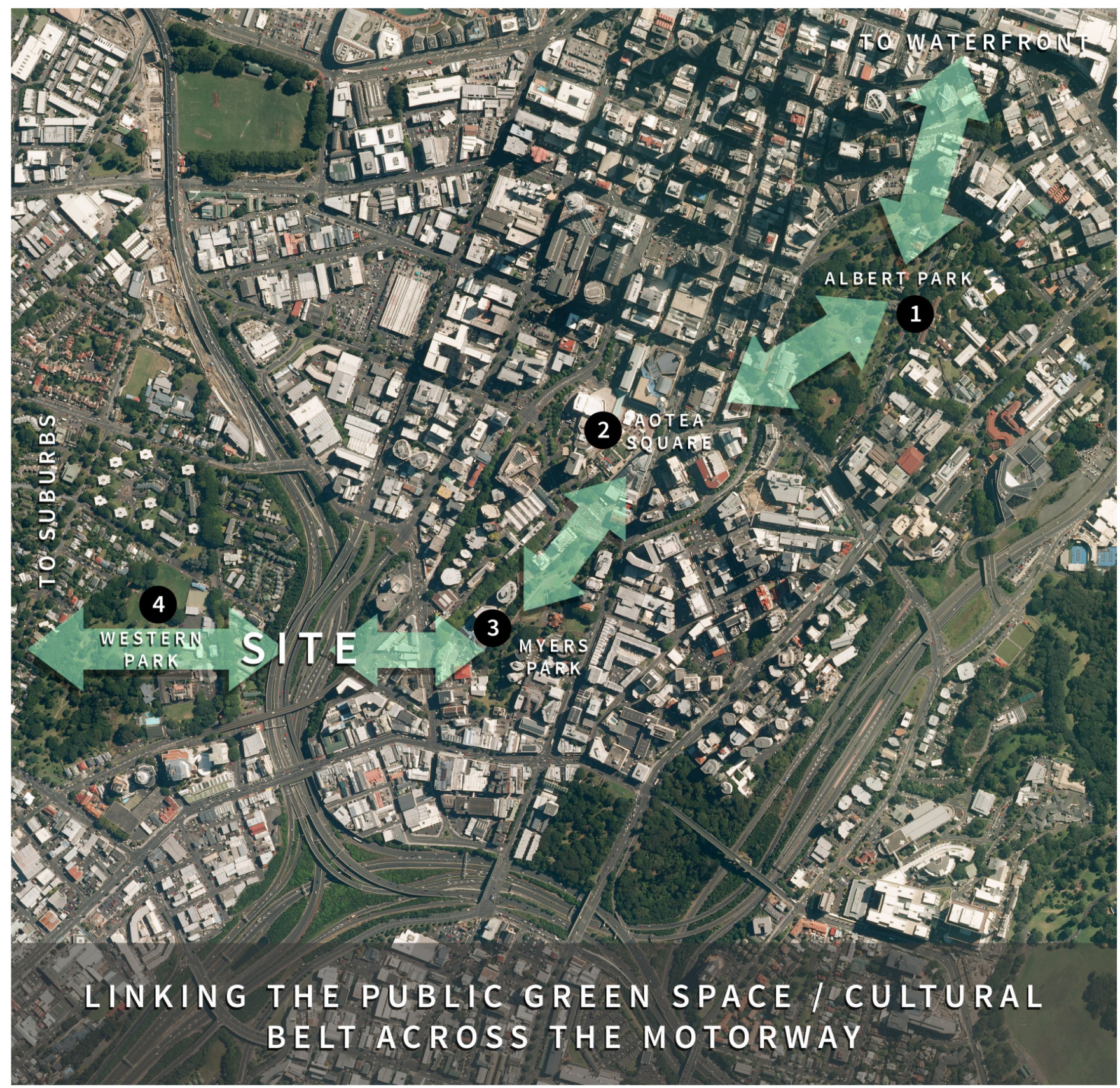

Figure 3.35: The extent of the cultural / green space belt can be seen in the wider scale of the city. Along this belt are cultural institutions such as: the Auckland Art Gallery, Central City Library, Aotea Centre, Auckland Town Hall, Performance Theatres, and Educational Centres. The design research intervention aims to extend this cultural / green space hub across the motorway and into the western suburbs through the reclamation of one of the city's largest lost urban spaces. 

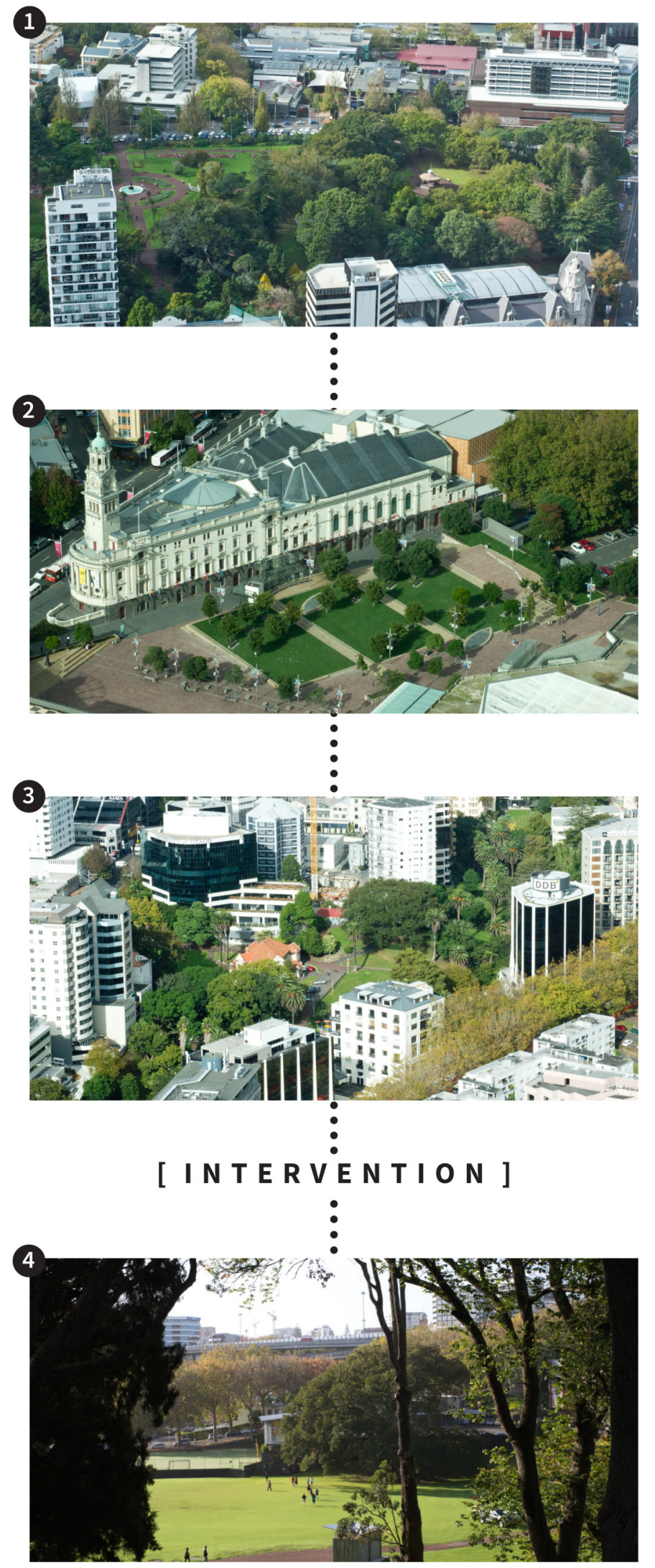

Figure 3.36: Elements of the cultural / green space belt. 


\section{[ BEYOND STORED OBJECTS ] - Seed Archive}

Addressing the findings from figures 3.35 - 3.36 an element of green space is desired across the CMJ site to strengthen the extension of the green / cultural belt and the sense of permeability.

Te Papa's archives only represent a portion of New Zealands' national cultural identity - a seed archive representing the nation's natural heritage is equally important to this identity.

The Seed Archive contributes to protecting the viability of New Zealand's Natural Heritage. It has the same didactic potential as the Te Papa archives for creating an awareness of the importance of these facilities and developing a greater understanding of our national identity and heritage.

Seed Archives require that seeds be planted at regular intervals to ensure their viability. For this reason, a public green space would be quite appropriate in the thesis design, in collaboration with the seed storage.

New Zealand's only seed bank, the New Zealand Indigenous Flora Seed Bank (NZIFSB), is quite small (see figure 3.37) and located just outside of Palmerston North. However, just like the Te Papa archive it is out of the pubic eye and hence, its importance is not recognised.

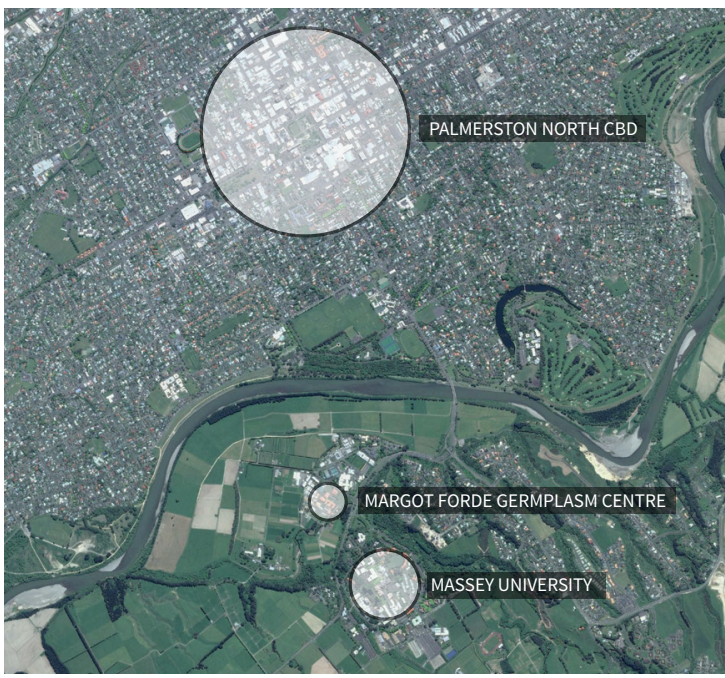

Figure 3.37: The NZIFSB stores seeds at the Margot Forde Germplasm Centre near Massey University.

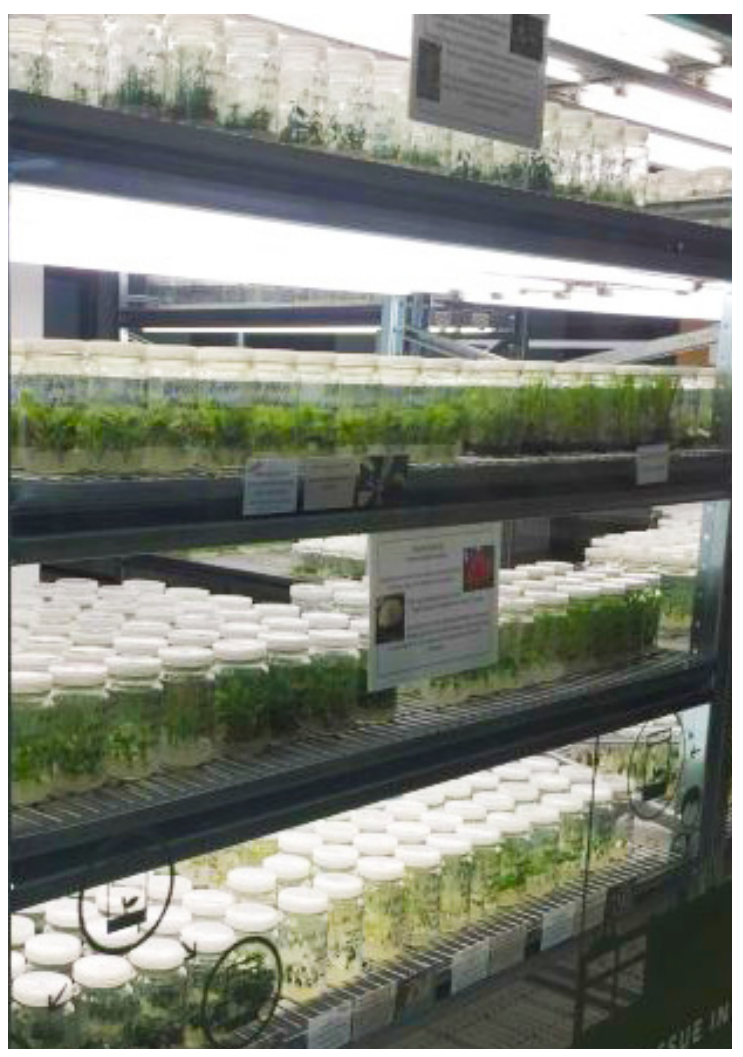




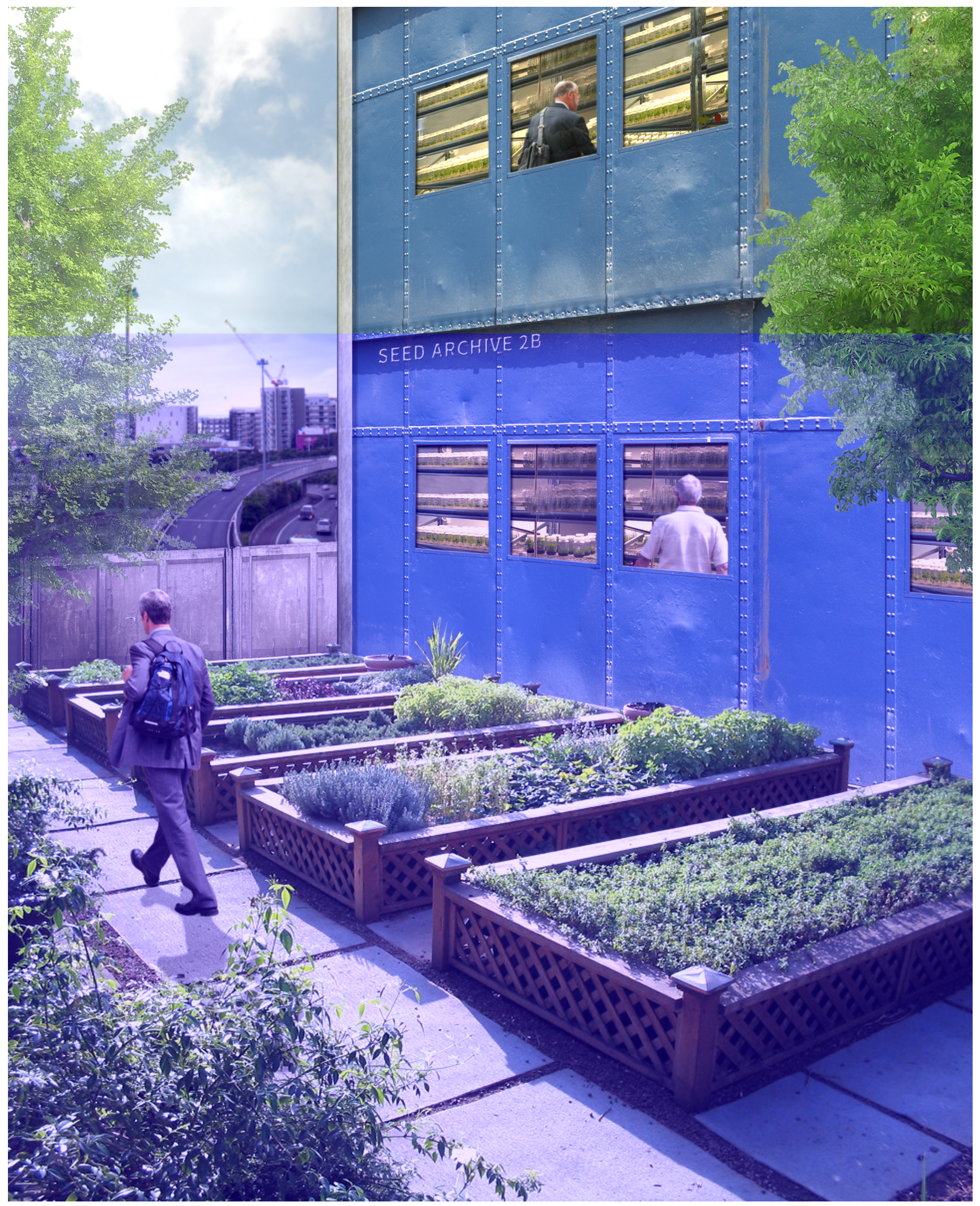

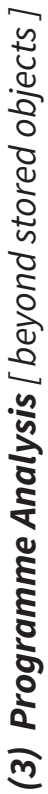

Figure 3.39 (Above): Initial experimental concept render by the author exploring the seed archive having both scientific and public green spaces intertwined. 


\section{[ BEYOND STORED OBJECTS ] - Seed Archive}

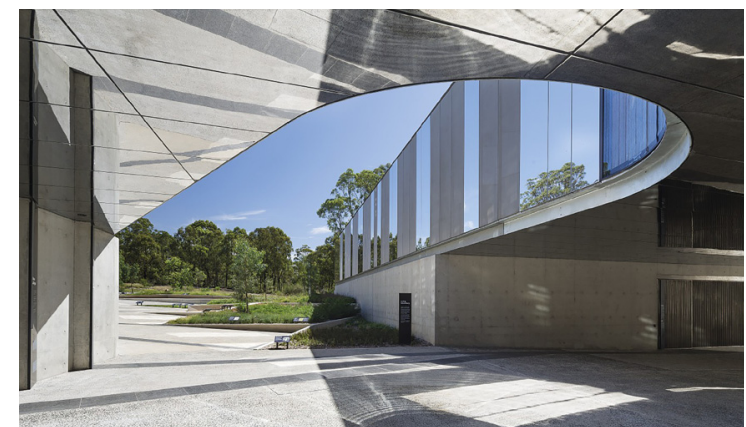

Figure 3.40: Australian Plant Bank.

BVN Donovan Hill | 2013 | Mt Annan, NSW.

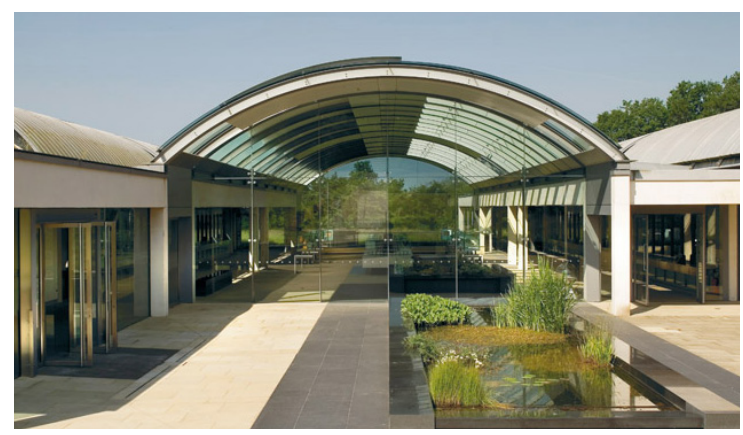

Figure 3.41: Millennium Seed Bank.

Stanton Williams Architects | 2000 | West Sussex, UK.
The Australian Plant Bank (Figure 3.40) and the Millennium Seed Bank in England (Figure 3.41) both exemplify the architectural potential of combining research spaces with public exhibition spaces and green spaces. Both of these facilities use transparent design elements and layouts to bridge the gap between science and the general public.

Educational and exhibition spaces are used to increase the awareness of the importance of each respective facility. The aim of each is to not only provide quality scientific centres for the researchers, but also to allow for a public platform to develop greater appreciation for the natural heritage of their country.
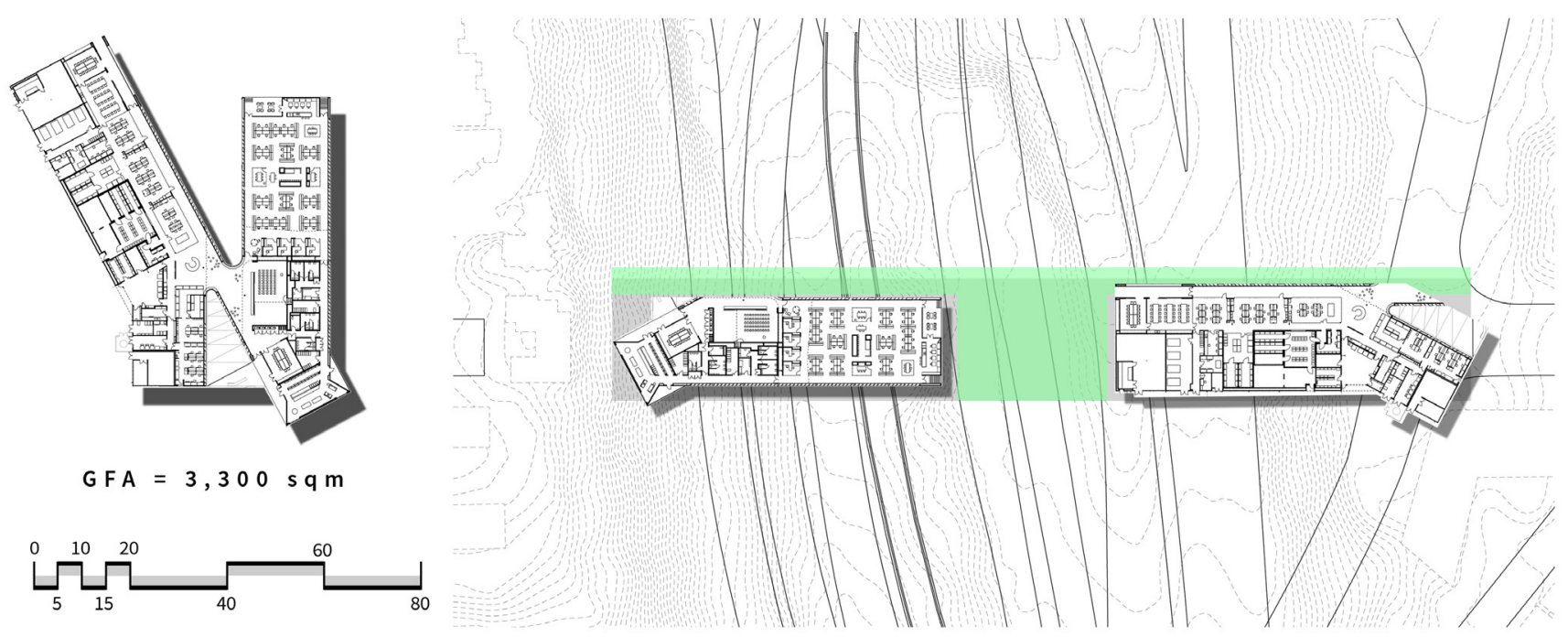

Figure 3.42: The floor plan and footprint of the Australian Plant Bank overlaid on a section of the CMJ site. 




Figure 3.43: Both the Millennium Seed Bank (above) and Australian Plant bank use design to bridge the gap visually and academically between the scientists and the general public.

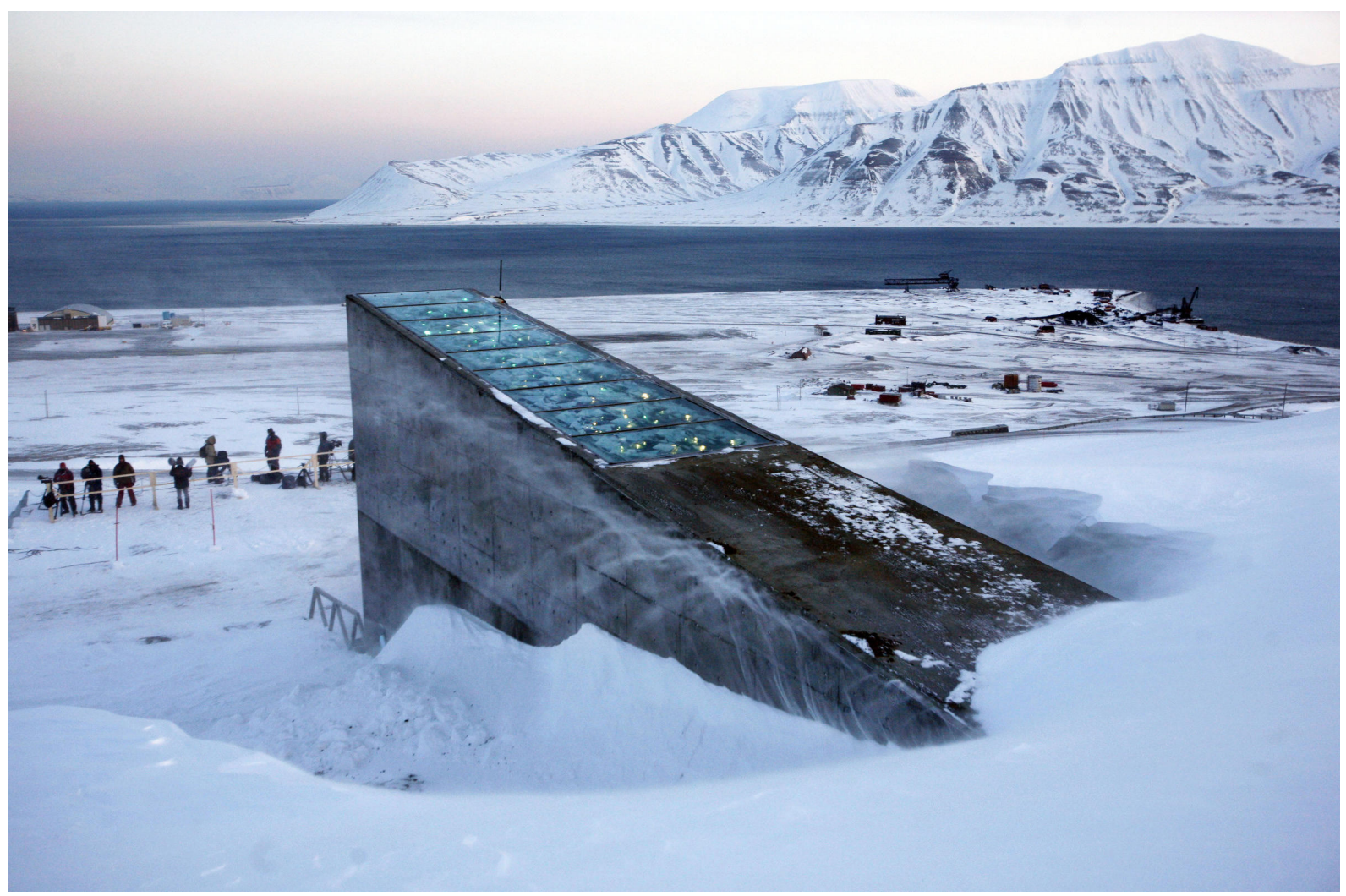

Figure 3.44: The Svalbard Seed Vault in Norway stores a large portion of the world's seeds in case of environmental disaster. Unlike the Millennium Seed Bank and the Australian Plant Bank, this seed vault is completely removed from the scope of general public due to its location and the higher criticality of the seeds it stores. 


\section{[ BEYOND STORED OBJECTS ] - Film Archive}

The Ngā Taonga Sound \& Vision - NZ Archive of Film, TV \& Sound is another significant elementofheritagesusceptible to earthquakes in Wellington. This programme would also fit well into the thesis investigation's 'archive collection' and its inclusion would provide some additional opportunities for enhancing public engagement with elements of national heritage.

The film archive programme would provide the ability to rear project moving and still images onto the architectural intervention. It would add significantly to the project in the evenings.

One of the thesis objectives is for elements of heritage to have much greater engagement with the public. By providing opportunities on the exterior facades of the design research intervention or allowing visibility into these spaces from the outside world, these heritage elements have the chance to be seen by a significantly larger portion of the public some of whom would never set foot in a museum space otherwise.
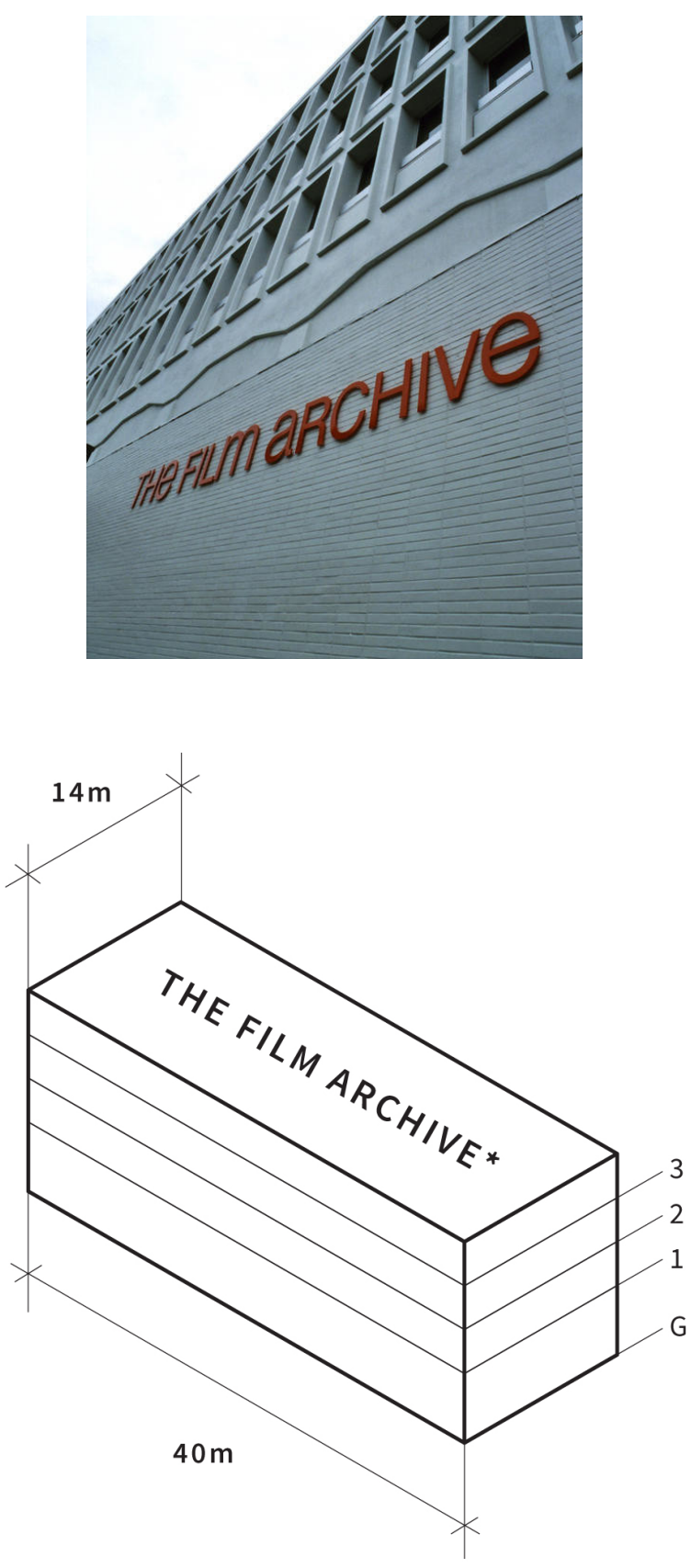

* current archive hosts viewing and eatery spaces 


\section{CURATION OF THREE HERITAGE ELEMENTS}

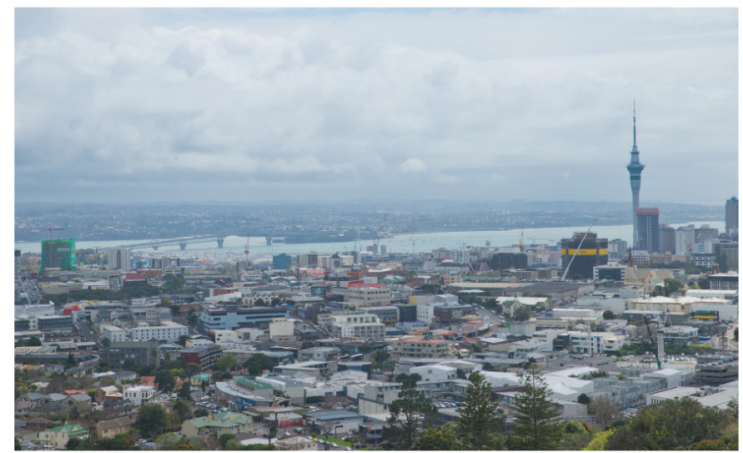

\section{the city}

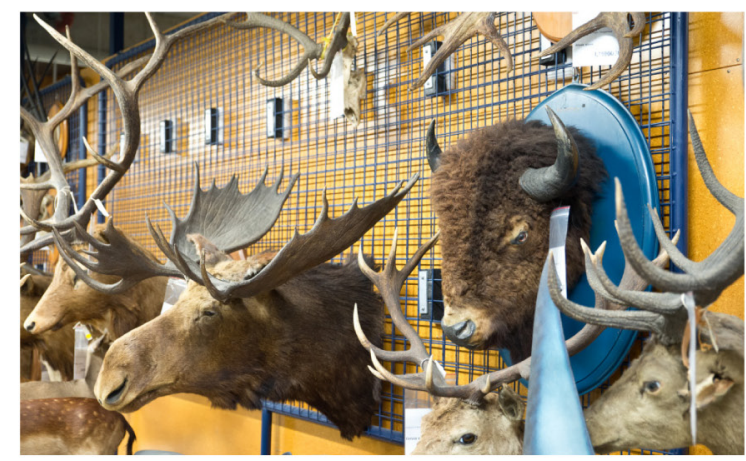

\section{the archived item (Te Papa + Film)}

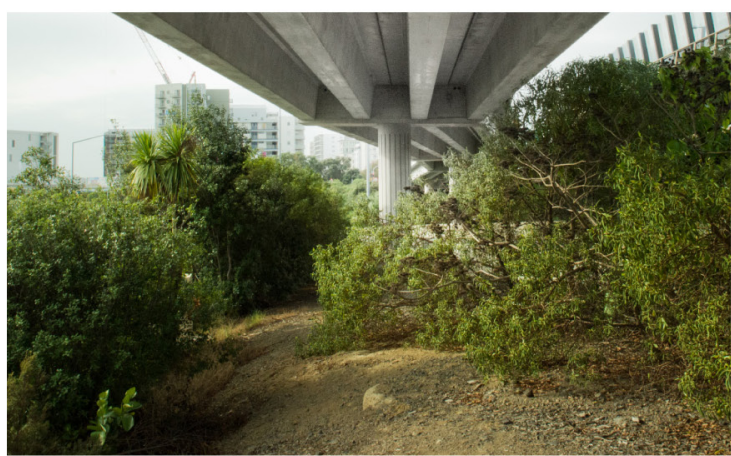

the seed

Figure 3.47: Another important element of programme is the 'city archive', framed views of iconic areas of the city, derived from context analysis (refer to figures 2.20 - 2.23). By curating specific views of the surrounding city in the design research intervention, the architecture can become a visual archive for the cityscape as it grows and develops in the years to come. The other three elements of programme are curation of the Te Papa archived items and curation of films and seeds. 


\section{[ CONCLUSIONS ]}

These four programmes, Te Papa stored collections, seed archive, film archive, and framed urban views, would provide didactic opportunities to contribute significantly to the city's urban and cultural identity if the design research intervention can enhance their engagement with the public realm.

\section{[ Hidden Heritage ]}

The research in this section examined the current issues around the Te Papa archives, including lack of secure storage space and lack of public engagement. Their significance needs to be given a much higher profile. Auckland City and the CMJ site provide an important opportunity for a large high profile public building in the heart of the public realm (RO4).

\section{[ Curatorial Opportunities ]}

To achieve the objectives of greater public engagement with the archive items a new system of storage is required. This thesis investigation proposes that stored heritage items no longer need to be carefully grouped by type alone, but rather they can be 'recatalogued' in relation to their ability to be viewed by the public (scale, light sensitivity, etc.) This will allow for groupings of objects that can be engaged with in a variety of different means by the public (RO5).

\section{[ Beyond Stored Objects ]}

The final section of this chapter explored elements of our 'hidden heritage' that are outside the current scope of the Te Papa collection but could still make significant contributions to the development of cultural identity on the site. This has resulted in the addition of a seed archive and a film archive - in addition to framed views of iconic areas of the city. The curation of these additional elements with the Te Papa archive will strengthen the design research intervention as a place that reveals elements of our national heritage that are otherwise hidden (RO6). 

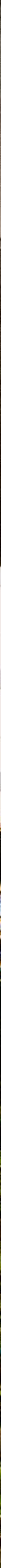

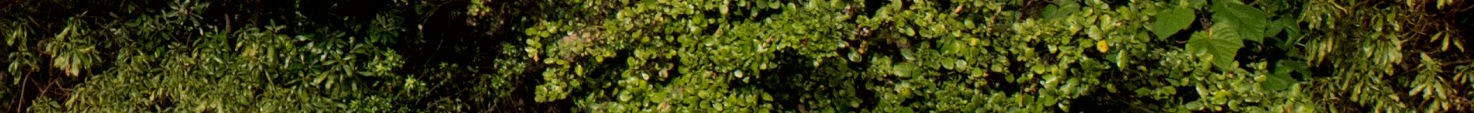

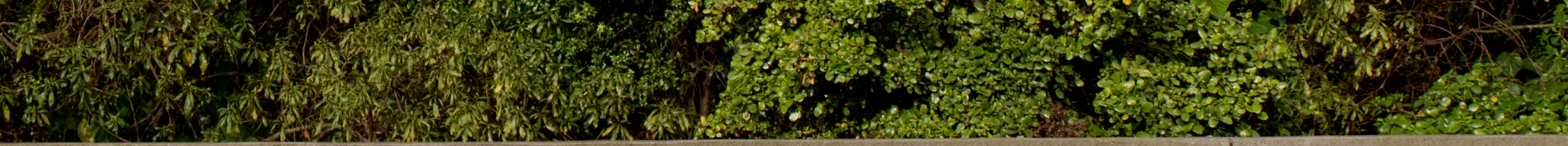

\section{IITERATURE + PROJECT REVIEW}




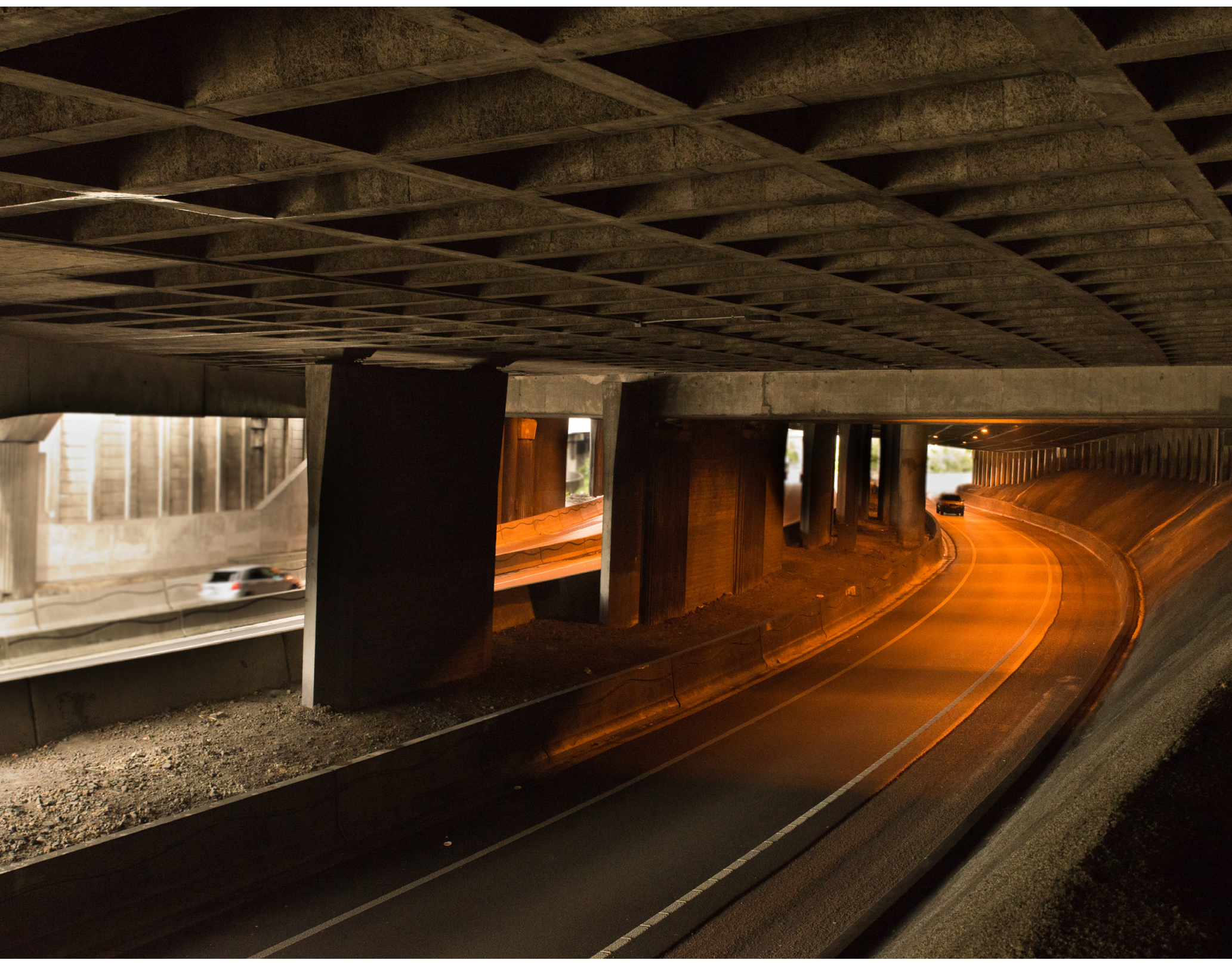

Figure 4.1 (Previous):The green gully belt once surrounding the CBD is now a thick concrete belt, with pockets of nature periodically framed inside giving reference to what once was.

Figure 4.2 (Above): Underneath the CMJ between Hopetoun Street and Karangahape Road. 


\section{4 | Literature + Project Review}

This literature and project review chapter is structured into six sections.

[ Lost Site ] The first section discusses what a 'lost site' or 'non-place' is in an urban context in order to better understand the implications of such sites and the application of related theory to Auckland's Central Motorway Junction. The key theorists used for this discussion include Roger Trancik and Marc Auge.

[ Place and Cultural Identity ] The second section explores what place identity is, and how the application of this theory through the design can help achieve the thesis aims of: diversifying the utilitarian motorway and developing sense of place (RO1 and RO2). The key theorists explored in this section are Roger Trancik and Avi Friedman.

[ Embracing Heritage ] Place identity is then discussed in relation to architecture embracing historic and contemporary heritage (RO6). Michael Ostwald, Pheobe Crisman, Richard Ingersoll, Maren Harnack and Martin Kohler are investigated as key theorists around heritage and architecture. Project review case studies on the Kranspoor Building and Landschafts Park are analysed as practical applications of these theories. The discussion throughout focuses on the significance of this to the thesis objectives of: embracing the heritage of the motorway (RO3), exposing elements of the site and the city's 'hidden heritage'(RO5), and enhancing permeability in urban space ( $\mathrm{RO} 2)$.
[ Monumentality ] The fourth section of the chapter explores monumentality in architecture, in terms of scale and metaphor. Michael Ostwald and Roger Trancik are used as the key theorists in this discussion in combination with a project review on Vancouver House. These discussions explore how the thesis objectives of engaging with the monumentality of the CMJ site and embracing the iconic nature of the motorway could be achieved through design ( $\mathrm{RO} 3$ ).

[ Didactic Design ] The fifth section of the chapter focuses on the objectives of the 'hidden heritage' programme. Martí Franch and James Elkins are used as the critical theorists in this section that explores the implications of didactic design. A case study review of Martí Franch's Tudela-Culip project looks at how design and programme choices can address the thesis objectives such as: enhancing public engagement with 'hidden heritage' and increasing cultural awareness (RO5 and RO6).

[ Heterotopia ] The sixth and final section of this chapter explores theories and case studies that will help achieve the overall research aim of shifting the CMJ site from the dystopian to the heterotopian (RO2). Michel Foucault and Walter Russell Mead are used as theorists to establish definitions of heterotopia. Then, the writing of Daan Wesselman on the New York High Line is used to analyse the design applications of heterotopic architecture and what a positive heterotopia can contribute to an urban environment. 


\section{THEORISTS CREDENTIALS}

\section{Roger Trancik}

Roger Trancik is a Professor at Cornell University in the City and Regional Planning Department. Used for theory topics of: lost site, and place and cultural identity.

\section{Michael Ostwald}

Michael Ostwald is a Professor and Dean of Architecture at the University of Newcastle Australia. Used for theory topics of: historic heritage and monumentality.

\section{Dr. Avi Friedman}

Dr. Avi Friedman is a Professor at McGill University in Montreal. Used for theory topics of: place and cultural identity.

\section{Marc Augé}

Marc Augé is a French anthropologist who coined the term 'non-place'. Used for theory topics of: place identity and lost sites.

\section{Maren Harnack \& Martin Kohler}

Maren Harnack is an architect, city planner and a university Professor of Planning and Urban Design at the Frankfurt University of Applied Sciences. Martin Kohler is a researcher and lecturer in urban design at the HafenCity University. Used for theory topics of: urban heritage.

\section{Pheobe Crisman}

Phoebe Crisman is Associate Professor of Architecture at the University of Virginia. Used for theory topics of: heritage and history.

\section{Dr. Richard Ingersoll}

Dr. Richard Ingersoll has a PhD in Architectural History and has taught at multiple universities around the world. Used for theory topic of: heritage.

\section{Martí Franch}

Martí Franch is a Landscape Architect and founder and principal of 'EMF landscape architecture'. Used for theory topic of: didactic design.

\section{James Elkins}

James Elkins is an Art Historian and Critic and Chair of Art History, Theory, and Criticism at the School of the Art Institute of Chicago. Used for theory topics of: archive programme and didactic design.

\section{Walter Russell Mead}

Walter Russell Mead is Professor of Foreign Affairs and the Humanities at Bard College. Used for theory topics of: heterotopia.

\section{Michel Foucault}

Michel Foucault (1926 - 1984) was a highly influential French philosopher and academic. Many of his theories and publications have direct application in the architectural realm. Used for theory topic of: heterotopia.

\section{Dr. Daan Wesselman}

Dr Daan Wesselman is a lecturer at The University of Amsterdam in the Faculty of Humanities department. Used for theory topics of: heterotopia. 


\section{[ LOST SITES ]}

In Roger Trancik's book Finding Lost Space he discusses the meaning of a 'lost site'.

Trancik describes lost sites as "the undesirable urban areas... anti-spaces, making no positive contribution to their surroundings or users. They are ill-defined, without measurable boundaries, and fail to connect elements in a coherent way" (4). Although the motorway through the CMJ site is an infrastructural system of connection it has an overwhelming sense of irony. The ease of vehicular connection it provides between distant suburbs is utterly contrasted by its destruction of coherence and connections as it forms an impenetrable urban barrier between the inner suburbs and the Auckland CBD.

The utilitarian nature of this motorway system represents a period in urban planning where the infrastructural system was given "autonomous technical priority over the landscape... thus somehow exempting it from having to function socially, aesthetically, or ecologically" (Paul 50). Infrastructural systems like the CMJ are so devastatingly focused on the functional that they sever essential urban elements of human connection, culture and place.

The Central Motorway Junction is a 'lost site', a non-place that eliminates urban coherence and connectedness - a space devoid of identity.

\section{6}

If a place can be defined as relational, historical and concerned with identity, then a space which cannot be defined as relational, or historical, or concerned with identity will be a non-place.

- Marc Augé, 77-78 


\section{[ PLACE AND CULTURAL IDENTITY ]}

The writings of academics Roger Trancik and Avi Friedman provide the theoretical bases for place identity in this thesis.

Trancik sees place identity in architecture as "the components of human needs and cultural, historical, and natural contexts" (Trancik 97). Avi Friedman considers place identity to arise when the inhabitants of the place are provided a deep sense of their own identity (10).

From this, place identity can be understood as a personal attachment to space, a greater sense of self. One's place in the wider context of life and one's surroundings is developed by responding to this place identity.

Creating deeper personal and cultural awareness for the users of the CMJ site will be the most successful way to create opportunities to develop the 'lost site's' place and cultural identity.

This enhanced awareness and understanding can be developed through architectural design that addresses thesis research objectives around hidden heritage, embracing existing typologies, and providing didactic design opportunities.
The theorists and related case studies provide important insights to help increase cultural and place identity in this lost CMJ site.

The three main objectives pertaining to the development of place and cultural identity are as follows:

- Embrace the heritage elements of both existing and historic aspects of a 'lost site' as ways to enhance the cultural awareness and 'place identity' of the site itself.

- Utilise the monumentality of the lost site to enhance the elevated motorway's identity as an iconic element in the urban environment.

- Use didactic design as a way to enhance cultural awareness and in turn identity. It can achieve this through greater engagement with the public realm and by providing people with opportunities to see or understand something they have not experienced before. 


\section{6}

While the geographic, topographic, and even climatic conditions of a place provide a rich framework for creating architecture, they can neglect the specific cultural, social and historical factors that in urban situations more cogently define a sense of 'place'.

- Ostwald, Tucker and Chapman, 11

\section{RE-ESTABLISHING HISTORIC LINKS}

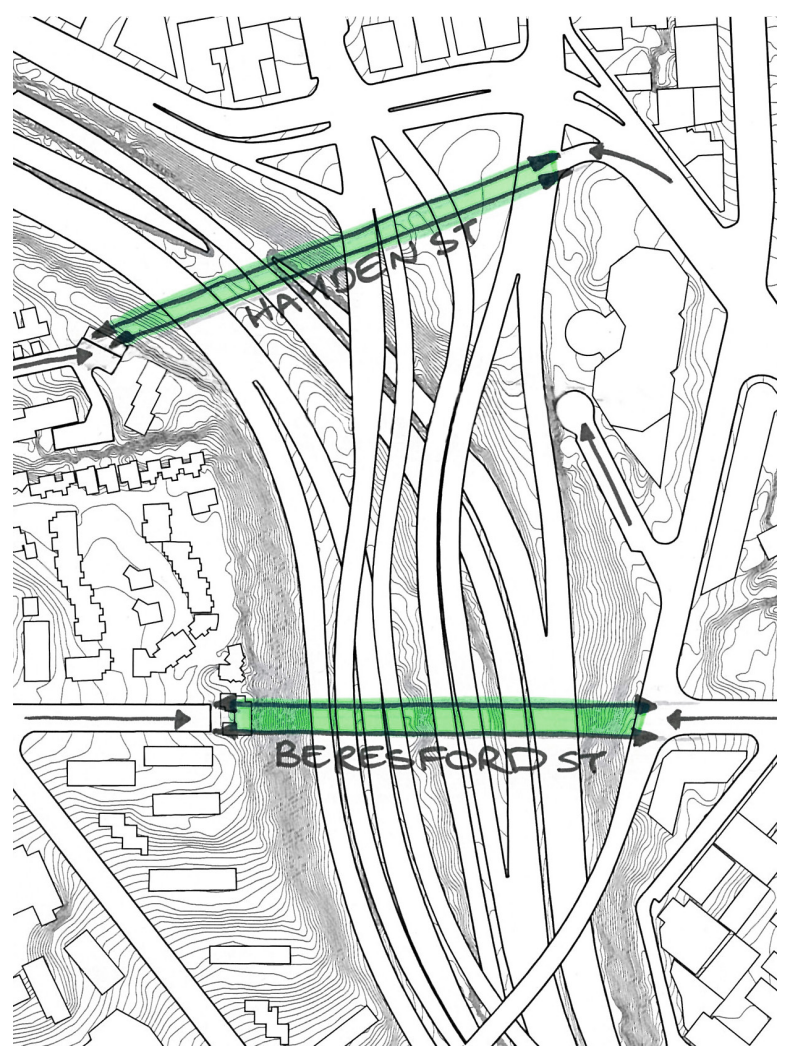




\section{[ EMBRACING HERITAGE ] \\ Historic Heritage}

In their book Residue : Architecture as a Condition of Loss, Michael Ostwald, Chris Tucker and Michael Chapman propose that architectural intervention, when used as a means to reveal the history of the site, creates opportunity for the development of place identity. It can achieve this by creating a deeper understanding within the inhabitants of the importance of the site historically to its surrounding landscape.

Pheobe Crisman argues that each site has "its own history and specific characteristics that must be revealed and engaged during the design process" (115). The reintegration of historic elements of the site can create an appreciation of the original meaning of the place that may help reunite the inhabitants with their community heritage.

The CMJ site has two strong original elements that have been erased from the memory of the city - the original links across the gully and the green space the gully originally provided.

Engaging with these two elements in the design process would create opportunities to reawaken a historic awareness of the site for those who inhabit and visit it. Exploration of this in the architecture will contribute to achieving the research objective of engaging with the non-archived elements of 'hidden heritage' in the project (RO6).

The following project reviews of the Kranspoor Building and Landschafts Park look at each design's ability to embrace the existing or historic elements of the site and frame them into a form of appreciation for the contemporary user. 


\section{KRANSPOOR}

\author{
Project Review \\ Embracing Heritage
}

Architects: OTH Architecten

Location: Amsterdam, The Netherlands

Year: $\quad 2007$

Size: $\quad 12,500$ sqm.

\section{- Office spaces}

The Kranspoor office building embraces the infrastructure of a derelict craneway and reinvigorates the waterfront space into a place for human inhabitation.

The intervention's success lies in its separation of the office building elements suspended above the historic industrial craneway. This separation clearly demarcates what is industrial history and what is contemporary intervention, celebrating the strength of this platform that once was a vital element of the city's shipping industry.

Through the separation of the old and new, and the mirroring of dimensions and form, the power and significance of the original craneway is not lost but rather enhanced through the design. The new intervention embraces the formal qualities and emphasises elements of the historic craneway.

This thesis investigation proposes that the new design experiment can embrace the typologies of the old historic missing roadway links as well as the intertwining motorway forms around it.

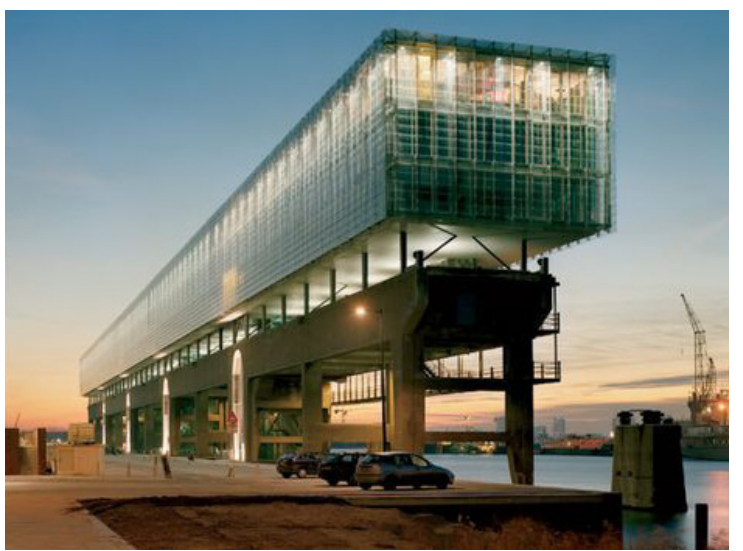

These lost historic and existing motorway elements are what have defined the site and its place in the city's history. By embracing them through the architecture the importance of these elements becomes more apparent to the inhabitants and this creates opportunities for users to reestablish a sense of 'place' in the site.

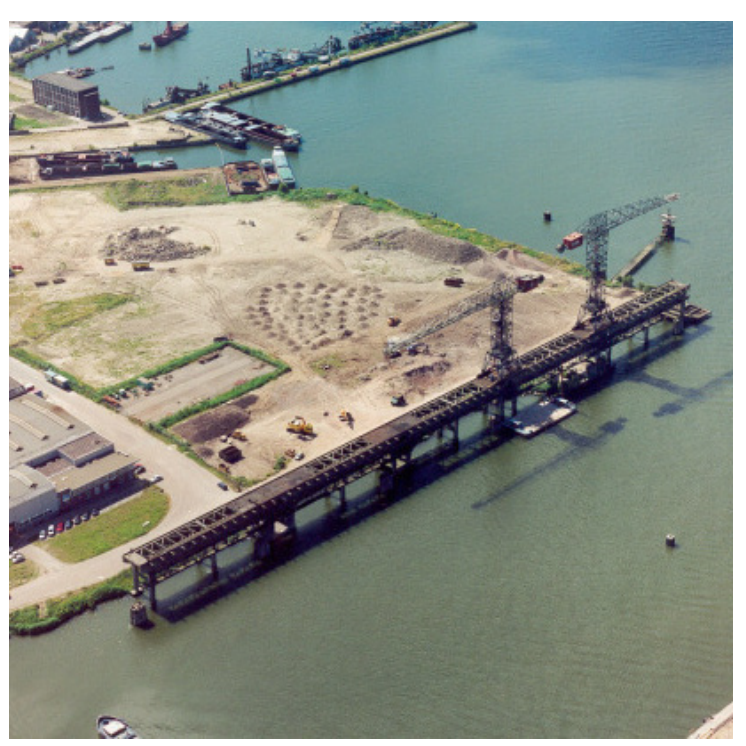



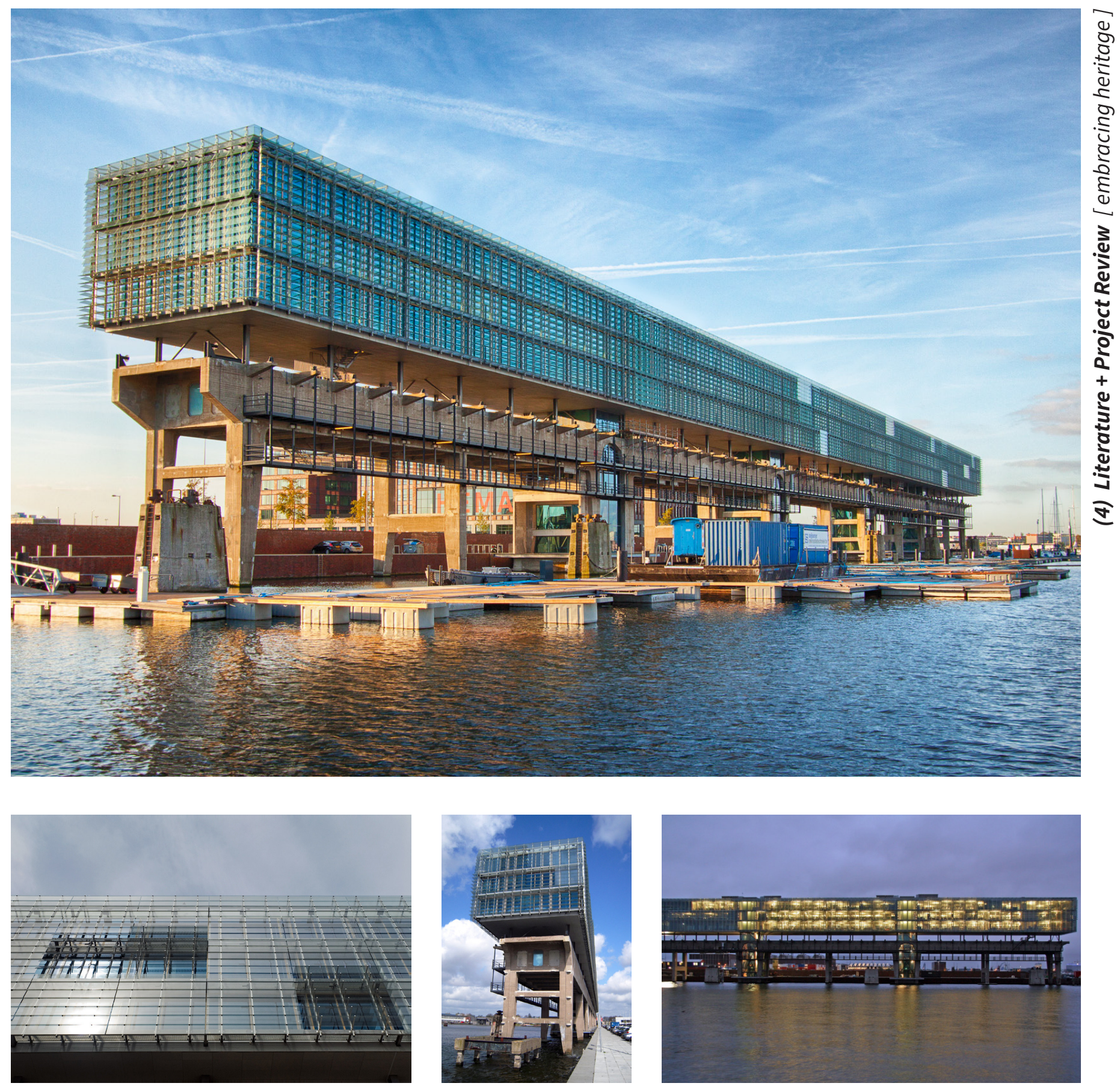

Figure 4.7: The industrial beauty of the craneway is retained. 


\section{LANDSCHAFTS PARK (Germany)}

\section{Project Review \\ Embracing Heritage}

$\begin{array}{ll}\text { Architects: } & \text { Latz + Partner } \\ \text { Location: } & \text { Duisburg Nord, Germany } \\ \text { Year: } & \text { 1992-2002 } \\ \text { Size: } & \text { 200 ha }(2,000,000 \text { sqm })\end{array}$

- Playgrounds + recreation + walking tracks

Landschafts Park is a mid-nineteenth century steel and coal producing plant that was turned into a landscape park and public recreation hub.

Latz + Partner have created spaces which fully utilise the features of the historic steel works by providing access, linkages, and revitalising space in the existing built forms.

This project was designed to help understand and heal its industrial past, rather than hiding or rejecting it (RO3). In this way, the project is very relevant to the thesis objectives around embracing existing components of the site rather than trying to hide them (RO6).

The juxtaposition of natural elements and planting against the brutality of iron and concrete exemplifies how textural aesthetics can be used to establish a clear dialogue between old and new, while enabling them to live together harmoniously.

This intervention successfully incorporates a contemporary and inhabitable intervention into a site that was considered industrial and mechanical. As Landschaft Park has exemplified, one of the best ways to achieve harmony between the two elements is by embracing the typology of the existing through the new.
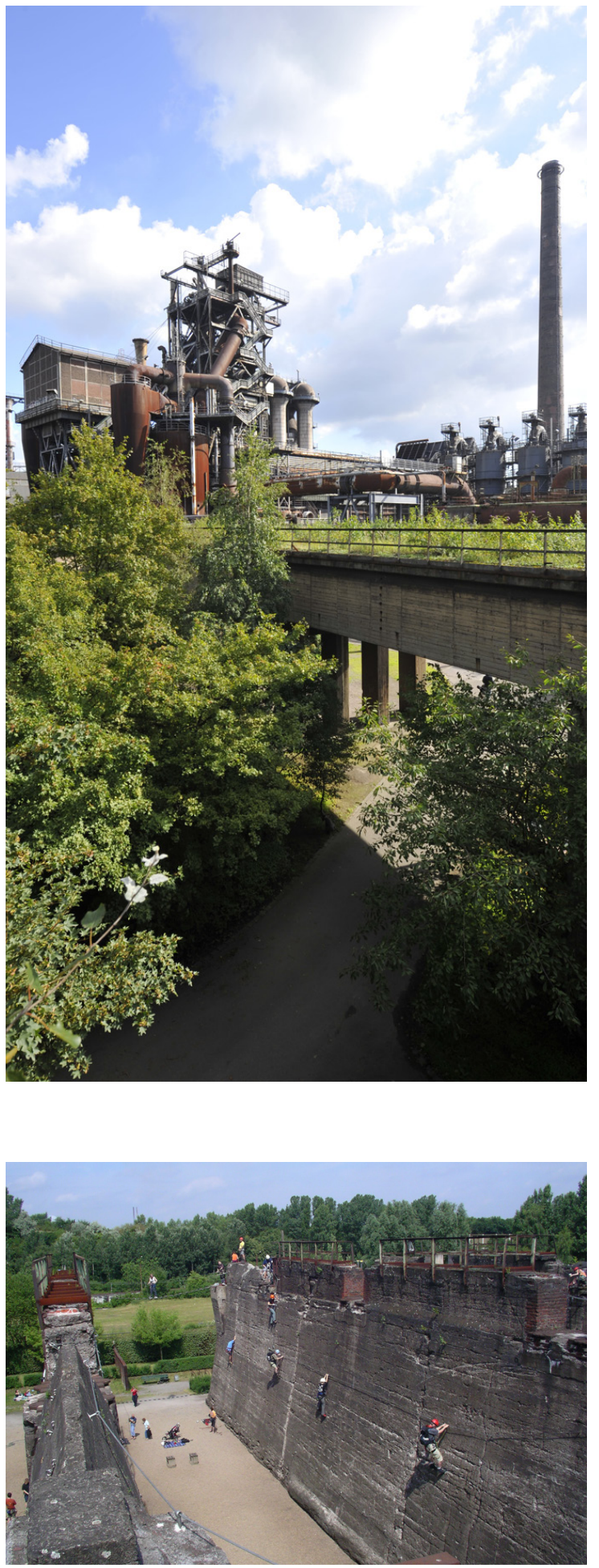

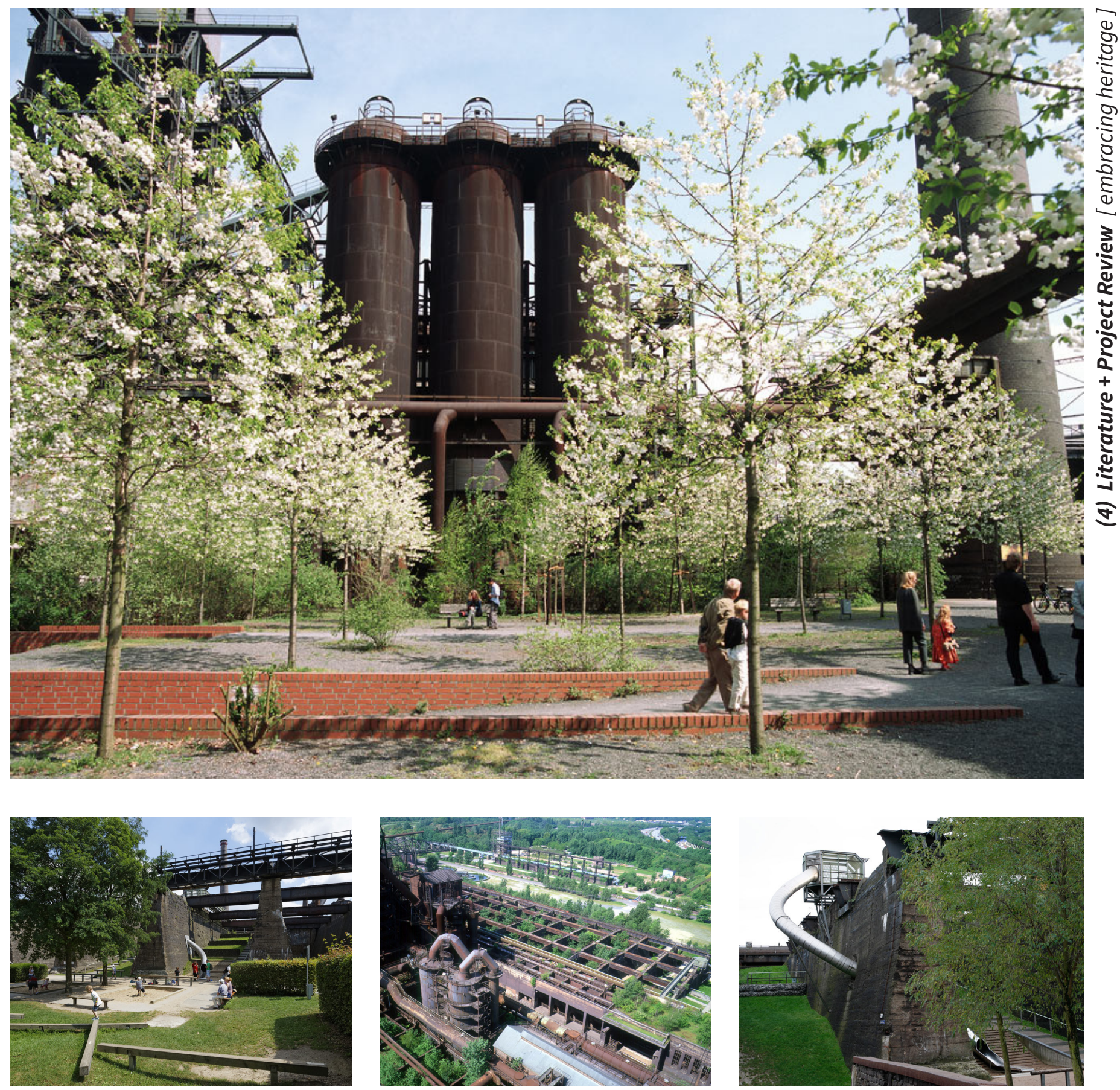

Figure 4.10 (top): A park space at the base of the steel works.

Figures 4.11, 4.12 \& 4.13 (bottom left - right): The industrial steel works has been reclaimed as green space for the public. 


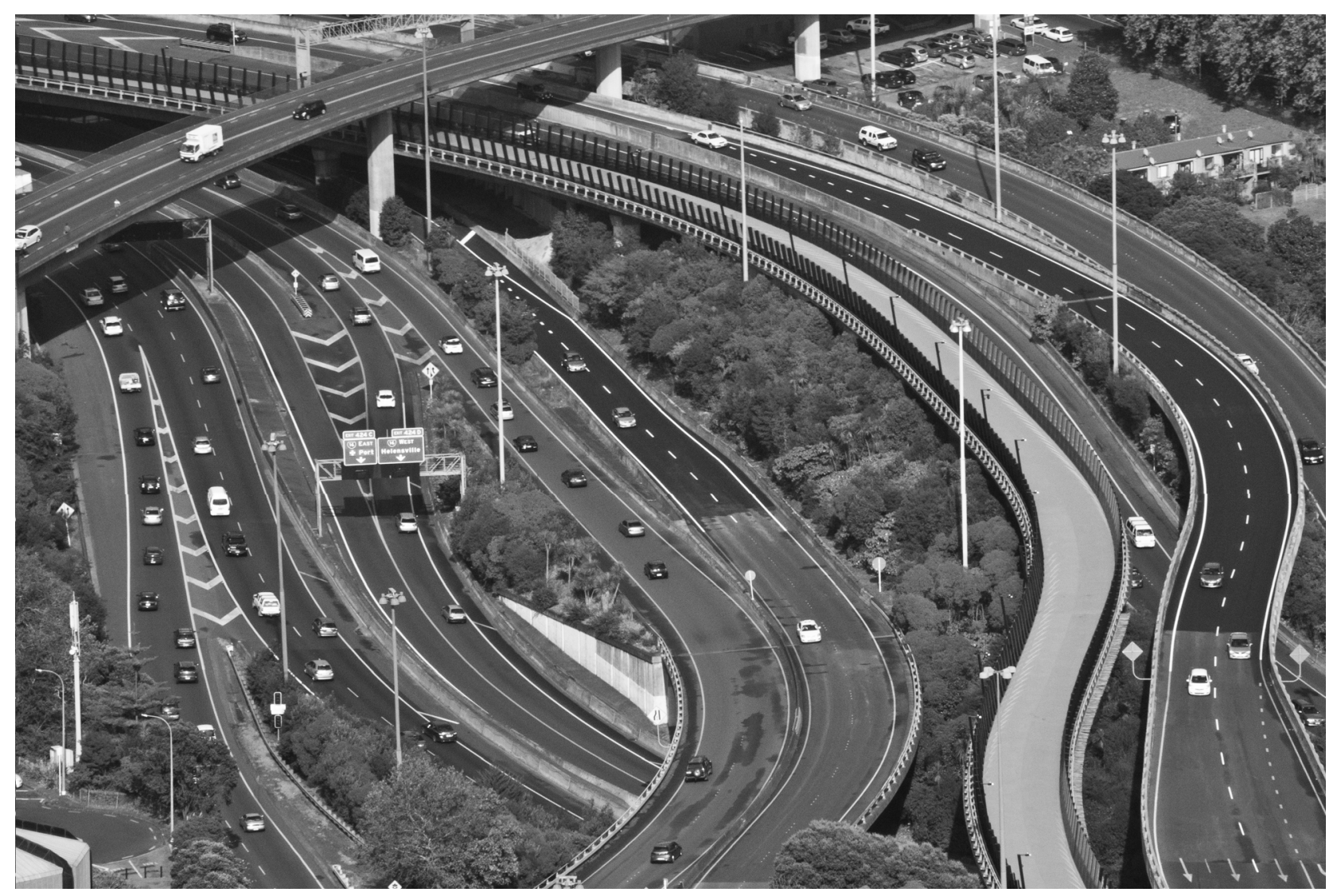

Figure 4.14: Auckland's impressive central motorway junction has its own heritage value as a defining element of the site and must be embraced in the design rather than ignored. 


\section{[ EMBRACING HERITAGE] Contemporary / Motorway Heritage}

The theories of Ingersoll, and Harnack and Kohler are discussed here in relation to embracing the positive heritage qualities of an urban motorway in a city's history.

In many cases elements of a 'lost site' hold a degree of heritage value which may not be immediately appreciated. However, framed through appropriate architectural means, these often defining aspects of heritage can be embraced as another component of the site's urban history. To assume these lost spaces are waiting to eventually become obsolete and demolished is to ignore the impact they have had on their surrounding environment. As Ingersoll states:
Embracing both the historic heritage of the site, as well as the more contemporary elements of the motorway's heritage offers the greatest opportunity for enhancing awareness by the inhabitants of the site's 'place' within the urban history of the city.

We have to consider the heritage value of urban motorways that very much represent a certain era of urban planning.

66 Works of infrastructure are ready-mades waiting to be decontextualized. This does not justify all infrastructures as being inherent works of art, but it does lead to the possibility that infrastructure can be discovered by designers, worked on by them, and framed into a mode of appreciation. - Ingersoll, 123 


\section{[ MONUMENTALITY ]}

\section{6}

Monumentality, by definition, transcends period styles, giving a timeless, and enduring historical framework to form and space.

- Trancik, 163

Although it would seem the New Zealand ethos is against the monumental in architectural design, the 'monumental' can be used to create iconic and defining moments in an urban landscape.

Using the theories of Ostwald, Tucker and Chapman this section argues that monumentality can enhance the iconic and monumental elements of 'lost sites' and turn them into positive marker spaces for their cities (RO3).

Buildings are bearers of meanings (Ostwald, Tucker and Chapman 14); through their metaphorical and physical form they are able to construct dialogues about both their place in the landscape and history, and their inhabitants' sense of place.

Architecture of monumental scale is a fitting response to both the nature of the site and the nature of the Te Papa archive programme.
For these reasons the form of the architecture in combination with the archive programme has:

... the ability to control or shape the way in which a memory is triggered. In this sense, architecture is perceived to be addressing a collective cultural, societal or transcendent memory (Ostwald, Tucker, Chapman 21).

The role of these interventions, "in forming a link between some historic event and the present day, resonates with the process of remembering" (Ostwald, Tucker Chapman 22). The combination of a very large programme on a very large site suggests that the design research experiment, can take advantage of being a monumental design to become a marker space in the city and through the archive programme help develop constructed memories for users of the site.

The integration of the monumental lost site with the archival programme is a mutualistic relationship. The lost site is given a diversified purpose as an iconic marker element in the city (RO1). The archive programme is given a monumental framework to place itself within a greater social and cultural landscape than the one in which it currently resides (RO4). 


\section{Project Review}

Monumentality in Design

$\begin{array}{ll}\text { Architects: } & \text { Bjarke Ingels Group } \\ \text { Location: } & \text { Vancouver, Canada } \\ \text { Year: } & 2014-2018 \\ \text { Size: } & 55,700 \text { sqm }\end{array}$

- Residential

- Offices

- Restaurants + Retail

- Garden space + Recreation space (pool)

- Public parking

Vancouver House, situated in the interstices of the Granville Bridge off ramp, is both a physical and metaphorical gateway into the Vancouver CBD. The project, once completed, will become a monumental icon in the skyline of the city.

The monumentality of this project is fully embraced by Bjarke Ingels Group with the architecture exploding though the awkward triangular form created by the off ramps, and then cantilevering itself over the roadways.

This project has been designed to become the iconic threshold into the city. Its form peeling back at its base, in combination with the building opposite - creates a significant gesture of this being the gateway into, and out of, the Vancouver CBD.

The design embraces the motorway as a viable way to experience the city - not relegating it simply as a transit corridor but understanding that driving along the motorway is an experiential journey that architectural design can enrich.

This has application to the CMJ site. By heightening the experience for motor vehicles on the motorway through the site, the otherwise utilitarian space begins to develop qualities that take it from 'transitory space' to 'experiential place' (RO3).

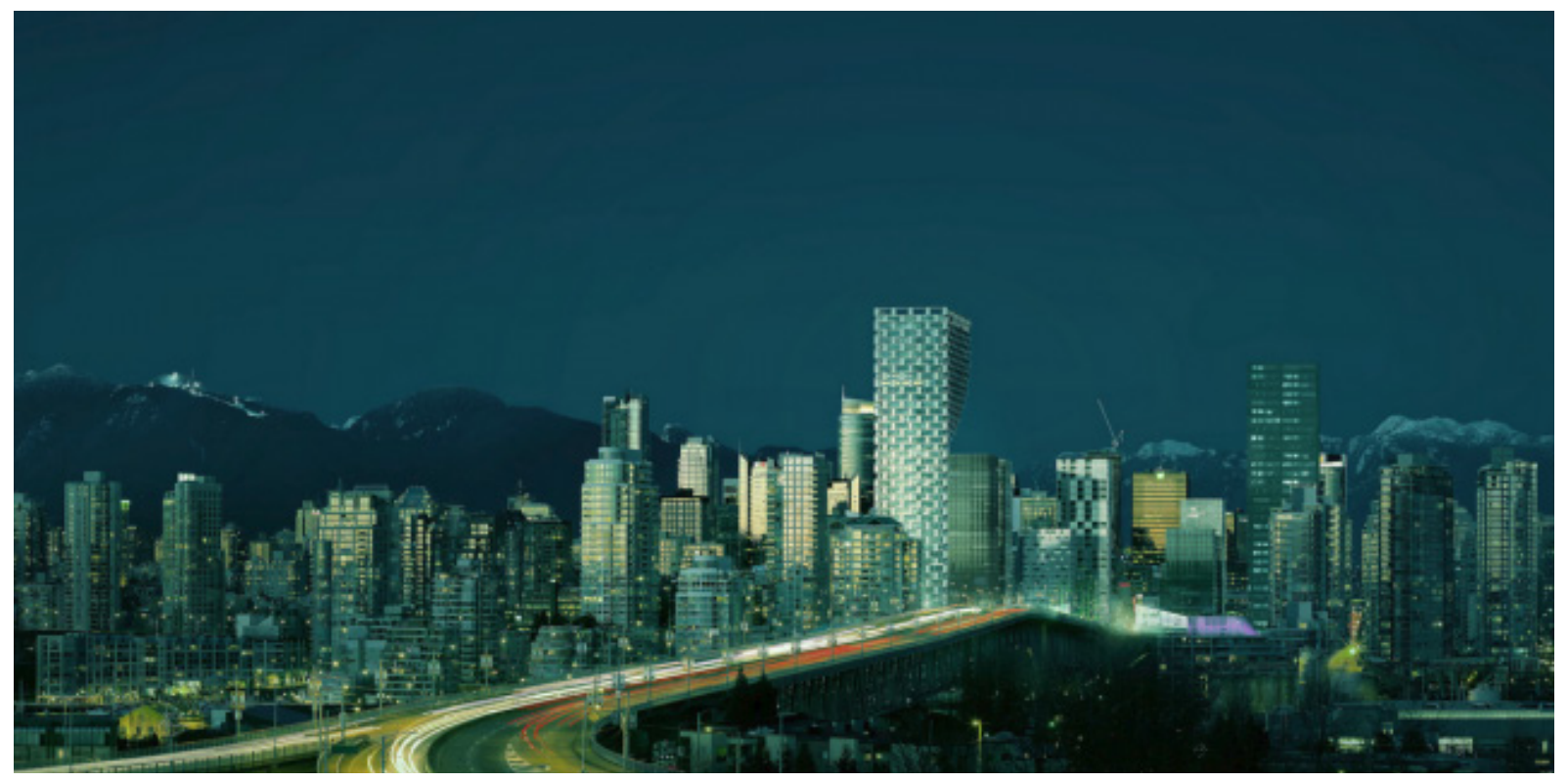

Figure 4.15 (Top right): The proposed 'gateway' into Vancouver. 

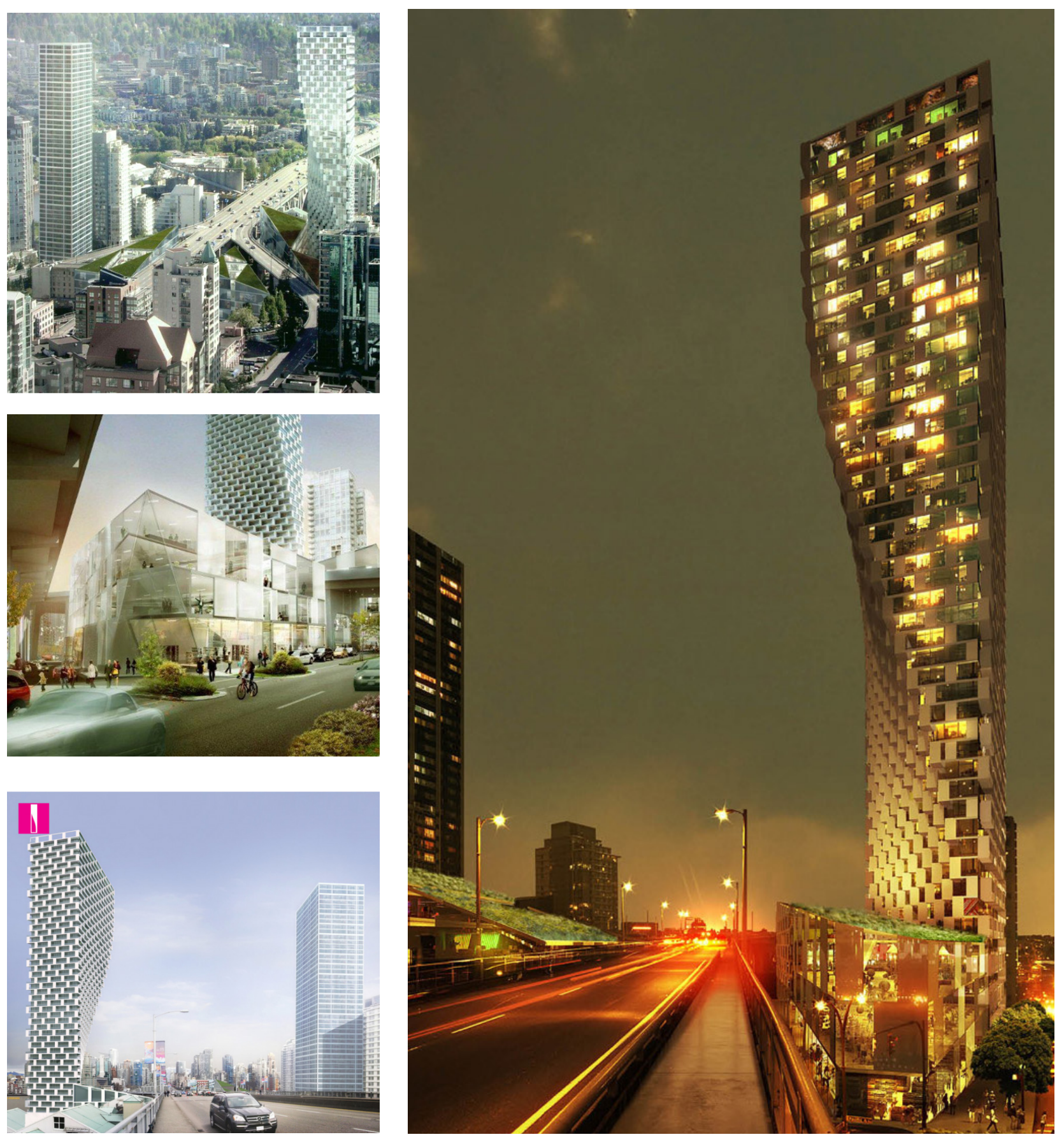

Figure 4.16 (left): Vancouver's new monumental tower.

Figure 4.17 (right): Vancouver House as the iconic marker of the city's entry / exit point. 


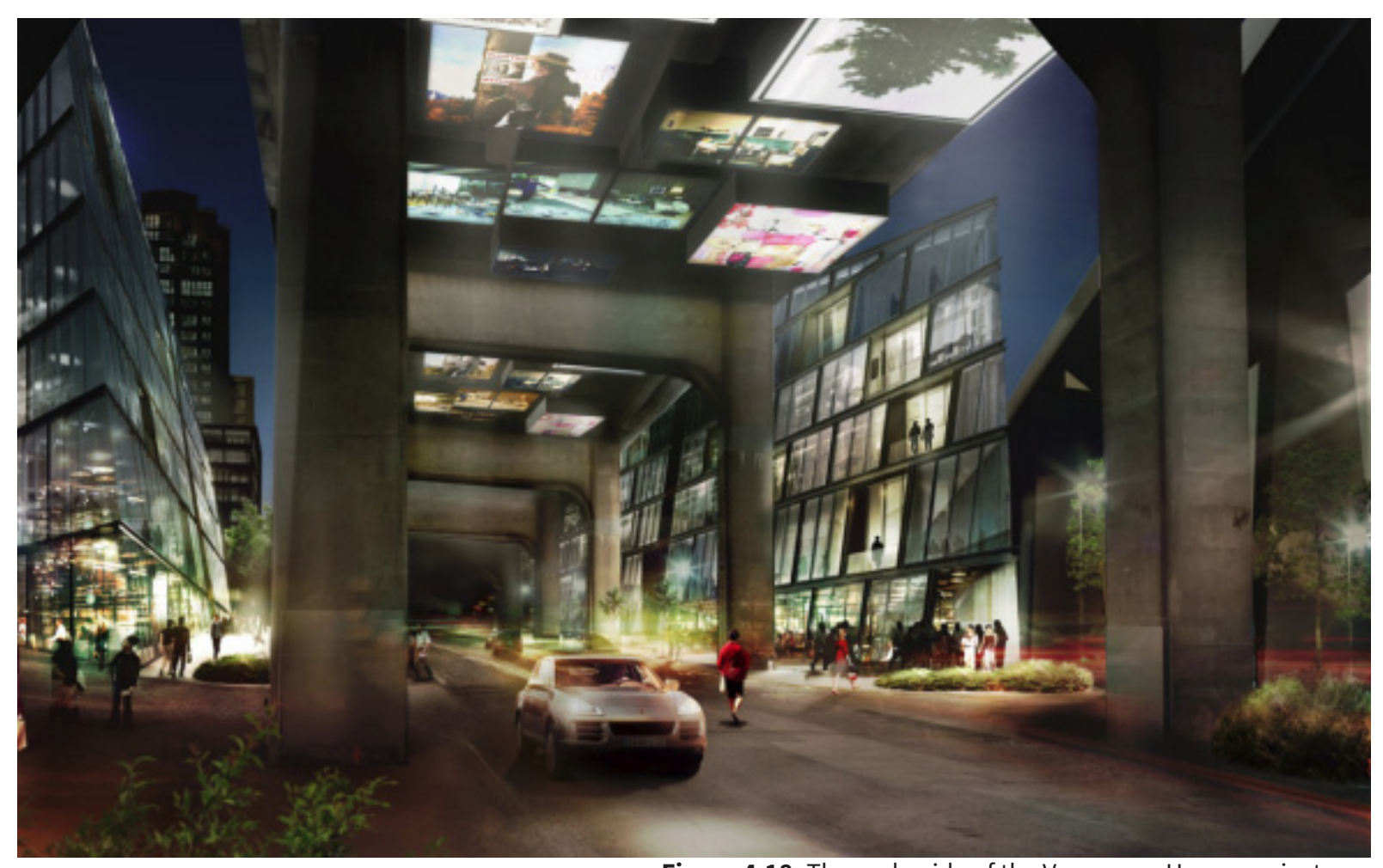

Figure 4.18: The underside of the Vancouver House project.

The underside of the Vancouver House project (shown in figure 4.18) engages with the motor vehicles as well as cyclists and pedestrians. This is crucial for successfully diversifying infrastructural elements in a city.

The Vancouver House proposal increases the range of user typologies by activating the underside of the elevated motorway infrastructure.
By doing this, the design creates moments for engagement by users other than vehicles.

Engaging with pedestrians and bicyclists in the CMJ site through typologies similar to that of projected displays and green spaces would help achieve the research objective of diversifying the utilitarian nature of the motorway (RO1). 


\section{[ DIDACTIC DESIGN ]}

\section{6}

The world is full of things that we do not see, and when we begin to notice them, we also notice how little we can ever see.

- Elkins, 63

In this section the theories of James Elkins and Martí Franch are used to argue that didactic design elements that create opportunities for people to understand something to a deeper level than they had before can contribute towards developing an increased sense of cultural or place awareness. This section explores how didactic design can be used to 'curate' elements and how this has useful application particularly to the archive programme, but also to the seed and city 'curation' programme.

Martí Franch, a Catalan landscape architect, discussed in his "City Talks Presentation" the use of "disruptive" interventions to make inhabitants engage in much greater detail with elements of the landscape. These interventions frame or change the way the viewer understands their surroundings and begin to create moments of pause for an enhanced engagement with the place.

To maximise the didactic design potential of the archive collection the items must be framed in a manner that highlights their uniqueness and encourages extended and intensive public engagement (RO5).
66

Our sense of ourselves is like a television station always going out of focus, and we tune and clarify ourselves by seeing.

- Elkins, 86 


\section{$T \cup \square E$
Project Review
Didactic Design}

$\begin{array}{ll}\text { Architects: } & \text { EMF Estudi } \\ \text { Location: } & \text { Girona, Spain } \\ \text { Year: } & 2005-2010 \\ \text { Size: } & 200 \text { ha. }\end{array}$

- Public Park

Franch uses design intervention to make users look at the landscape in more contemplative ways. In this case, small engravings along the path make viewers stop to appreciate the rugged forms of the rocks around them. The alignment of planes and surfaces is also utilised to point the viewer in specific directions of the landscape.

\section{(Spain)}
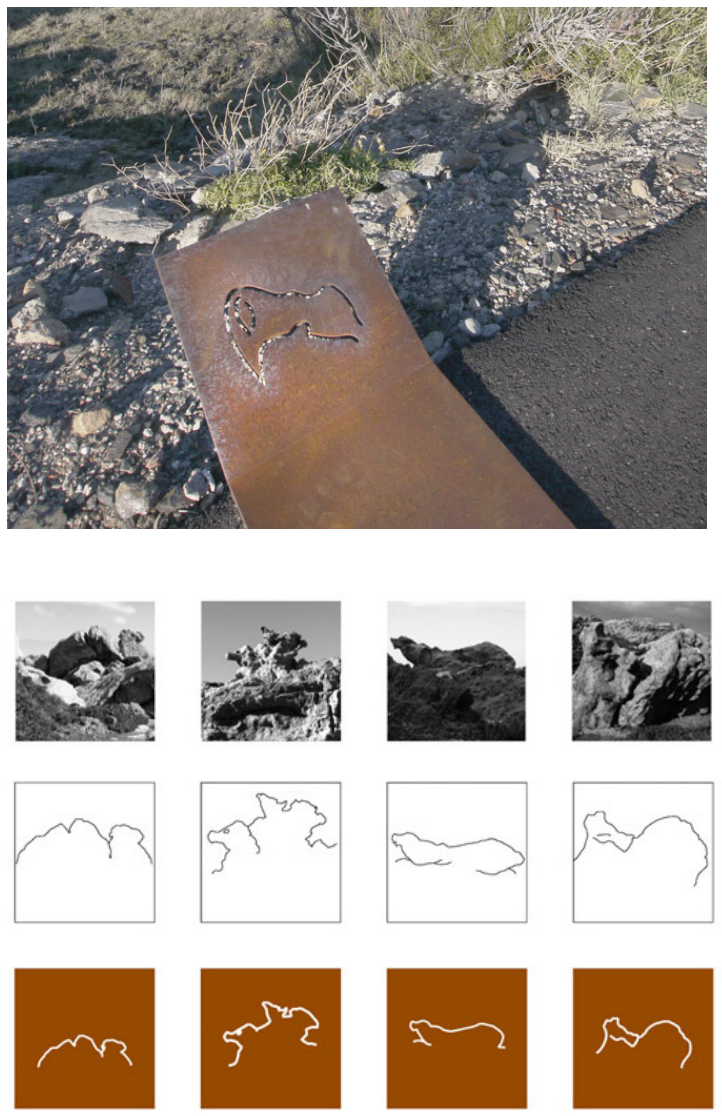

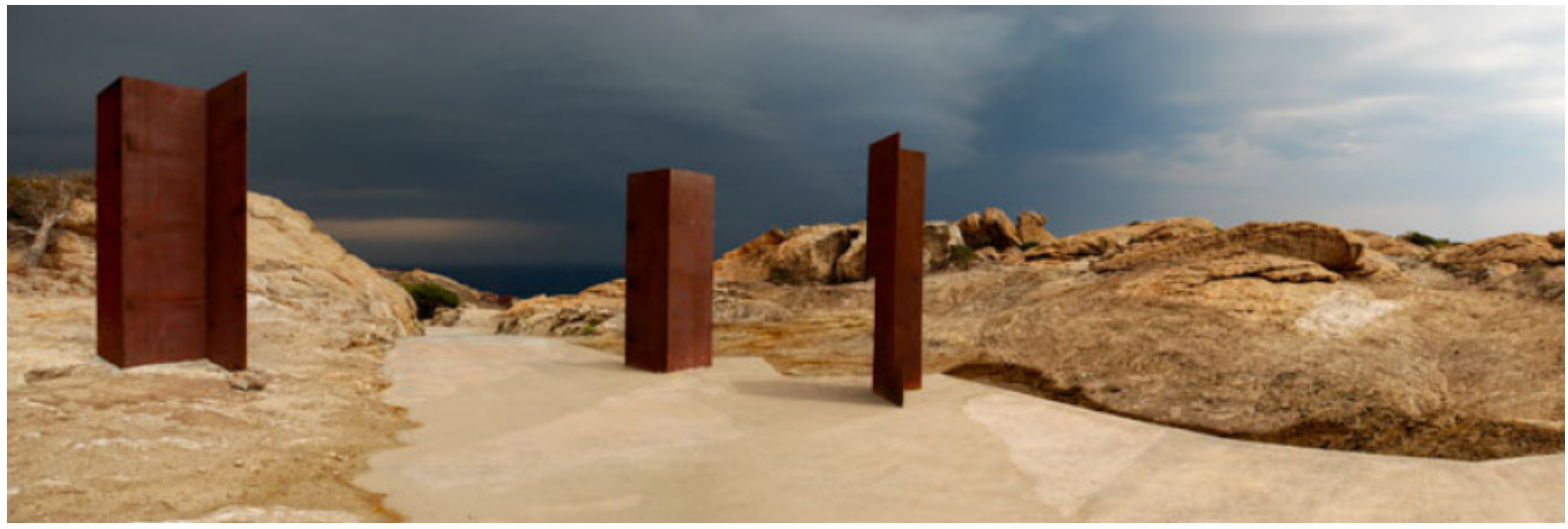

Figures 4.19, 4.20 \& 4.21: Tudela-Culip Restoration project details. 


\section{6}

Heterotopias "inject alterity into the sameness, the commonplace, the topicality of everyday society"

- Dehaene \& Cauter, 4 


\section{[ HETEROTOPIA ]}

Michel Foucault argued that 'heterotopias' act as 'counter-sites', inverting what would traditionally be considered 'real place' (34). This thesis investigation argues that by understanding the CMJ as a heterotopia, architecture can help visitors to such a site straddle the fine line that separates utopia from dystopia.

As a lost site, or non-place, the CMJ represents a dystopian condition. This section explores research objective two: how the motorway site can be shifted from the dystopian into the heterotopian (RO2). Michel Foucault and Walter Russell Mead are the two theorists used to consider the implications of 'heterotopia'; then Daan Wessellman and his writings on the High Line in New York are considered in relation to the application and benefits of these heterotopian theories in an urban environment.

Heterotopias are seen as the 'other' spaces of society, places that are an accumulation of time (Foucault and Miskowiec 26), places that are parallel to normal society. Walter Russell Mead describes a heterotopia as neither a utopia nor a dystopia, but rather a place "where things are different - that is, a collection whose members have few or no intelligible connections with one another" (13).

By engaging with the historic and contemporary heritage of the CMJ site, as well as the rich didactic nature of the Te Papa archive collections, the architecture has the potential to become a space that is a palimpsest of components, a complex layering of time and history in one intervention.

Its engagement with the motorway infrastructure and its surrounding urban context allows the design to address the commonplace of driving, cycling, or walking through the site in a completely unusual manner. The experience of passing through the motorway junction can shift from the dystopian to the heterotopian - this urban infrastructure being experienced in a completely unprecedented manner.

It is this redefined, alternative experience of the city which makes the potential of the architecture as a heterotopia so rich. The design research intervention can become a place that offers a completely unique experience of Auckland City and allows the users to engage with something much greater than themselves. 
Project Review

Architecture \& Heterotopia

Architects: James Corner,

Location: $\quad$ Miller Scofidio + Renfro

Year: 2009

Size: $\quad 2.33 \mathrm{~km}$

- Cycleways + walking tracks

- Green space and recreation

- Performance and exhibition space

The New York High Line is possibly the most high profile example of adaptive re-use of an infrastructural space.

Considered by Daan Wesselman as a heterotopia (16), the High Line is an "otherwordly experience", a "disruptive space suspended over (and suspending the logic of) the grid" (23).

Where the High Line is the disrupter to the spatial regularity of the Manhattan Grid, conversely, at the Auckland site the intervention could become the orderer linearly linking the historic streets across the madness of concrete spaghetti motorway.

They are both places that fight against the grain of their direct surroundings and in doing so offer unique, literal and figurative platforms for different perspectives on the urban environment. Its elevated nature already provides a completely unconventional outlook on the city from that of the footpath. It couples this with opportunities for moments of pause, little pocket spaces with seats, or areas outside of the consistent plane of the High Line.

\section{6}

With the viewer suspended over the middle of the street, the viewpoint is a displacement of the position from which the city is normally seen... Yet there is nothing of particular interest about this part of 10th Avenue... The theatre simply shows the street and cars below from a different perspective, transforming the everyday functional use of the urban space into a spectacle itself.

- Wesselman, 23

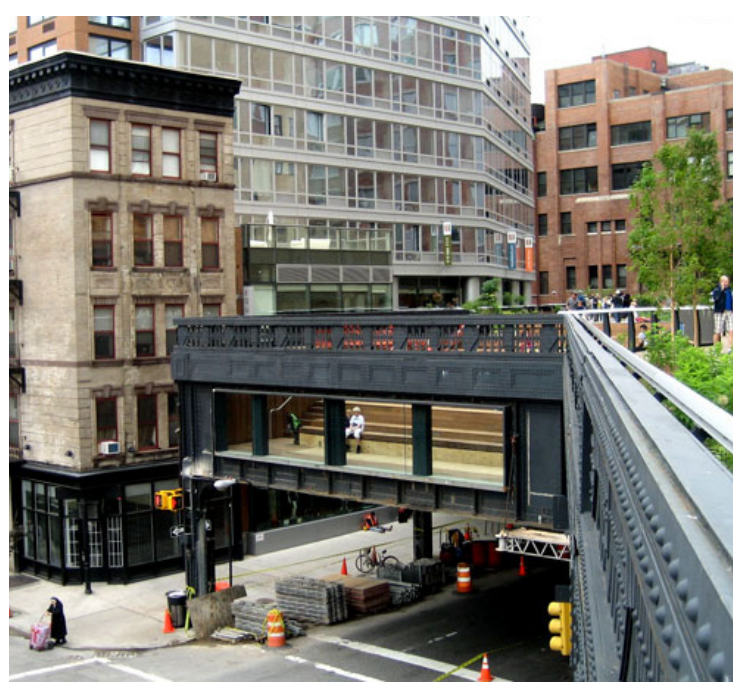




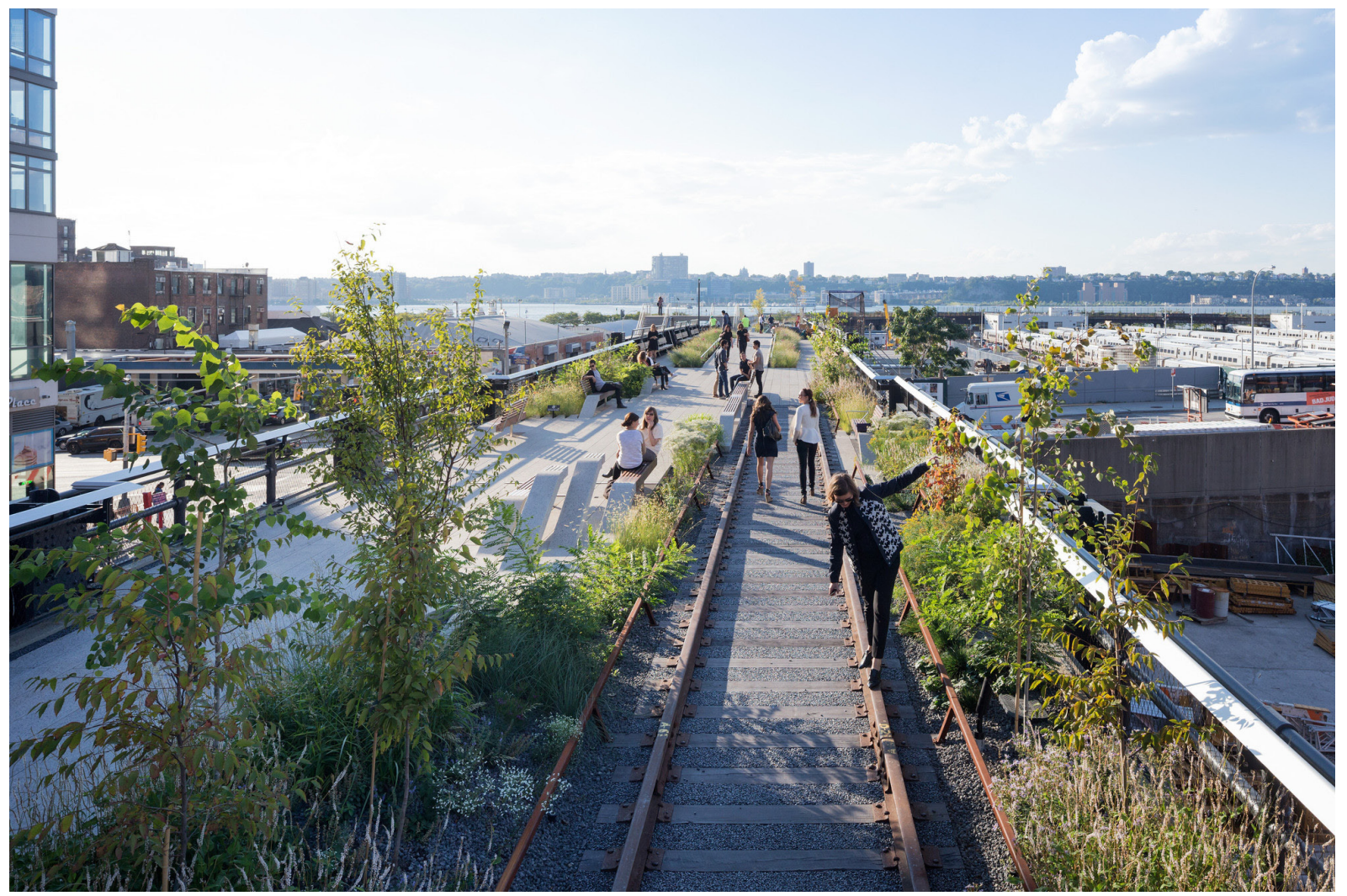

This simple change in perspective generates an enhanced engagement with the users, revitalising their interest in elements of the urban environment that have always been there. It is these moments in the High Line design that are highly relevant and applicable to the CMJ project - creating opportunities

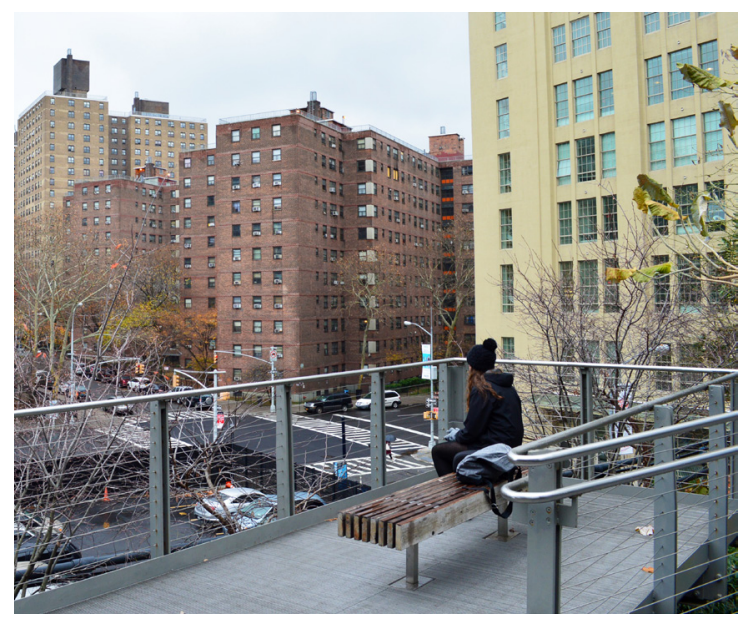

for people to engage with the urban environment in ways they have not before. This enhanced awareness and appreciation of surroundings can contribute to the research objective of revealing elements of the 'nonarchived' hidden heritage such as the site and city (RO6).

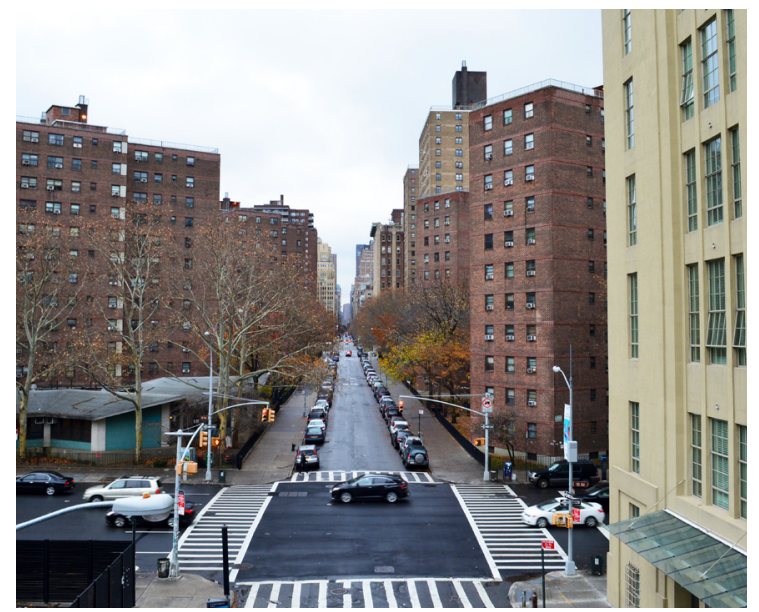

Figure 4.23 (top): The High Line pointing out towards the Hudson River.

Figures 4.24 \& 4.25 (bottom): Moments along the High Line that frame the surroundings in a new perspective. 


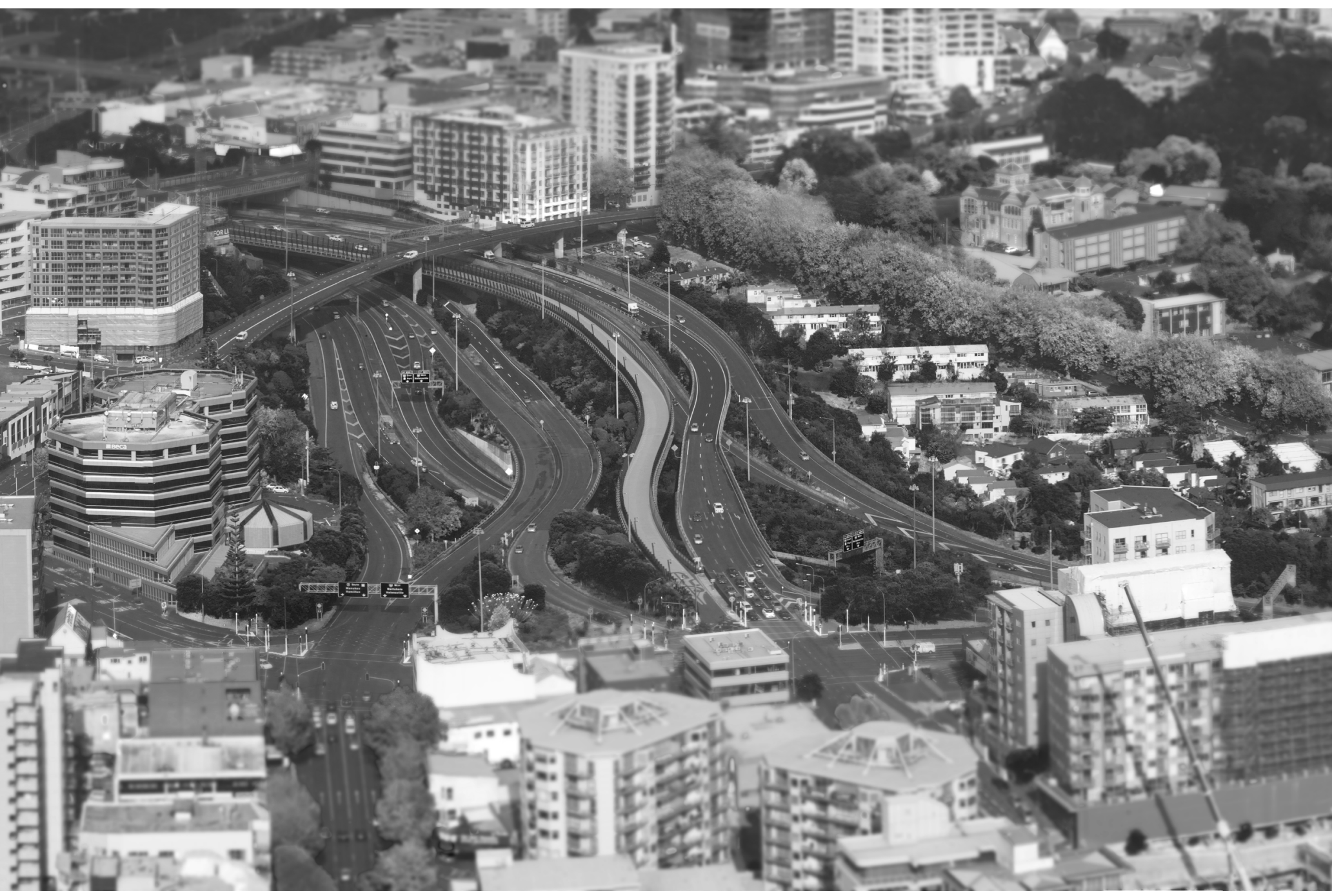




\section{[ CONCLUSIONS ]}

- [ Lost Sites ] This research argues that the CMJ can be understood as a 'lost' site in the City of Auckland. It is a utilitarian space that lacks place.

- [ Place and Cultural Identity ] To turn this 'lost' site into a diverse and positive contributor to the urban environment, place and cultural identity must be established. Place and cultural identity can be understood as the human aspect of architecture, where an intervention gives inhabitants a deeper sense of self and the world around them - a greater understanding of who they are and how they fit into their surroundings.

- [ Embracing Heritage ] Embracing the heritage of the site - both historic and the more contemporary motorway heritage - is a viable way to enhance the 'place identity' of a lost site. Embracing heritage elements of the site can also help achieve the research objectives of exploring the alternative elements of hidden heritage (RO6), and embracing the typology of the motorway as a viable urban contributor (RO3).

- [ Monumentality ] Utilising theory and design aspects of monumentality in the design research intervention can transform the lost CMJ site into an iconic marker space for the city, a celebration of theelevated motorway and its significance in the urban environment (RO3).
- [ Didactic Design ] By creating moments in the architecture where the users are able to see something they have not experienced before, or understand something to a greater depth, there is an enhanced sense of awareness and in turn, enhanced sense of place. Didactic design theories can be utilised in areas where an increase in public engagement is desired (RO5). This is where the programme of curating the city, curating the archive, and curating the seed and film archives becomes important.

- [ Heterotopia ] One of the design research intervention's objectives is to transform the dystopian motorway site into a heterotopia. For this to be possible the intervention must integrate elements of time utilising both site history and the archive collection, becoming a space that offers unique perspectives on the city, resulting in an architecture that removes its user from the commonplace of the everyday. Successfully achieving the objectives around place identity, heritage, monumentality, and didactic design will all contribute significantly to the architecture becoming heterotopian. 


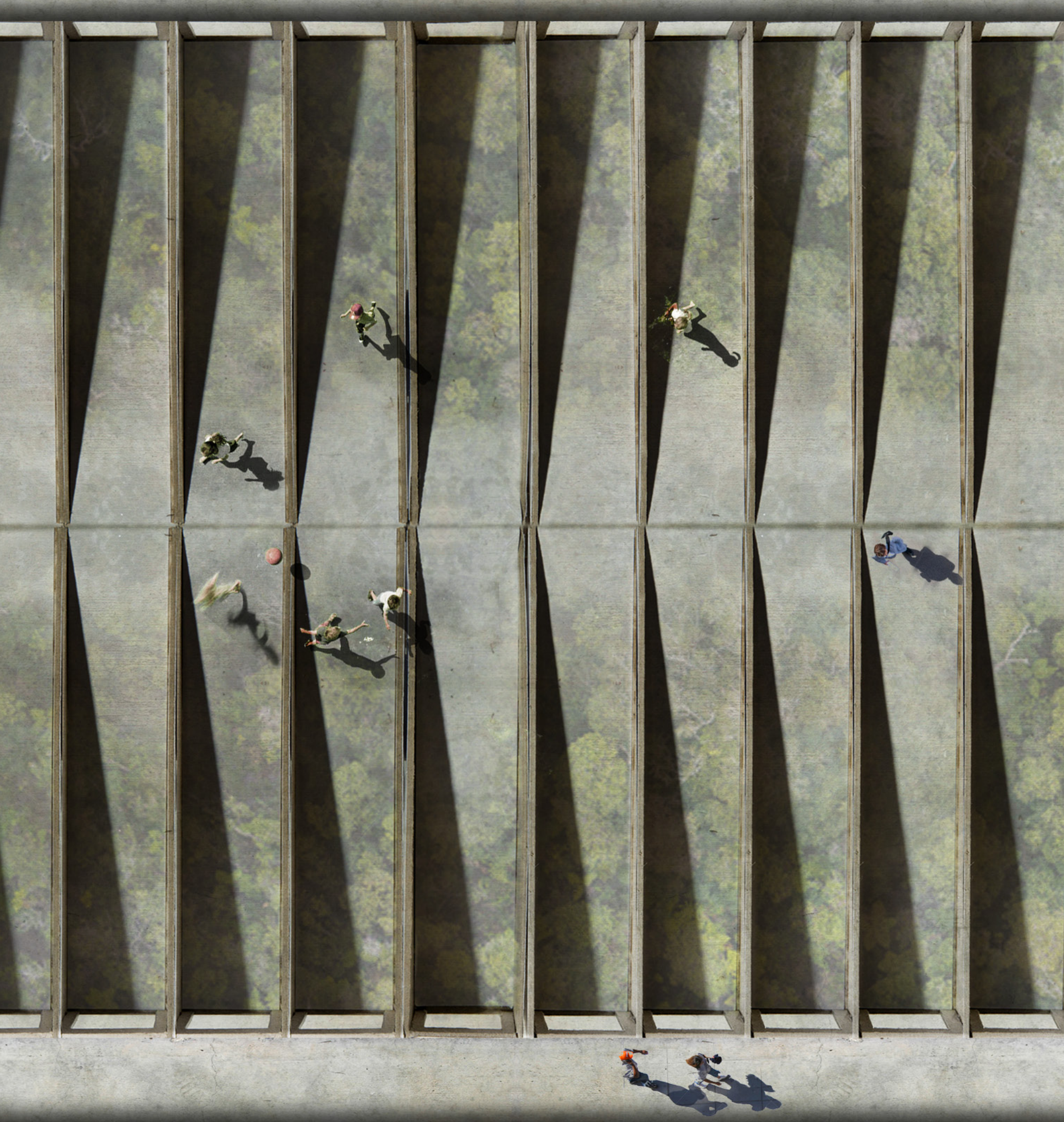

\section{I CONCEPTUAL + PRELIMI NAF}



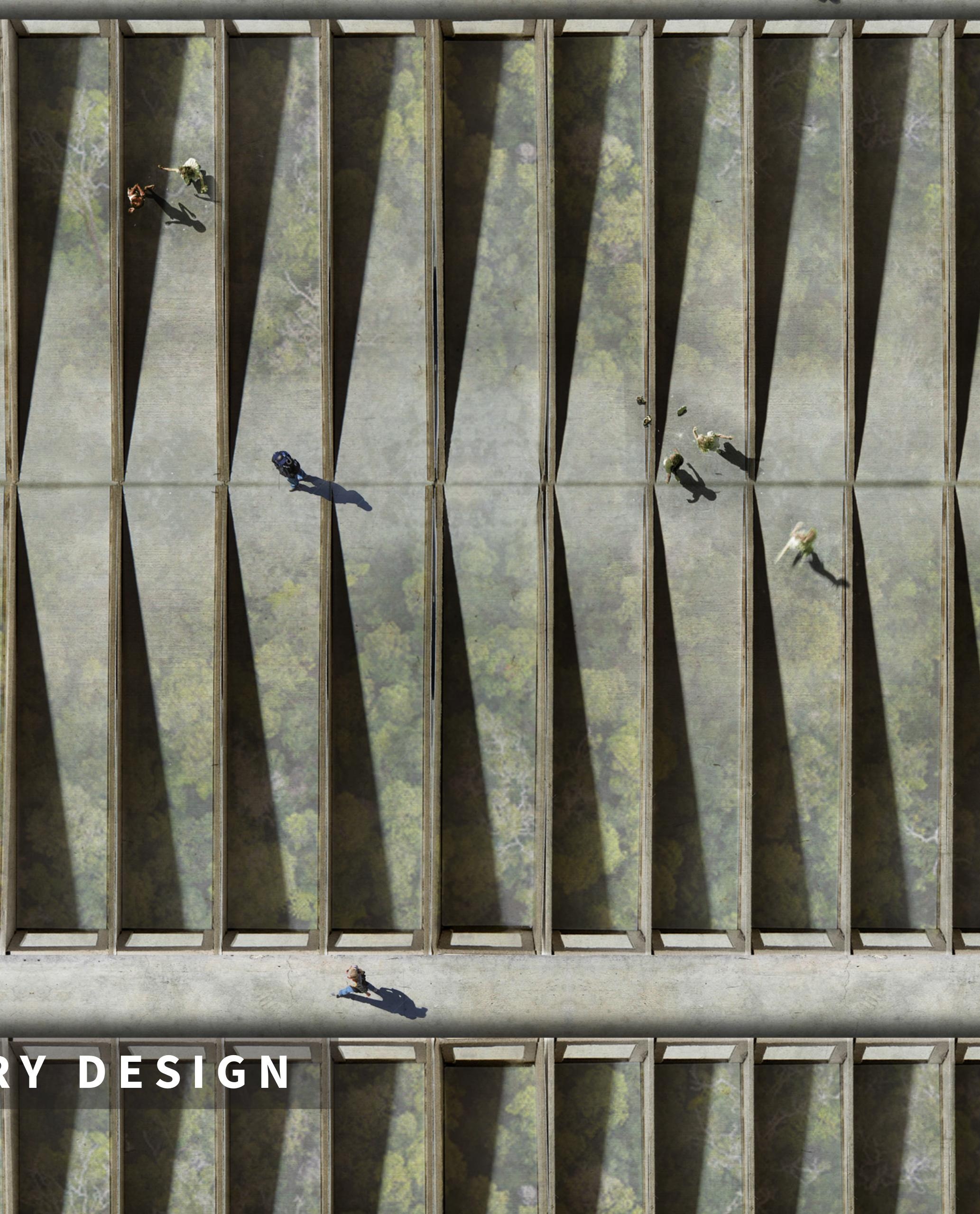


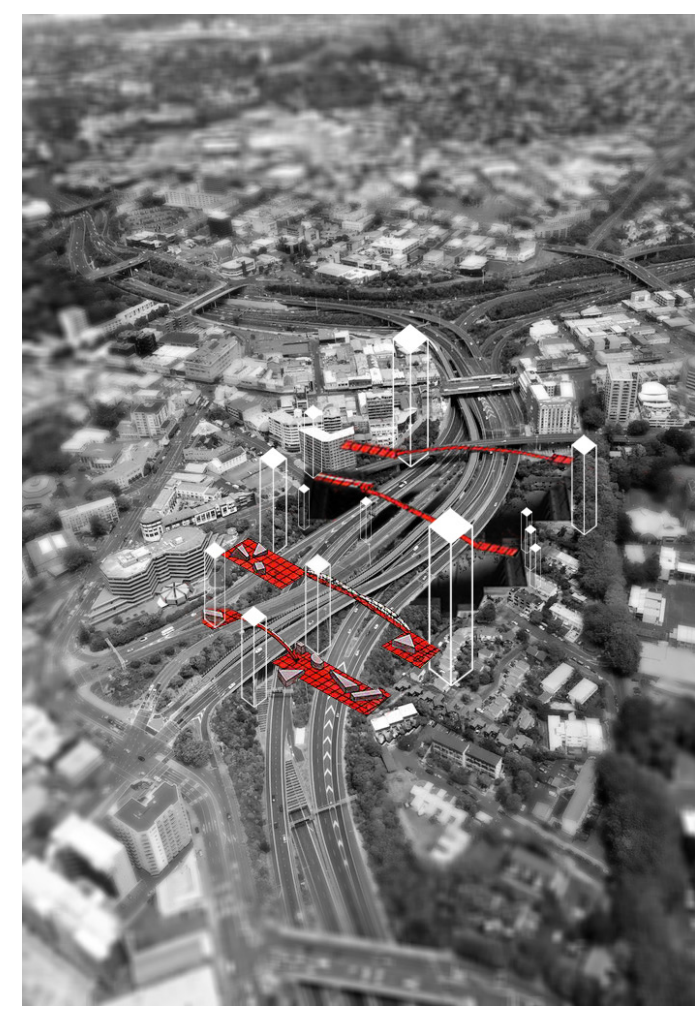

Figure 5.2: Initial sketch experiments exploring linkages across and under the motorway.

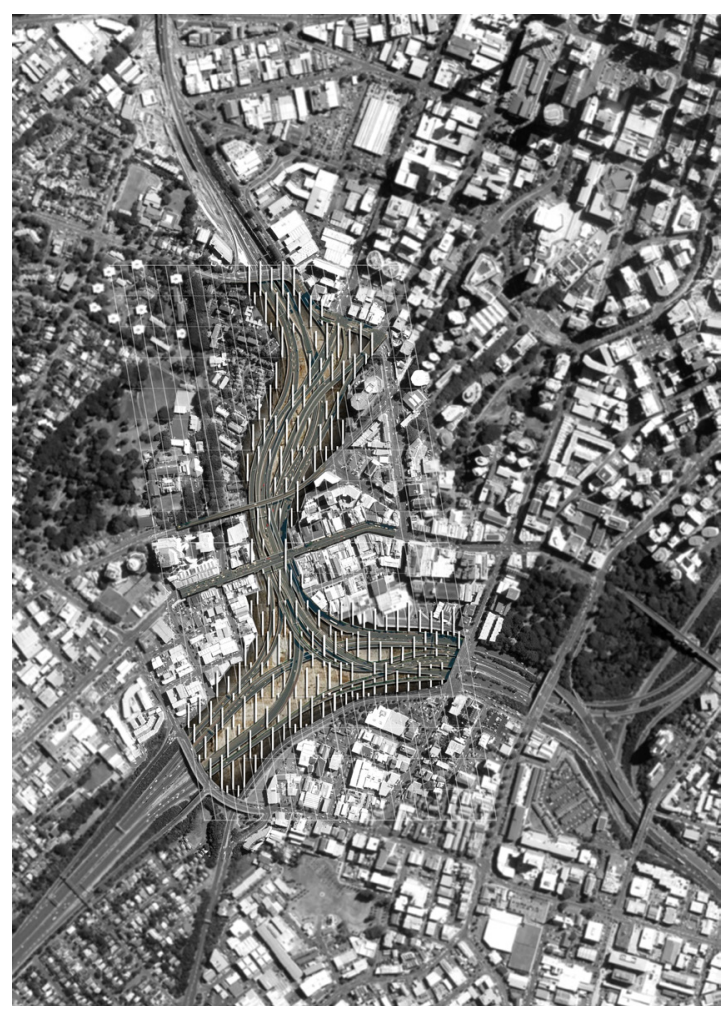

Figure 5.3: Initial sketch experiments exploring design opportunities underneath the motorway infrastructure as well as above. 


\section{5 | Conceptual + Preliminary Design}

Initial Conceptual Design ideas were developed and tested in relation to site and programme constraints and opportunities; these were developed into Preliminary Design concepts driven by ideas derived from the related literature and project reviews.

Due to the large scale of the structure, the Preliminary Design experiments explored formal, civic, social and cultural opportunities, as well as broad conceptual ideas for the programme. Detailed consideration of programme opportunities were developed more fully in Developed Design.

All design ideas have arisen in relation to meeting the aims and objectives of the thesis.

The initial Concept Design sketches explored:

- Architecture as a link or bridging condition to increase permeability through the barrier-like site and re-introduce elements of historic site heritage.

- Architecture as a framing condition / visual curation through architecture that addresses non-archived elements of 'hidden heritage'.

- Architecture as a threshold or gateway space in the motorway.
Upon completion of the Conceptual Design Phase, the first critical review was held, where members of the profession provided guidance and insights.

The Preliminary Design Phase built upon the initial conceptual designs, in relation to the critique, and expanded the exploration further with an explicit focus around achieving the six research objectives pertaining to Lost Site and Hidden Heritage.

Many Preliminary Design ideas explored an integration of concepts and research objectives, the design experiments aiming towards developing a final preliminary design that was the accumulation of the most successful elements of each idea. Ideas were tested through a wide variety of media including: hand sketching, physical modelling, photography, use of Photoshop and collage, 3D and 2D CAD modelling, and computer rendering.

The final section of this chapter is devoted to critical reflection about the Preliminary Design. It includes input from members of the profession and critically reflects on opportunities moving into the Developed design phase. 


\section{[ CONCEPTUAL DESIGN ]}

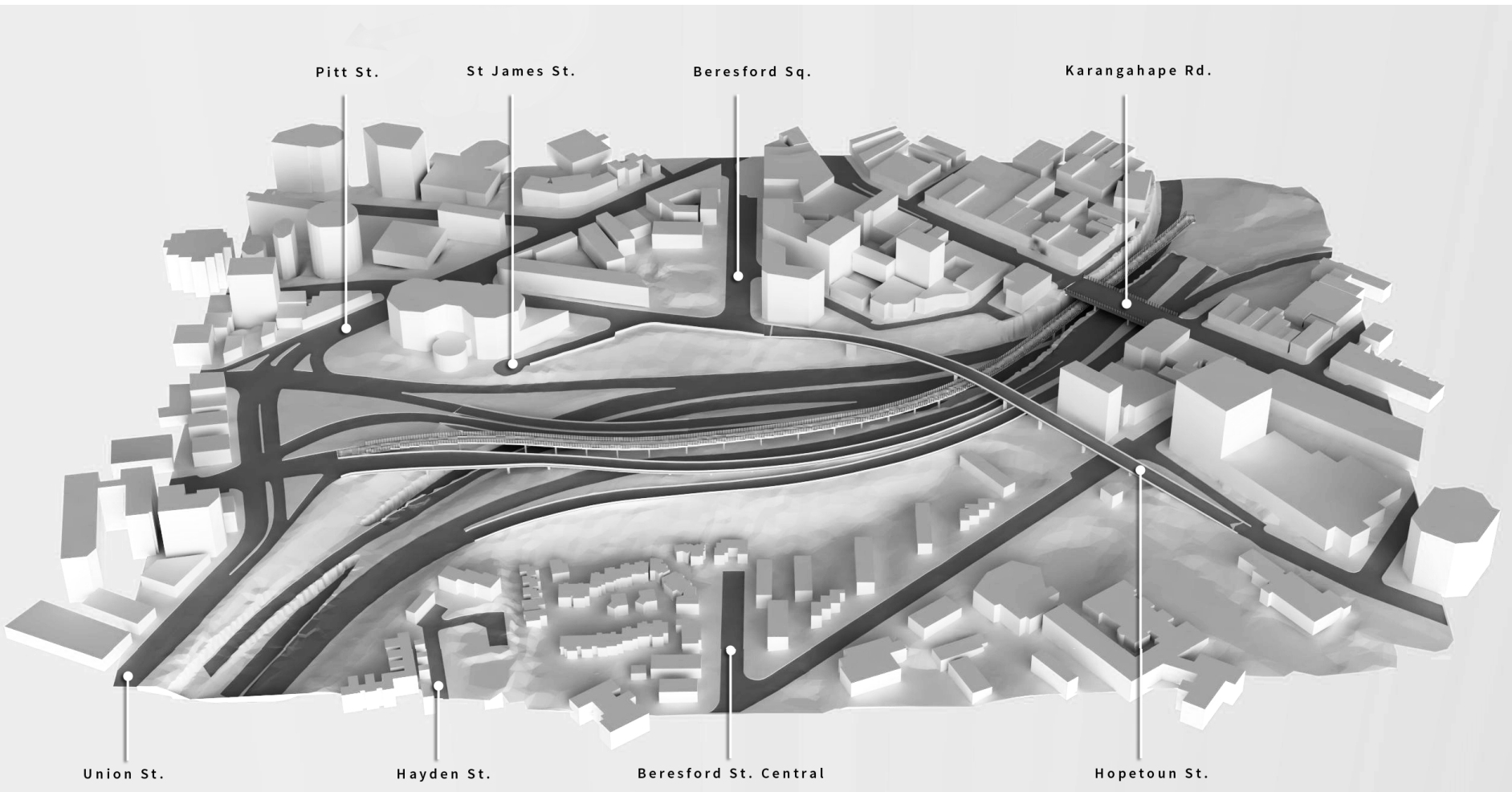

Key to the success of the design is understanding the multiplicity of conditions the architecture must engage at different points on the site.

It is also crucial to repair the link between Beresford Street Central on the west and Beresford Square on the east. Doing so will both engage with the historic site heritage and increase permeability through the $\mathrm{CMJ}$ (RO2 and RO6).

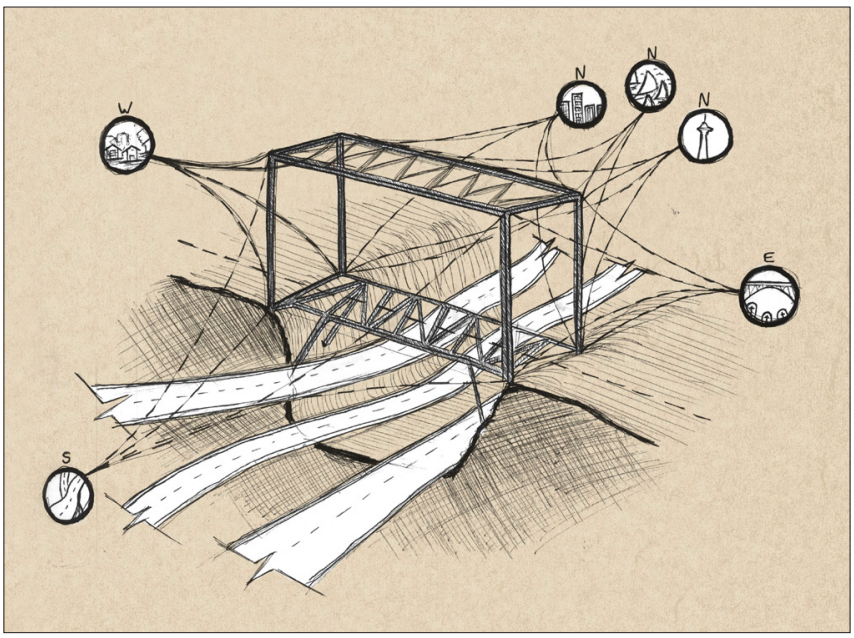

Figure $\mathbf{5 . 5}$ (bottom right): Sketching a bridging element over the motorway. 


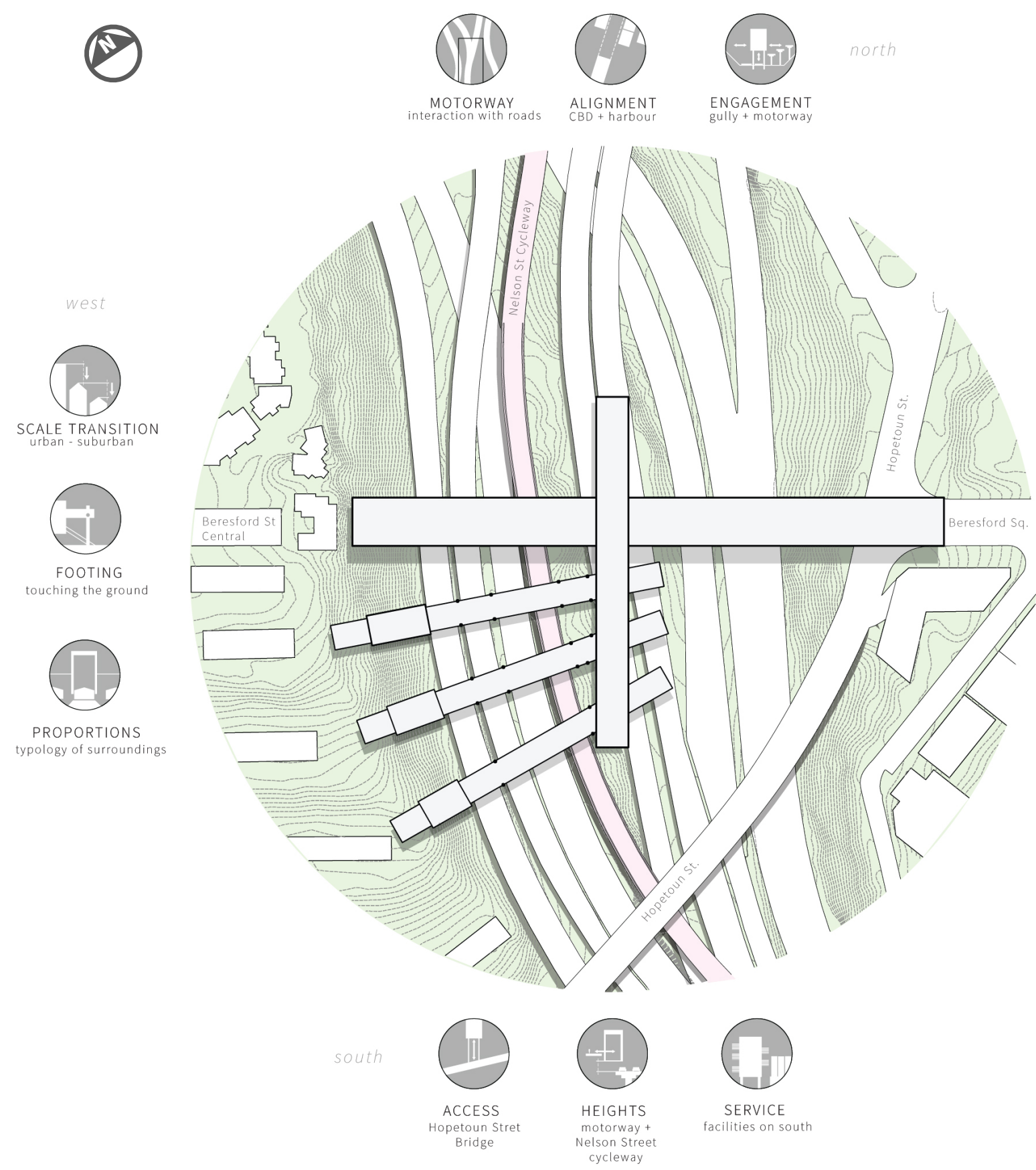

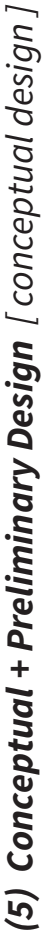

Figure 5.6 (above): The design parameters at the north, south, east, and west. 


\section{[ CONCEPTUAL DESIGN ]}

These early concept experiments investigate two broad design approaches - the 'bridge' and the 'cantilever' - for how the architecture could be used to reestablish the historic link of Beresford Street, and achieve greater public permeability through the motorway junction site.

\section{SKETCH CONCEPT A - the BRIDGE}

This concept idea conceives a new architectural intervention as a bridging element from the CBD to the suburban side. The solution is challenging due to the height changes of both the topography and the motorway.
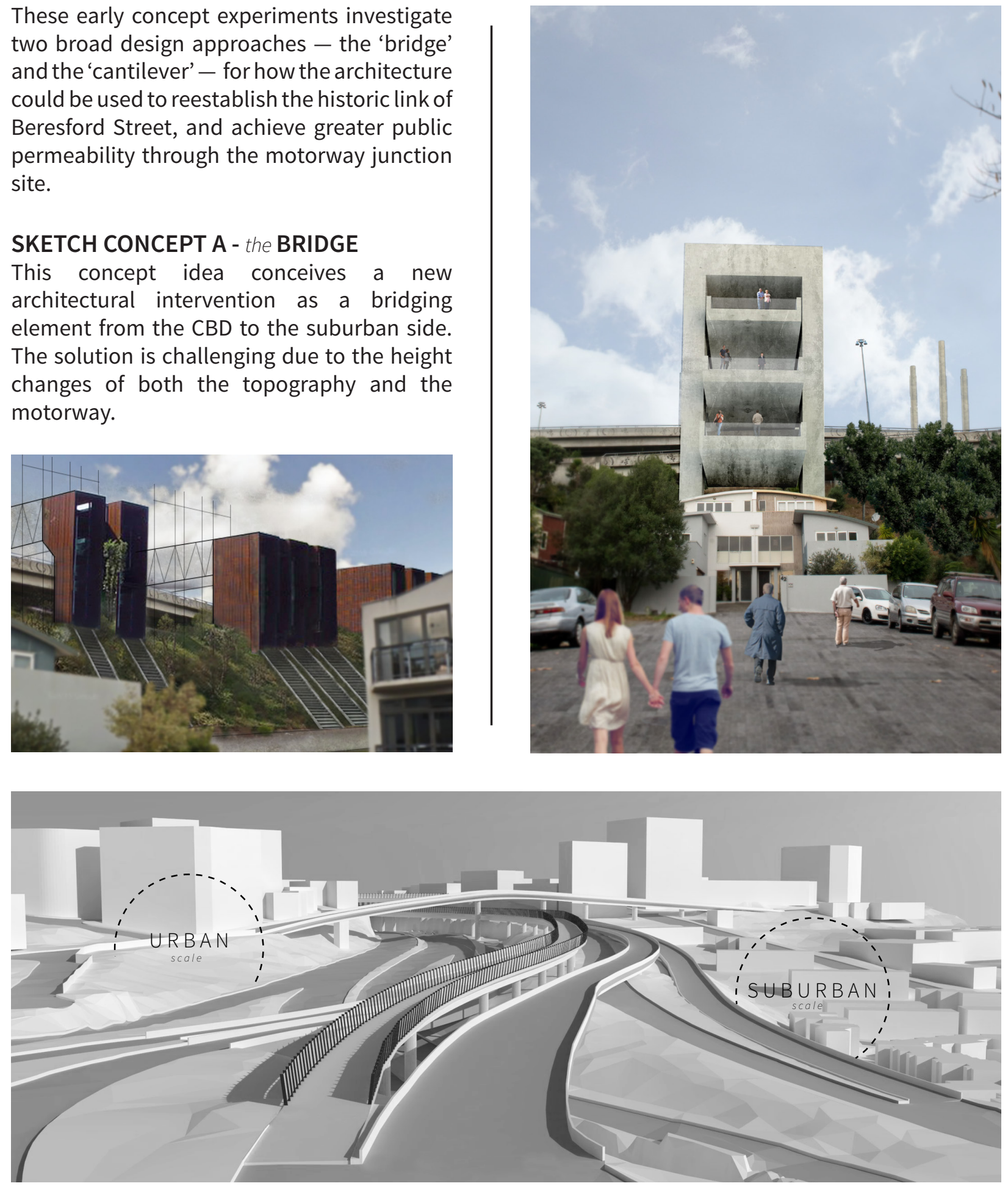

Figure 5.7 (top): Design sketches investigating how architecture as a bridging element could meet the suburban edge. Figure 5.8 (bottom): Looking south down the CMJ, the conditions on either side of the motorway infrastructure have vastly different design implications in terms of density, scale, and form. 

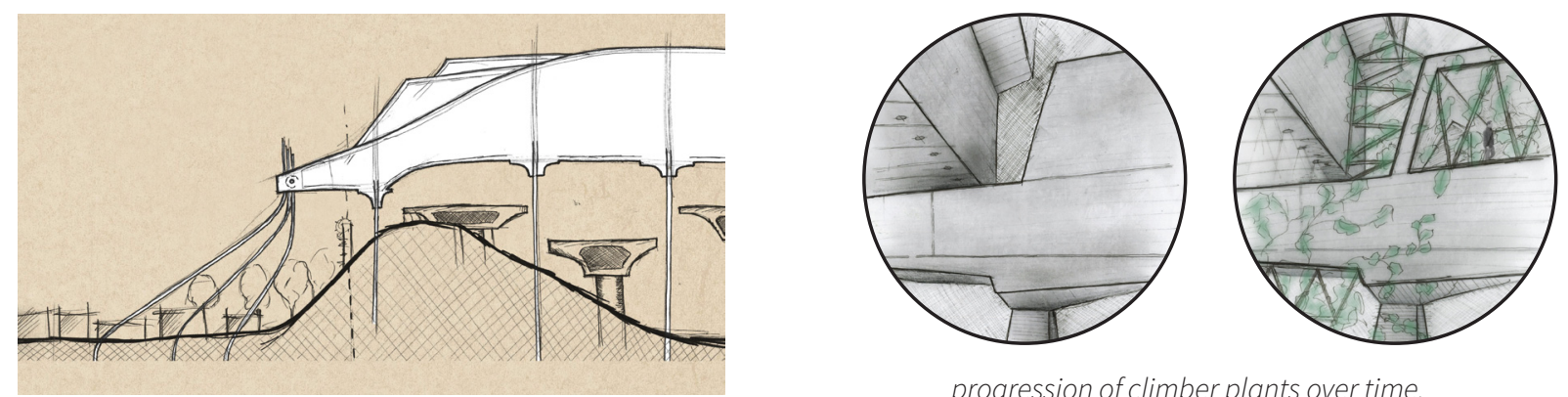

progression of climber plants over time.

\section{SKETCH CONCEPT B - the CANTILEVER}

This concept idea explores cantilvered elements reaching over the motorway and down to the suburban side. The metal framework systems creating the cantilever could also provide opportunity for climber plants to envelop the structure as a green space over time - a metaphor for nature claiming back its domain over the man-made infrastructure that has engulfed it.
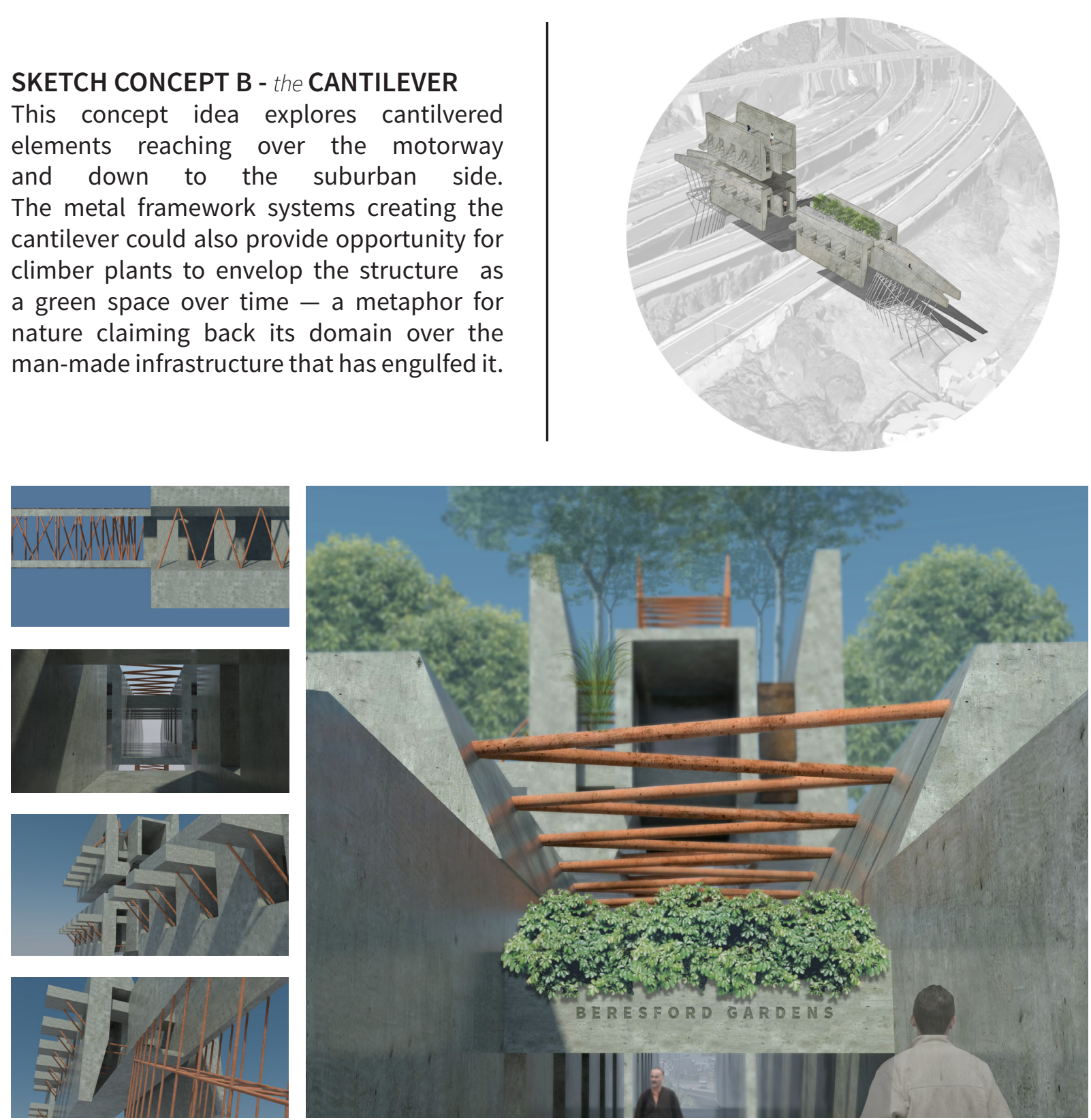

Figure 5.9: Design sketch experiments exploring a cantilever element that becomes an elevated green space across the CMJ. 


\section{[ CONCEPTUAL DESIGN ]}
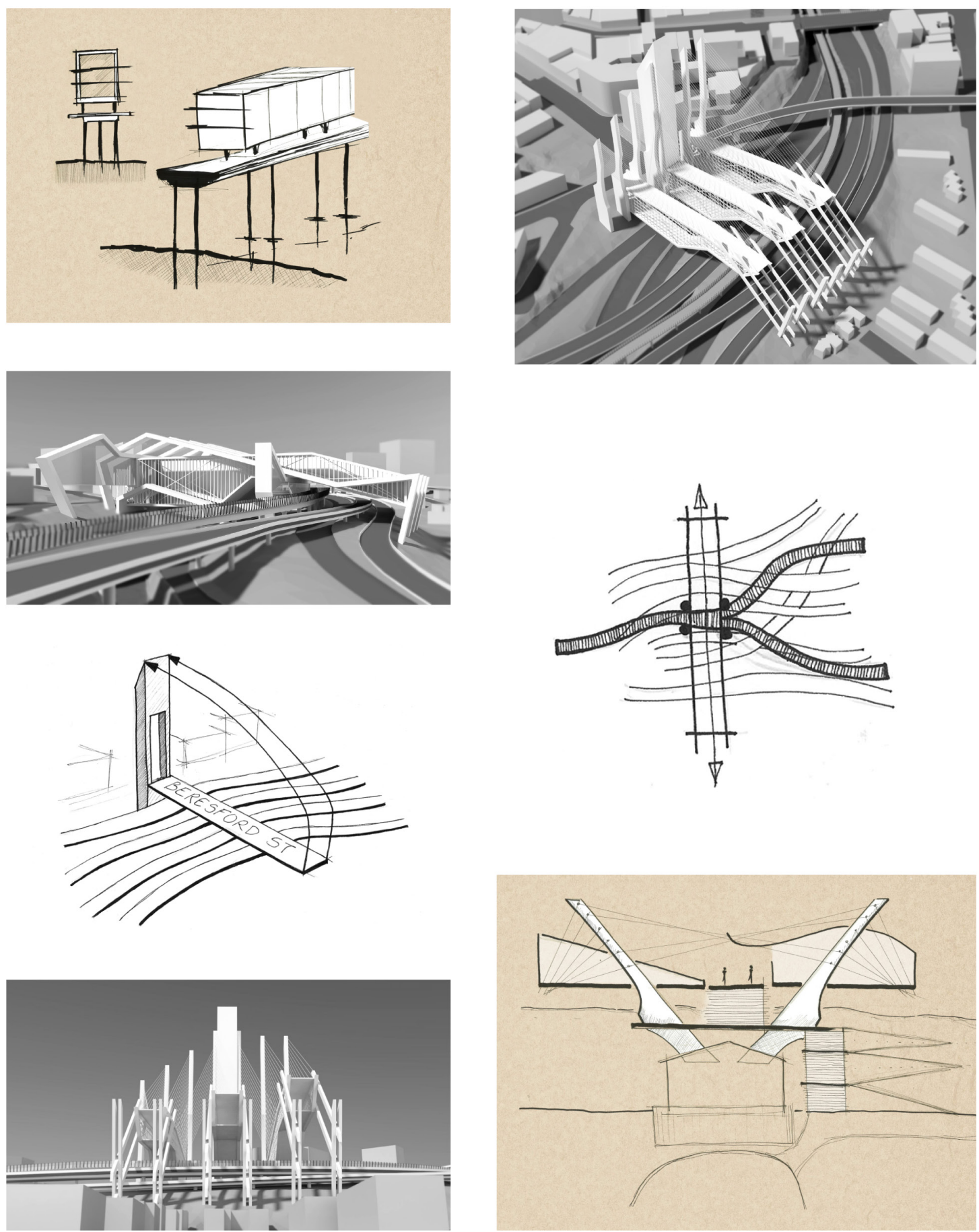

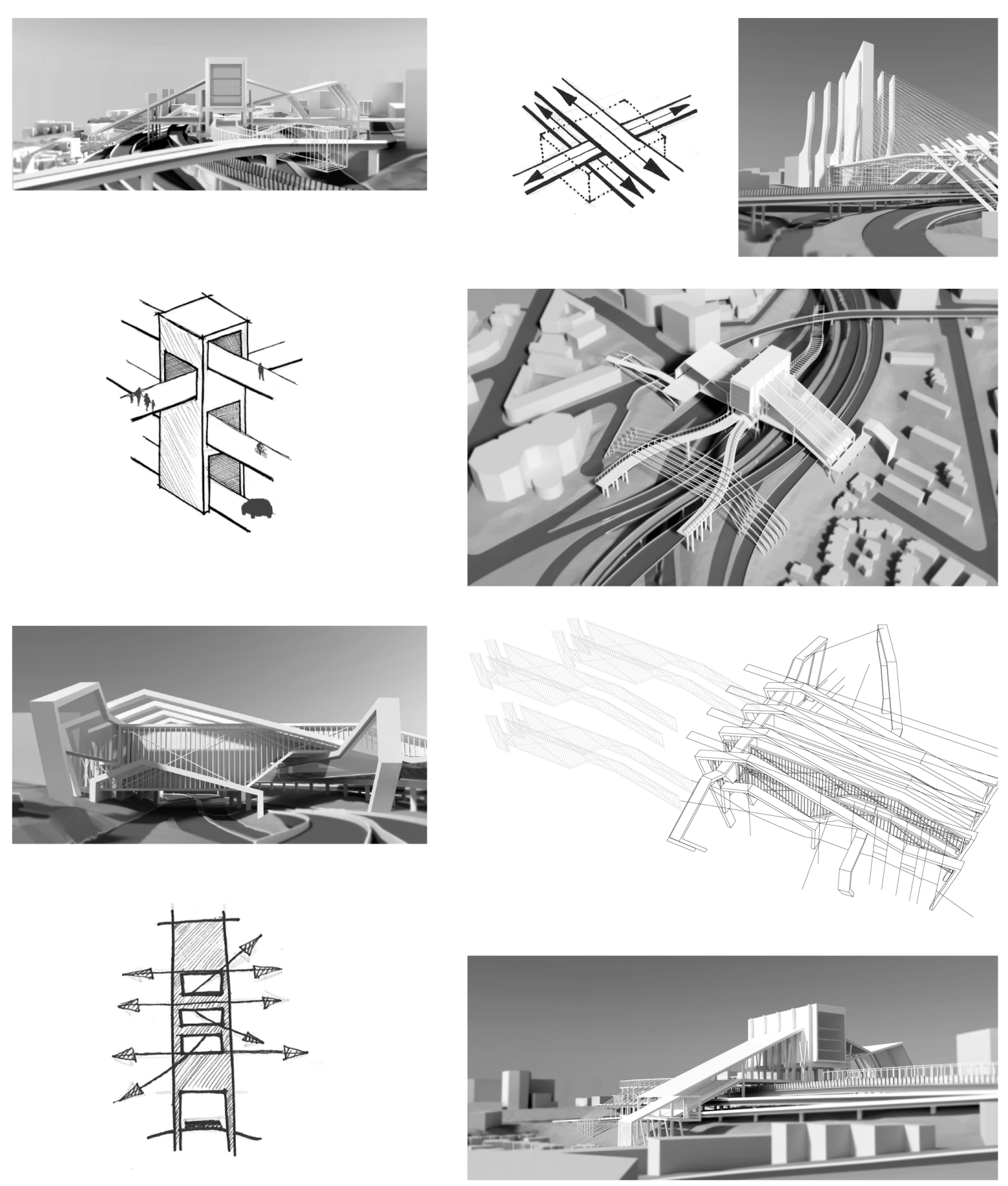


\section{CONCEPTUAL DESIGN ONE}

The collected early concept sketches led to Conceptual Design One, which aims to reestablish the historic Beresford Street link in the site, achieve greater permeability through the motorway junction, and enhance motorists' awareness of positive elements of their urban surroundings through curation of views of the cityscape.

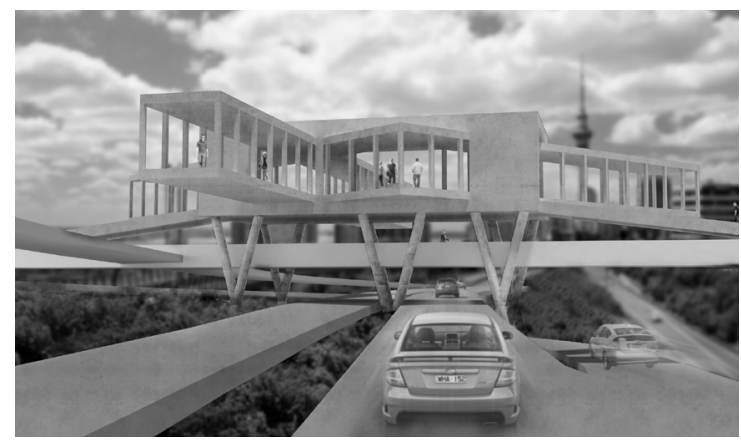

\section{[ DESIGN PRECEDENT - The Octospider ]}

Conceptual Design One looked at several relevantcase studies, including the Octospider by Exposure Architects (completed in 2004). This precedent was explored for its ability to curate exterior views through architectural form.

\section{STRENGTHS}

- Strong physical and visual axes in the intervention.

- Delicacy of architecture touching the ground and water.

\section{WEAKNESSES}

- No hierarchy of views, change in volumes or shifts in materiality.

- Simplified extruded shapes.
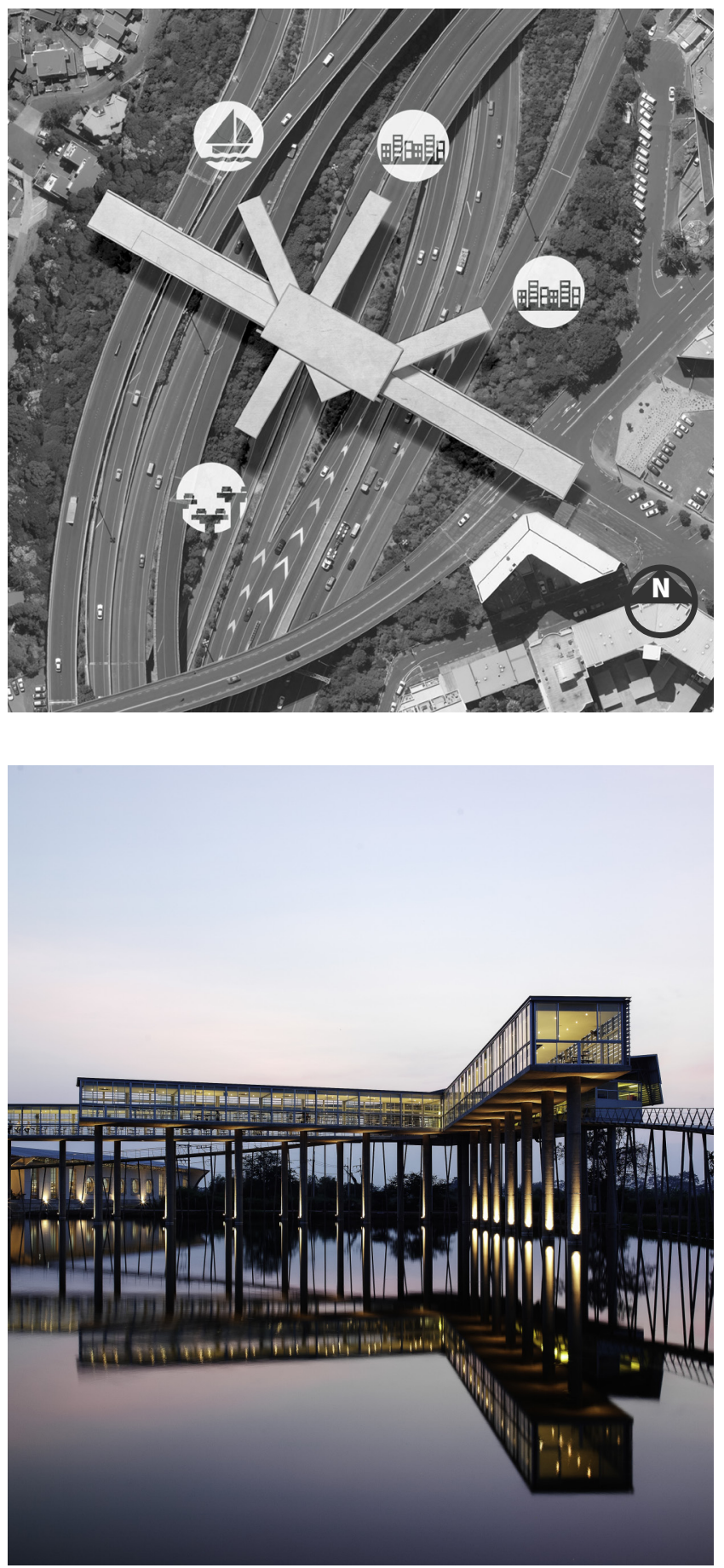

Figure 5.11 \& 5.12 (top left \& top right): Sketch renders by author of Concept One utilising the design typology of the Octospider to curate views of Auckland City.

Figure 5.13 (bottom right): The Octospider Design. 


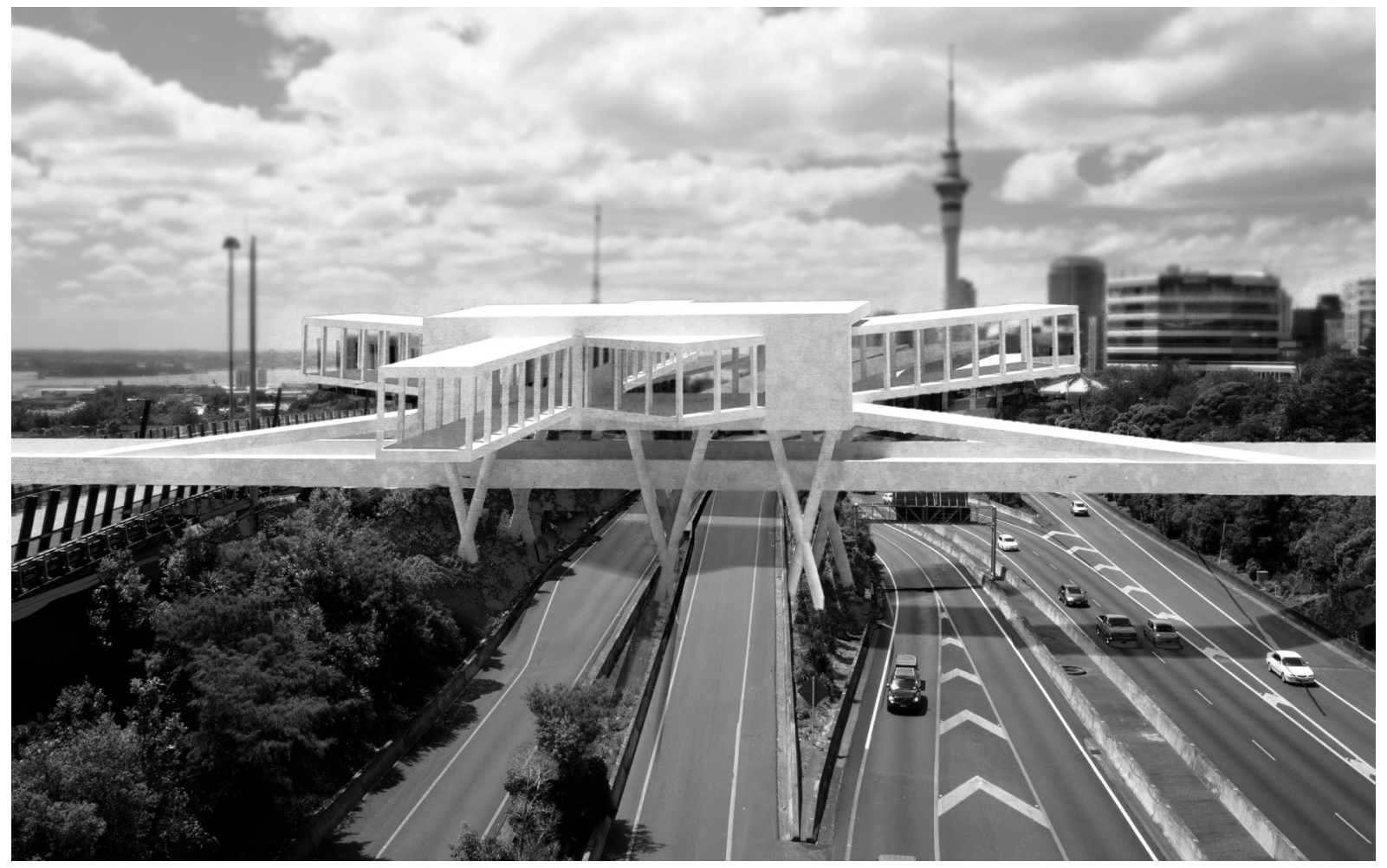

\section{[ CRITICAL REFLECTION ]}

Integrating and developing relevant elements of the Octospider precedent into the site works as a basic framing and bridging device but lacks the complexity and depth to engage with all the intricacies of site.
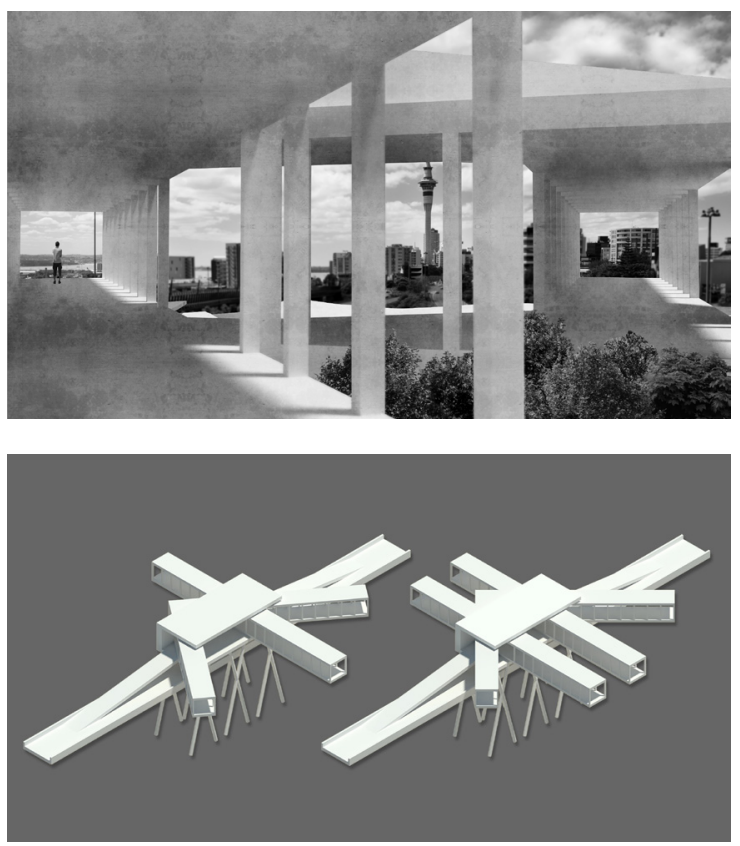

Figure 5.14 (top): Concept One integrated into site.

Figure $\mathbf{5 . 1 5}$ \& $\mathbf{5 . 1 6}$ (bottom right): Interior of Concept One and diagrammatic development of form. 


\section{CONCEPT TWO PHYSICAL MODELLING}
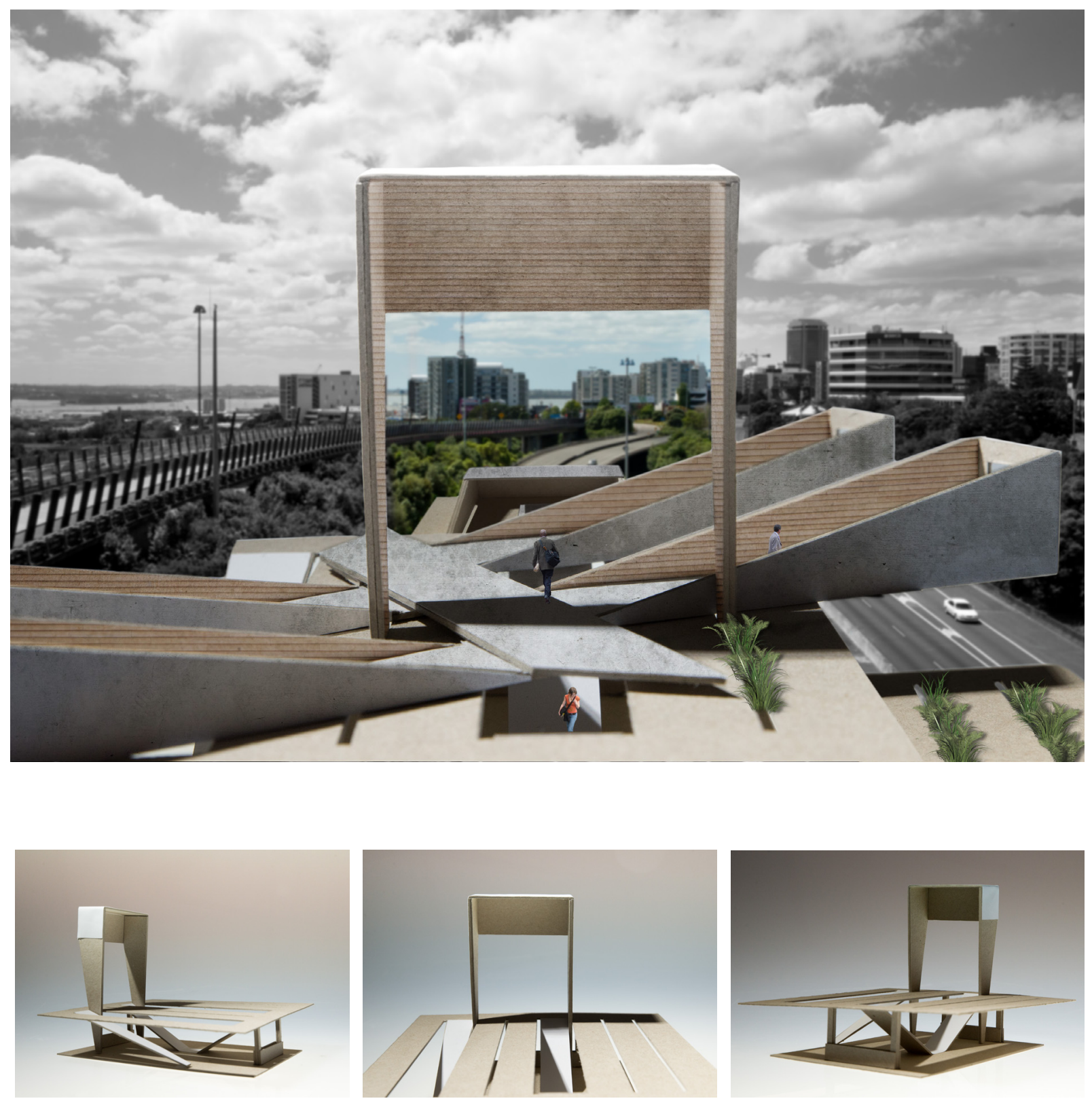

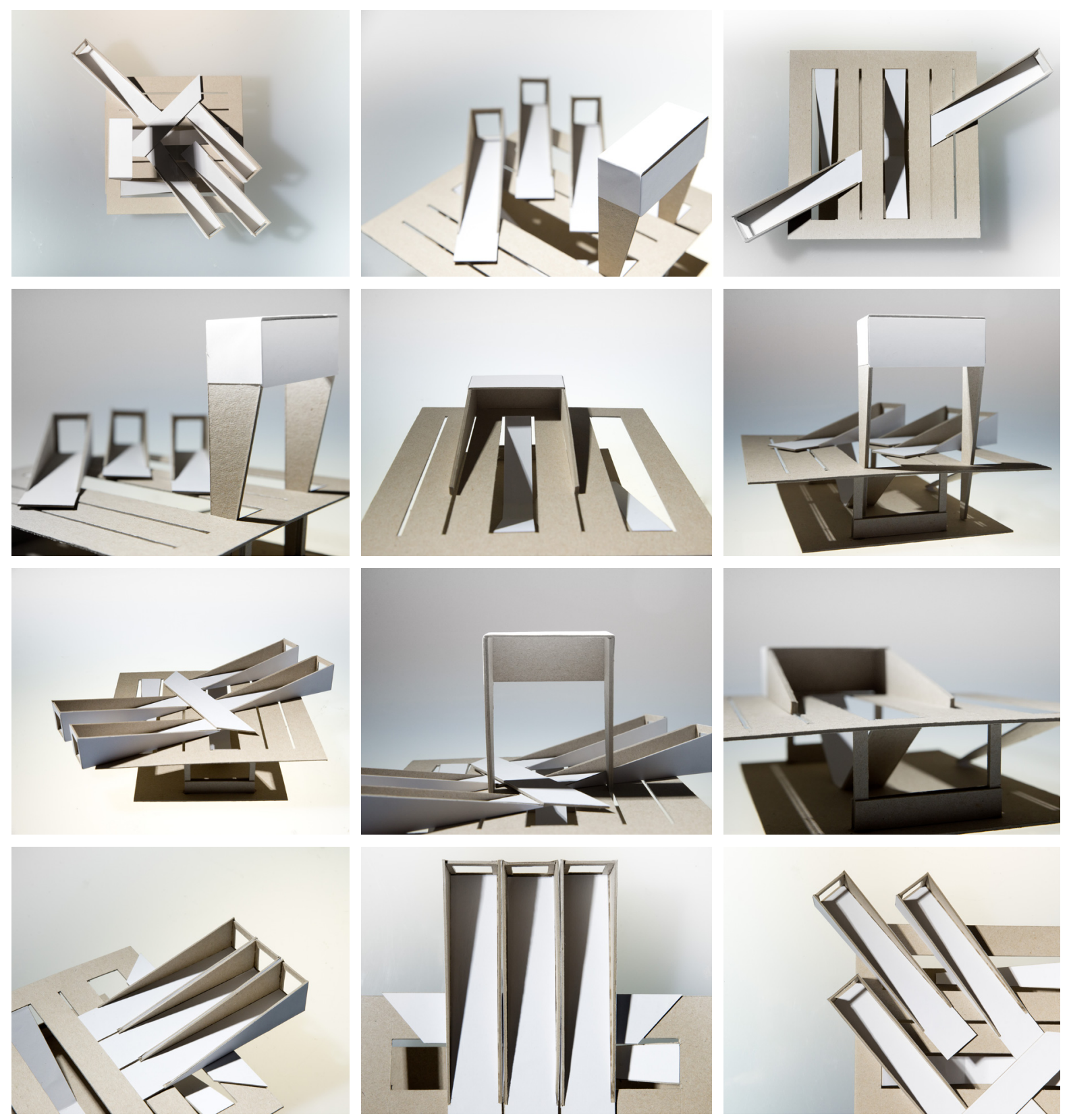

Figure 5.18: Further exploration of physical modelling to develop 


\section{CONCEPT TWO PHYSICAL MODELLING}
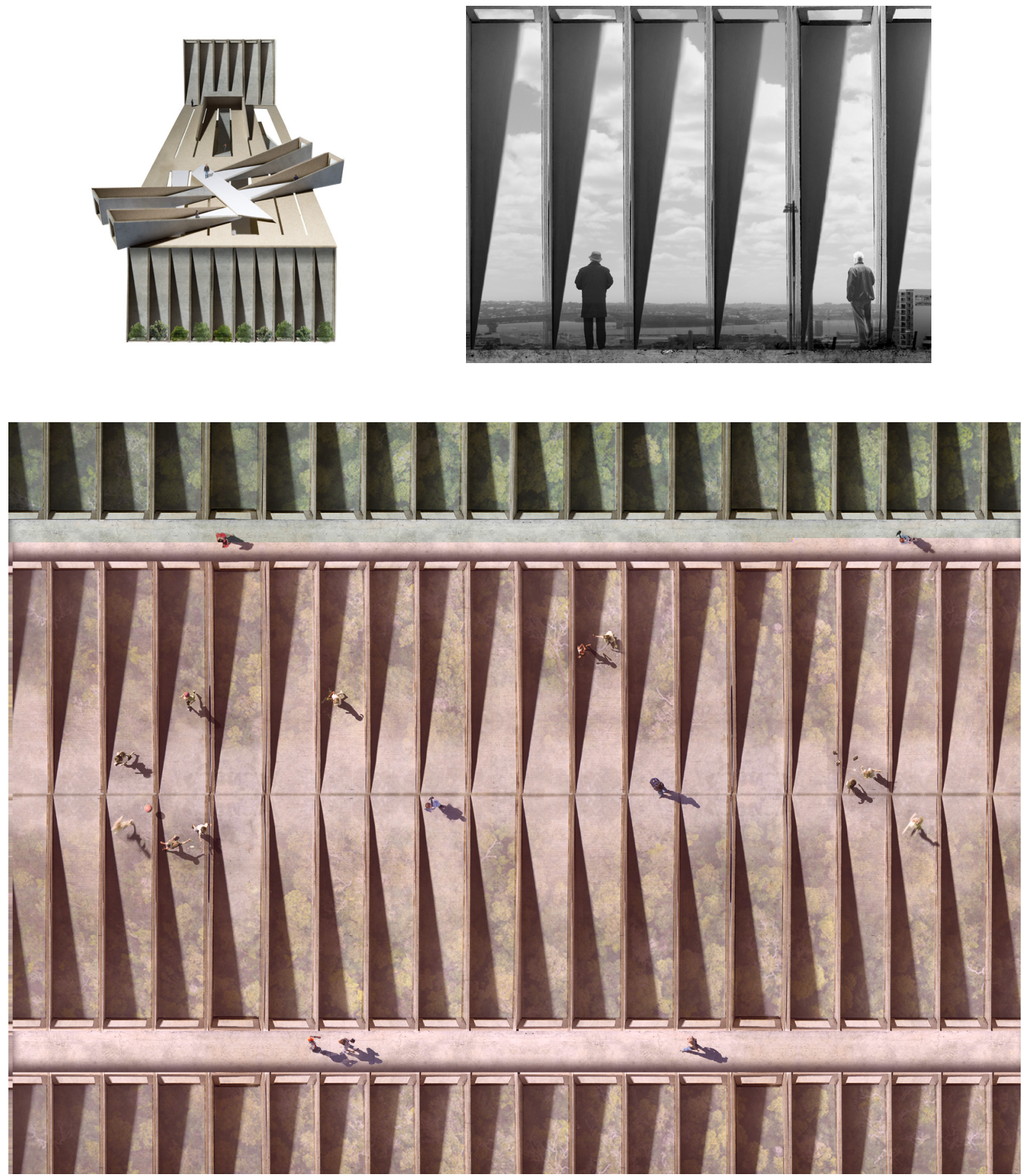

Figure 5.19: Physical modelling in combination with Photoshop and photography to further explore this angular form's ability to frame elements of programme and site. In plan the repetition of the form has the potential to frame elements of green space as a courtyard typology, whereas, in elevation the forms could be used to frame / curate views out to the city. 


\section{CONCEPTUAL DESIGN TWO}

This concept retains the view shaft typology from Concept One as it is a simple but effective way to frame views of 'heritage' elements around the site. Additionally, Concept Two integrates smaller framing elements in between these two main enclosures that can curate green space planting and other minor views for public engagement.
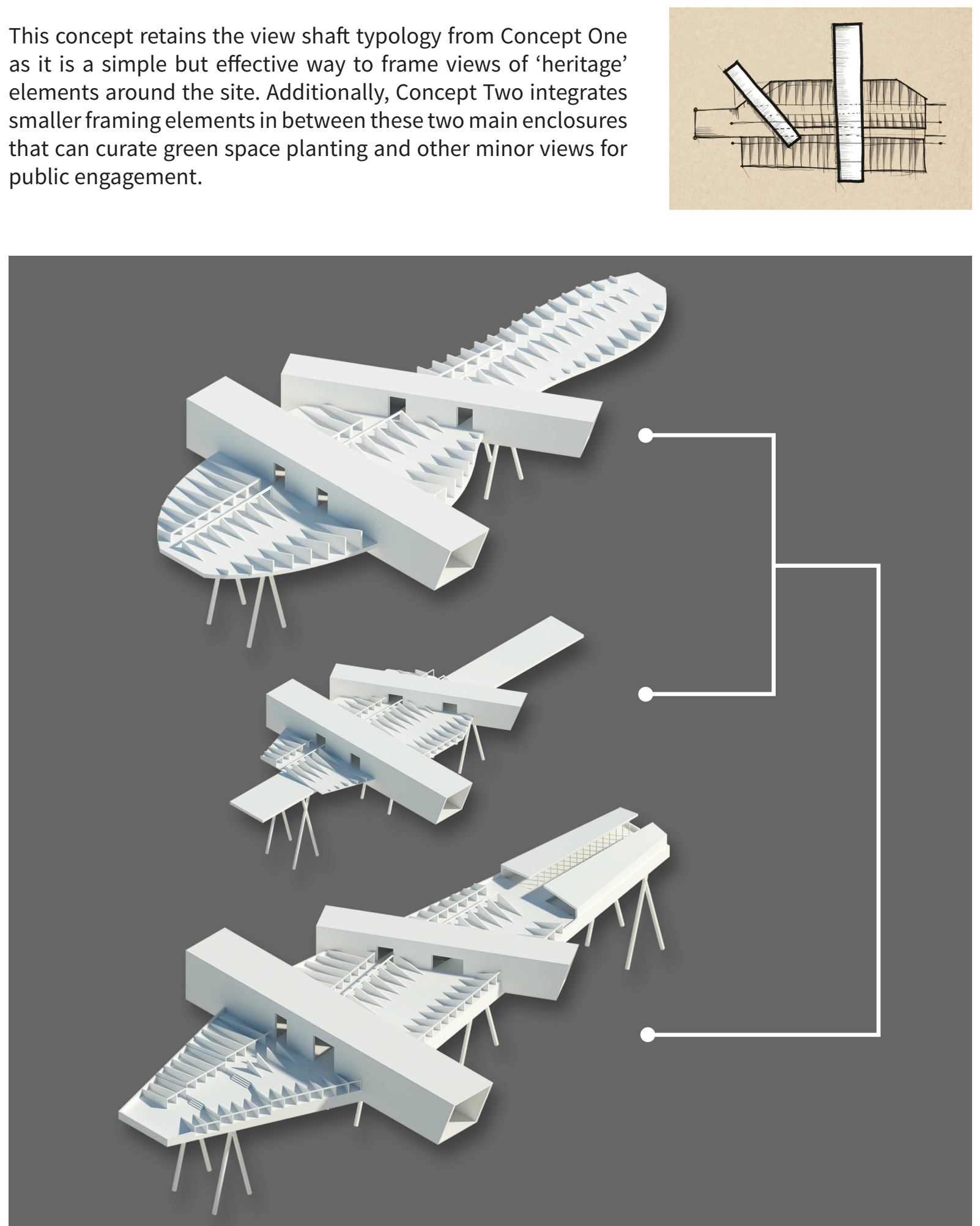

Figure 5.20: Integrating two major architectural 'view shaft' elements with the textural and formal qualities explored through physical modelling, creating pocket courtyard spaces in-between. 


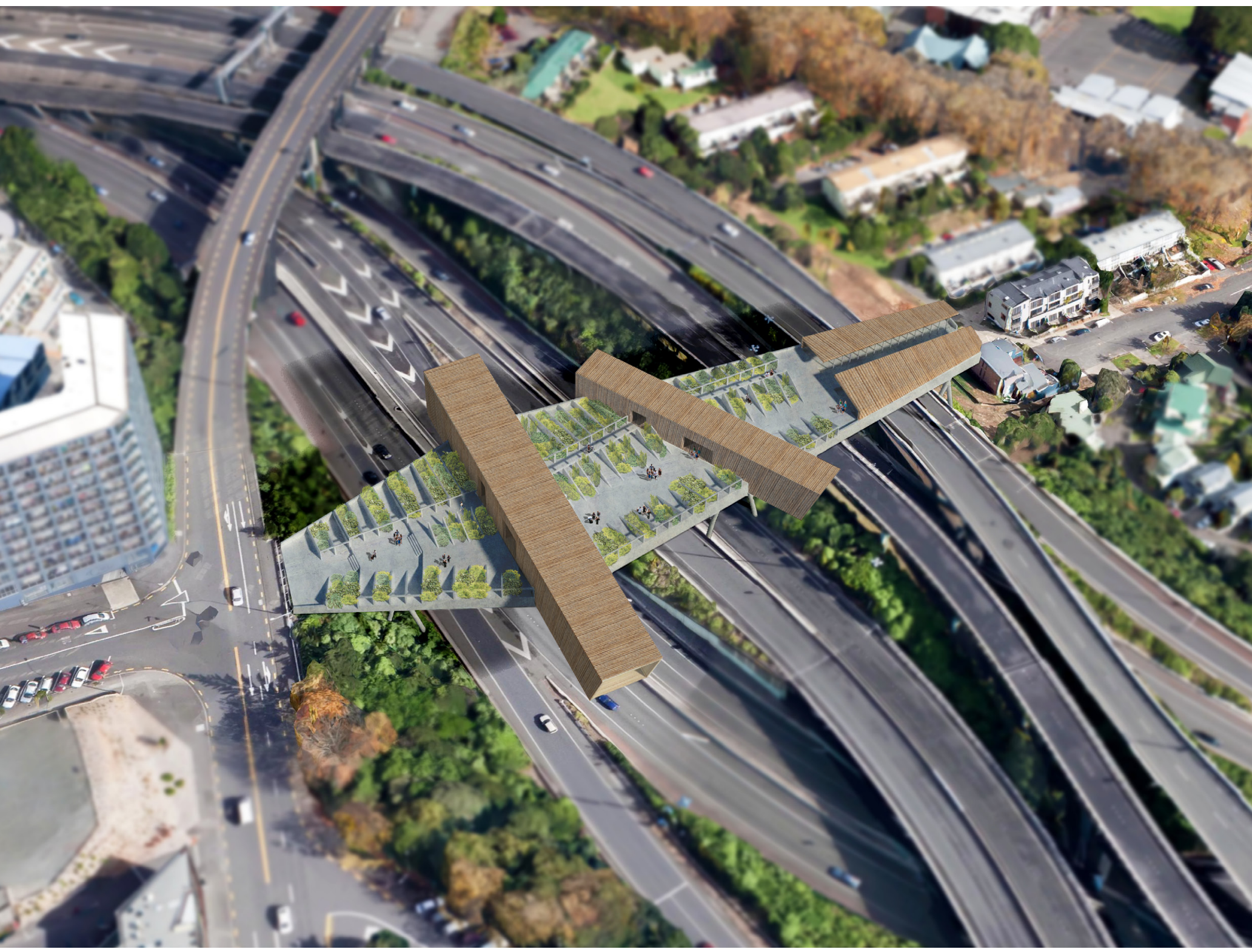

\section{CONCEPTUAL DESIGN TWO}

The design focuses around the view shafts towards the main CBD skyline and the harbour. The framing of these iconic elements of city heritage aims to create moments of pause for the pedestrians, making them slow down and appreciate these defining urban elements of the city's identity. There are two main pedestrian routes through the intervention - one that acts more as a direct transitory corridor space, while the other is wider and more winding, for slower engagement by the public. By offering a dual of pathway opportunities through the architecture users can choose how they engage with the intervention. 


\section{CRITICAL REFLECTION - Conceptual Design Two}

At the completion of Conceptual Design Two, a formal critique was held on 20 May 2016. The author's critical reflections were as follows:

\section{STRENGTHS}

- The nature of the slower more experiential path provides greater engagement with the architecture. It is along this path that the archive collection programme could be placed so that the items could be engaged with intimately.

- The view shafts are able to frame two iconic elements of the city's heritage, although in a simplistic manner.

\section{WEAKNESSES}

- How the intervention addresses its entry/exit points is weak. It is not strong as a threshold space for vehicles or pedestrians.

- The design is not embracing the monumental scale of the CMJ and integrates unsuccessfully with its surrounding context.

- Engagement with the motor vehicles below is not strong, an the design does not embrace the typology of the motorway well.

\section{MAY DESIGN REVIEW (20.5. 2016)}

Design and project critique with feedback from professional architects Fleur Palmer, Nick Barratt-Boyes \& Kerstin Thompson.

- "More sectional exploration through the site is required. How will the architecture touch the earth at the interstices between the motorways?"

- There are opportunities on site to explore the design cutting through the valley, in particular the steep motorway berm on the suburban side.
- " Embrace the bigness of the scale."

- The scale and nature of the site lend themselves to an architecture with a degree of monumentality that needs to be committed to.

- "What is the tension between public and private spaces on the site?"

- There are design opportunities with how the public pathways and courtyards can weave through, encompass or sit adjacent to semiprivate and privatised spaces of the archive programme.

- "Explore the sinuosity of the motorway below. Does the intervention react with this grain or against the grain of the roads?"

- The dynamic flow of the motorway has a distinct typology that is strong on the site and should be embraced rather than ignored.

- "How can the 'framed views' be designed in subtle and integrated ways?"

- Subtlety in framing views will lead to a more critical architecture. It is important to avoid the literal box framing of crucial axes on site.

- "What is the difference between architecture and infrastructure? Can we design architecture as motorway?"

- There is a degree of architectural beauty in the motorway. Can certain aspects of motorway infrastructure and the beauty of its engineering and structural elements be drawn into the design? 


\section{CONCEPTUAL DESIGN THREE}

Concept Design Three investigates the design as a series of thresholds with which motor vehicles interact on their commute so the motorway is embraced as a viable urban experience. The original plan for this design (figure 5.23) retains perpendicular elements at a consistent spacing; however this does not respond well to the more irregular layout of the surroundings. An revised plan (figure 5.24) shows how the thresholds could be arranged in response to the dynamics of the surrounding site, alleviating the dense regularity of the initial plan.

\section{[ Strengths + Weaknesses ]}

- $\quad$ Strength\} Engages with the motorway as an iconic gateway into the city, but does so in a somewhat diagrammatic manner.

- $\{$ Weakness $\}$ Engagement with the pedestrian is poor which is detrimental to creating diversity in the $\mathrm{CMJ}$, but it provides opportunities to address this.

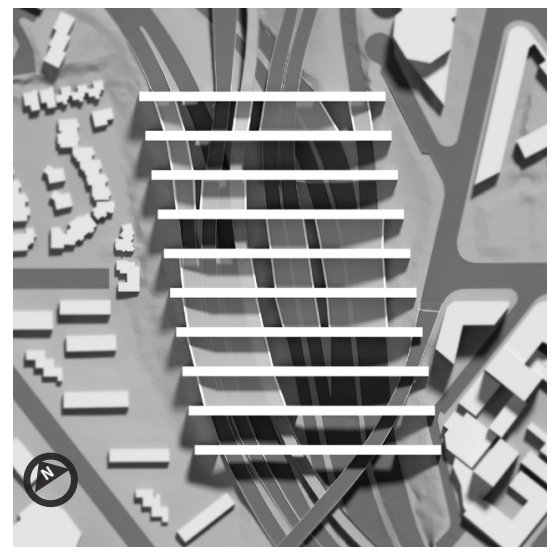

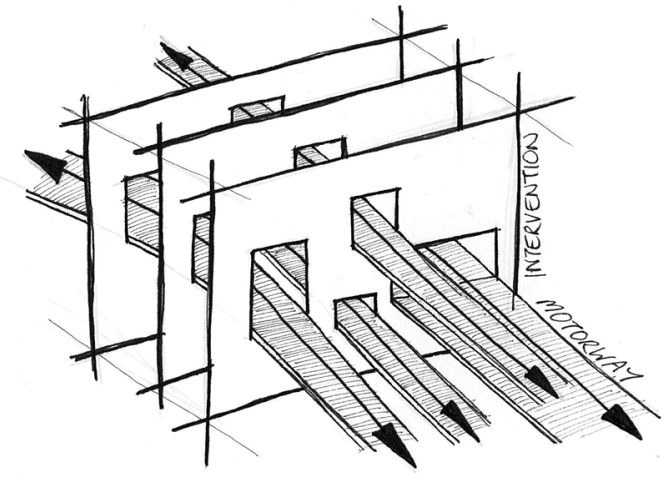

PENETRATIVE THRESHOLD

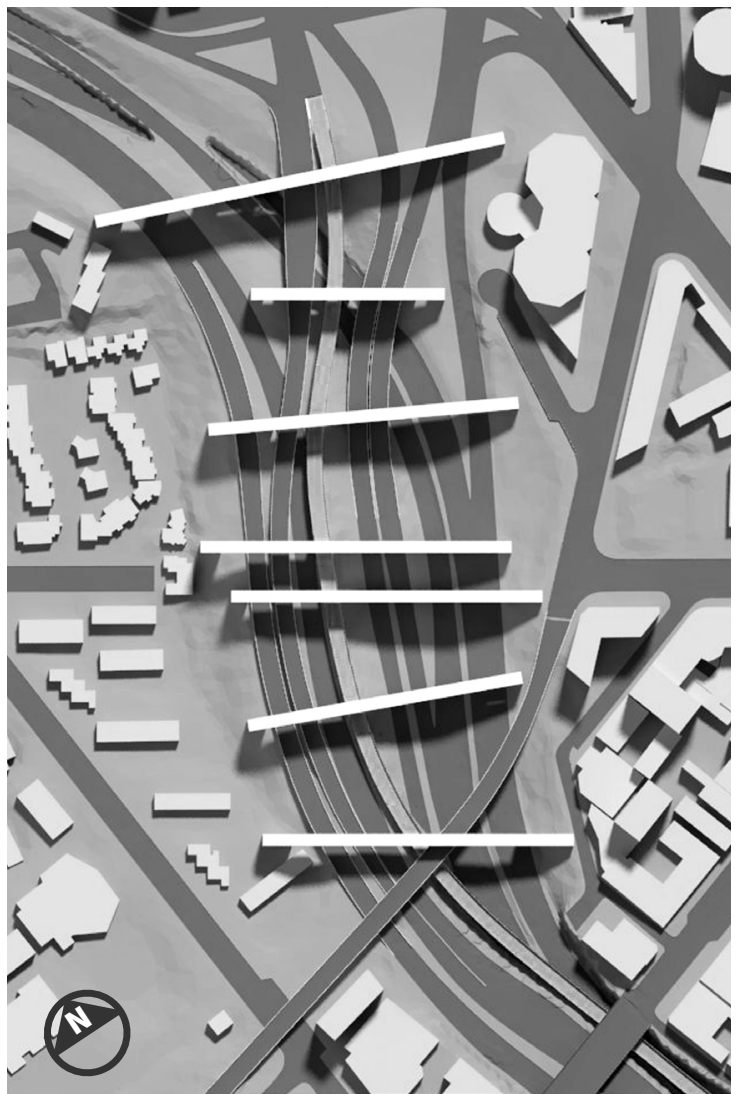

Figure $\mathbf{5 . 2 3}$ (left): The original scheme (A.1) as a series of thresholds.

Figure $\mathbf{5 . 2 4}$ (bottom right): An altered scheme (A.2) that responds to the site conditions. 


\section{CONCEPTUAL DESIGN FOUR}

This design also explores architecture as a bridge and threshold diversifying user typology through the CMJ via the main crossroad intersecting between the vertical elements.

The vertical elements create two types of thresholds in the design. Closer to the residential side, the threshold is tight and squeezes cars through the site, whilst on the CBD side the threshold opens itself up to the city.

However, the horizontal threshold typology as shown in figures $5.22-5.24$ is much more successful in terms of creating a series of gateways that vehicles experience on their journey through the CMJ.
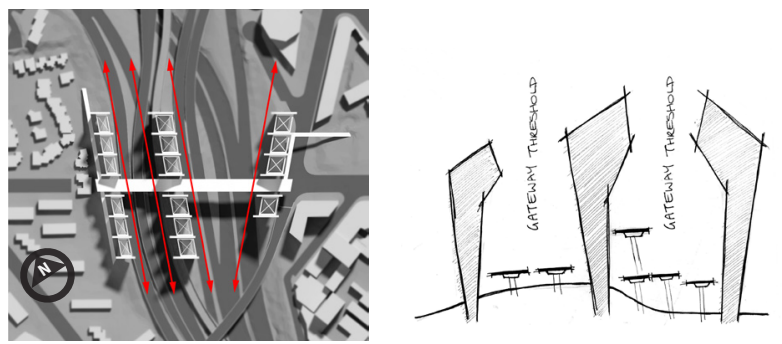

\section{[ Strengths + Weaknesses ]}

- $\quad$ Strength\} Starts to engage with, and reflect the monumental scale of the site and embraces the CMJ as an iconic entry point into the Auckland CBD.

- $\quad$ Weakness\} Lack of diversity for pedestrian circulation through the site.

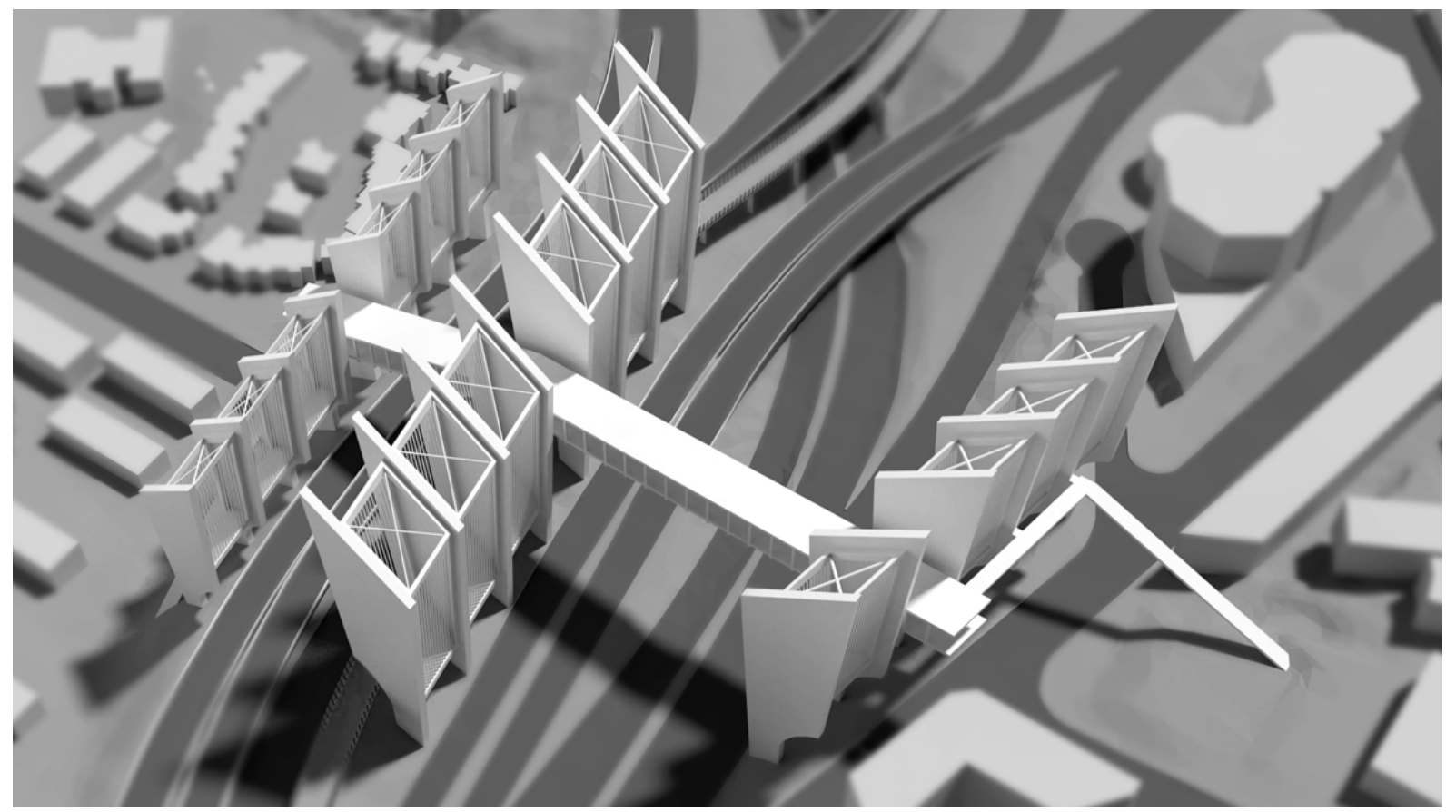

Figure 5.25 (top left): Exploring how the two threshold corridors could work. 


\section{CONCEPTUAL DESIGN FIVE}

This design idea explores how the intervention could create a defining entry and exit gateway into the heart of the CBD.

\section{[ Strengths + Weaknesses ]}

- $\quad$ Strength\} The design creates a strong sense of enclosure on its north side that visually and physically emphasise it as the entry threshold for the city.

- $\quad$ Weakness $\}$ The threshold entry space on the south side is extremely flat and weak.
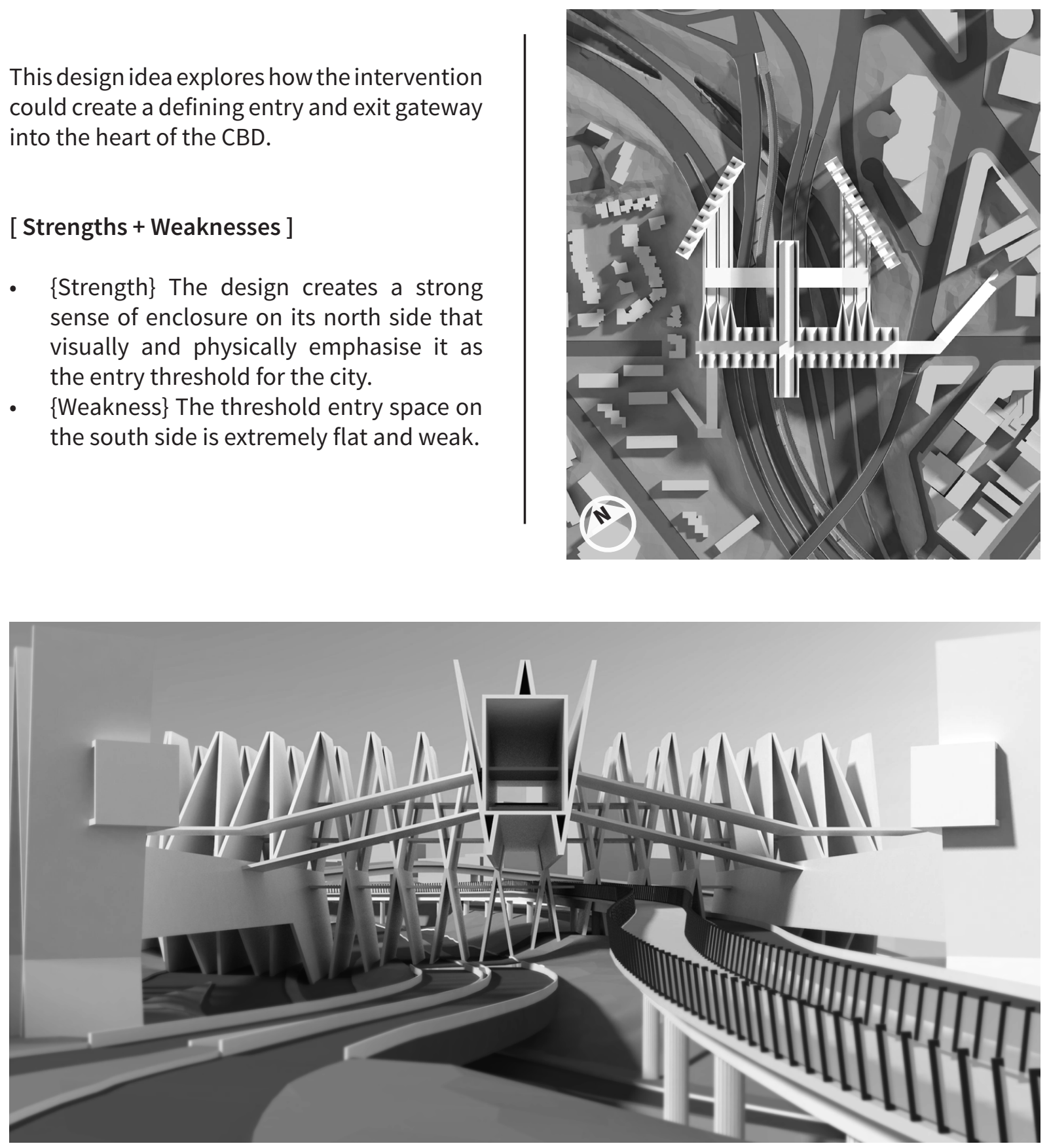

Figure 5.28 (top right): The design in plan view, highlighting the pinch of the four lanes between the two 'clamp' elements. Figure $\mathbf{5 . 2 9}$ (bottom): The north end of the design defines a space of enclosure making it a stronger exit / entry point in the city. 


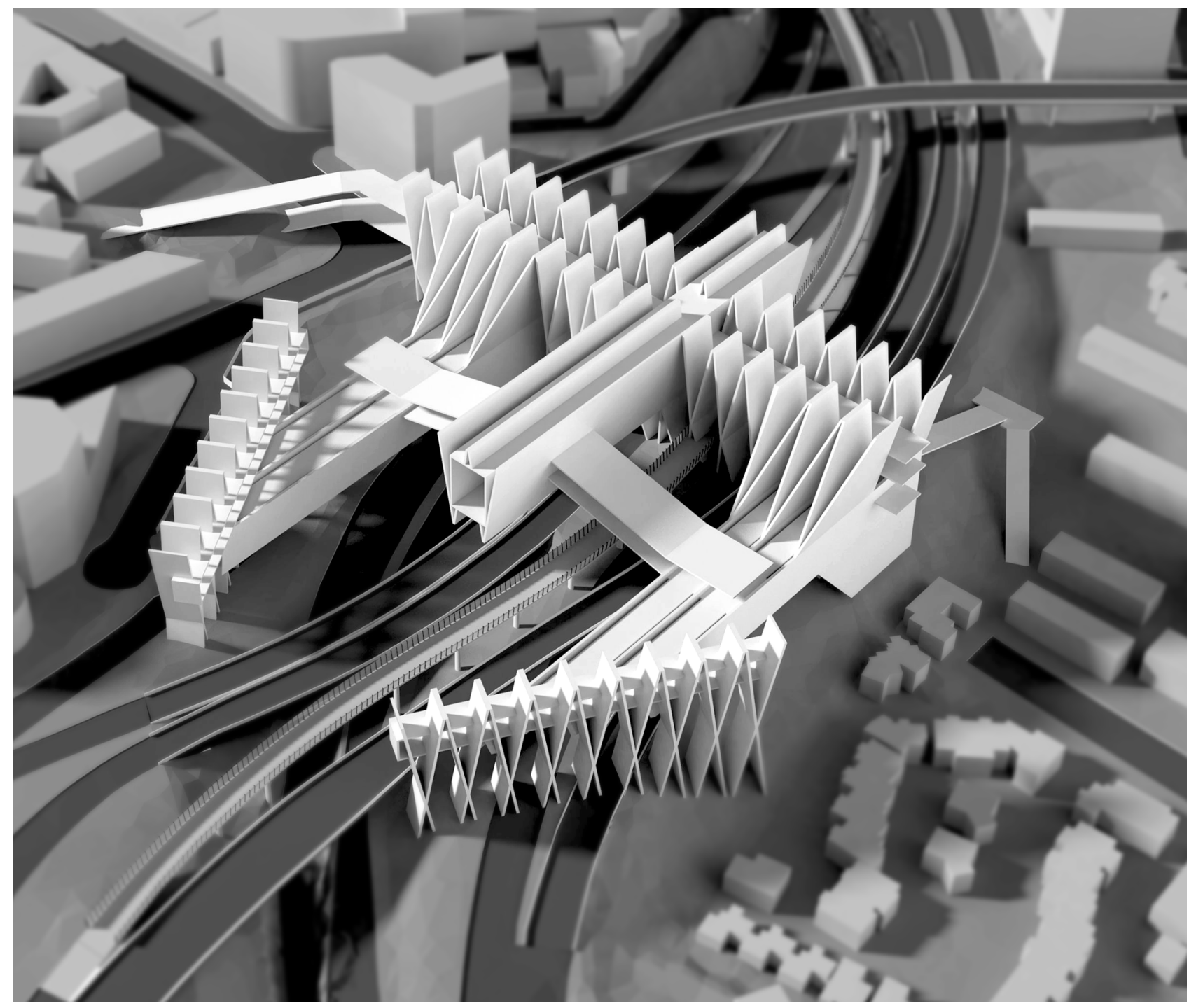

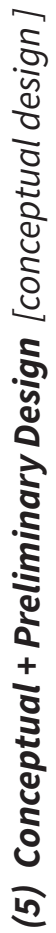

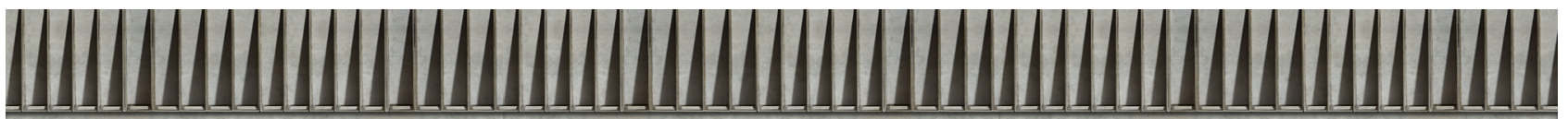 ||||||||||||||||||||||||||||||||||||||||||||||||||||||||||||||||||}

Figure 5.30: Elements from physical modelling in conceptual design are integrated in the elevations / facades with the intent to create smaller pocket spaces and thresholds through the design. 


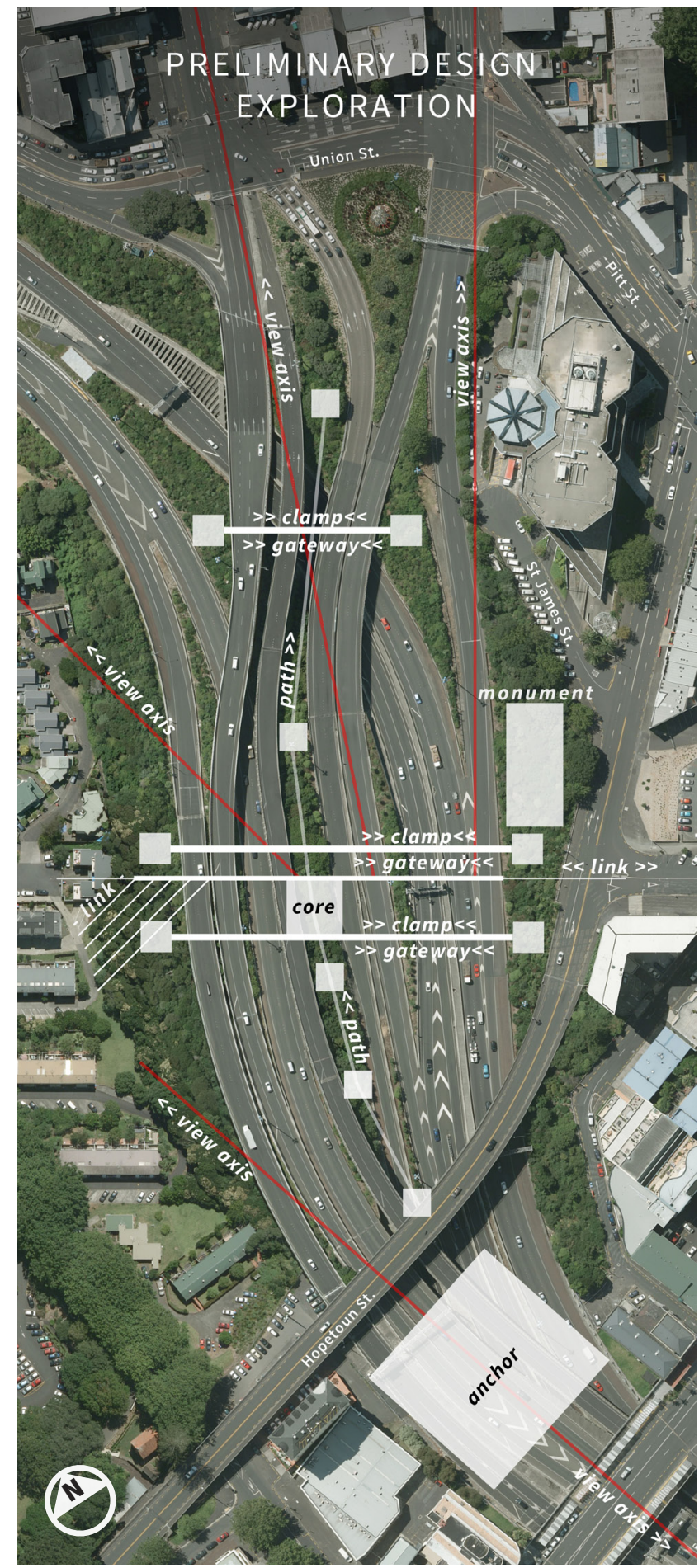

\section{[ PRELIMINARY DESIGN ]}

Testing the design as a bridging element across the site, as a framing condition to key aspects of city heritage, and as a threshold space for the motorway were explored in Conceptual Design as important ordering and narrative principles. These explorations had successful aspects but there was opportunity to explore more of the dynamics on a micro level on site in terms of its interstitial space and motorway interaction. 


\section{[ LOST SITES ]}

The Preliminary Design experiments incorporated positive results from the early Conceptual Design experiments with ideas explicitly targeting the three Research Objectives relating to Lost Sites:

Lost Site Research Objective 1 (R01): to diversify the utilitarian nature of the elevated inner city motorway by incorporating a suitable architectural programme. - The stored Te Papa archives were incorporated as the programme for the Preliminary Design experiments.

Lost Site Research Objective 2 (RO2): to reduce the 'urban barrier' characteristics of the inner city motorway. - Preliminary Design experiments explored architecture that links users across and through the site both against and with the grain of the motorways to increase the physical and visual permeability of the site.

Lost Site Research Objective 3 (RO3): to embrace and celebrate the 'motorway typology'. - Preliminary Design experiments explored:

Architecture as monument - embracing the size of the site by exploring the design in the monumental scale and the motorway as an iconic element of the city.

Architecture as motorway - exploration as to how the motorway typology can be celebrated and embraced in the design.

\section{[ HIDDEN HERITAGE ]}

Preliminary Design experiments also targeted the three Research Objectives relating to Hidden Heritage. Some of these research objectives are explored in much greater detail in the Developed Design.

Hidden Heritage Research Objective 4 (RO4): enhance engagement with stored national heritage artefacts. - Preliminary Design experiments explored how transitional spaces through the CMJ for motor vehicles, cyclists, and pedestrians could be utilised as the media with which the archives are interacted with in the public realm.

Hidden Heritage Research Objective 5 (RO5): to 'curate' stored national heritage artefacts in ways that maximise the didactic potential of the archive collection. - Preliminary Design experiments explored how the facades of the architecture could be used to expose archives to the public, using rich visual engagement to increase cultural awareness around the collections. This research objective was investigated in even greater depth in the Developed Design.

Hidden Heritage Research Objective 6 (RO6): to explore the 'non-archived' elements of the cityand site. - Preliminary Design experiments continued exploration from Conceptual Design of 'architecture as a framing condition' that explored the surrounding heritage of the city. Experiments also further investigated the hidden heritage of the site though the reestablishment of its historic links. 


\section{PRELIMINARY DESIGN EXPERIMENT 1}

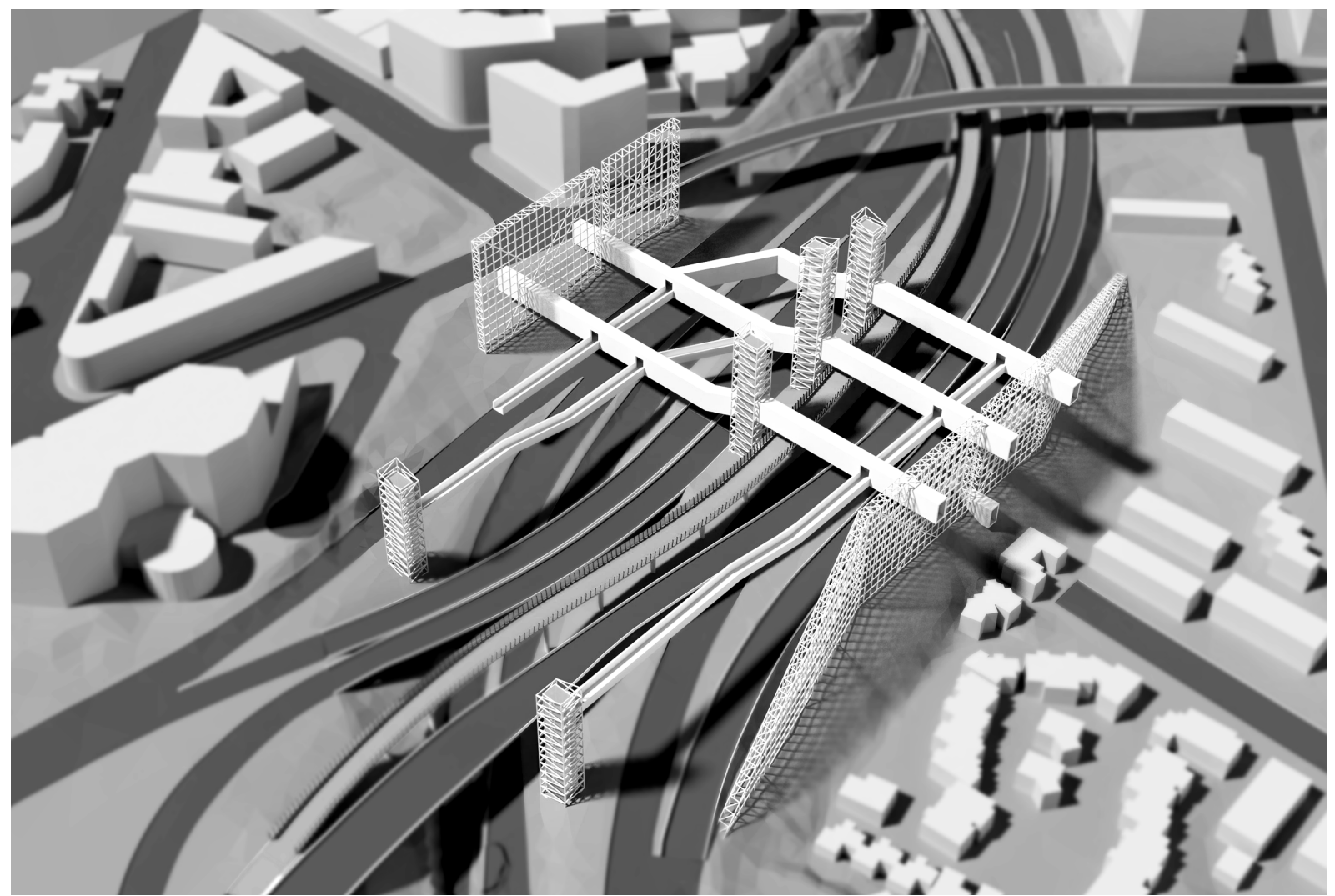

This Preliminary Design Experiment explores concepts relating to Research Objective Two (RO2) and Research Objective Six (RO6). It uses open truss frameworks and pedestrian links that react in both parallel and perpendicular directions to the motorways below to increase permeability through the $\mathrm{CMJ}(\mathrm{RO} 2)$.

Figure 5.34 shows the most interesting opportunity for development of this concept - where the pathways penetrate through the frame wall creating a distinct threshold for the pedestrians and their potential to curate views towards the suburbs (RO6).

\section{[ Strengths + Weaknesses ]}

- $\quad$ SStrength\} The elements penetrating the framework at the western and eastern sides create intriguing threshold and framing conditions that help address both $\mathrm{RO} 2$ and RO6.

- $\quad$ Wheakness The design is more transitory than inhabitable; introducing elements of programme that help promote public engagement will become problematic. 

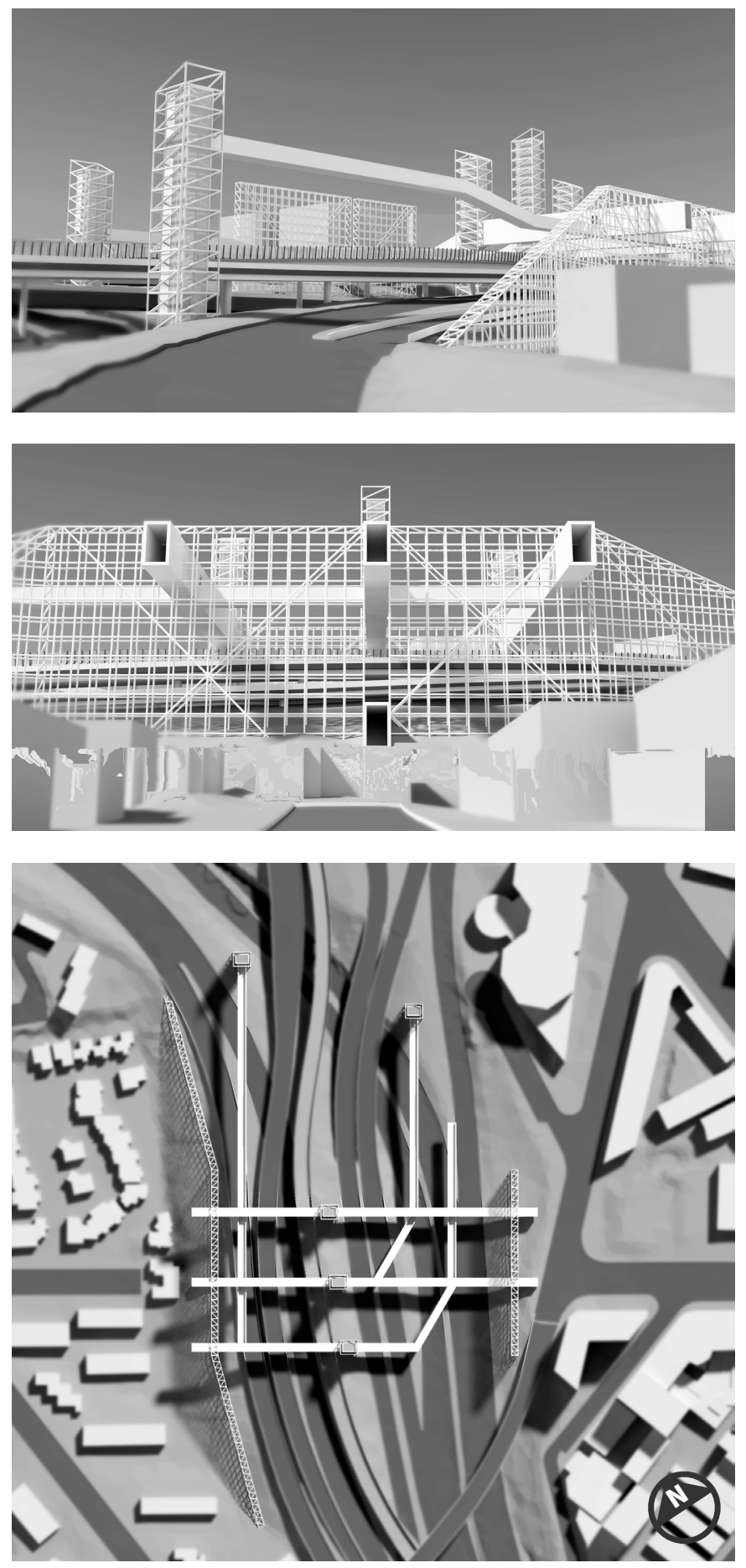

Figure 5.33 (top): Viewed from the northern end near Union Street. 


\section{PRELIMINARY DESIGN EXPERIMENT 2}

This iteration addresses research objectives and theoretical themes including increased permeability through the motorway (RO2), embracing the typology of the motorway (RO3), and engaging with the monumental scale of the site. It explores north - south motorway forms penetrating through a series of framework thresholds (intended to host the archive programme) all originating from an architectural anchor between Hopetoun Street and Karangahape Road.

The most crucial move in this design is the integration of the Karangahape building element between the Hopetoun Street and Karangahape Road. It acts as the anchor point for the architecture and enhances public awareness of the grain of the urban heritage of Karangahape Road. Road. Programmatically, it will hold the smallest Te Papa stored artefacts, to give them public visibility to visitors who enter along Karangahape Road.

\section{[ Strengths + Weaknesses ]}

- $\{$ Strength\} The introduction of the Karangahape building element anchoring the design in the urban grain of Karangahape Road.

- $\quad$ Weakness\} Better scale hierarchy between the Karangahape building element and Beresford link is required.

- $\quad$ Weakness\} The scale of the elements curving across the CMJ are too thin and need to reflect the scale of the motorway typology better.
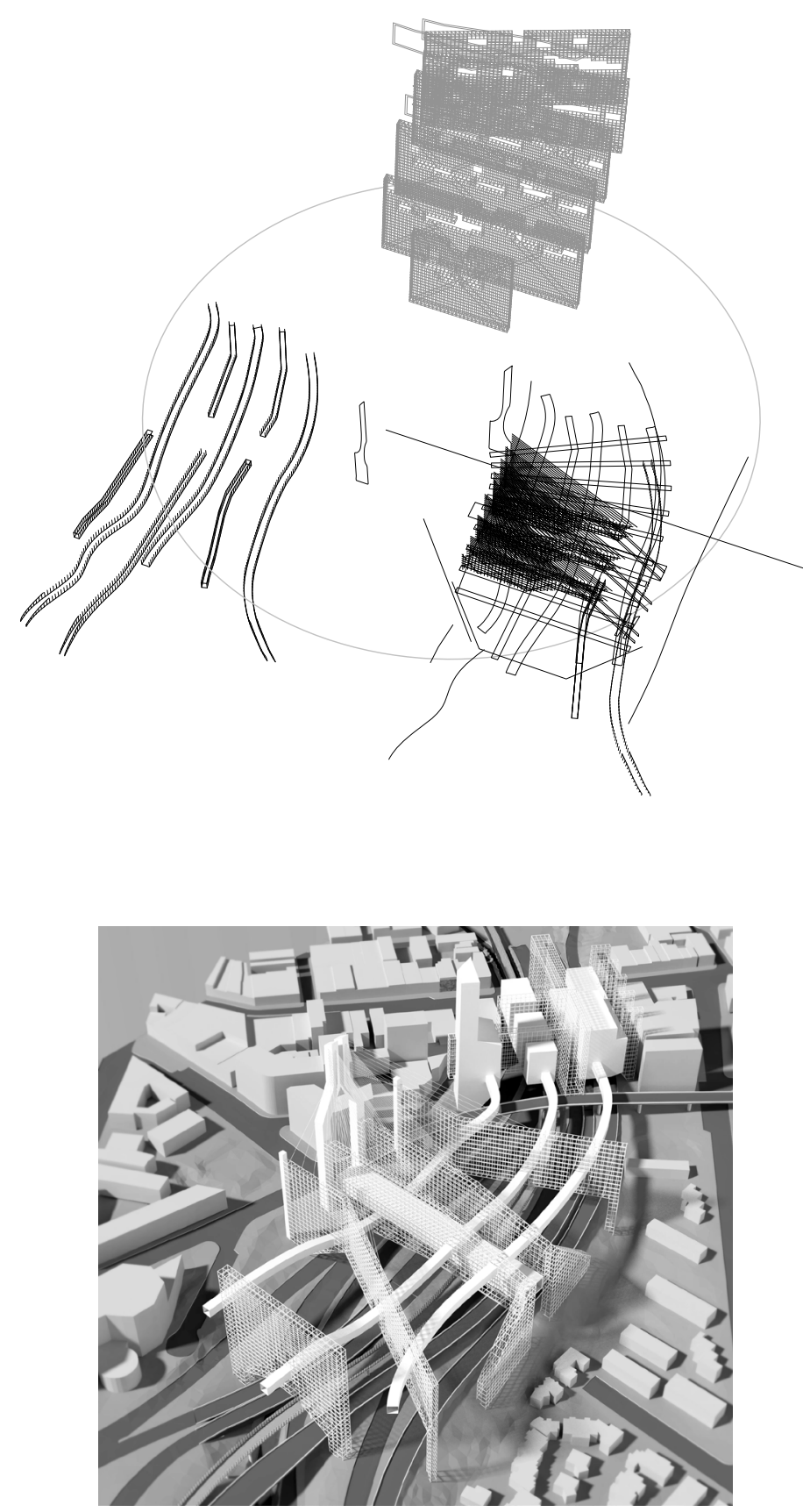

Figure $\mathbf{5 . 3 7}$ (bottom left): The design with its anchor in the urban grain then extending out into the CMJ. 


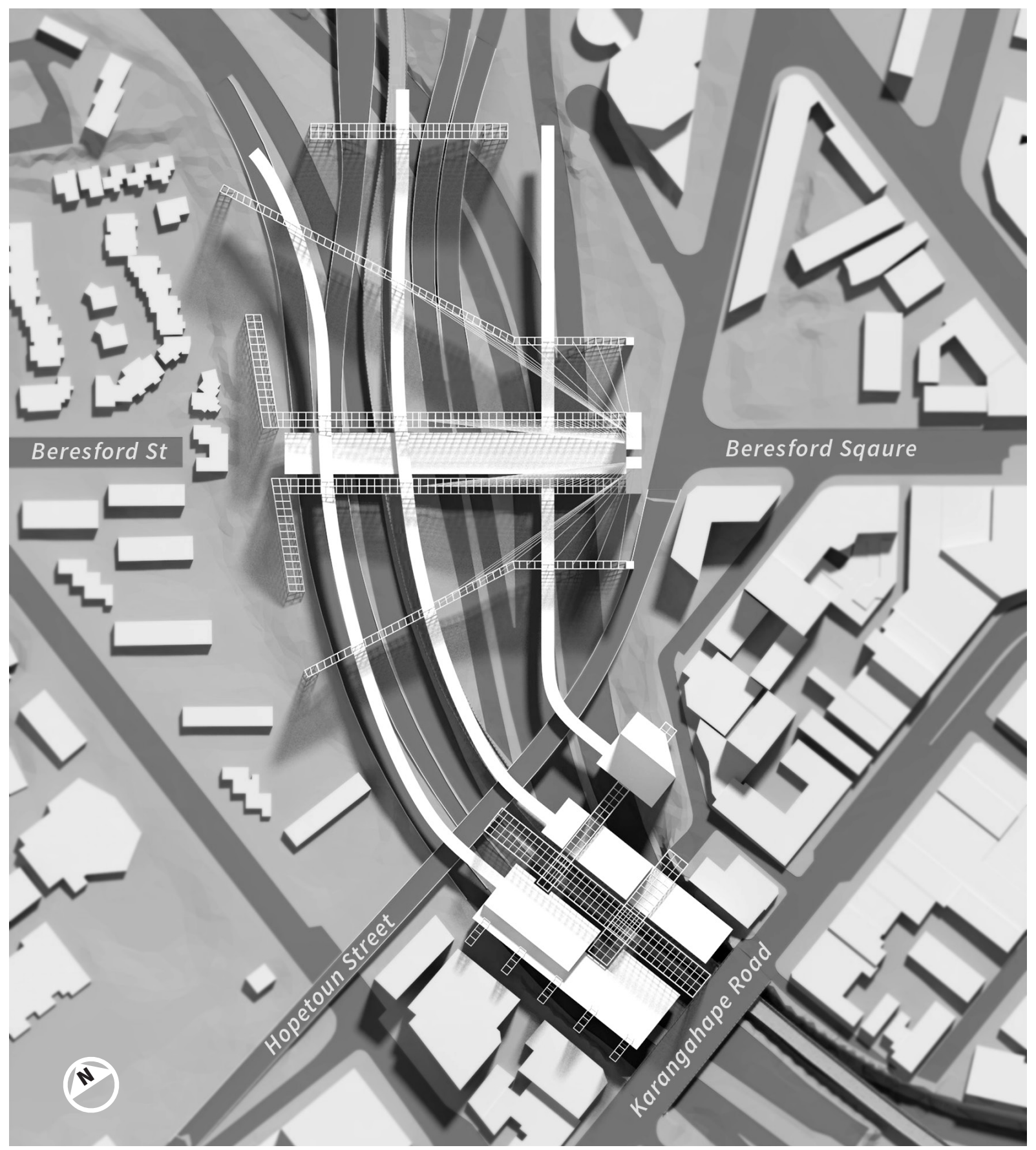

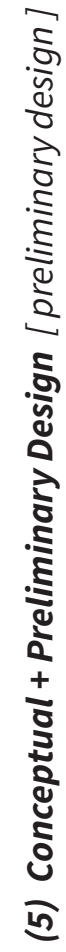

Figure 5.38 (above): The design in plan, essentially in two elements. The Karangahape building to the south and the paths and links stretching into the CMJ to the north. 


\section{PRELIMINARY DESIGN EXPERIMENT 3}

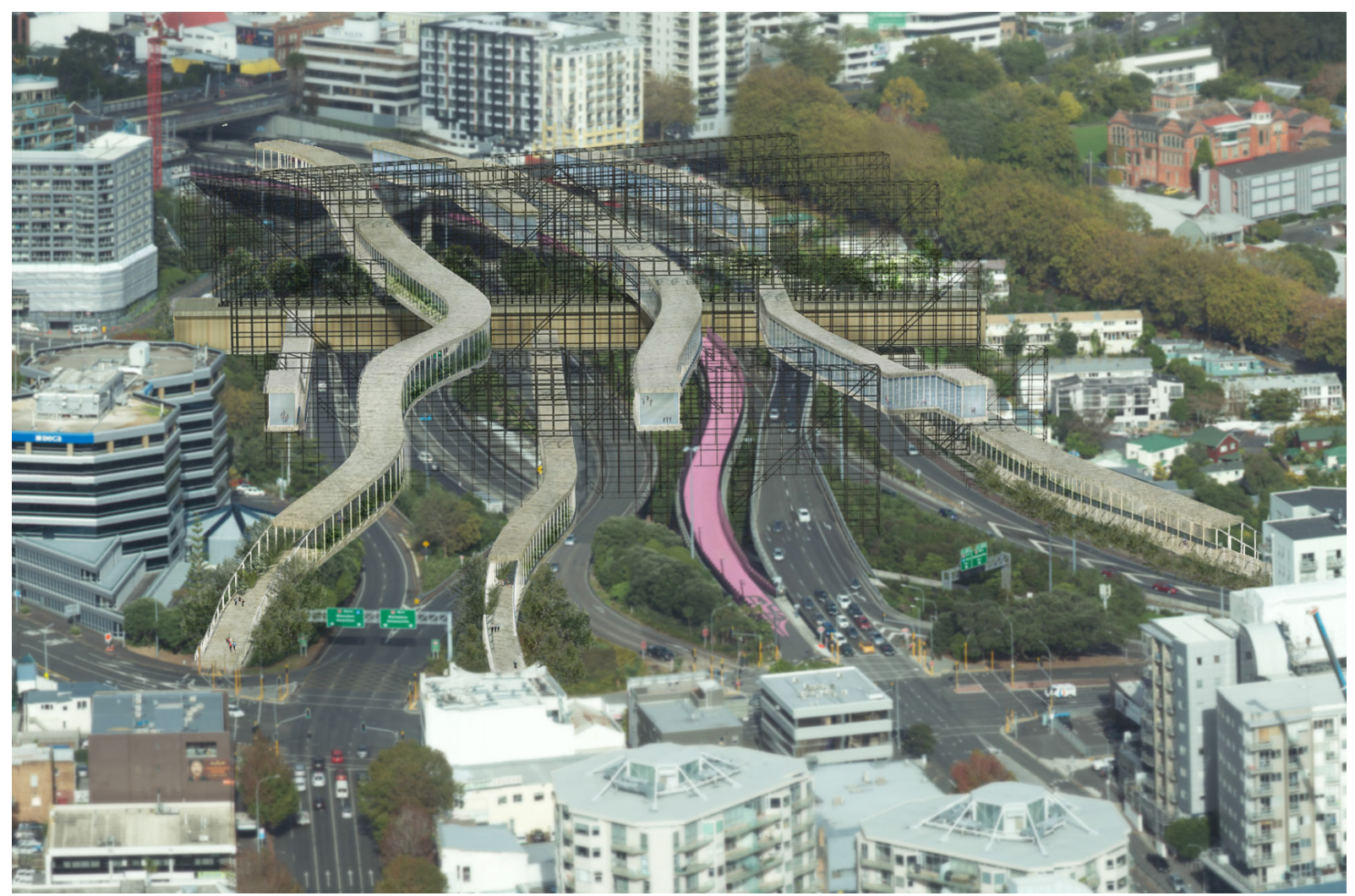

Preliminary Design Three explores 'architecture as motorway' (RO3). Elevated elements rise and fall through the site at a variety of levels, following and crossing over the existing roads. The design is given a sense of order through a series of wall frameworks that create threshold / gateway spaces engaging with the motor vehicles below.

\section{[ Strengths + Weaknesses ]}

- $\quad$ SStrength $\}$ The way the design embraces and celebrates the typology of the motorway ( best understood in plan).

- $\quad$ Strength\} The multiplicity of paths and links in the design vastly increases the permeability of the site (RO2) and allows for more diversity (RO1) through pedestrian engagement.

- $\quad\{$ Weakness $\}$ The hierarchy of elements in the design needs to better emphasise the 'lost' historic link being reestablished. 


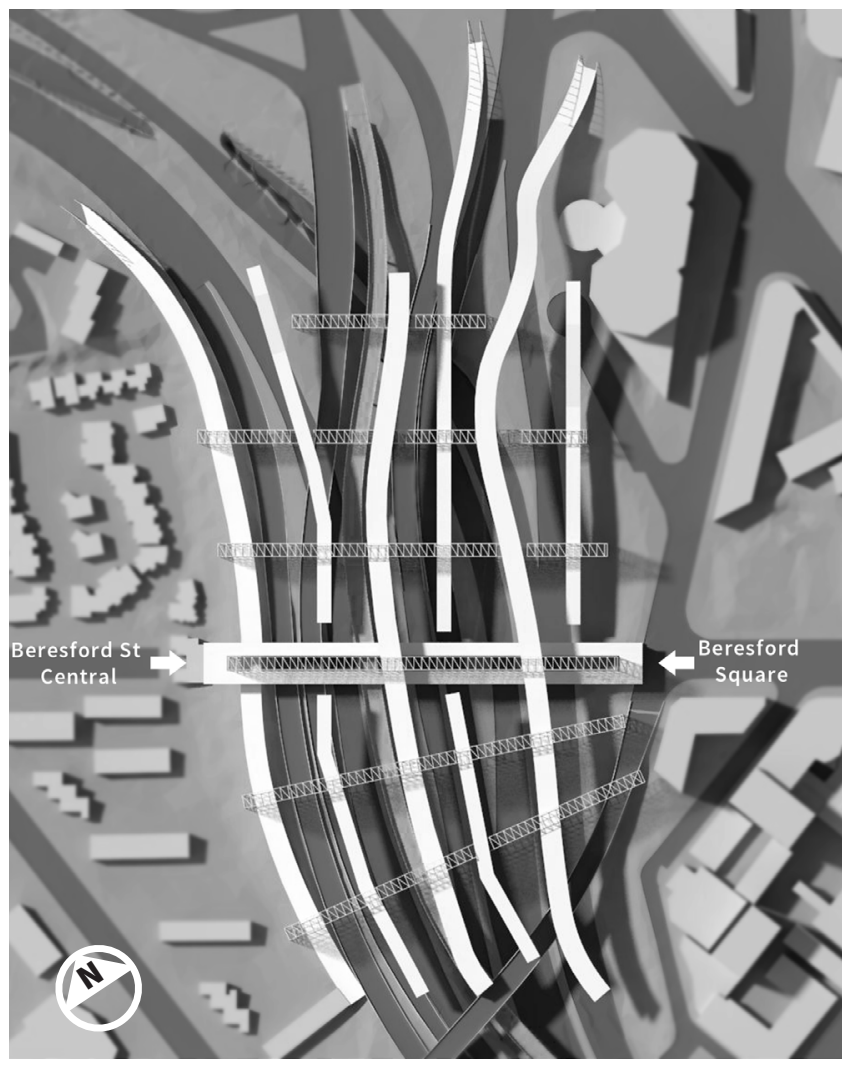

ปे

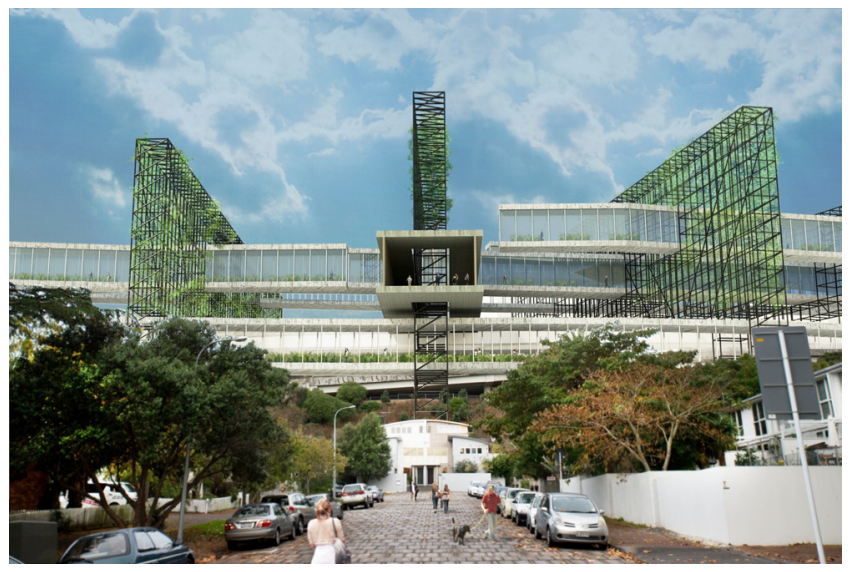

Figure 5.40 (top): As seen in plan, the curving elements have a chance to interact with the motorway in a way that previous design experiments lacked.

Figure $\mathbf{5 . 4 1}$ (bottom): The intervention as it would be seen from the suburban side on Beresford Street. 


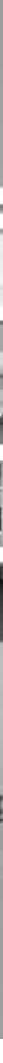




\section{PRELIMINARY DESIGN EXPERIMENT 4}

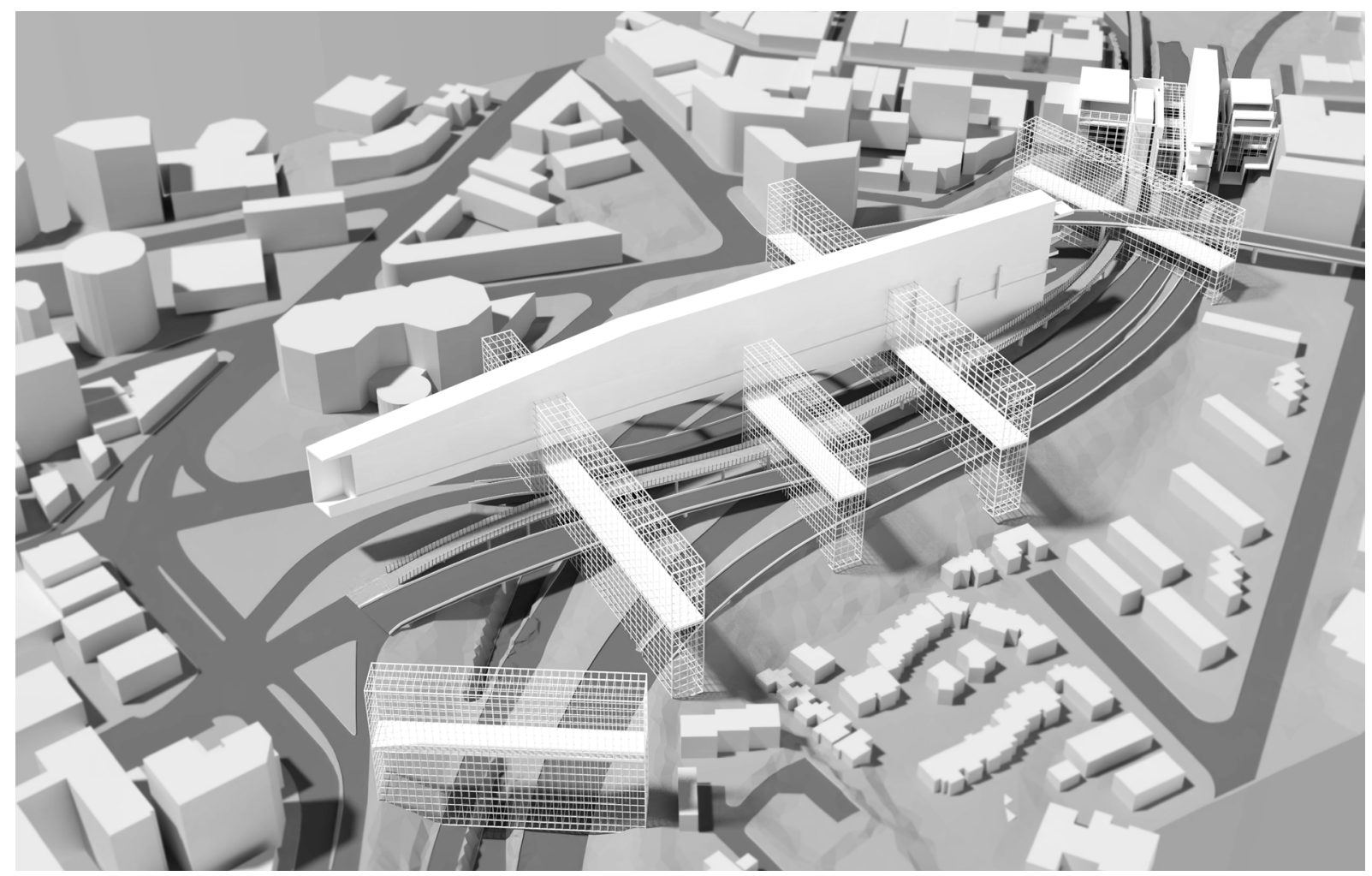

This design retains the Karangahape building element from Preliminary Design Experiment Two and transforms the CMJ design into more of an architectural body whilst retaining its elevated nature and dimensional widths of the motorway.

Wall frame typologies will host the archive collections and provide order and linkage perpendicular to the motorway; these frames create a series of thresholds for the motor vehicles to pass through and engage with. On this journey the inhabitants of the site experience the city and the archives from a unique and unprecedented perspective helping transform the CMJ from a dystopian to a heterotopian condition.

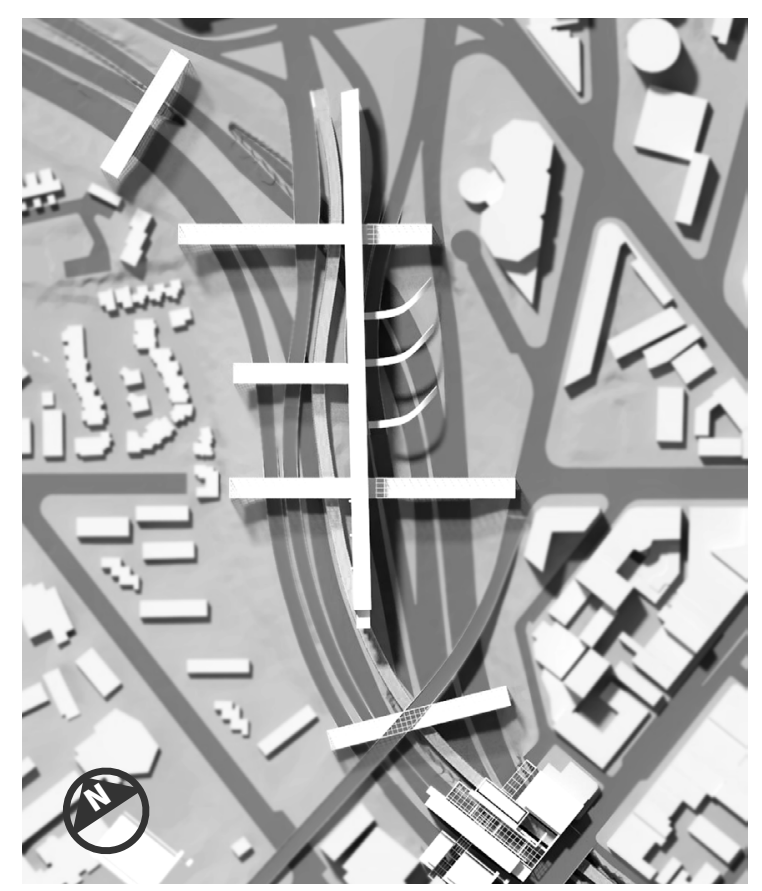

Figure 5.43 (top): The 'spine' that runs through the centre of the CMJ with 'wings' either side.

Figure $\mathbf{5 . 4 4}$ (bottom right): Plan view of the design. 


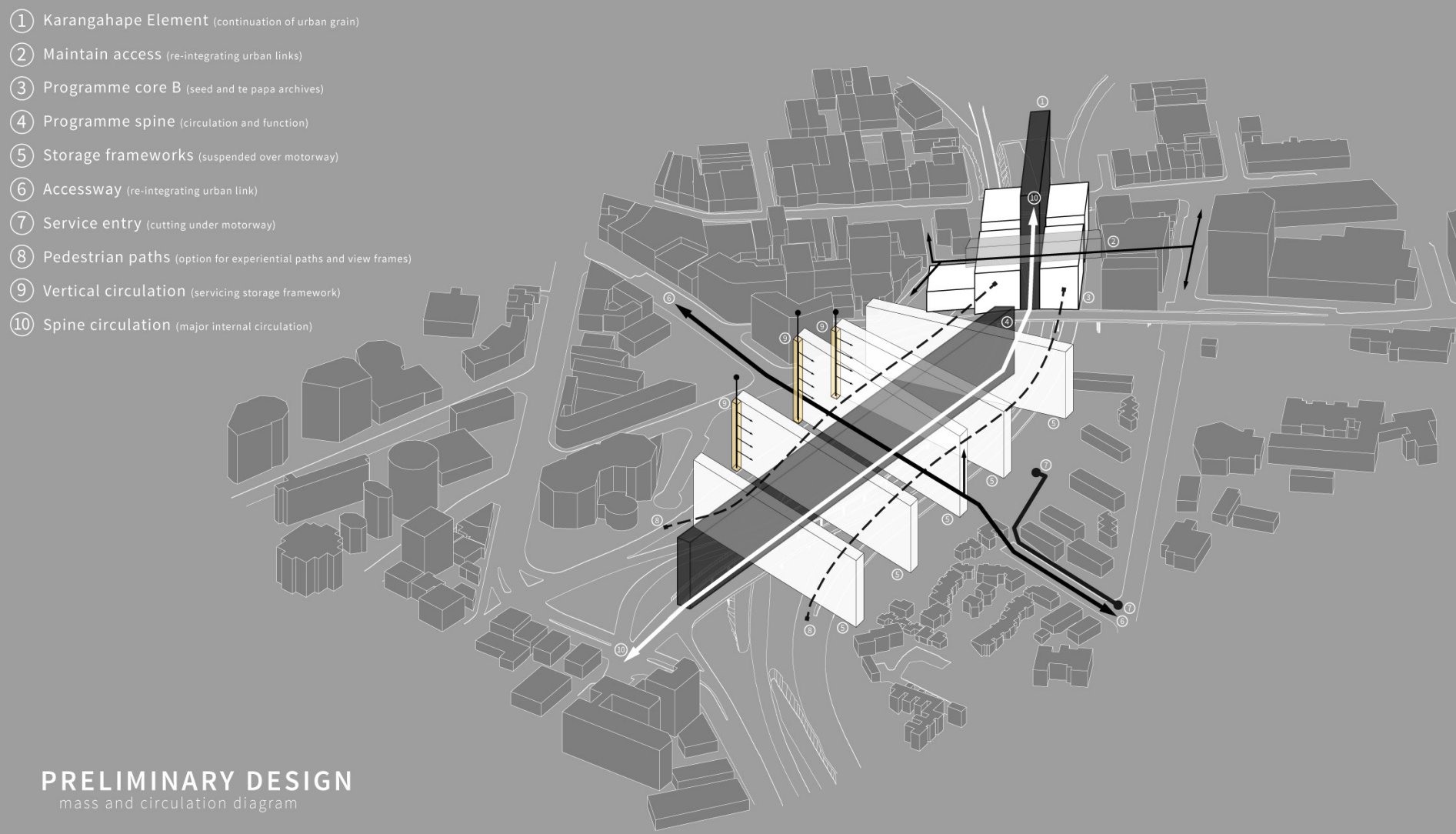

Preliminary Design Experiment Four provided a strong framework for further exploration. The diagram above shows the crucial elements of the design that will be further explored in the final stages of Preliminary Design.

The architecture is in two main bodies to respond to the two different sets of urban dynamics in the CMJ. The Karangahape building to the south creates the dense hub space whilst the spine element running $\mathrm{N}-\mathrm{S}$ and wing elements running W-E provide greater pedestrian permeability through the site (RO2). Along these links the 'hidden heritage' of the nation will be stored/displayed in a manner that can be engaged with in the public realm (RO4 and RO5).

The wing frameworks will act as the main storage for Te Papa's archives (RO1 and RO4) with their profile perpendicular to the motorways below. This allows them to be both display canvases (RO5) and gateway thresholds to the vehicles that pass below so the design and the archive programme are able to engage with all typologies of users in the site.

Historic street links that were broken due to the introduction of the motorways are relinked through the design to engage with the non-archived elements of hidden heritage (RO6).

The main 'spine' element is sited in the interstitial space at the centre of the CMJ and its dimensions reflect that of the motorway typology (RO3).

In these ways, the design research intervention can become a place that offers a completely unique experience of Auckland City, a heterotopian condition that allows the users to engage with something much greater than themselves (RO2).

Figure 5.45 (top): The design driver diagram for Preliminary Design moving forward. Preliminary Design Experiment Four is developed to greater detail resulting in the final Preliminary Design solution. 


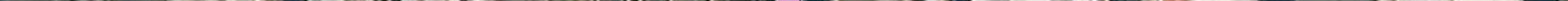




\section{3 \\ ME 41}

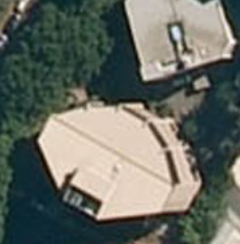

$\$$

ty

I

4.5 ही

(IIIII) (9.7) th:

Tis. - in:

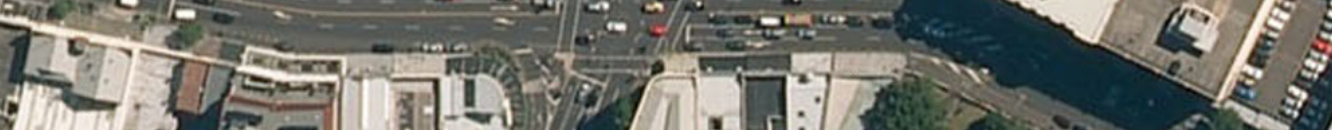

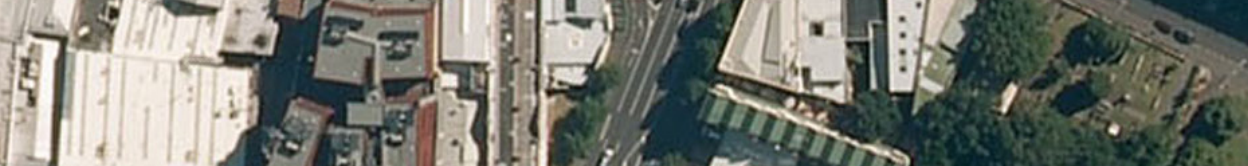

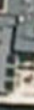
a er 140 n 47 J. [PRELIMINARY DESIEN SOLUTION] II. II 12 


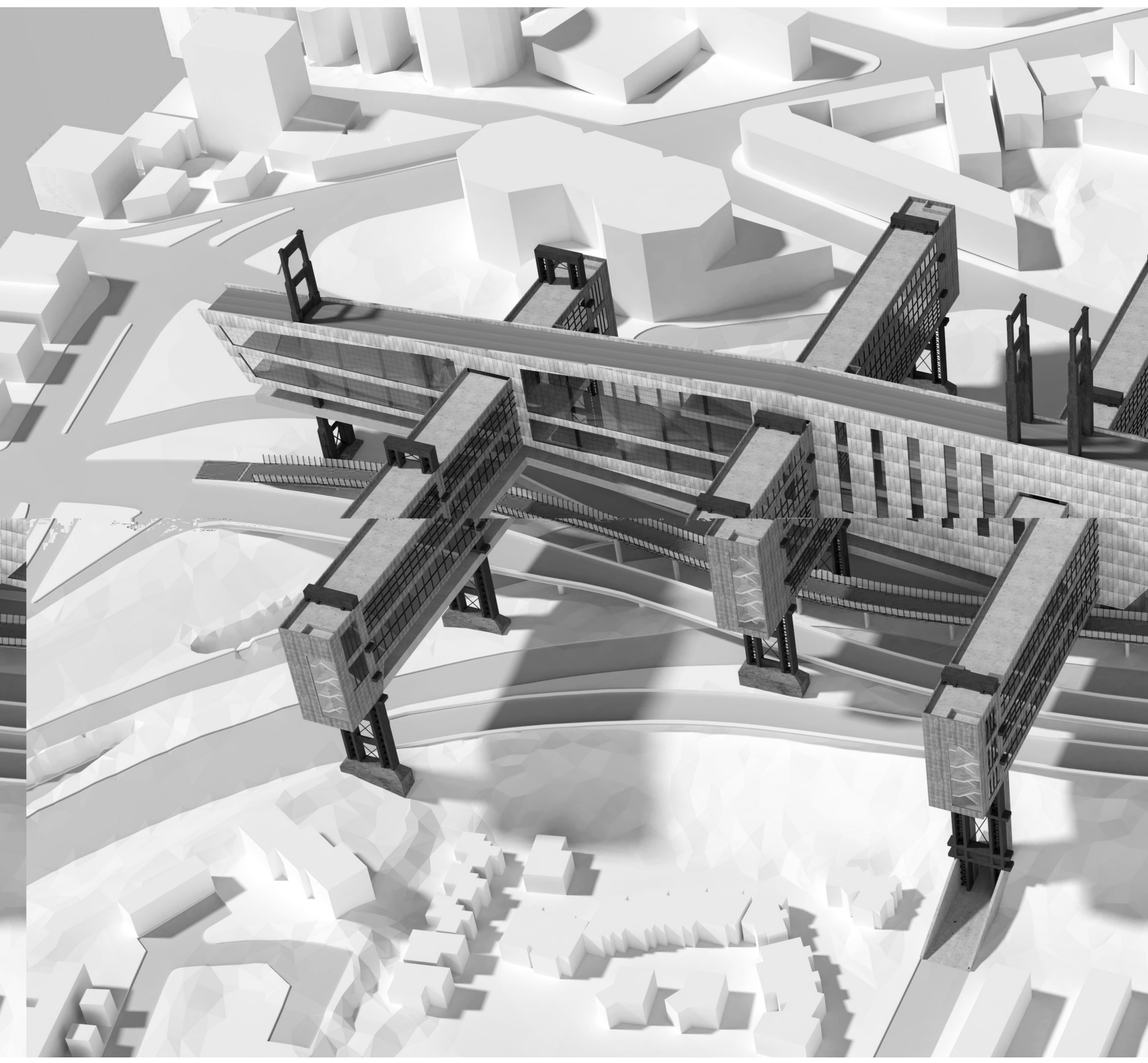

148 Figure 5.46 (previous spread): The site plan of the final Preliminary Design solution.

Figure 5.47 (above): A view of the intervention from high above the motorway site. 


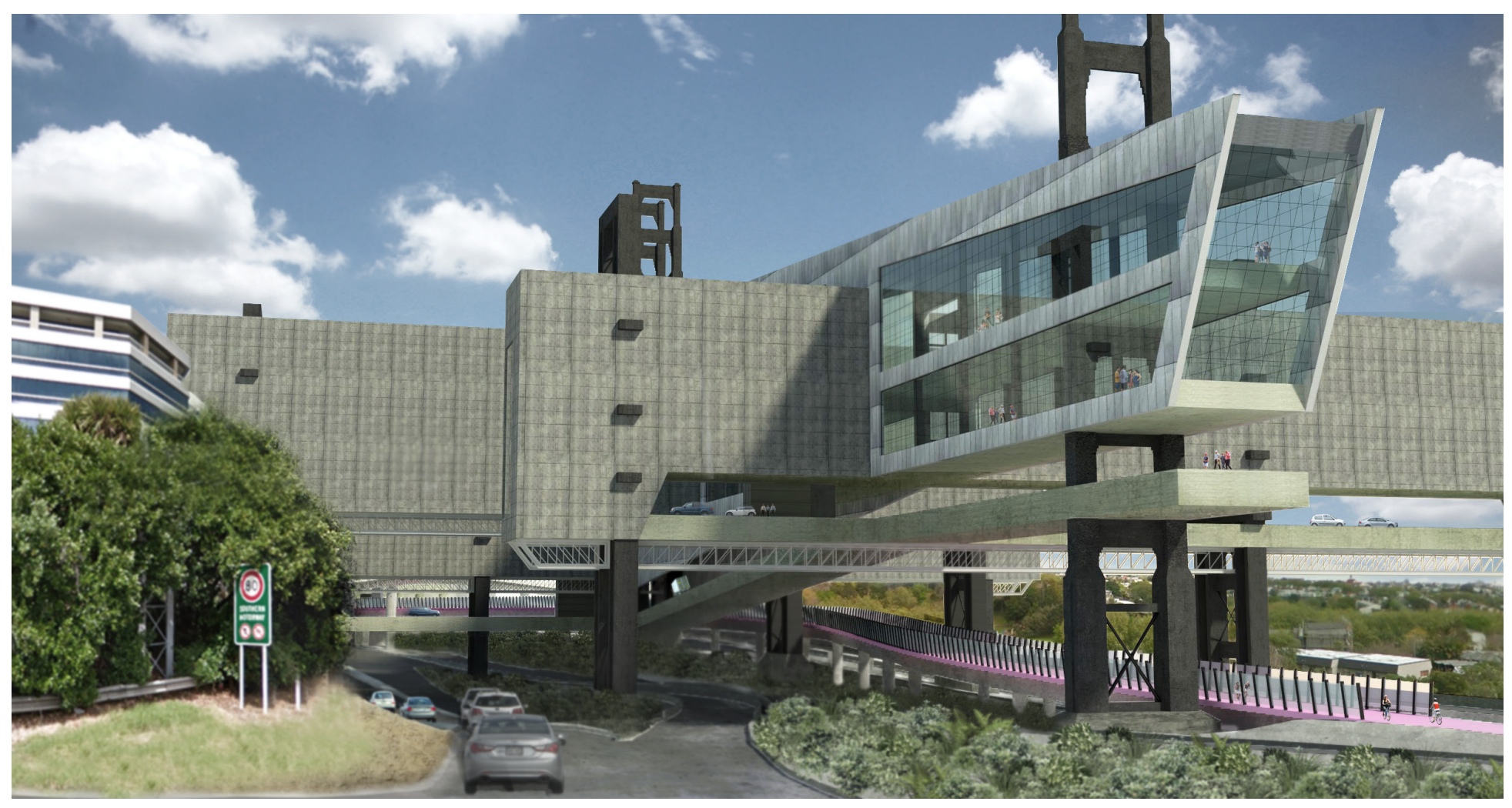

Figure 5.48: Entering the motorway from Union Street below through the thresholds created by the wing walls. 


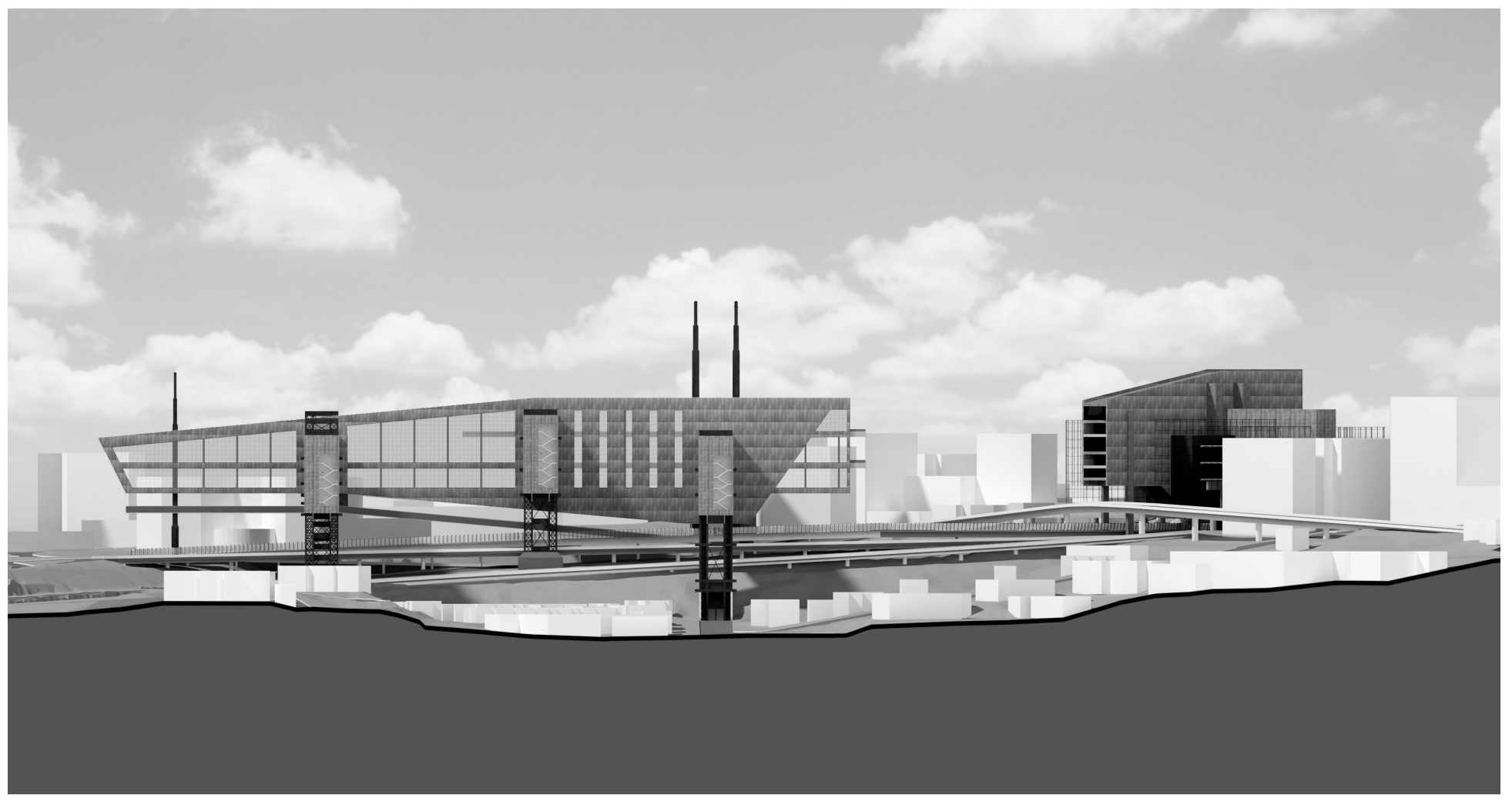

Figure 5.49: First floor of intervention retains the motorway typology (RO3) as a car parking level. 
(3)

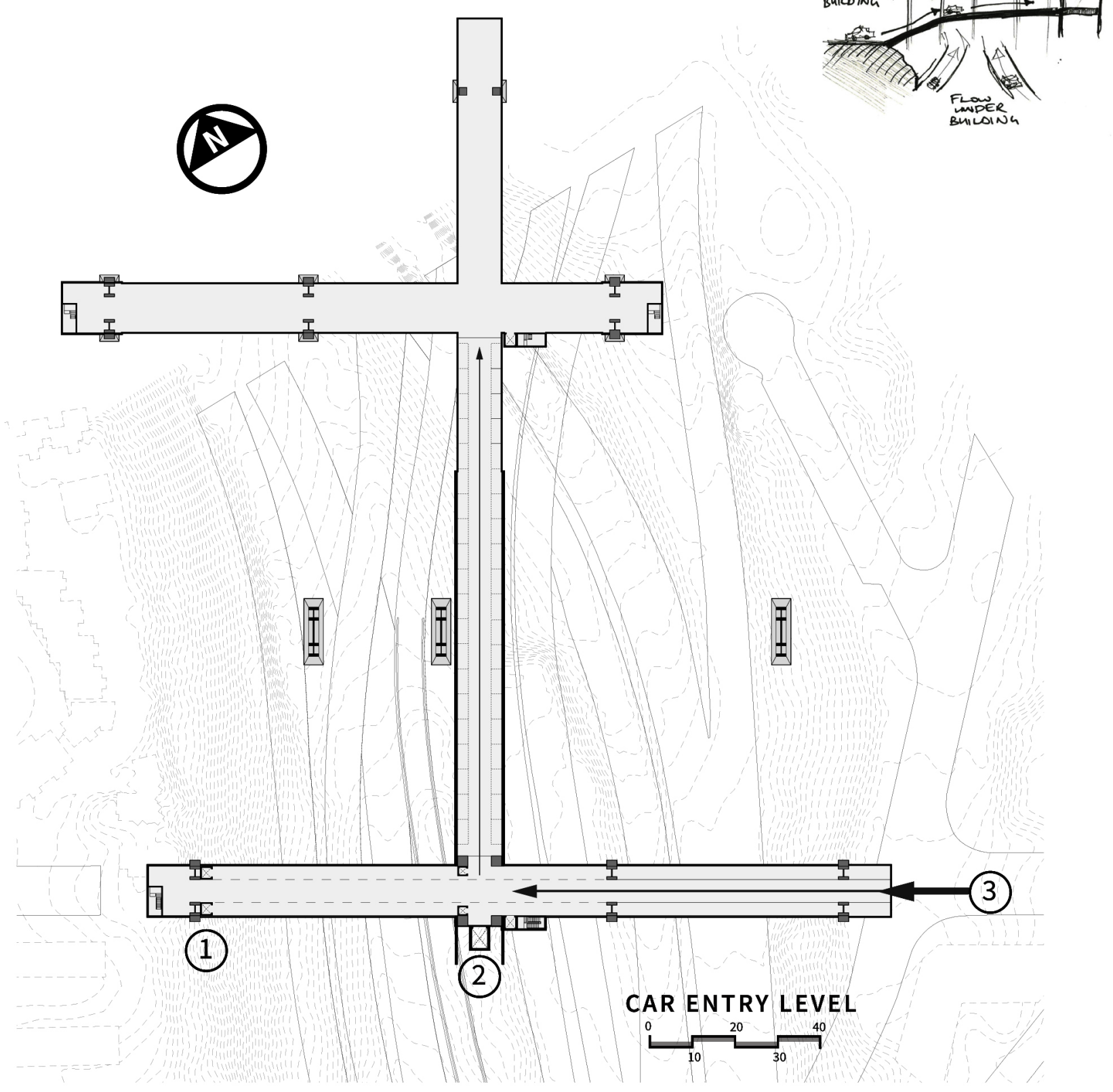

1. Vertical entry access from Beresford Street Central

2. Service Entry Elevator access underground off Beresford Street Central

3. Entry off Beresford Square

Figure 5.50: Level One.

The first level of the building (figure 5.50) retains a motorway typology as the carparking level for staff and visitors (RO3). The levels above this allow for archive storage and pedestrian access (RO1 and RO2). 


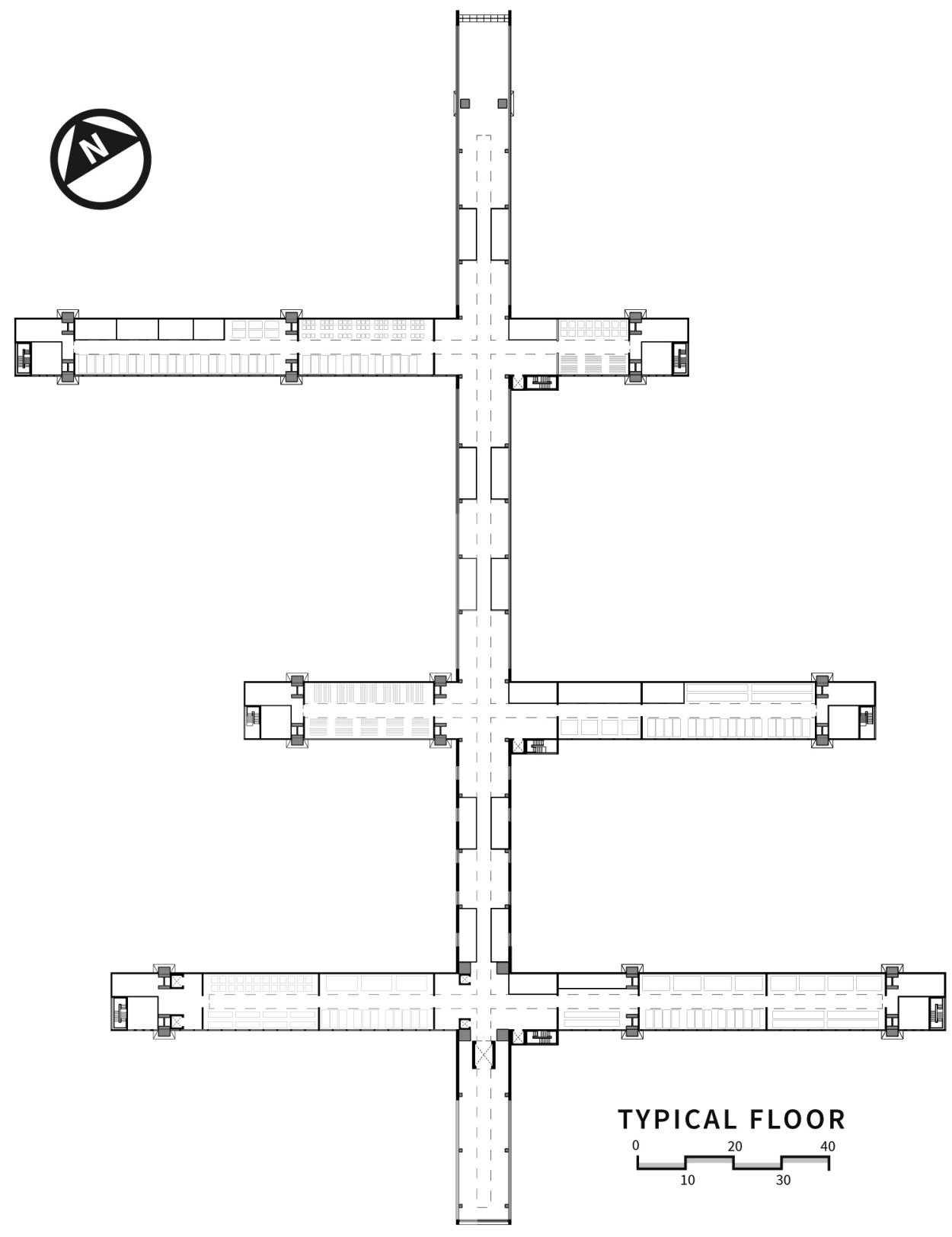

TE PAPA ARCHIVE STORAGE
flat area - no stacking

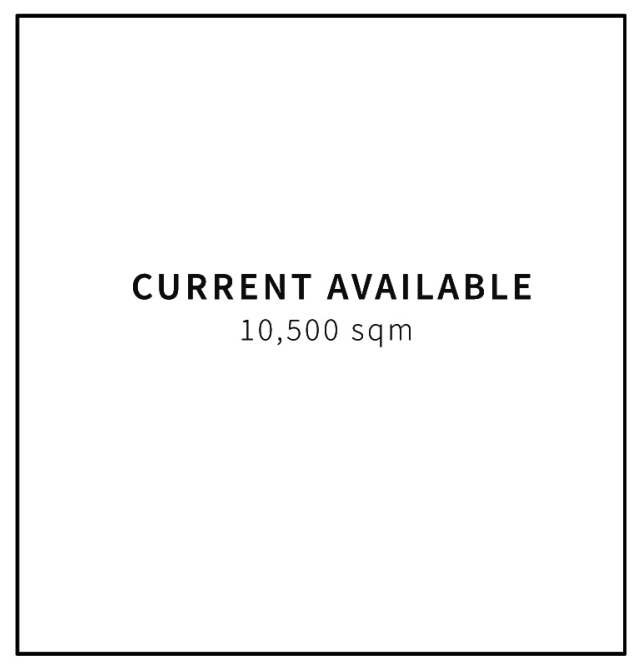

CURRENT EXTRA REQUIRED

3000 sqm

\section{ADDTIONAL FUTURE} REQUIREMENTS

$7000 \mathrm{sqm}$

Figure 5.51: Typical Floor Level.

The extent of the Te Papa storage requirements can be understood in figure 5.51. Although the space required is more than the floor plan shown, once the design introduces several levels and the Karangahape Road element is included the building will provide ample space for the archive programme as well as room for growth (RO1). 


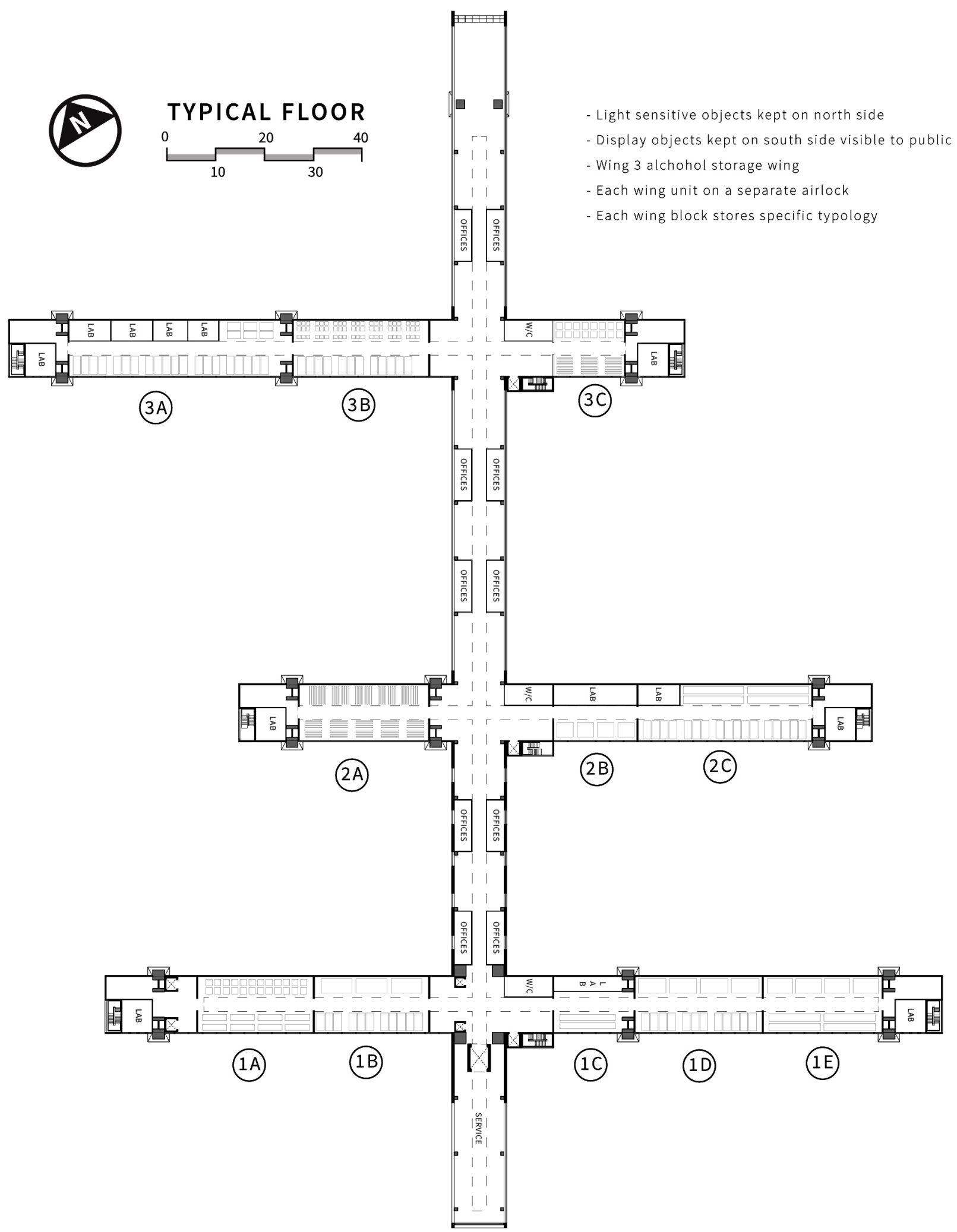

Figure 5.52: The southern facades of the wing walls become the display facades for the less sensitive archives so they are integrated in the public realm and can be viewed by pedestrians, cyclists, and motor vehicles passing through the site (RO4 and RO5). 


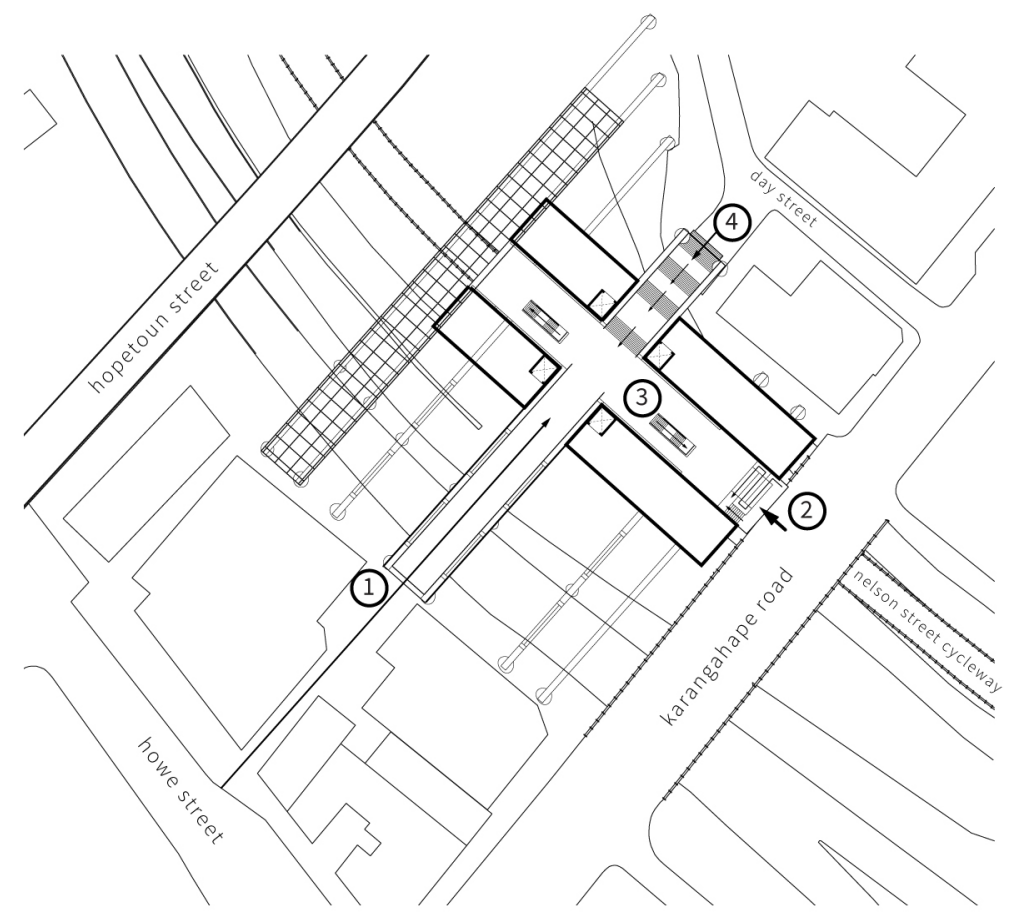

K-ROAD BUILDING

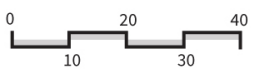

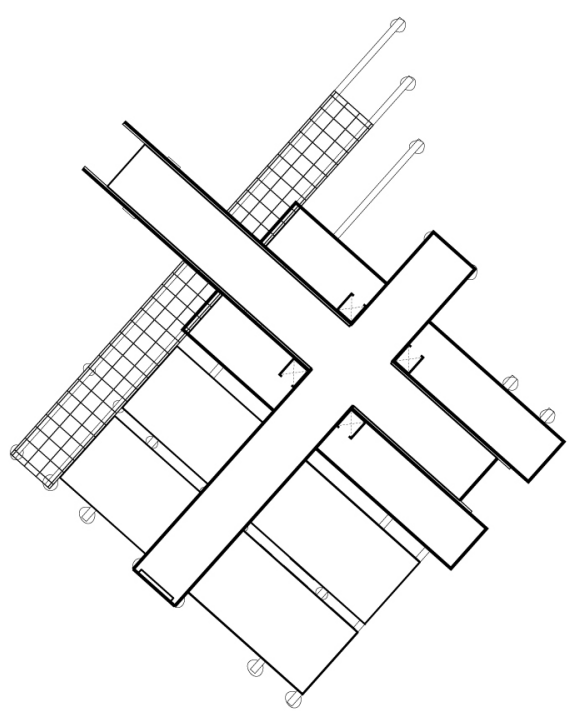

TYPICAL FOOTPRINT

1. Vertical entry access from Howe Street

2. Main entry on Karangahape Road

3. Entry from Nelson Street Cycleway

4. Entry off Day Street

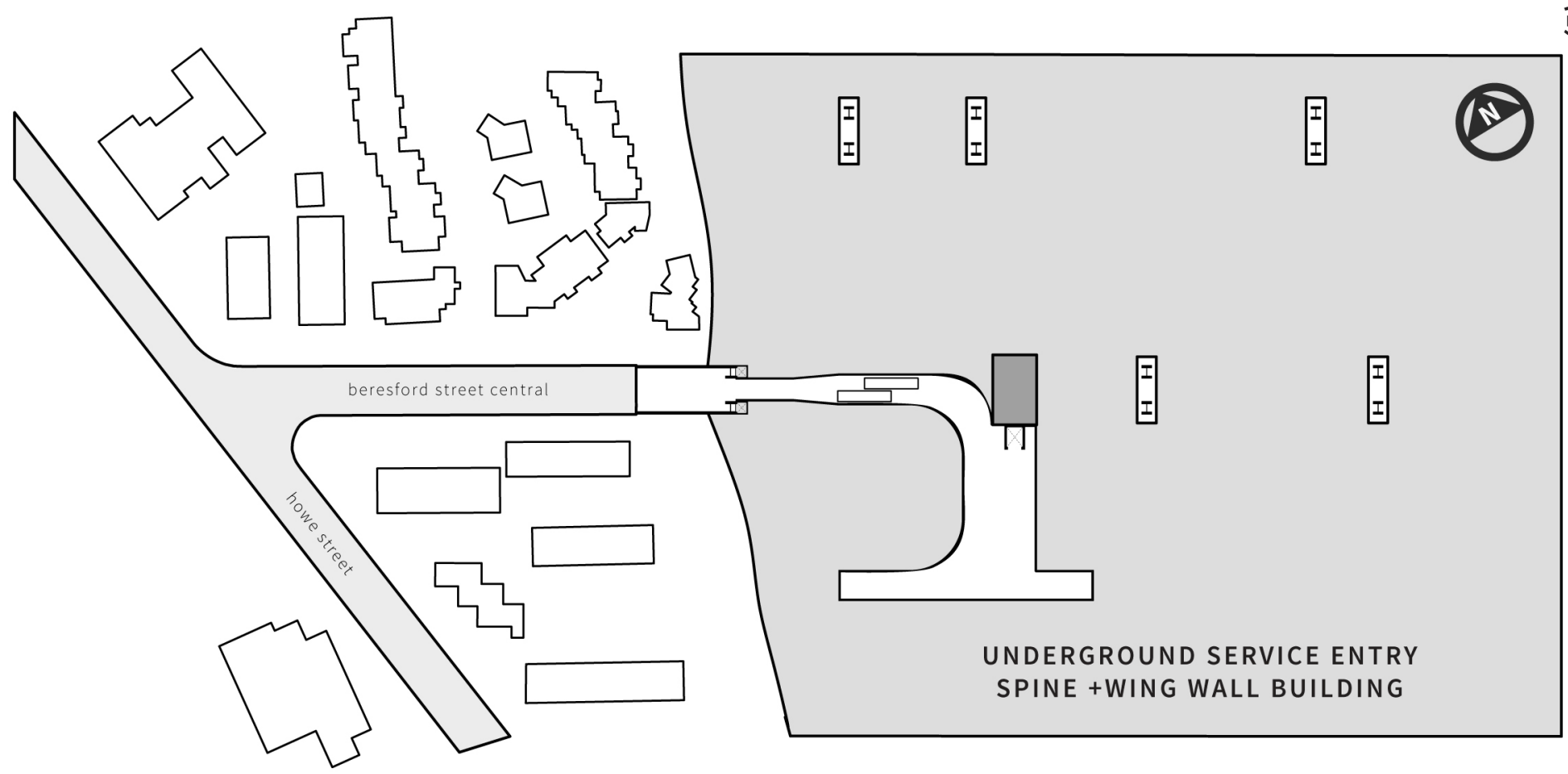

Figure 5.53: The top plans show the Karangahape Road (K-Road) building which will be used as additional storage space for sensitive items as well as research and administration facilities. The bottom plan shows the loading dock and service access through the motorway berm at Beresford Street, underneath the motorway and up into the core of the spine building. 


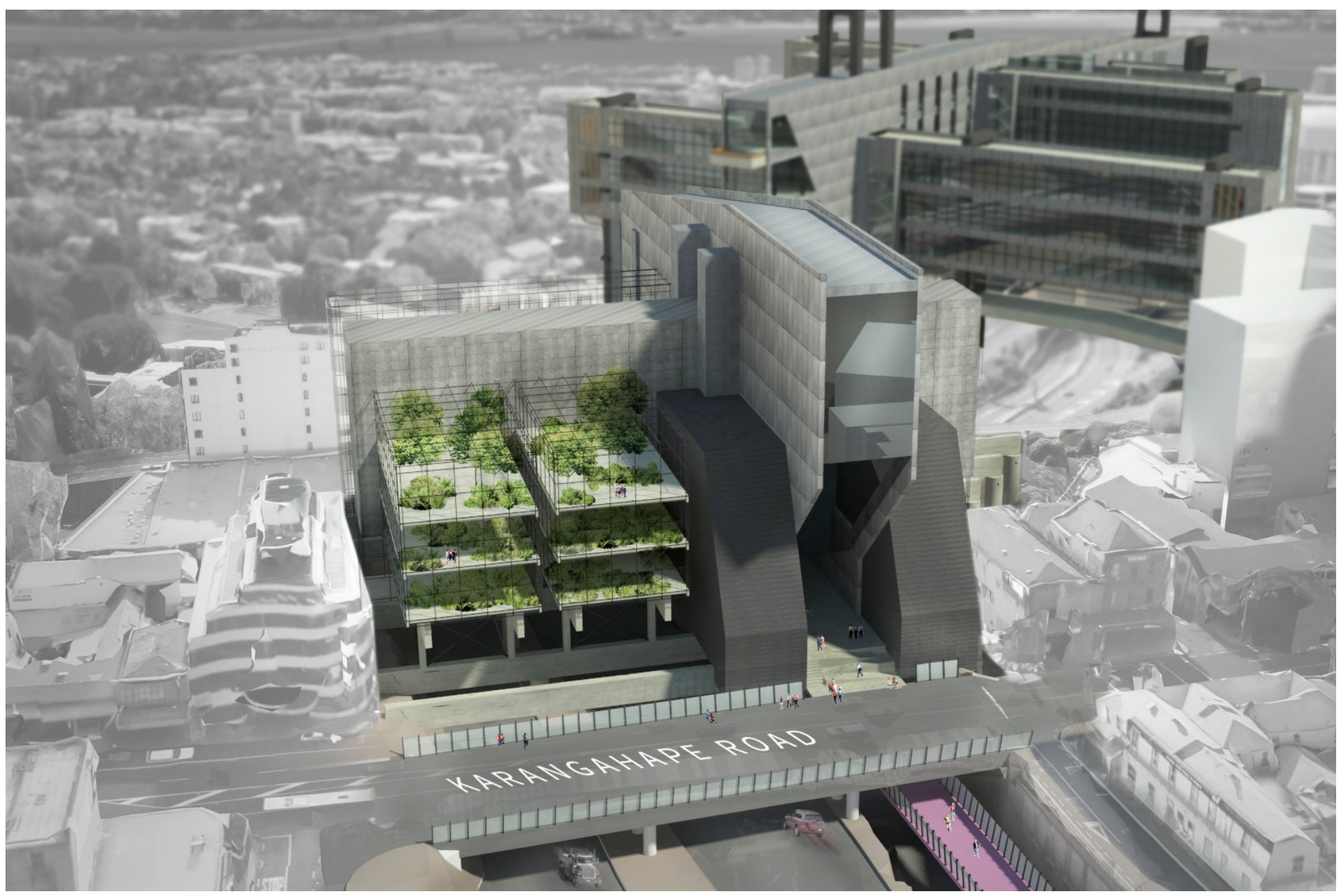

Figure 5.54: Main access into the Karangahape building via Karangahape Road. The pink Nelson Street cycleway disappears underneath the architecture and vertical access is provided from it up into the building. 


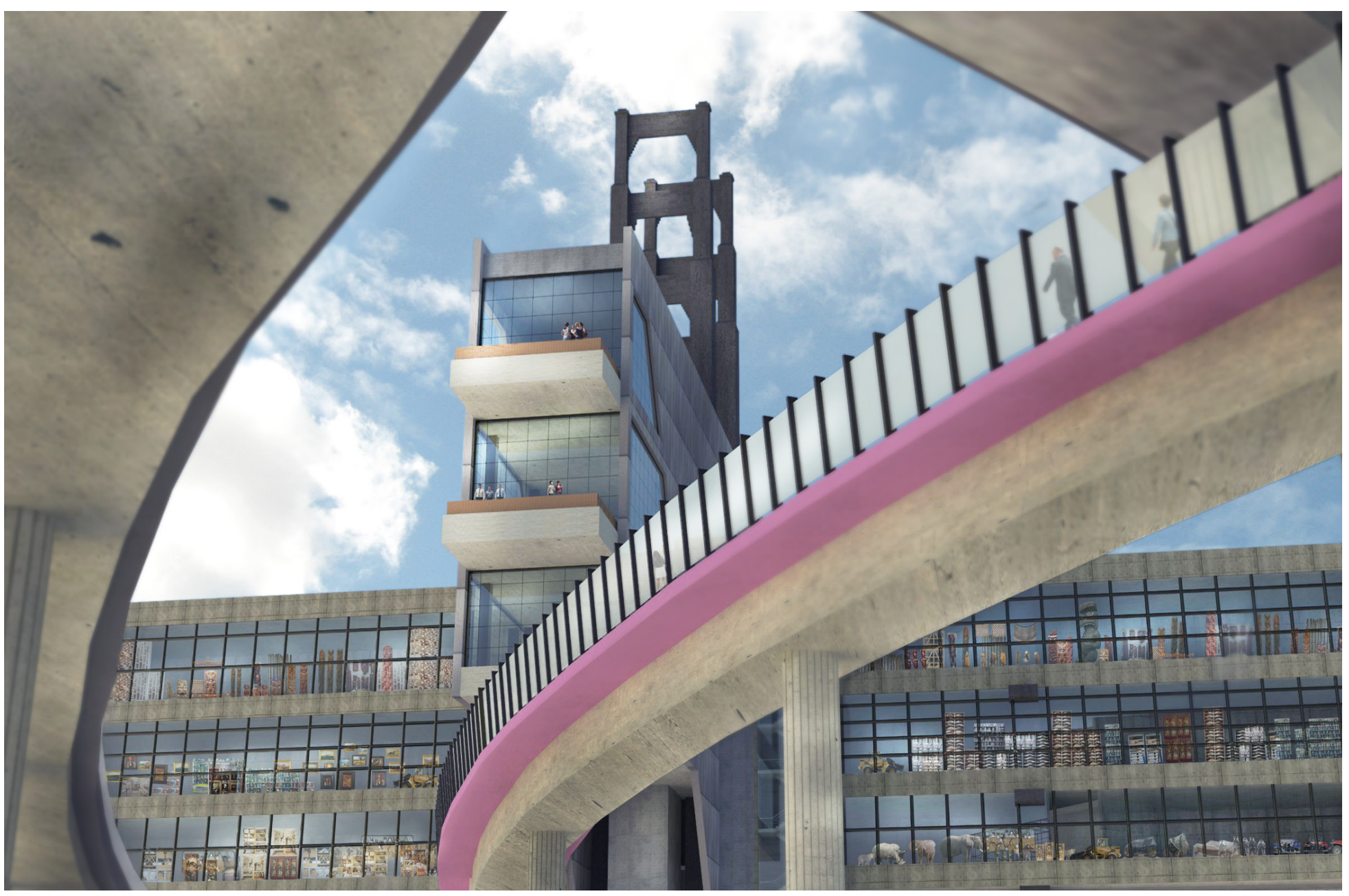

Figure 5.55: Headed south on the motorway the building facades display the 'hidden heritage' of the Te Papa archives to drivers as they weave in and out of the design and through the central motorway junction (RO3 and RO4). 



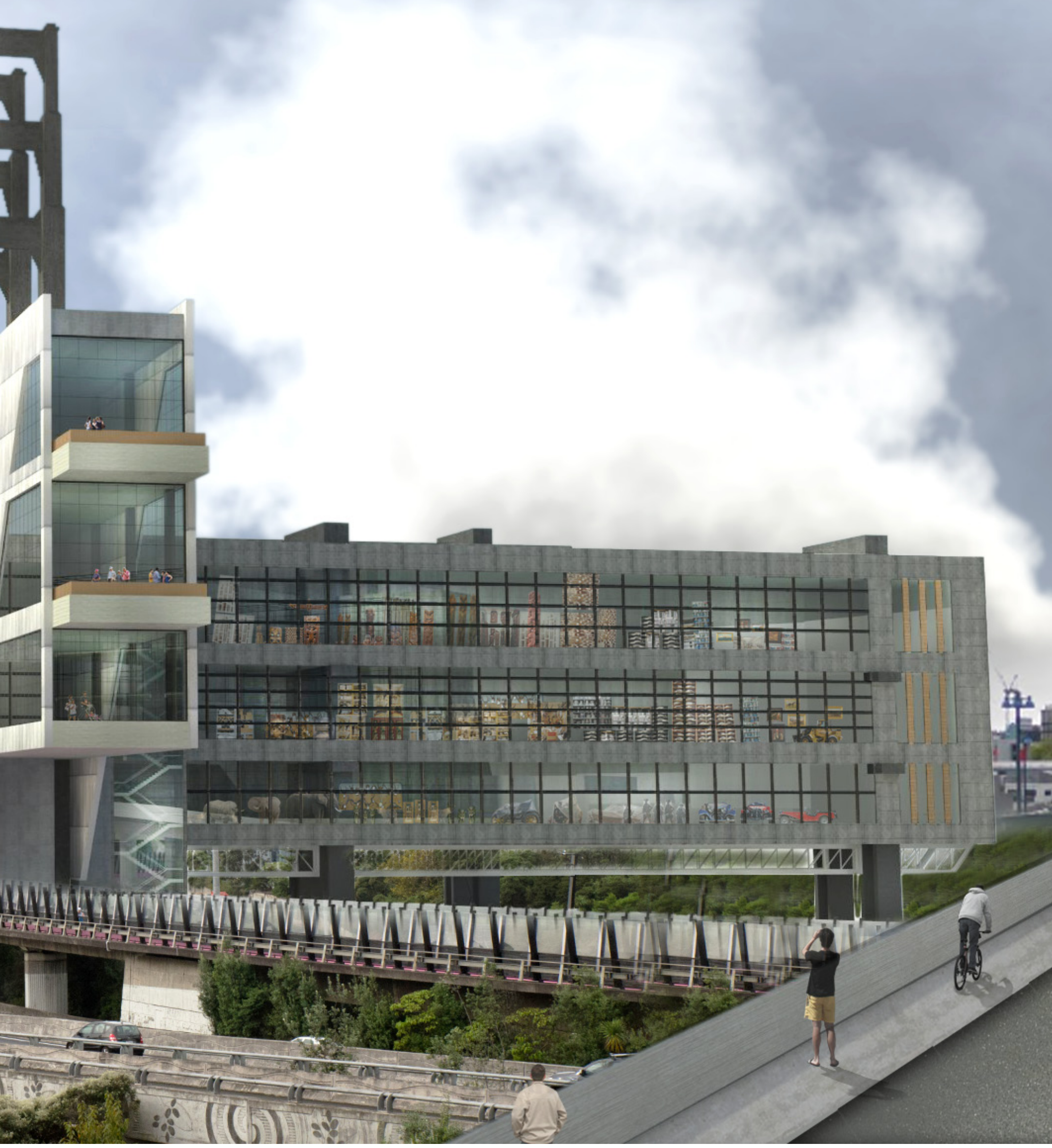




\section{[ CRITICAL REFLECTION ] - Addressing Aims + Objectives}

\section{Lost Sites}

RESEARCH OBJECTIVE ONE (RO1)

The enormous and complex scale of the site has been embraced in the Preliminary Design through an architectural programme that establishes itself in the heart of the CMJ, creates distinct threshold spaces, and utilises the prominence of the motorway as a medium for which the extensive archive programme can be engaged. The utilitarian nature of the site can be diversified further by introducing more aspects of pedestrian engagement.

\section{RESEARCH OBJECTIVE TWO (RO2)}

The barrier characteristics of the site are reduced in the design by providing pedestrian links across the motorway lanes. However there is opportunity to further increase the permeability of the site by creating more pedestrian paths both across and along the CMJ.

\section{RESEARCH OBJECTIVE THREE (RO3)}

The motorway has been embraced in the design as a viable way from which the city and the archive programme can be experienced. However, the fluid formal qualities of the 'motorway typology' need to be much better integrated in the design to truly celebrate the iconic nature of the elevated motorway.

\section{Hidden Heritage}

RESEARCH OBJECTIVE FOUR (RO4)

Enhanced engagement with the stored archives is being achieved through design elements and facade treatments that are able to visually establish the collections in the public realm. The archives are able to be viewed and experienced by all typologies of visitors to the site.

\section{RESEARCH OBJECTIVE FIVE (RO5)}

Whilst the collections and objects are being integrated into the public realm, in the current preliminary design they are not curated in a way that maximises their didactic potential. Developed Design will focus on how these archives can have a higher degree of curation to the public that accounts for the velocities and manner of interaction that occurs with them.

RESEARCH OBJECTIVE SIX (RO6)

The non-archived elements of heritage are the weakest elements of the Preliminary Design. Currently the only element of site heritage the design addresses is the reestablishment of the Beresford Street link. Several other opportunities will be explored in Developed Design.

Preliminary Design has begun to establish place and cultural identity through embracing heritage, re-establishing a historic link in the site, and through the manner in which it exhibits the stored archives - creating didactic design opportunities. However greater exploration of the archive collections' integration with the design and changing users' perspectives of the city will need to be explored to increase the Heterotopian qualities of the architecture. 


\section{[ CRITICAL REFLECTION ] - Preliminary Design Solution}

At the completion of Preliminary Design, a formal critique was held on 19 August 2016. The author's critical reflections were as follows:

\section{Opportunities Going Forward}

- There are opportunities to link the two separate buildings to enhance permeability through the site.

- Diversify the relentlessly straight corridor lengths in the building by integrating more fluid qualities of 'motorway typology'.

- Increase diversity of use through greater amounts of pedestrian access across and through the site, internal and external.

- The scale of the spaces and public engagement with the archives need to be better articulated to integrate the different velocities, and different manners in which the motor vehicles, bicyclists, and pedestrians engage with the architecture.

\section{AUGUST DESIGN REVIEW ( 19.8 .2016$)$}

Design and project critique with feedback from Julian Watt, Zelia Alves, Christina Mackay and Marc Aurel Schnabel.

\section{Form + Depth}

- Define the driver for placement of the frames. How can these frames be better aligned in the design to reveal elements of the site's and city's 'hidden heritage'.

\section{Public Space}

- How can better public space links and green areas be introduced across the site?

\section{Wing Wall Placement}

- How do the two northern-most wing wall elements engage with their surroundings?

- How do the entry points at the end of each of the wing walls work in terms of the surrounding context?

\section{Velocity}

- Velocity of engagement with the building becomes of critical importance now.

- How do time and velocity distort space?

- How is the experience in each lane different?

- Engage with the fast car, the slow car, the cyclist, the pedestrian.

\section{Human Scale + Links}

- Break up the corridor spaces so they are not so excessively long and straight.

- Improve the spatial qualities of walking through the site.

- Add more pedestrian linkages to increase permeability across the motorway.

- There needs to be much better linkage established between the two building forms on site.

\section{Away from the Orthogonal}

- See the design in a wider context; is it appropriately responding to its surrounding environment?

- Does this suggest a step away from the orthogonal and perpendicular forms and a shift to the more fluid forms of the motorway?

\section{Programme}

- Investigate how to properly store these items safely yet still maximise the public engagement with them. 


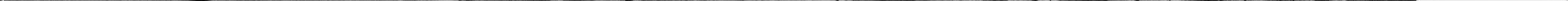




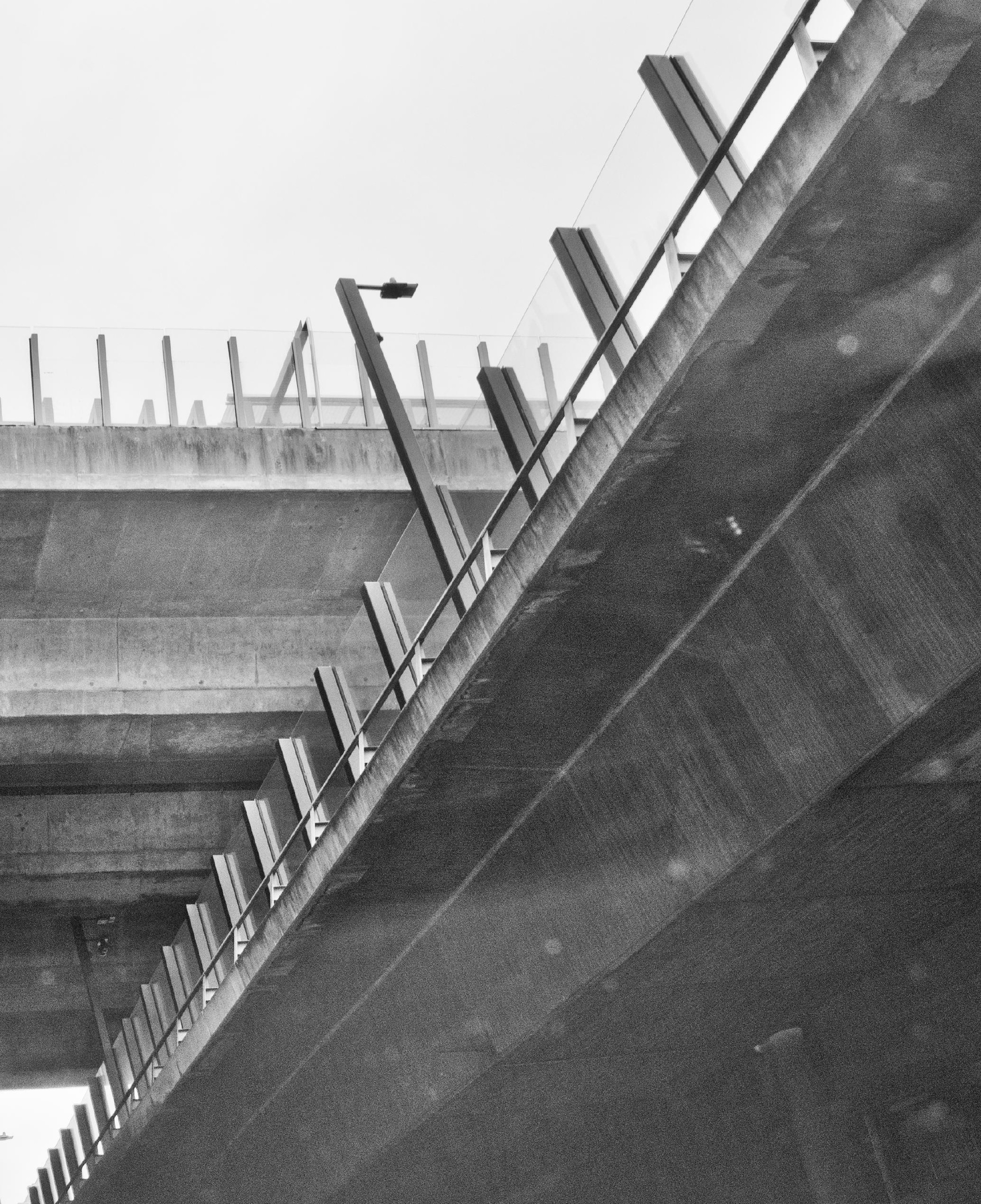




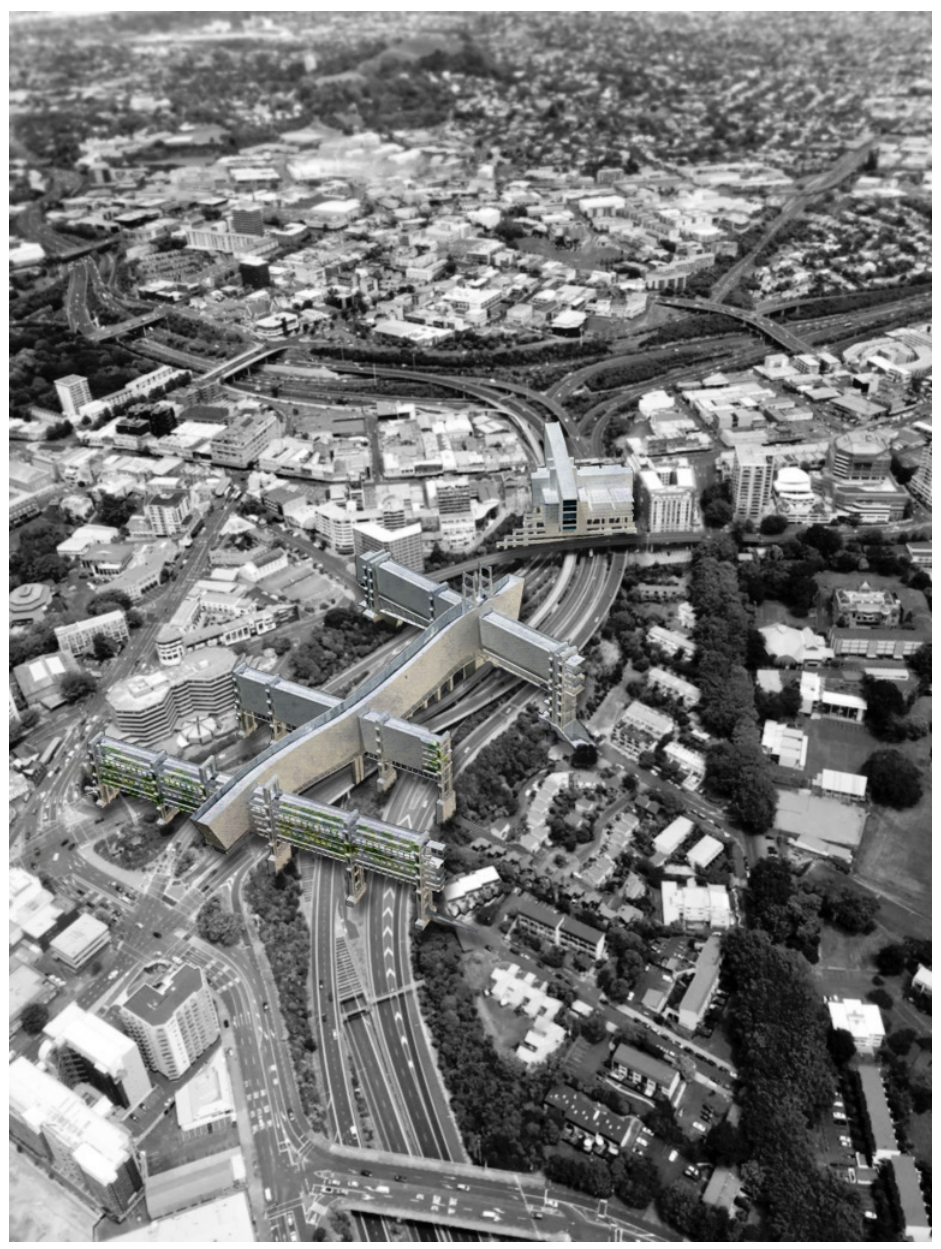




\section{6 | Developed Design}

Following on from Preliminary Design, Developed Design focuses in particular on achieving research objectives pertaining to 'hidden heritage': curating the archives to maximise their didactic potential in the public realm, and exploration of the non-archived elements of heritage (RO4 - RO6).

This chapter will also further investigate and strengthen the design's ability to achieve research objectives relating to 'lost site': increasing the diversity through the site, increasing permeability, and embracing the motorway typology and its iconic nature (RO1 - RO3).

The public elements of the spine building (centred in the heart of the CMJ) will be the primary focus of development, due to the very large scale of the design intervention.

Developed Design will seek to further enhance the Preliminary Design experiments by exploring the following;

\section{[ Embracing Heritage ]}

- Further enhancing the 'lost heritage' of the CMJ site through better placement of the wing walls to engage with the original historic links across the site.

- Integration of the seed archive into the design to incorporate green spaces and links across the CMJ that engage with its historic green gully heritage.

- Development of the didactic design opportunities, such as curating the heritage of the surrounding city and curating archives so these elements are better engaged by the diverse typology of users.

\section{[ Pedestrian Access ]}

- Increased pedestrian access through the site and through the architecture itself to enhance diversity, permeability, and to reduce the barrier-like nature of the current motorway junction.

\section{[ Linking Space ]}

- Explore opportunities to coherently link the Karangahape building and the spine building together.

\section{[ Structure ]}

- Integration of the motorway typology into the structural and tectonic form of the intervention, to further embrace and celebrate the motorway.

\section{[ Interior Space ]}

- Development of interior spaces that allow the public to have more personal engagement with the collections whilst still allowing for practical and safe storage of the archives.

\section{[ Facades ]}

- Better curation of the archives in the wing wall facade designs to have greater engagement with the three typologies of public viewers who move through the site - the motor vehicle, the cyclists, and the pedestrian. 


\section{[ EMBRACING HERITAGE]}
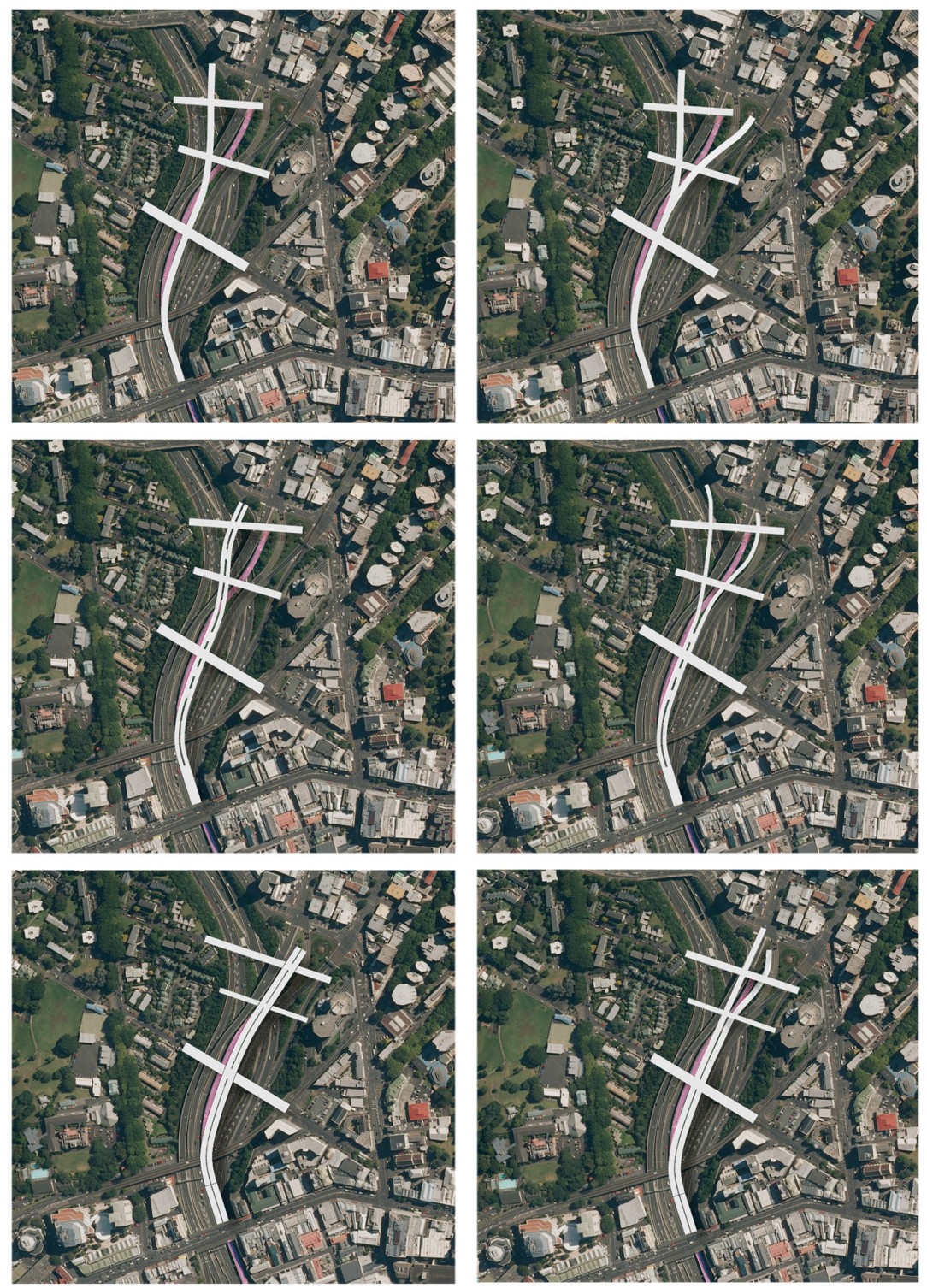

\section{EMBRACING HISTORIC HERITAGE + MOTORWAY HERITAGE}

The experiments above and to the right explore embracing the historic heritage of the surrounding site and greater urban context by reestablishing traditional street links. They also

embrace and celebrate the motorway typology by making the spine form more fluid.

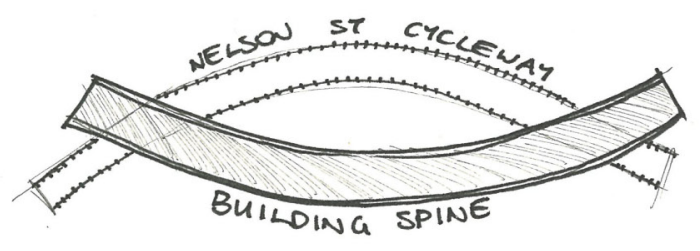




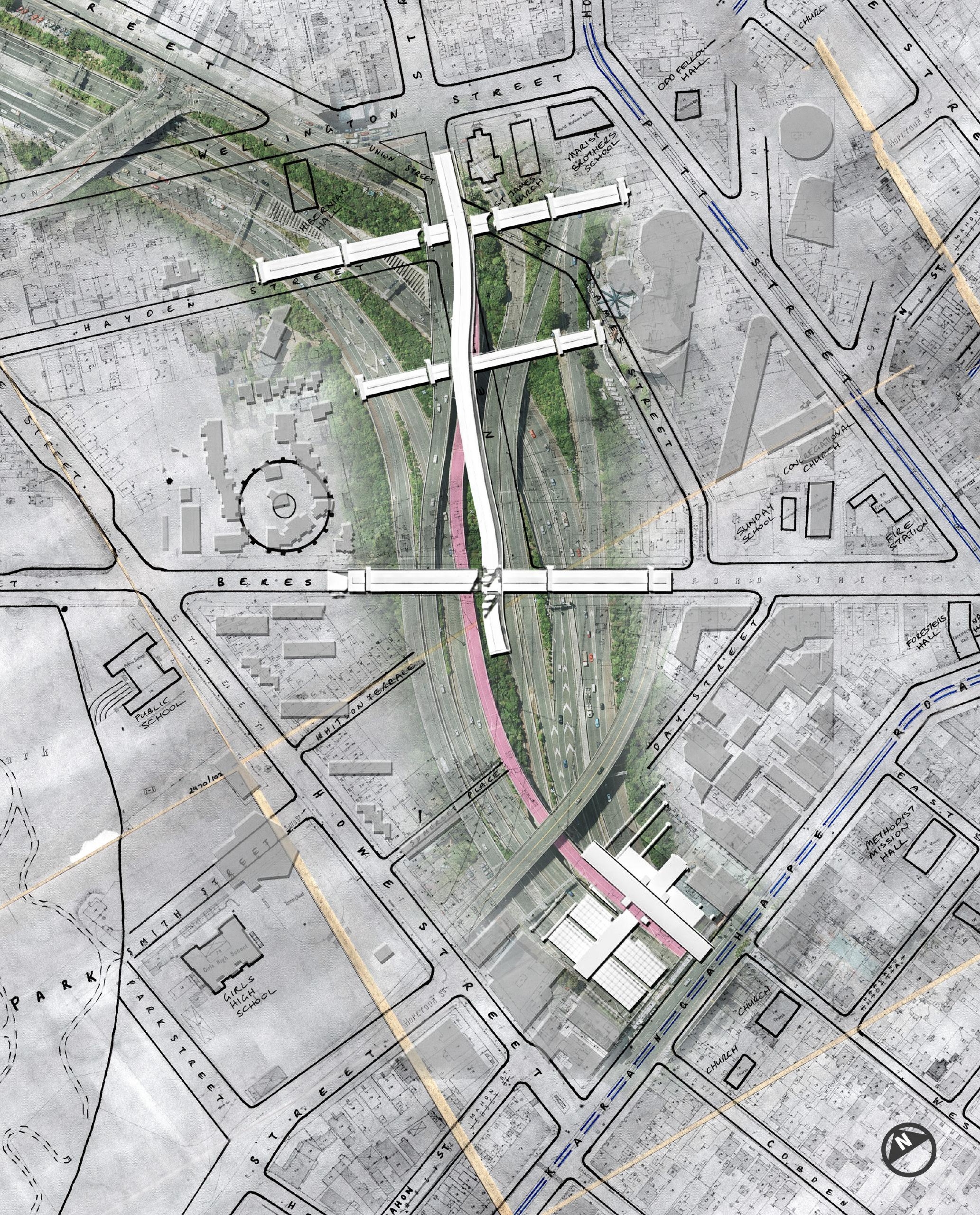




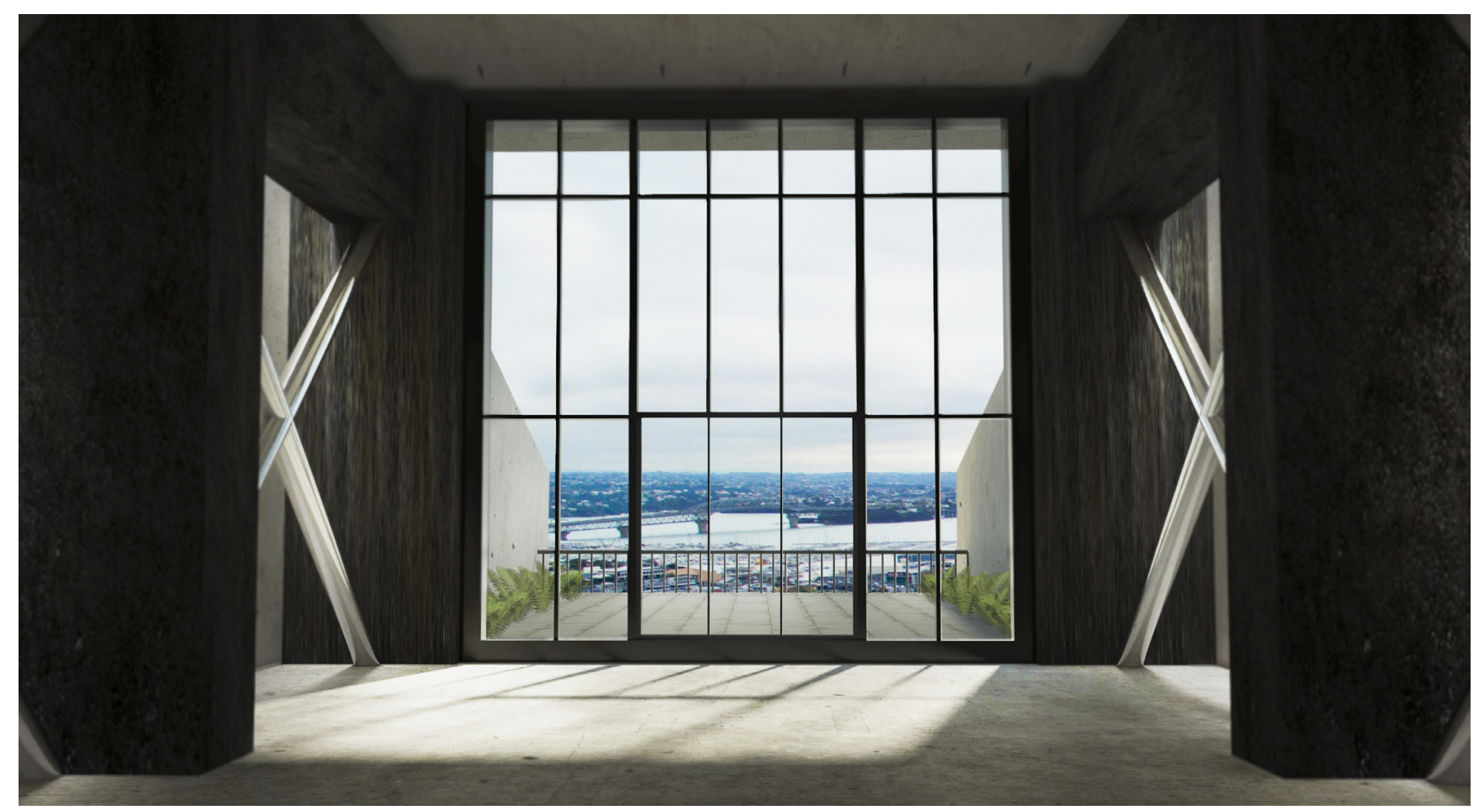

NORTH VIEW

[ harbour bridge ]

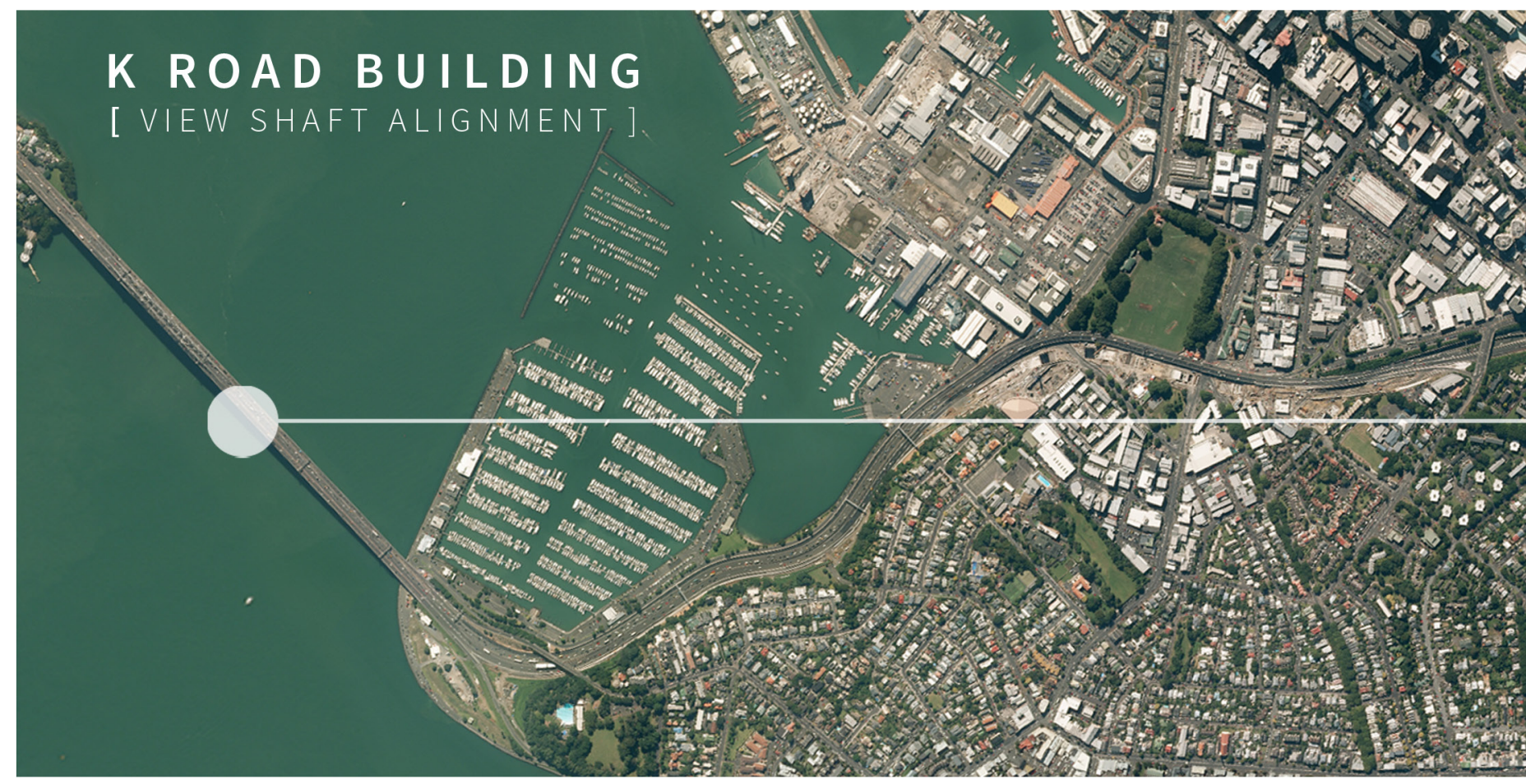

h a r bour.

Figure 6.4 (above spread): The top floor of the Karangahape building curates the non-archived elements of heritage (RO6). Pointing towards the Harbour Bridge and Mount Eden it frames these Auckland icons so their importance in the landscape and the urban environment is clear. 


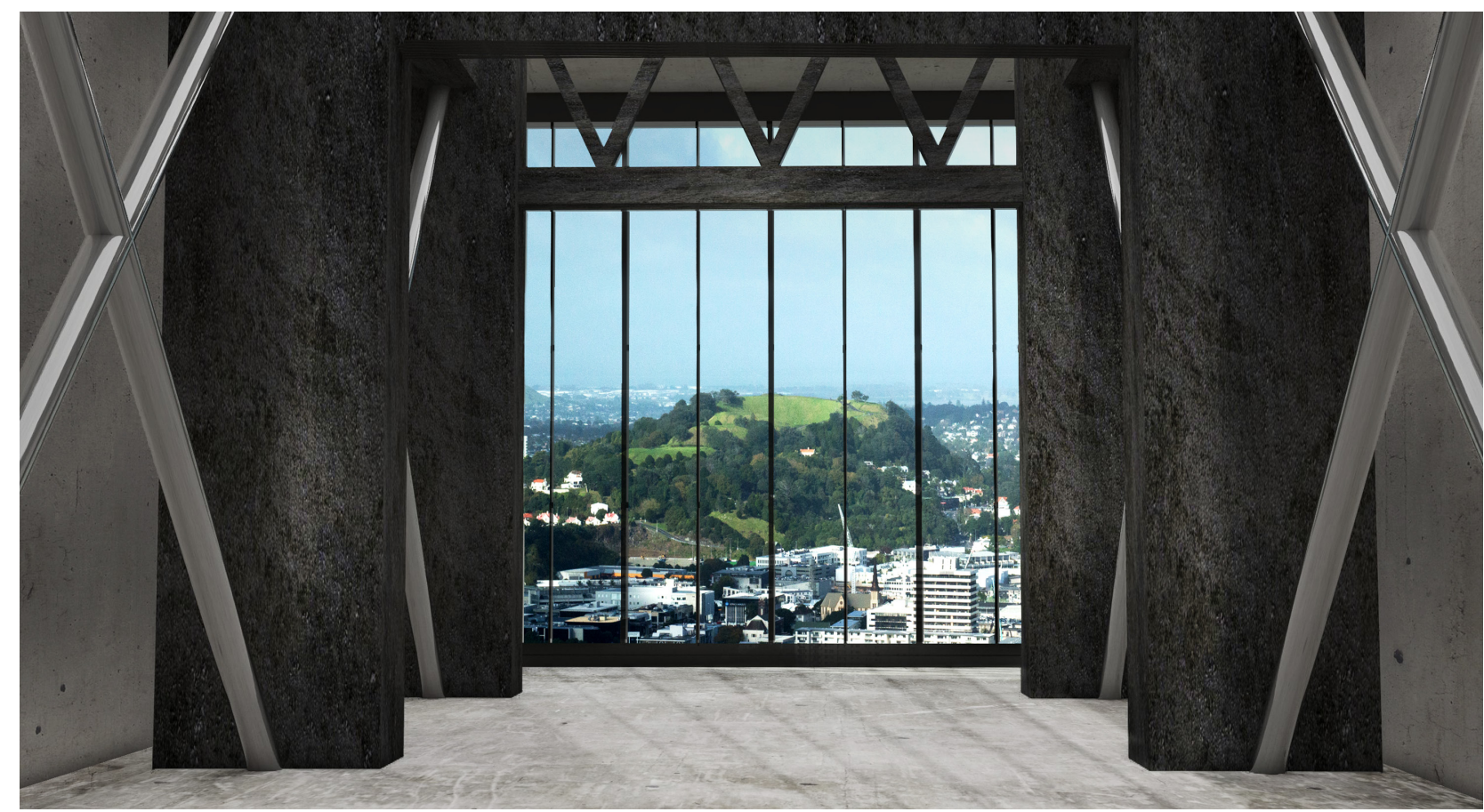

SOUTH VIEW

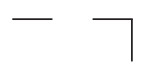

[mount eden ]

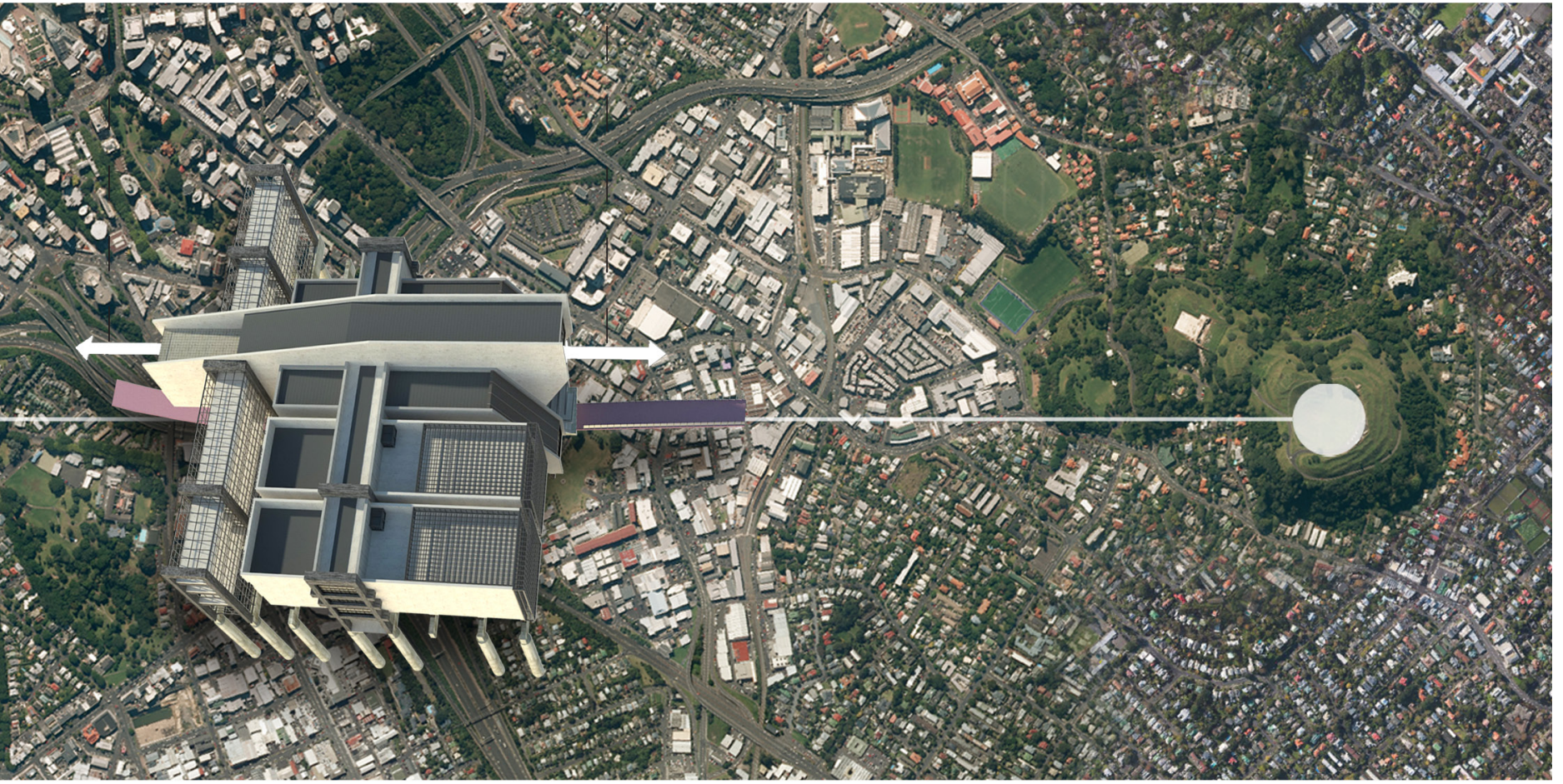



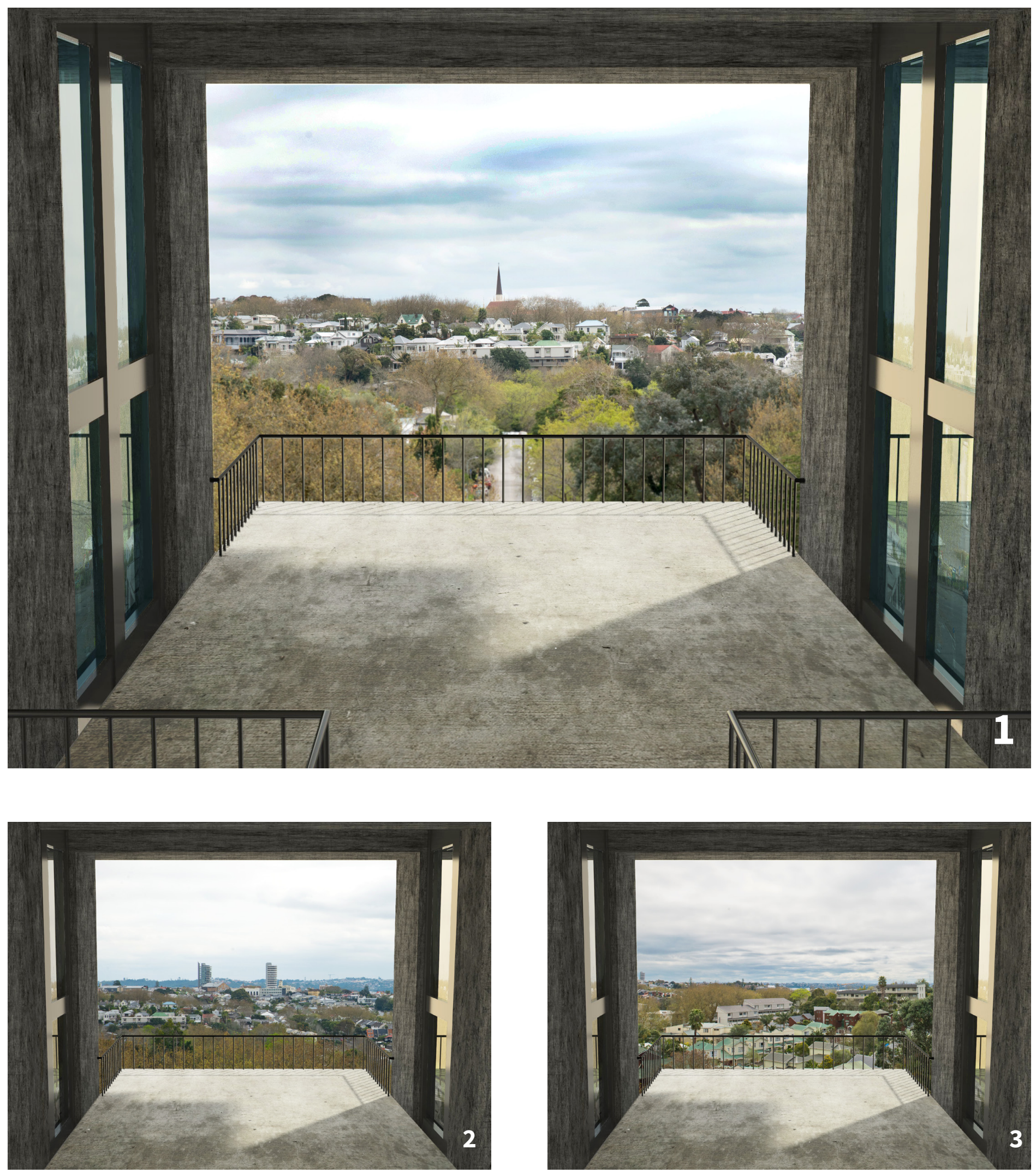

Figure 6.5 (above spread): Using the design to curate the non-archived elements of heritage - the cityscape (RO6). The end elements of the wings frame views of the western suburbs - dynamic views that will change as Auckland continues to grow. 


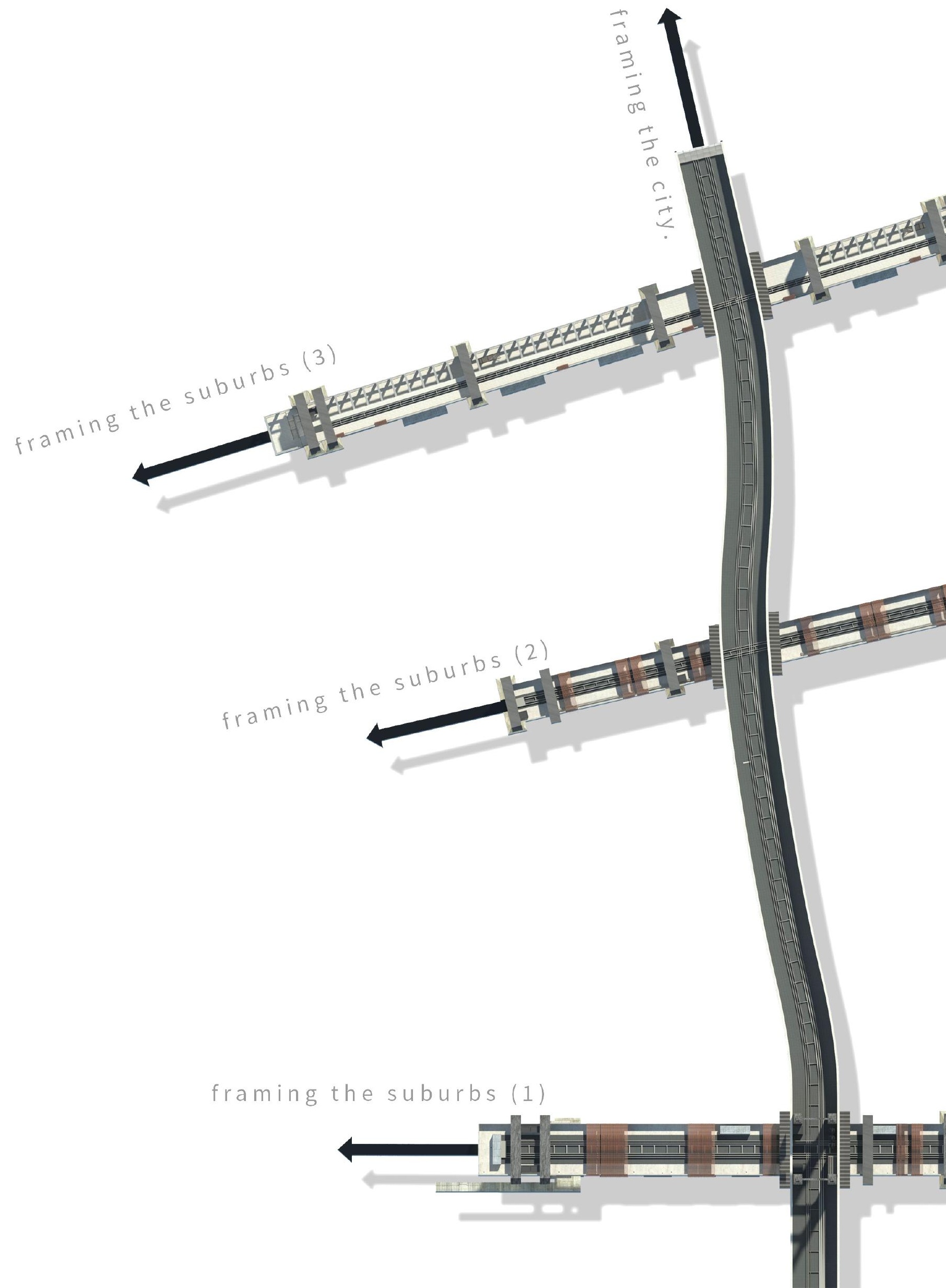




\section{[ PEDESTRIAN ACCESS ]}

This design developement dedicates a level of the architecture as entirely public access to increase the diversity of pedestrian users and the permeability through the CMJ. Along these pedestrian links seed and archive spaces are introduced to makes these paths both green spaces as well as places where the public can engage with elements of the collections.

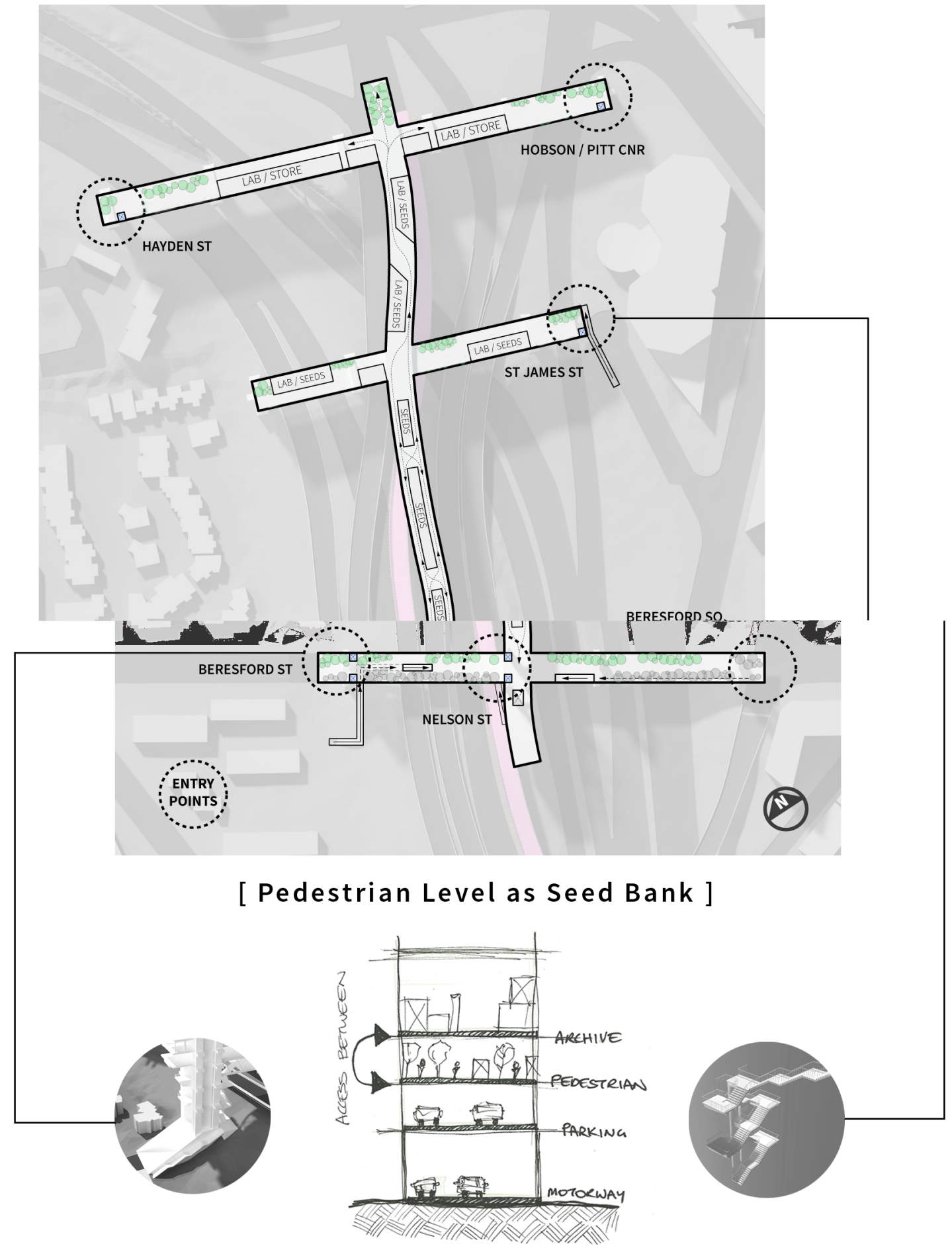




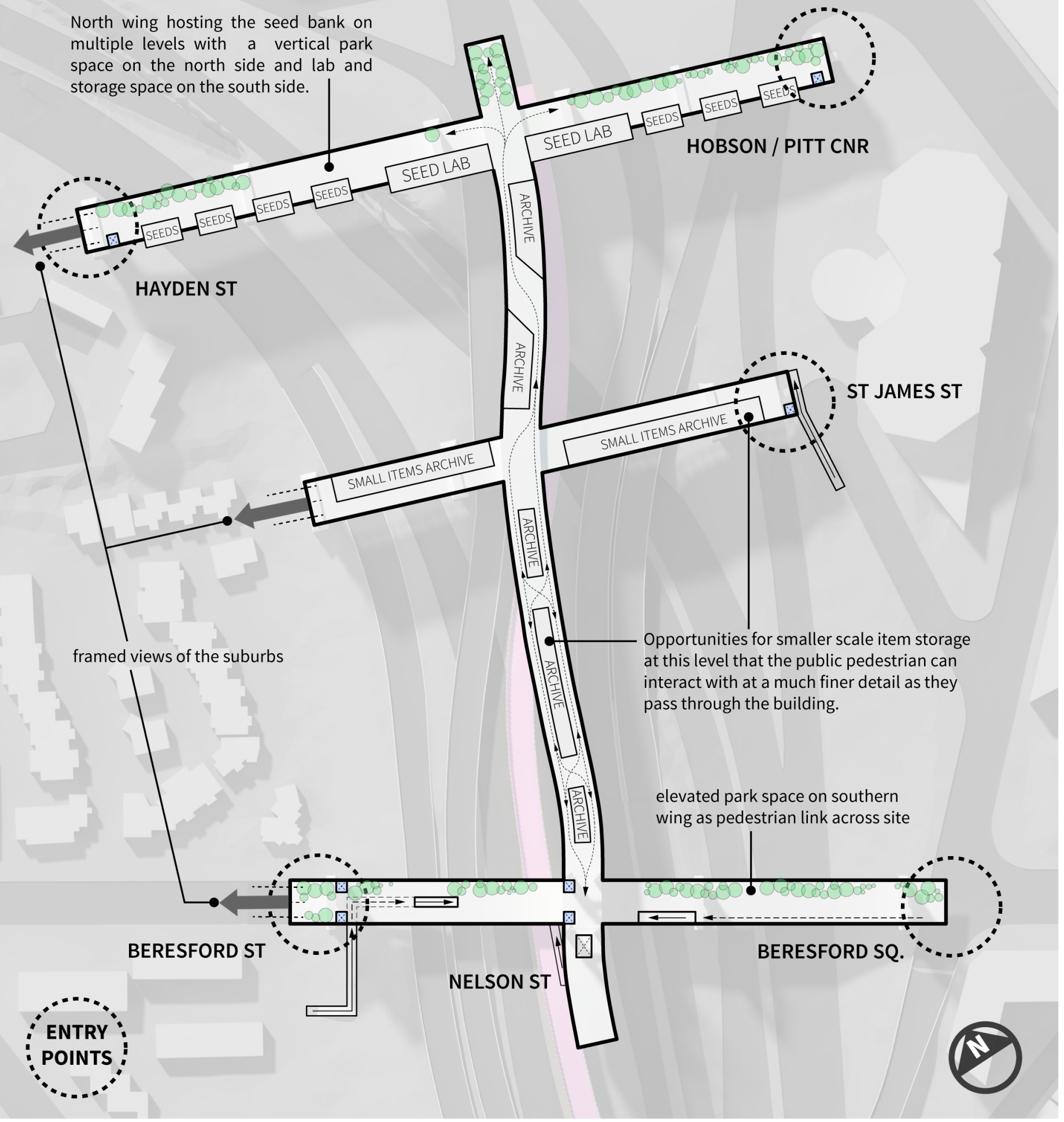

[ Pedestrian Level as Seed Bank + Archive ]

seed bank + lab space + seed planting + public throughfare /

elevated park + display for small light sensitive archive items 


\section{[ LINKING SPACE ]}

These experiments create covered links between the two design elements to increase the permeability through both the CMJ site and the architectural spaces.

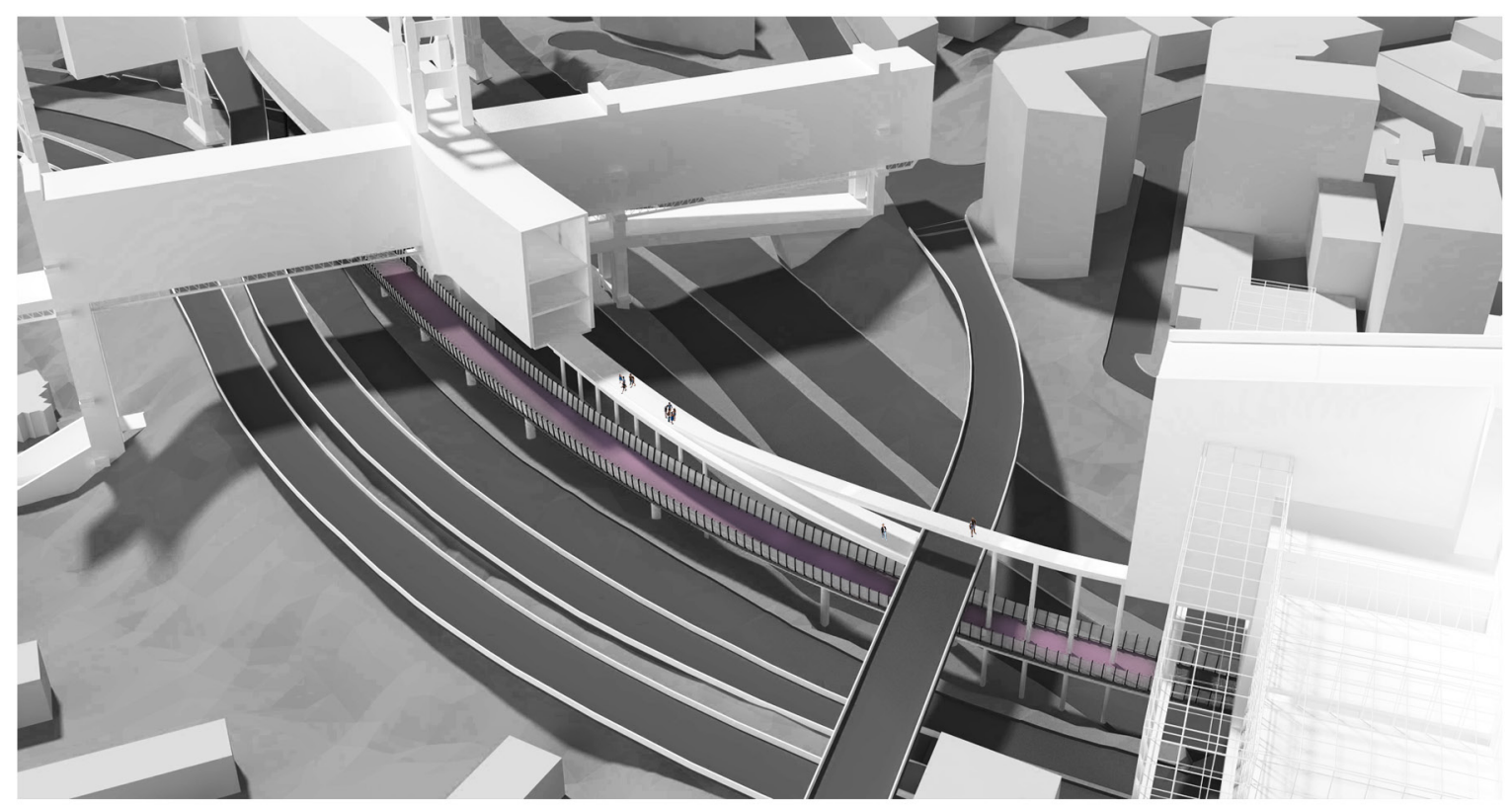

As open ramp spaces connecting to Hopetoun Street Bridge and Karangahape building.

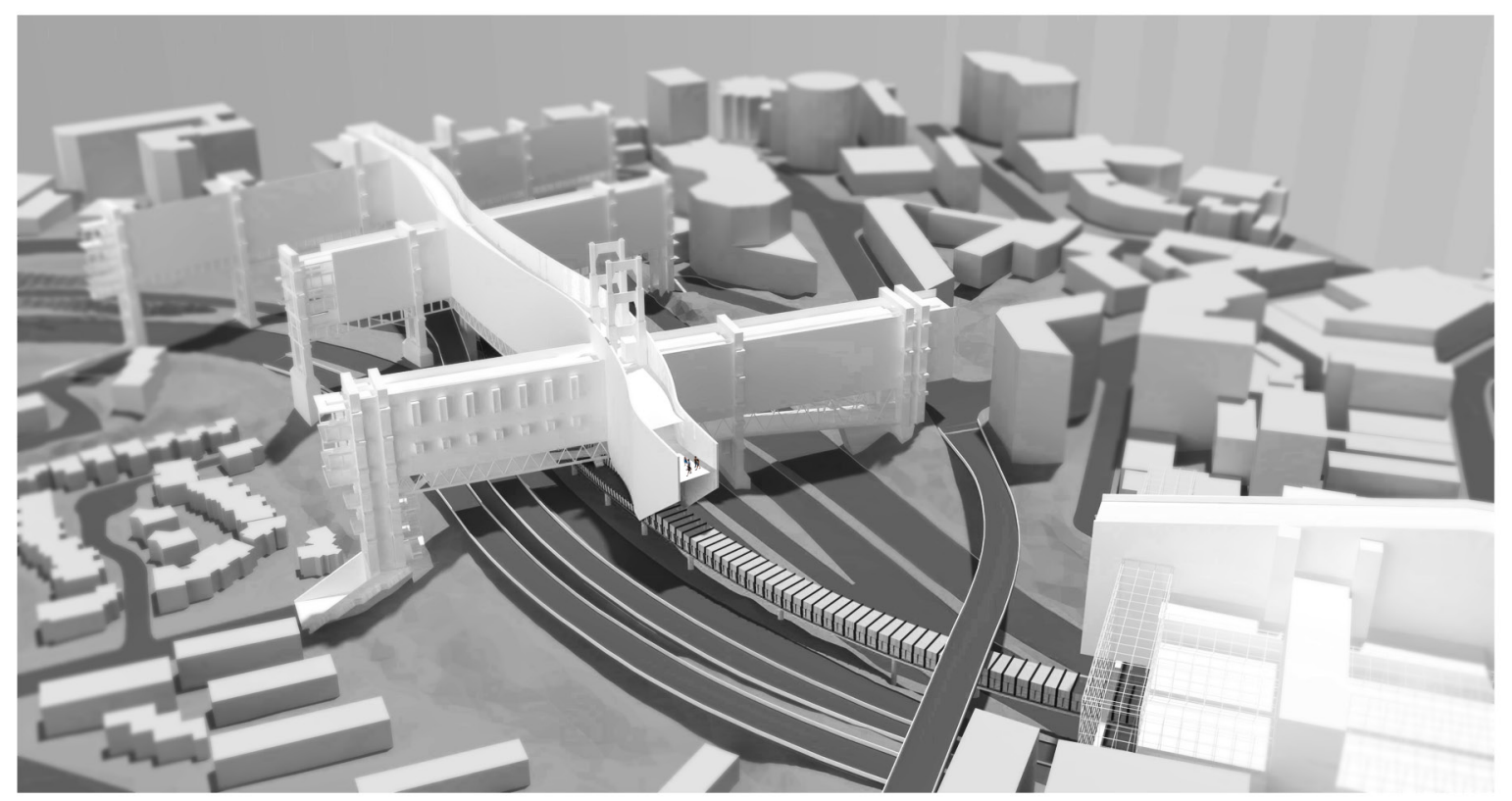

Utilising the existing Nelson Street Cycleway.

Figure 6.7: The top option provides a good additional link onto Hopetoun Street, but is far too thin and is not the an appropriate scale for the typology of current intervention. The bottom option is the simplest way to link the two elements but by only using the cycleway there will be issues between public and private circulation. 

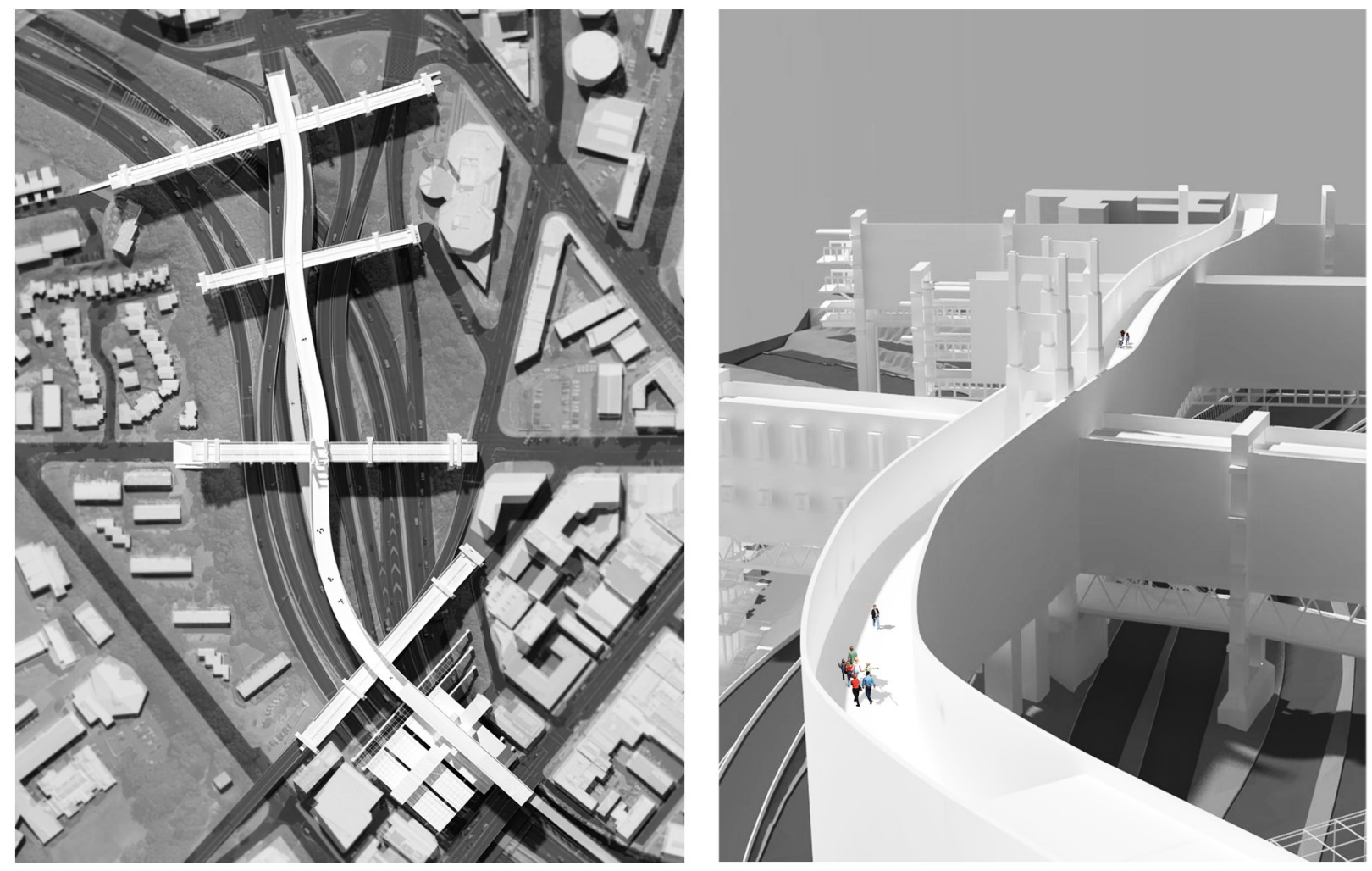

This experiment links the two buildings with a continu ous spine.

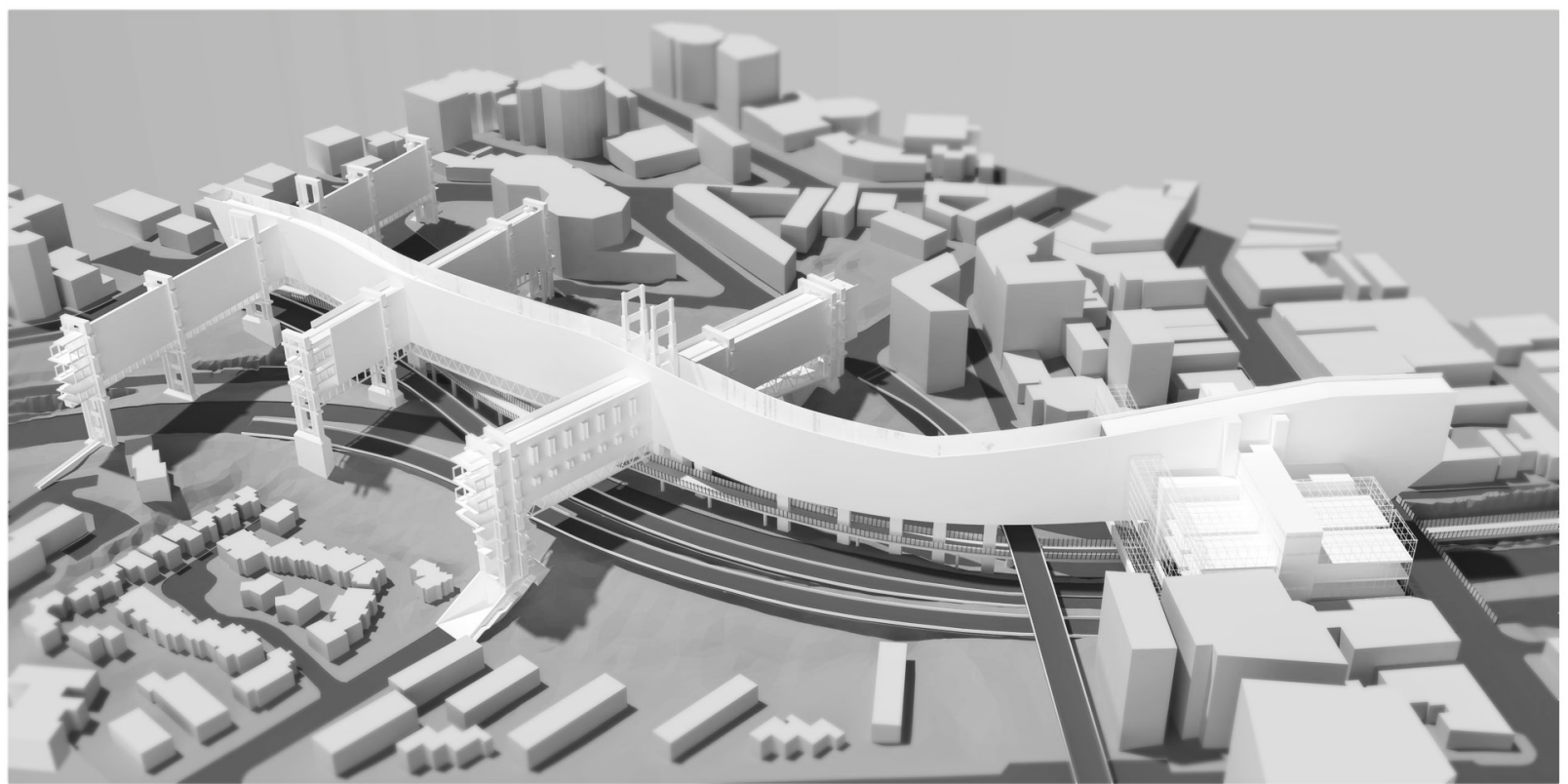

Figure 6.8: In the image above the architecture is explored as a continuous spine through the CMJ. This provides optimal linkage between the two buildings. 


\section{LINKING BETWEEN BUILDINGS}

This experiment utilises two links between elements - one public, one private ]
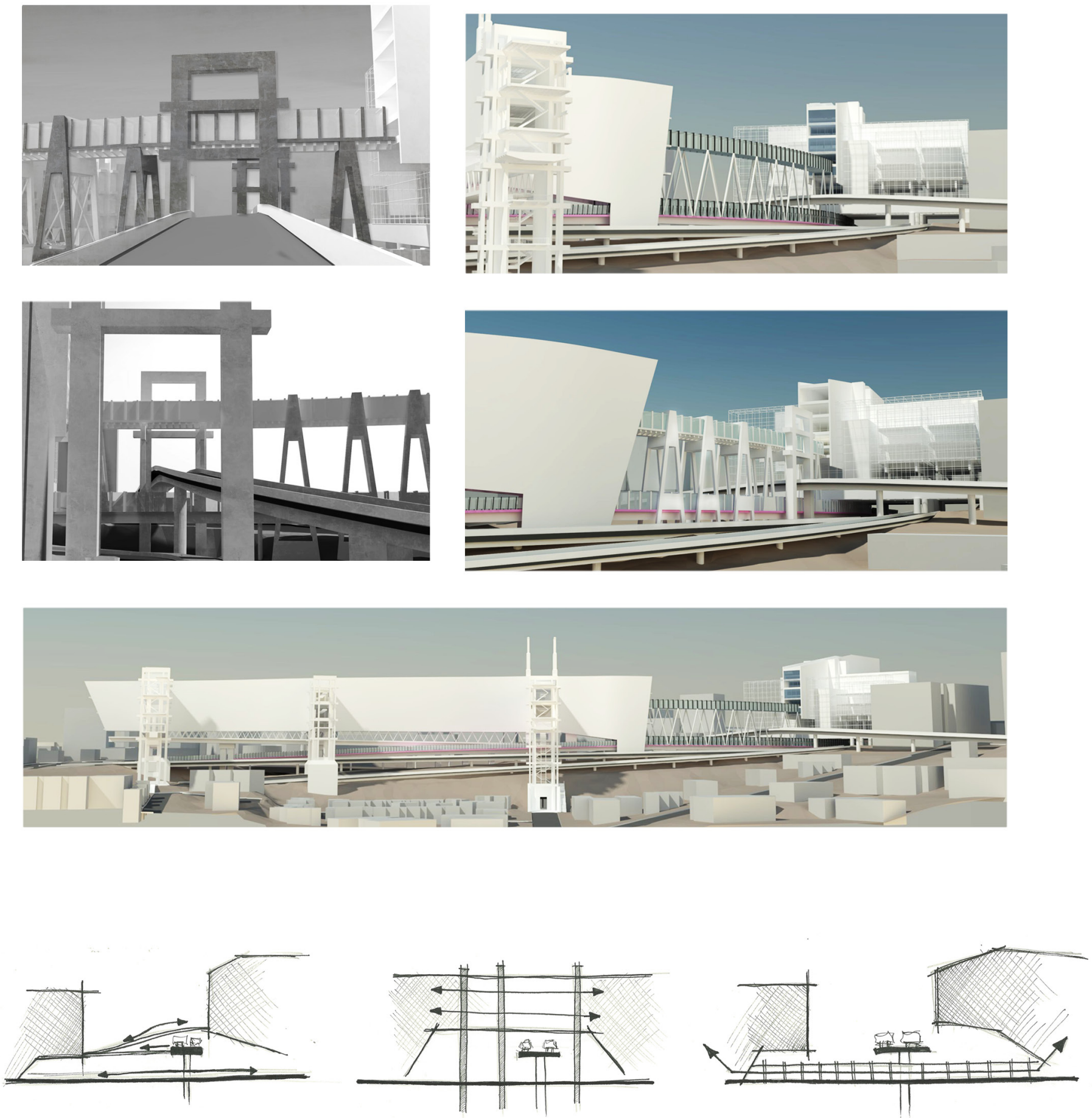

Figure 6.9 (above spread): Investigating two links between the elements - one for public circulation utilising the existing Nelson Street Cycleway, and the other as an elevated space that supports more private circulation. By having this vertical spacing between the two links there are also opportunities to develop a threshold element for the Hopetoun Street bridge. 


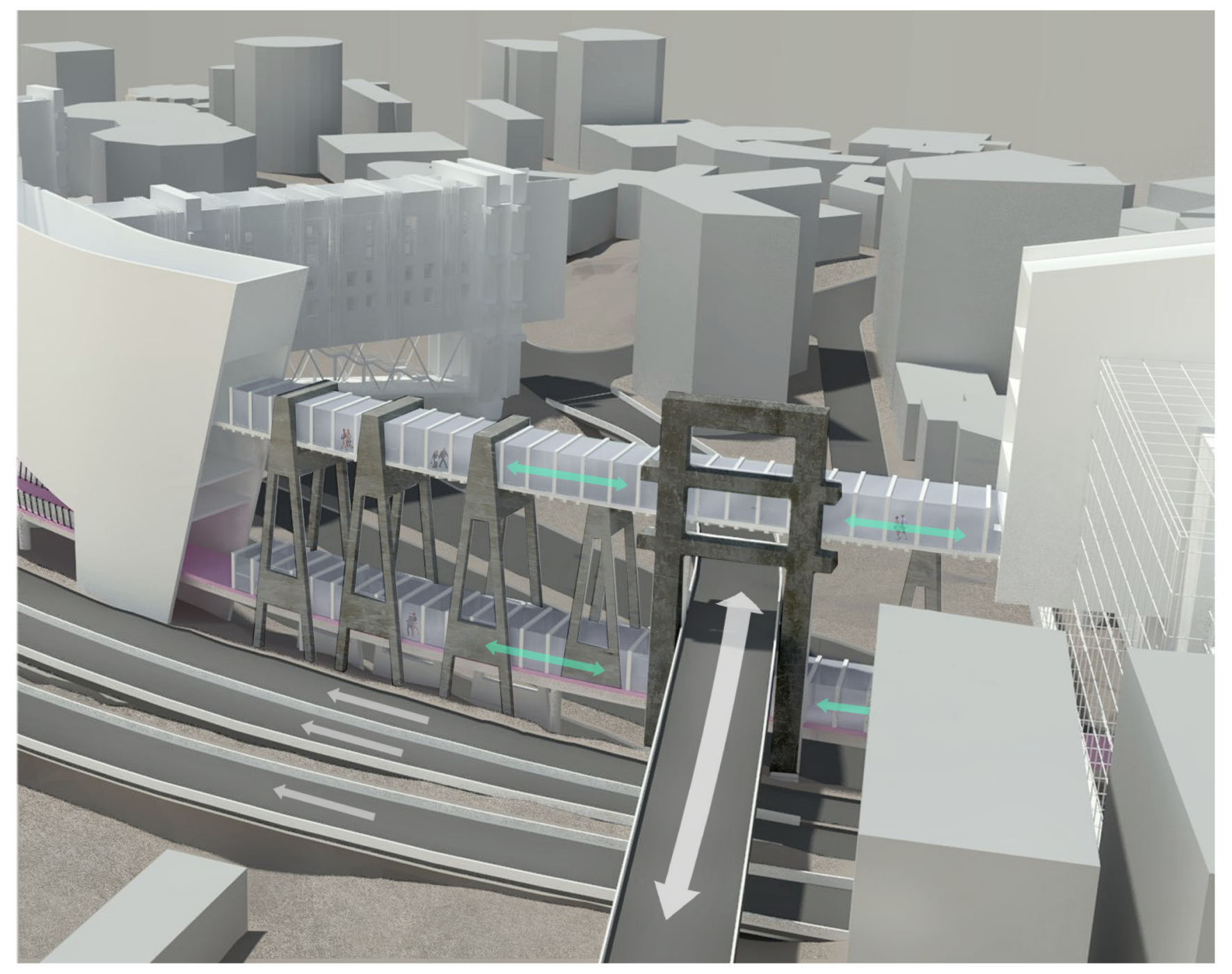

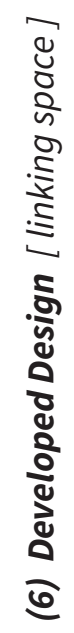
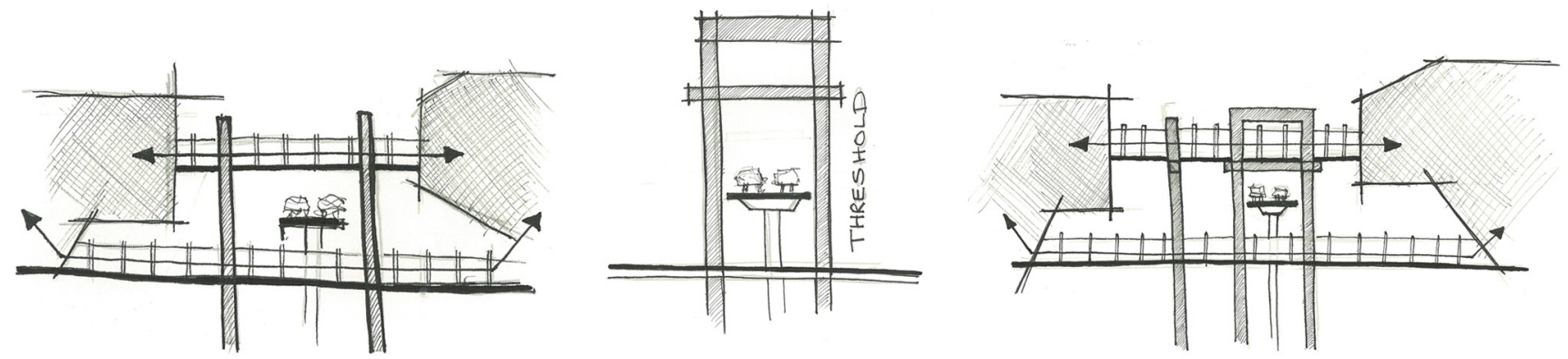


\section{[ STRUCTURE ]}
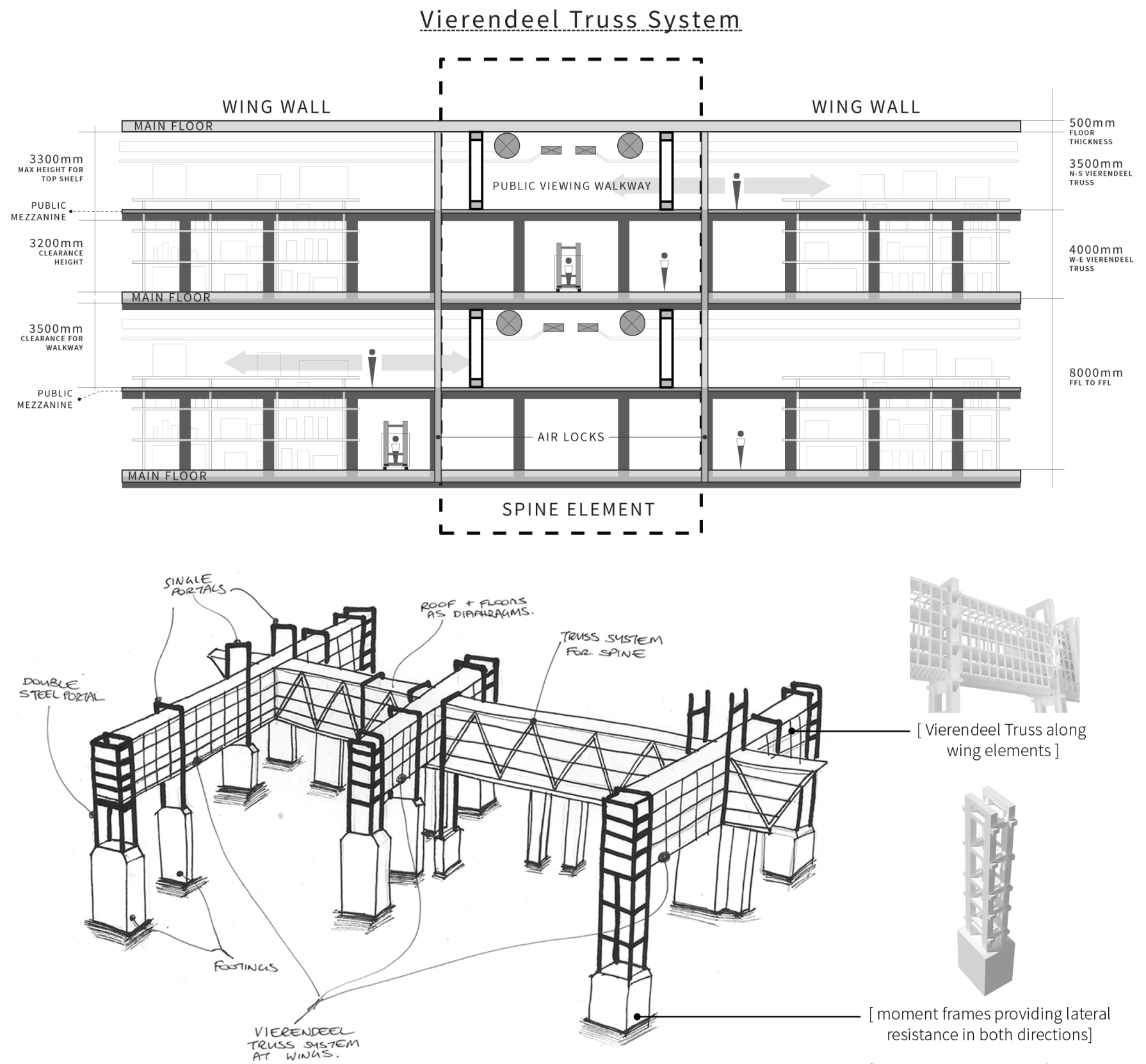

Figure 6.10: Structural systems.

The structural design (see figure 6.10) is based on the typology of bridge pylons to further embrace the iconic nature of the elevated motorway, rather than trying to hide it (RO3). Massive moment frames sit in the interstices of the motorway junction and provide the main structure for the building. The wing elements of the building are structured with vierendeel trusses spanning between the moment frames and the floors are hung from these trusses. The structure in the spine is a floor to roof truss that is partially supported by the spanning vierendeel trusses that cross it, in combination with its own moment frames and piles. 


\section{STRUCTURE IN X \& $Y$}

[ structure resisting lateral loads in both directions]

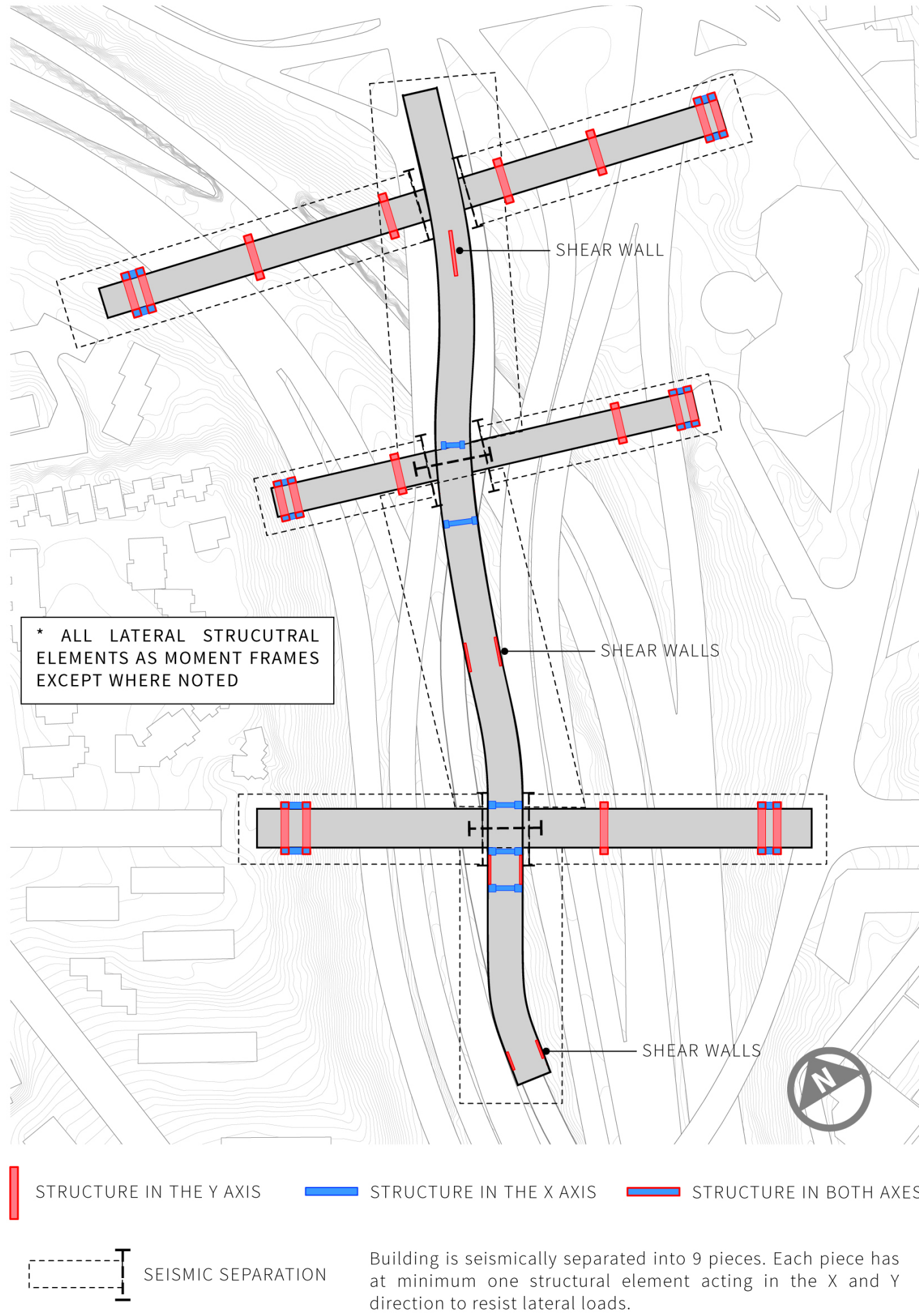




\section{[ INTERIOR SPACES ]}

\section{EXISTING MUSEUM / ARCHIVE TYPOLOGY}
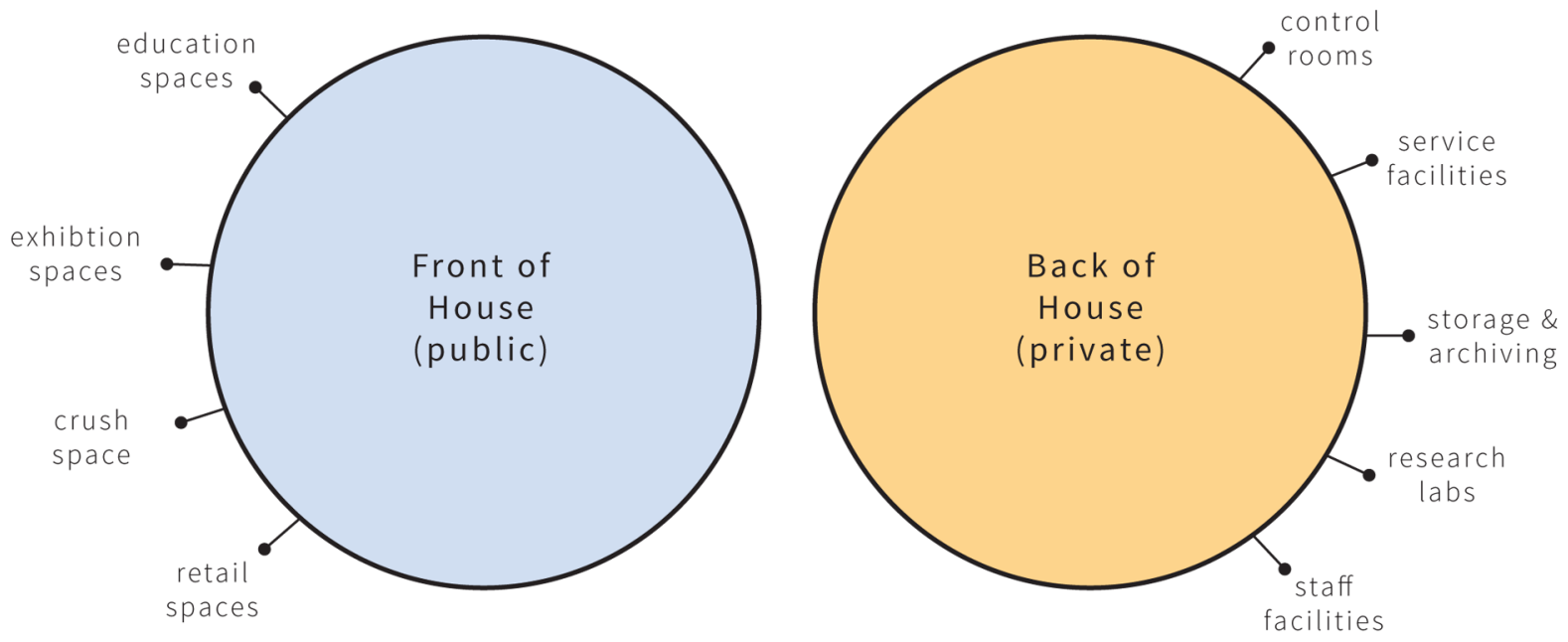

PROPOSED MUSEUM / ARCHIVE TYPOLOGY

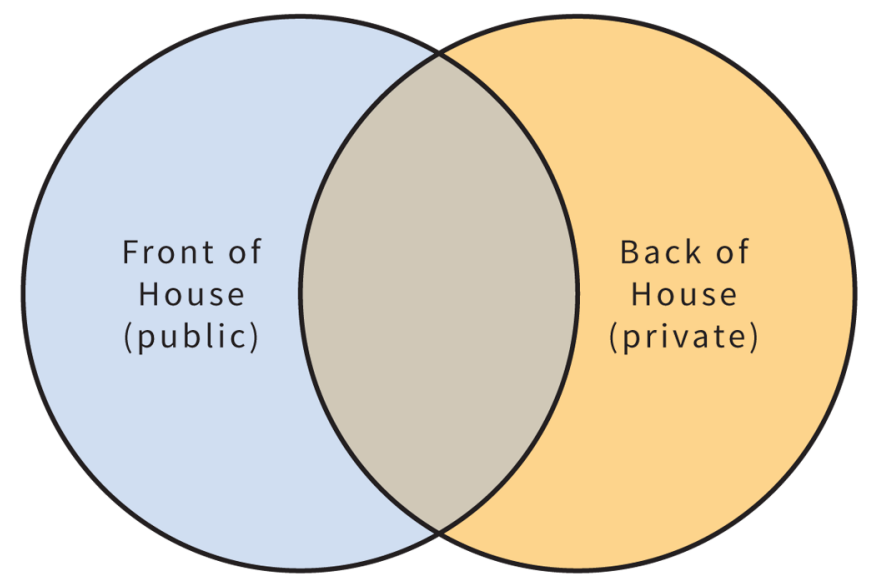

Current museum storage and archive spaces have a distinct separation between what the public engage with and what is private. By increasing the public interaction into these 'back of house' spaces there are opportunities to increase awareness around the importance of these spaces and the cultural significance they hold.

This research proposes an innovative new approach for re-cataloguing archived objects in ways that will make them more visually accessible to the public (RO4 and RO5). Because current technology allows archives to be digitally tracked, items of similar historic categorisation no longer need to be grouped together in specific sections. Instead they can be stored by size and light sensitivity - the design research intervention is conceived to take advantage of this, by placing non-light sensitive, and appropriately sized items into viewing opportunities for motor vehicles, cyclists, and pedestrians outside of the architecture. 

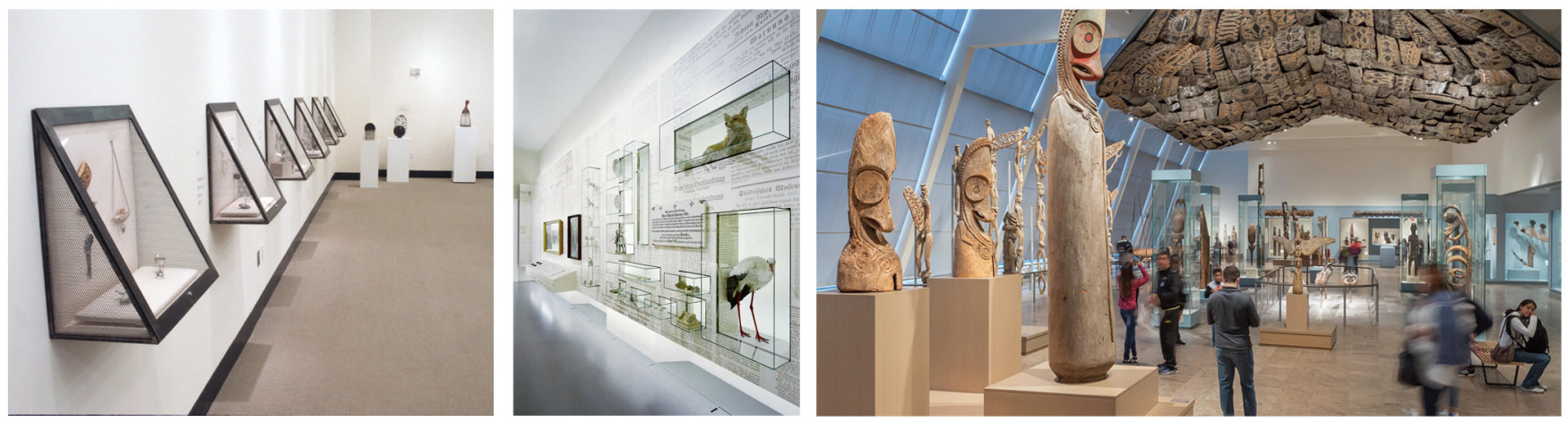

\section{TYPICAL MUSEUM EXHIBTION TYPOLOGY}

- Low Density Display - Curation of elements - not practical working/cataloguing space - maximising public interaction
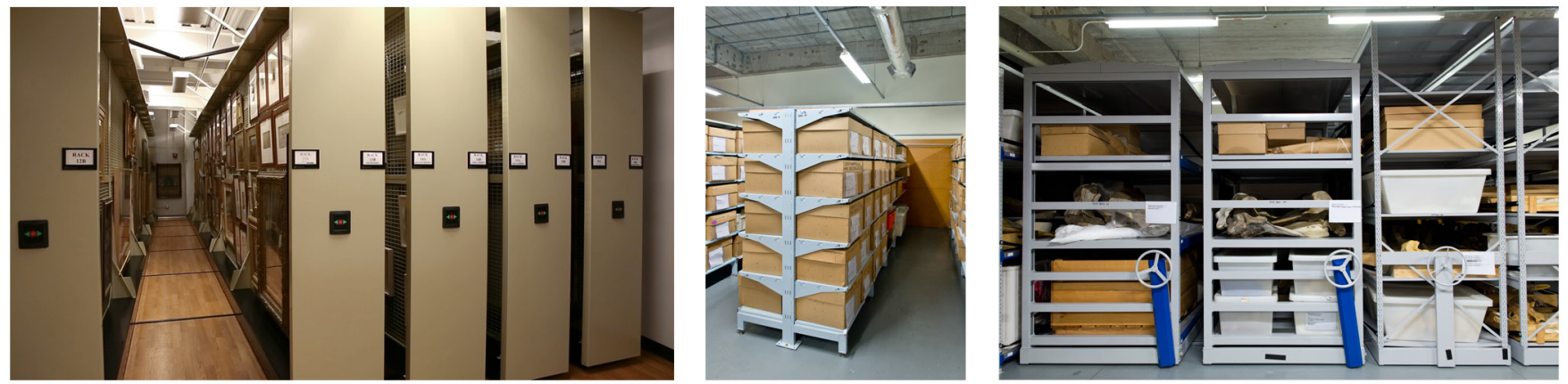

TYPICAL ARCHIVE STORAGE TYPOLOGY

- High density storage - Elements hidden - Practical cataloguing space - minimised public interaction
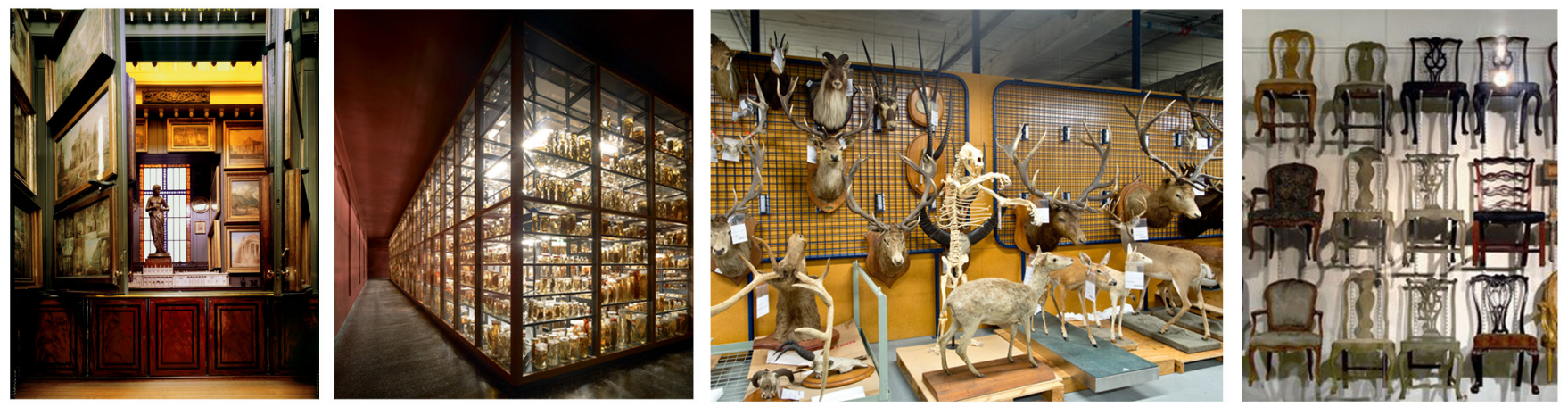

\section{PROPOSED ARCHIVE STORAGE TYPOLOGY}

- Dense storage - Elements curated in storage - Still allow for cataloguing and working space - increased public interaction

Figure 6.12 (above spread): Exploring current museum archive storage and proposing a new typology of storage that can maximise the didactic potential of the items in the public scope (RO5). 


\section{DEVELOPING INTERIORS}

interior of the archive as a secure space but still allowing public interaction

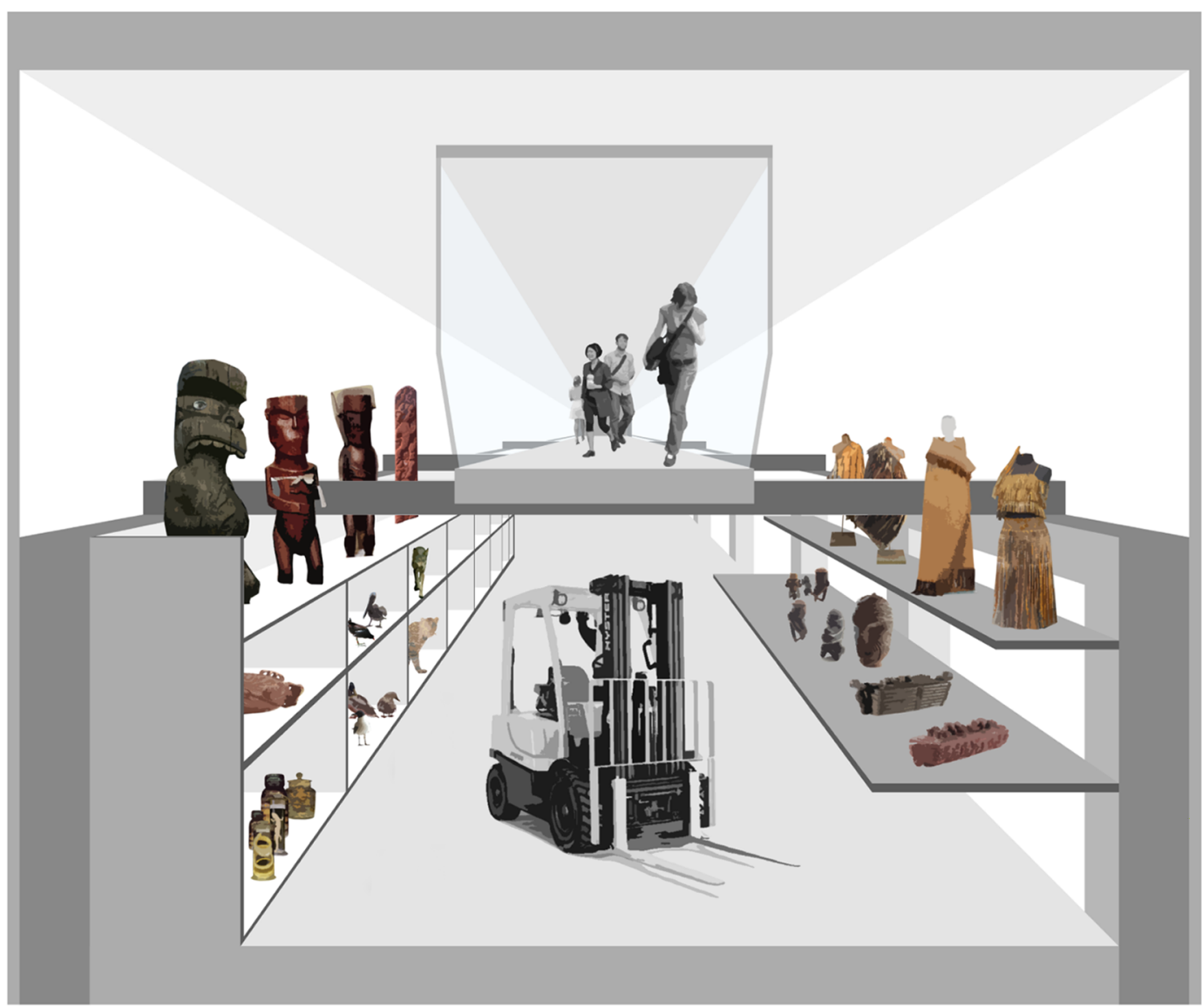

public accessway
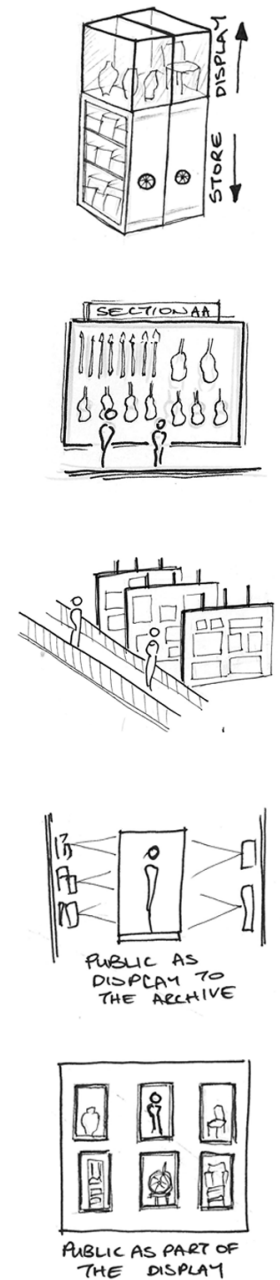

Elevated public mezzanines allow visual access with physical separation.

Instead of preventing the public from entering archive storage areas this thesis proposes an elevated mezzanine system that allows visual access whilst maintaining physical separation. This not only makes the items visually accessible, but it also allows people to witness the processes of preservation and restoration. Allowing the public to be even more engaged with their New Zealand heritage (RO4 and RO5). These mezzanines also act as alternate routes for pedestrians travelling across the CMJ site. 


\section{CURATING THE PUBLIC AS AN ELEMENT OF THE DISPLAY}

creating opportunities along the public elements of the wings for public engagement with the facade

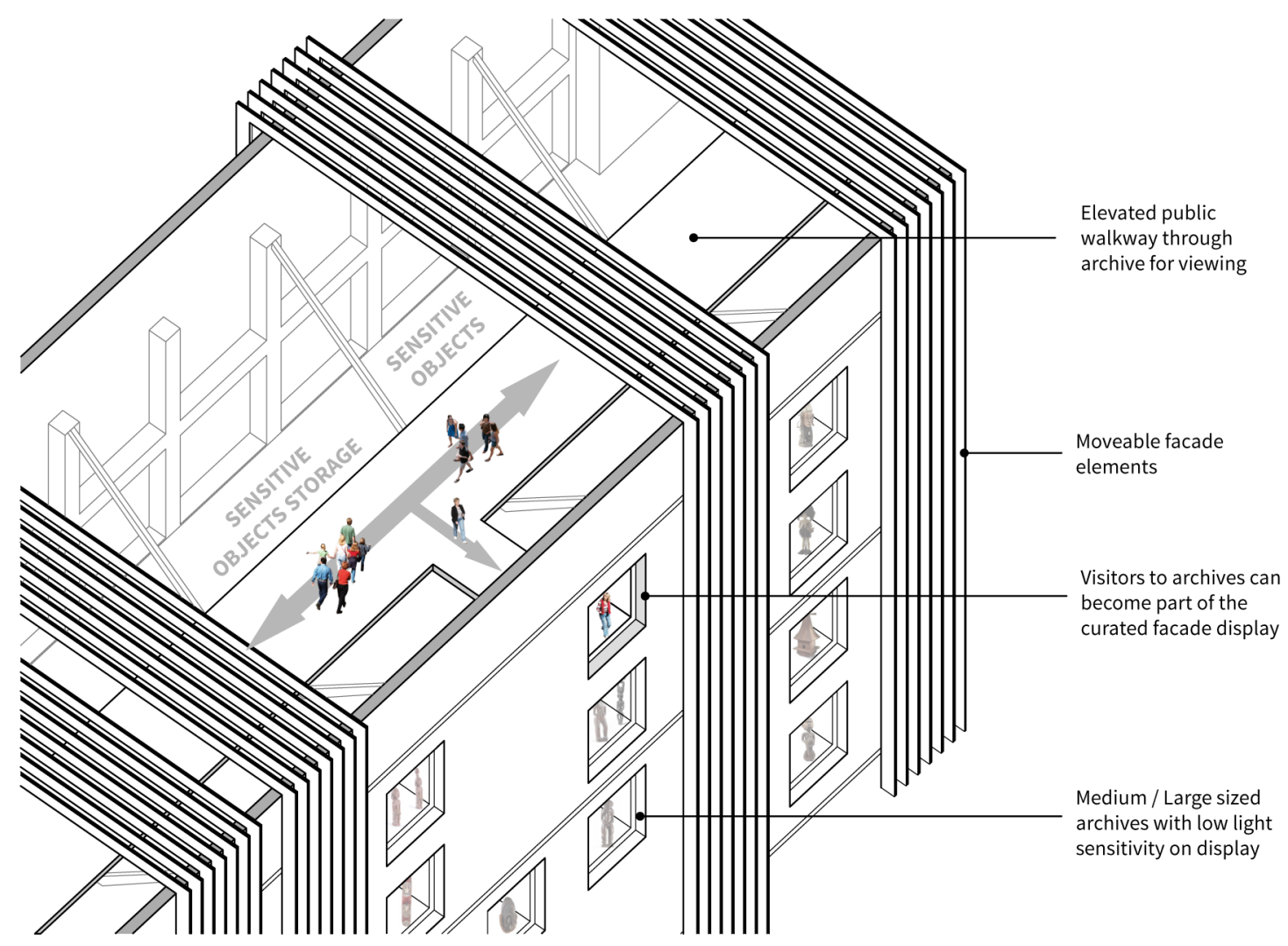

Along this elevated public mezzanine there are moments where the public can walk up to the edge of the facade and become part of the external display - for a brief moment making them a metaphorical and literal part of the 'curated collection' of the nation's heritage.
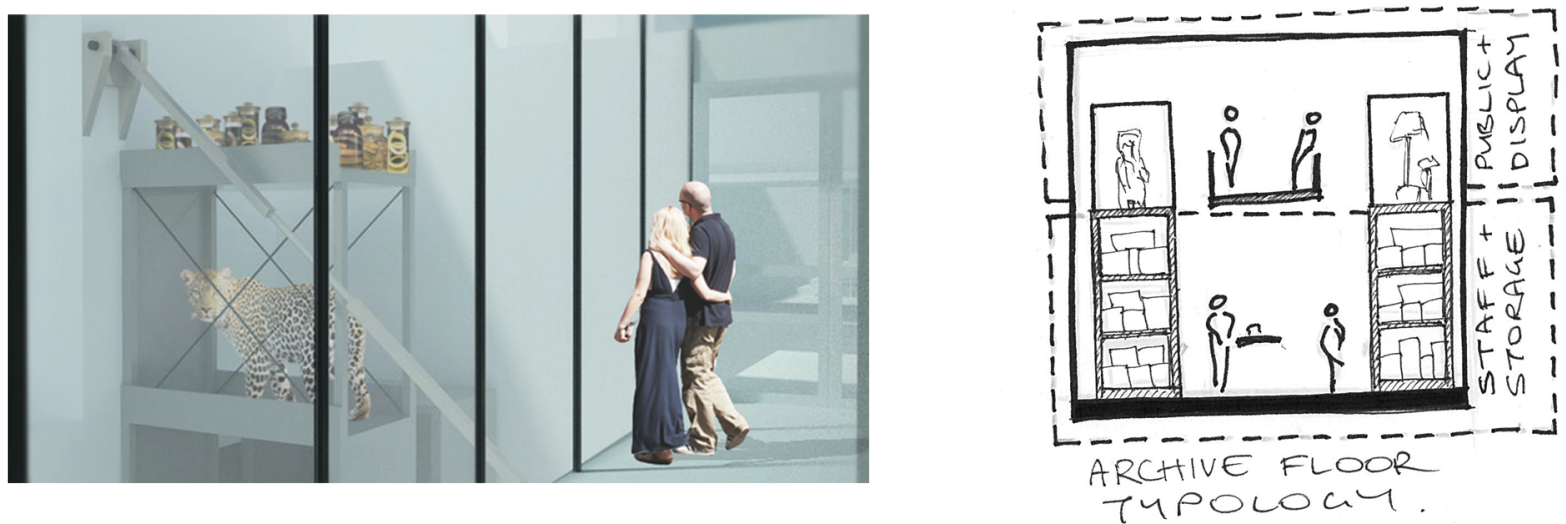


\section{[ FACADES ]}

\section{FACADE AS ARCHIVE DISPLAY}

[ southern facades of the wing buildings used to curate archive pbjects ]

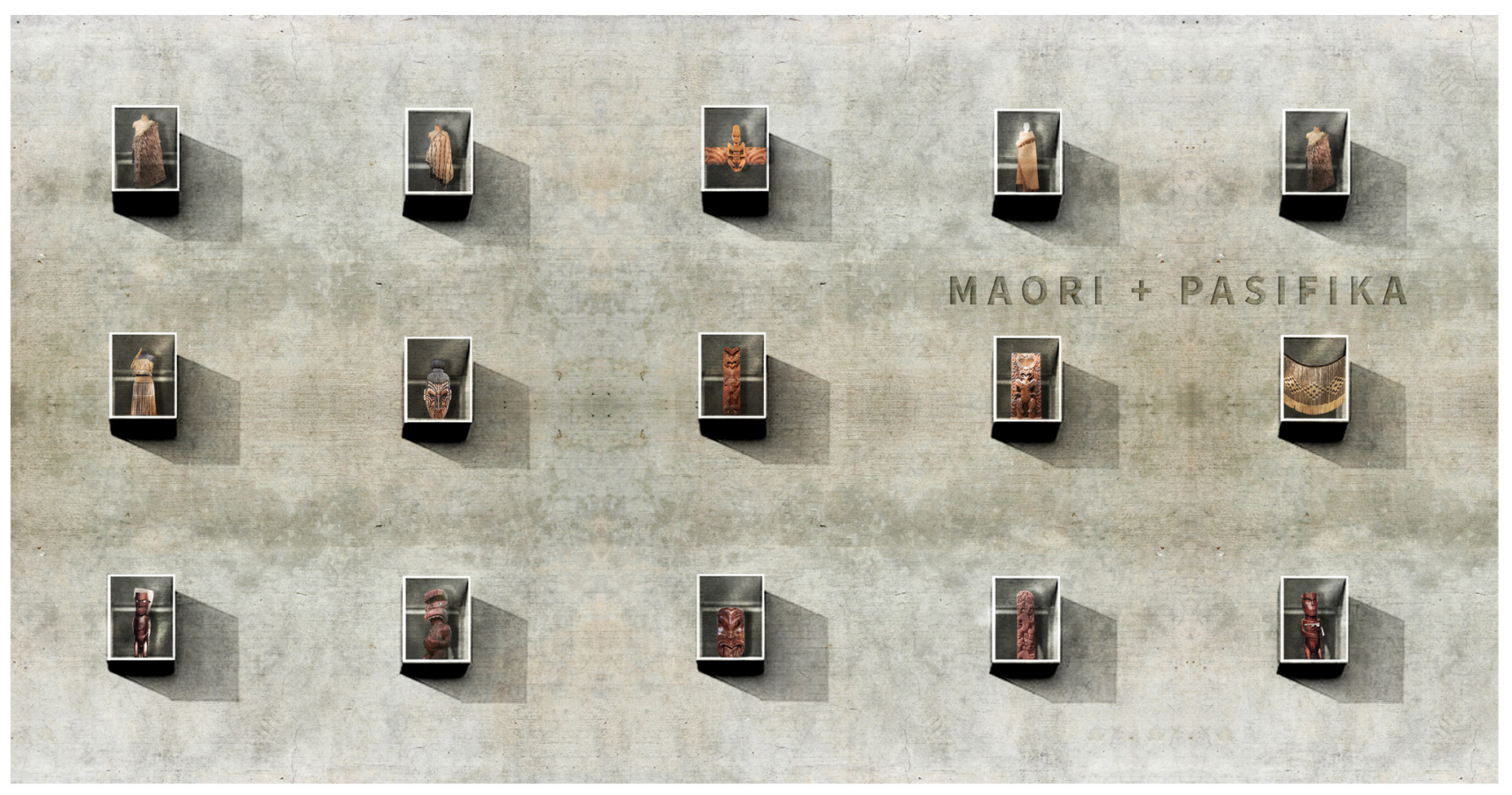

[ Unlike this image facades will likely have a combination of items on display.

This give opportunites for unusual pairings and compositions of archive items ]

To increase the didactic opportunities in the building and develop cultural awareness of the archive collections there needs to be an enhanced level of public engagement. By curating some of the archive collections in the southern facades of the architecture the items can be engaged not only by the people inside the spaces but also by the pedestrians, cyclists, and motor vehicles moving through the site. The way this facade interacts with the public must account for the velocity of the viewers, the manner in which the items are viewed, as well as the nature of the items themselves. 


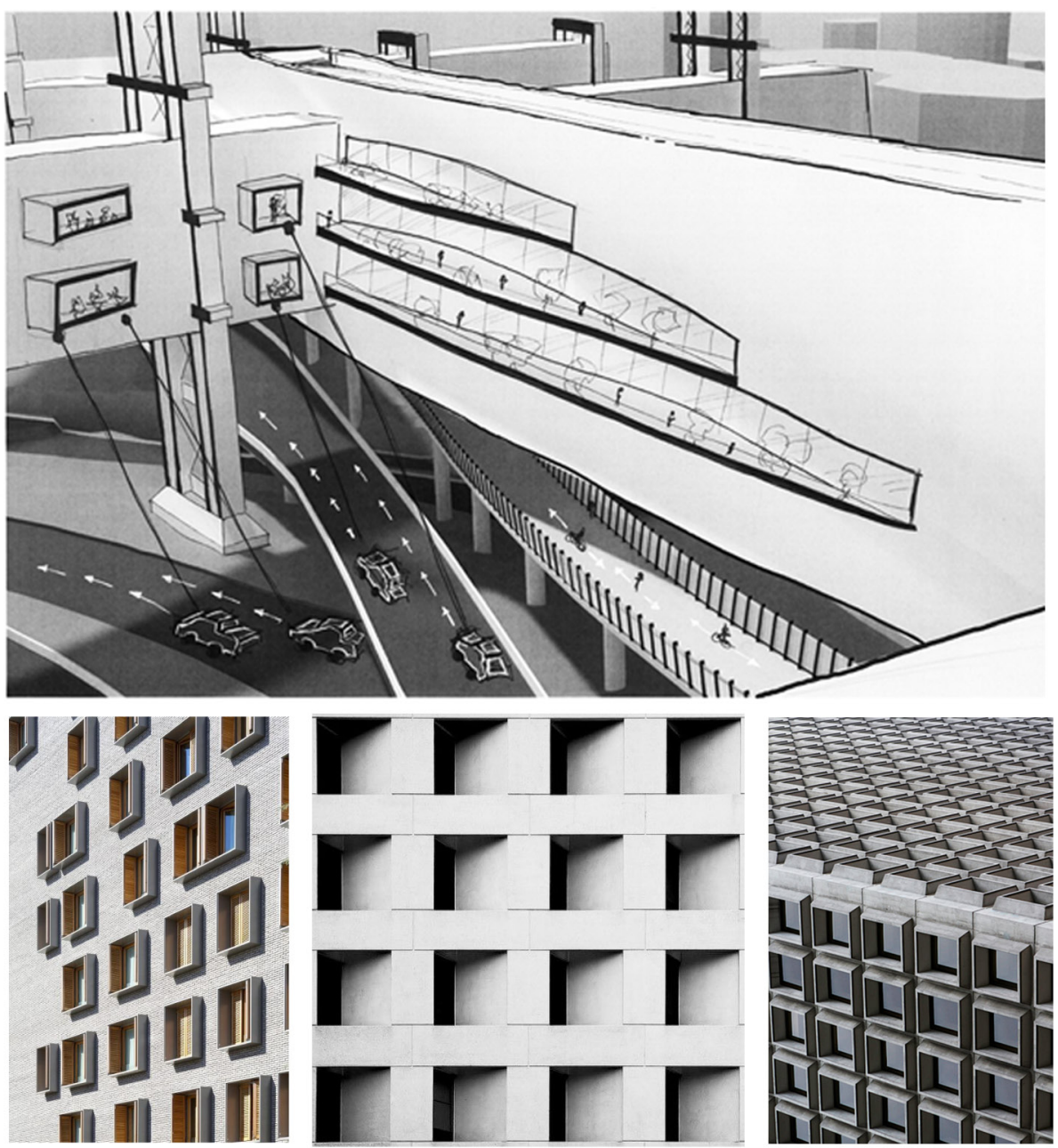

Figure 6.15: Exploring facade typologies that create apertures and framing 
FACADE TREATMENTS

wing elements

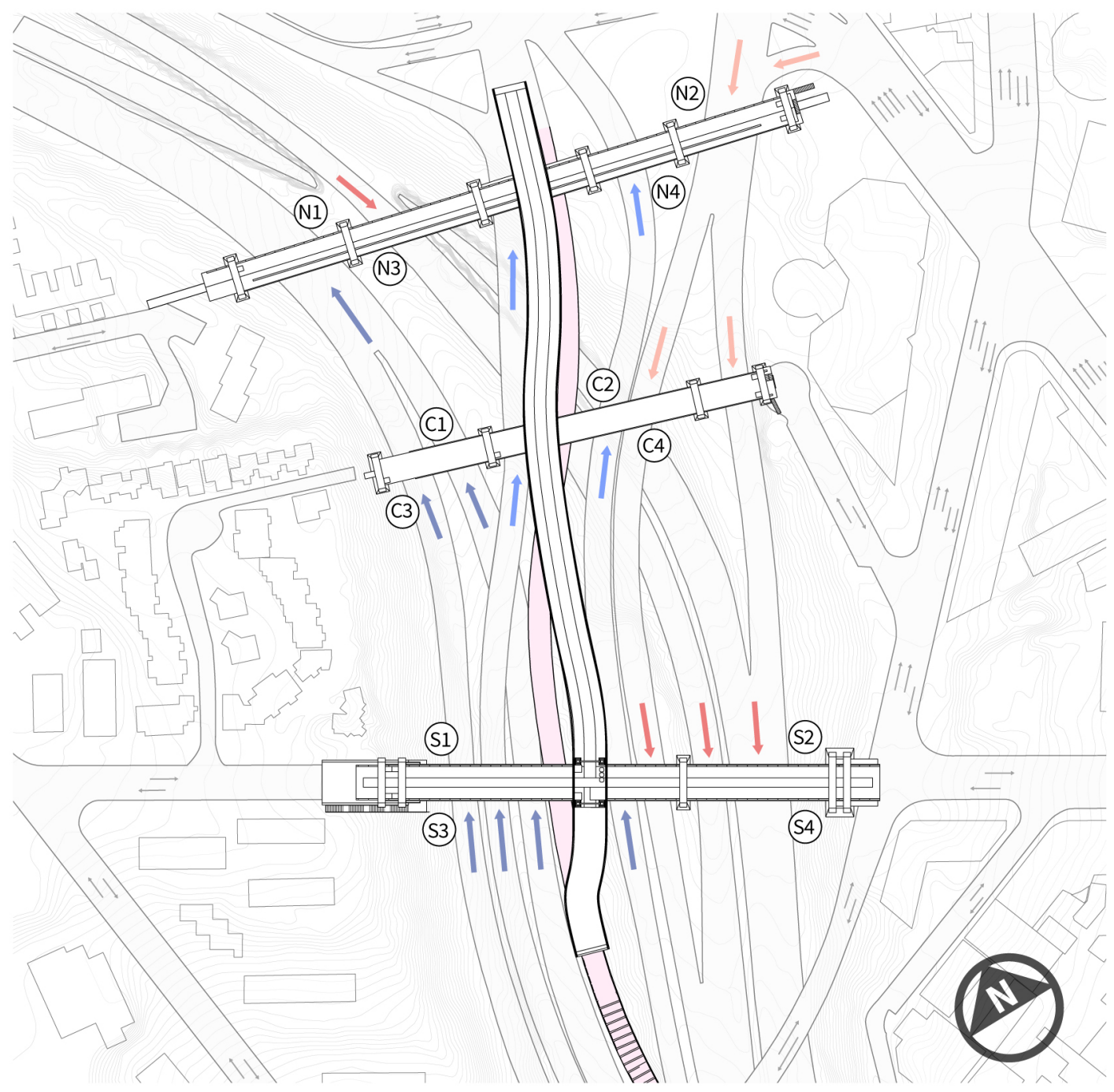

SHADE.

SUNLIGHT

(C4) (C3) (53) (S4) (N3) (N4) (C2) (S2) (51) (C1) (N2) (N1) $\backsim$

BICYCLE / PEDESTRIAN.....

(S4) (S1)

(N1) (N2) (S3) (C3) (C2) (N44)

..VEHICLE

NORTHBOUND TRAFFIC.... SOUTHBOUND TRAFFIC

(53) (C3) (N3) (N4) (54) (C4)

(C1) $($ S1)

(N1) (C2) (N2) (S2)

OUTWARD FACING

INWARD FACING

(N1) (N2) (S3)

(S1) (S2) (N3) (N4) (C1) (C2) (C3) (C4)

SLOW ENGAGEMENT.

(N2) (N4) (C4) (C2)

(N3) (C3)

.FAST ENGAGEMENT

(52) (54) (53) (N1) (C1) (S1)

\footnotetext{
* facade does not face direct traffic
} 
PROGRAMME ELEMENTS

\begin{tabular}{|c|c|c|c|}
\hline ARCHIVES & $\begin{array}{l}\text { MAX LIGHT } \\
\text { LEVEL }\end{array}$ & $\begin{array}{c}\text { ENGAGEMENT } \\
\text { MODE }\end{array}$ & $\begin{array}{c}\text { ENGAGEMENT } \\
\text { SPEED }\end{array}$ \\
\hline Small + Highly Light Sensitive & enclosed & pedestrian & Slow \\
\hline Small + Least Light Sensitive & shaded & pedestrian & Slow \\
\hline Medium + Highly Light Sensitive & enclosed & pedestrian + cycle & slow \\
\hline Medium + Least Light Sensitive & shaded & pedestrian + cycle & Slow \\
\hline Large + Highly Light Sensitive & enclosed & All modes & Fast \\
\hline Large + Least Light Sensitive & shaded & All modes & Fast \\
\hline Not Light Sensitive & sunlight & All modes & \\
\hline \multicolumn{4}{|l|}{ OTHER PROGRAMME } \\
\hline Green space & sunlight & All modes & Fast \\
\hline Lab spaces & shaded & pedestrian & - \\
\hline Administration spaces & sunlight & pedestrian & - \\
\hline Service spaces & sunlight & pedestrian & - \\
\hline
\end{tabular}

\section{FACADE TYPOLOGY FOR STORAGE}

Small + Highly Light Sensitive Enclosed north facing. Outside engagment minimal.

(C1) (S1)
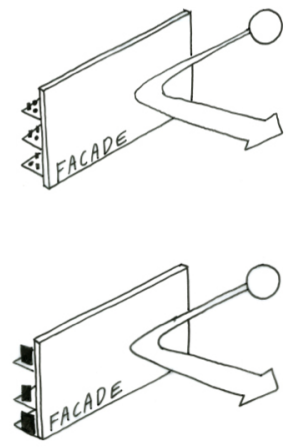

Outside engagement minimal.

(C1) (S1)

Large + Highly Light Sensitive Enclosed north facing.

Outside engagement minimal.

(C1) (S1)

\section{Not Light Sensitive}

North facing open or

transparent facade.

(52) (N1) (N2)

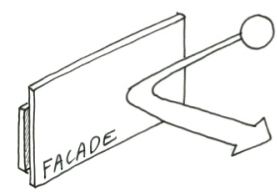

Small + Least Light Sensitive

shaded south facing.

Pedestrian engagement.

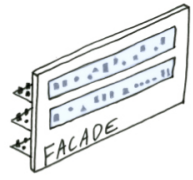

จ

Med + Least Light Sensitive

shaded south facing.

Low speed engagement.

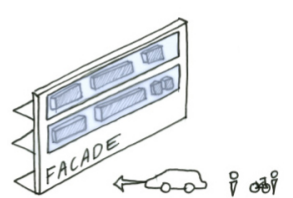

(54) (N4) (C)

Large + Least Light Sensitive

south facing shaded.

High speed motorvehicle engagement.

(S3) (N3)

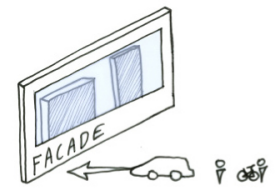

Green space North facing open facade.

Lab spaces North facing enclosed or south facing shaded.

Admin spaces North facing transparent/ south facing shaded.

Service spaces North facing transparent/ south facing shaded.

Figure 6.16 (opposite): Site, programme, and environmental conditions that affect the nature of the facades.

Figure 6.17 (above): Categorising the typology of the facades so the items stored in them have the best opportunity to be engaged in the appropriate manner on site. 


\section{POTENTIAL FACADE TYPOLOGIES}

[ For medium sized archives with low light sensitivity (N4) (C3) (C4) (S4) ]

(54) (N4) (C3) (C4)

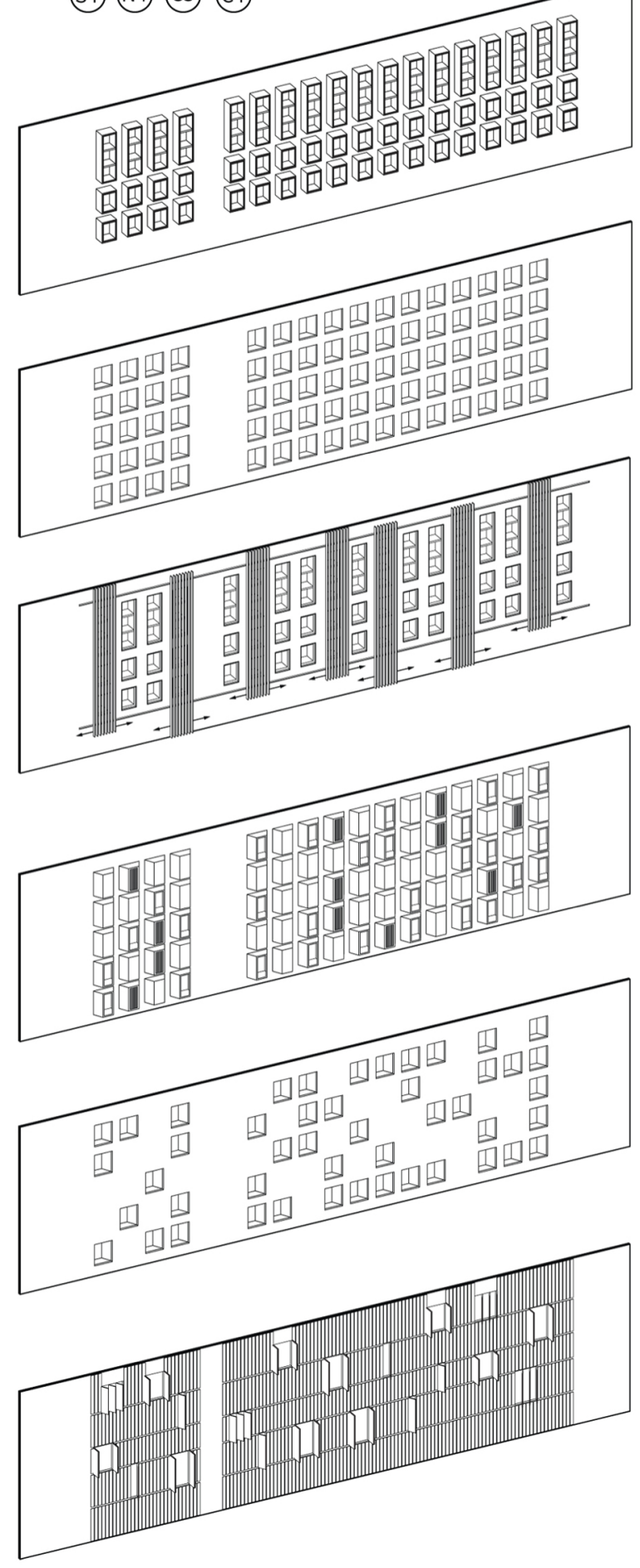

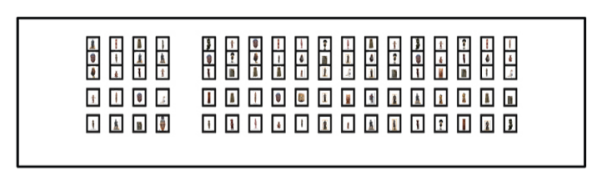

boxed + protruding

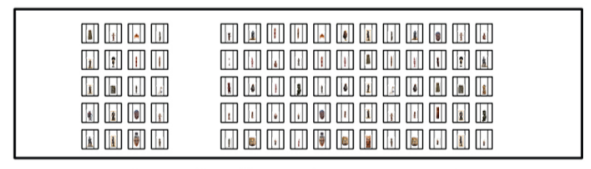

beveled boxed + recessed

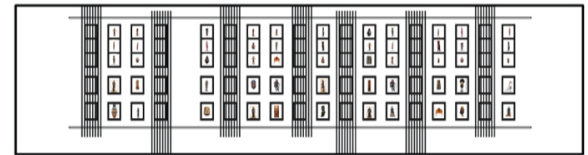

boxed + recessed + screened

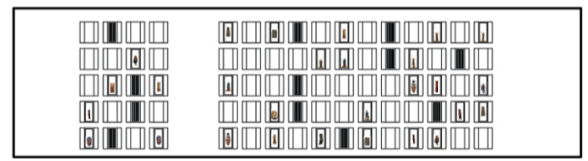

beveled boxed + protruding

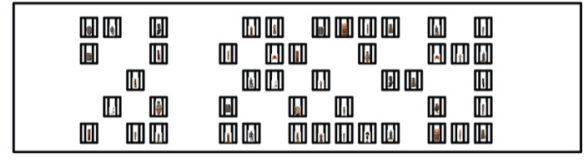

beveled boxed + recessed + irregular

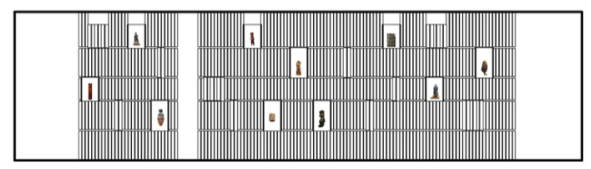

opening + irregular

Figure 6.18 (above spread): Investigating facades that could 'frame' or 'curate' the archive items to the exterior environment. 


\section{POTENTIAL FACADE TYPOLOGIES}

[ For large sized archives with low light sensitivity (N3) (S3) ]

(53) (N3)
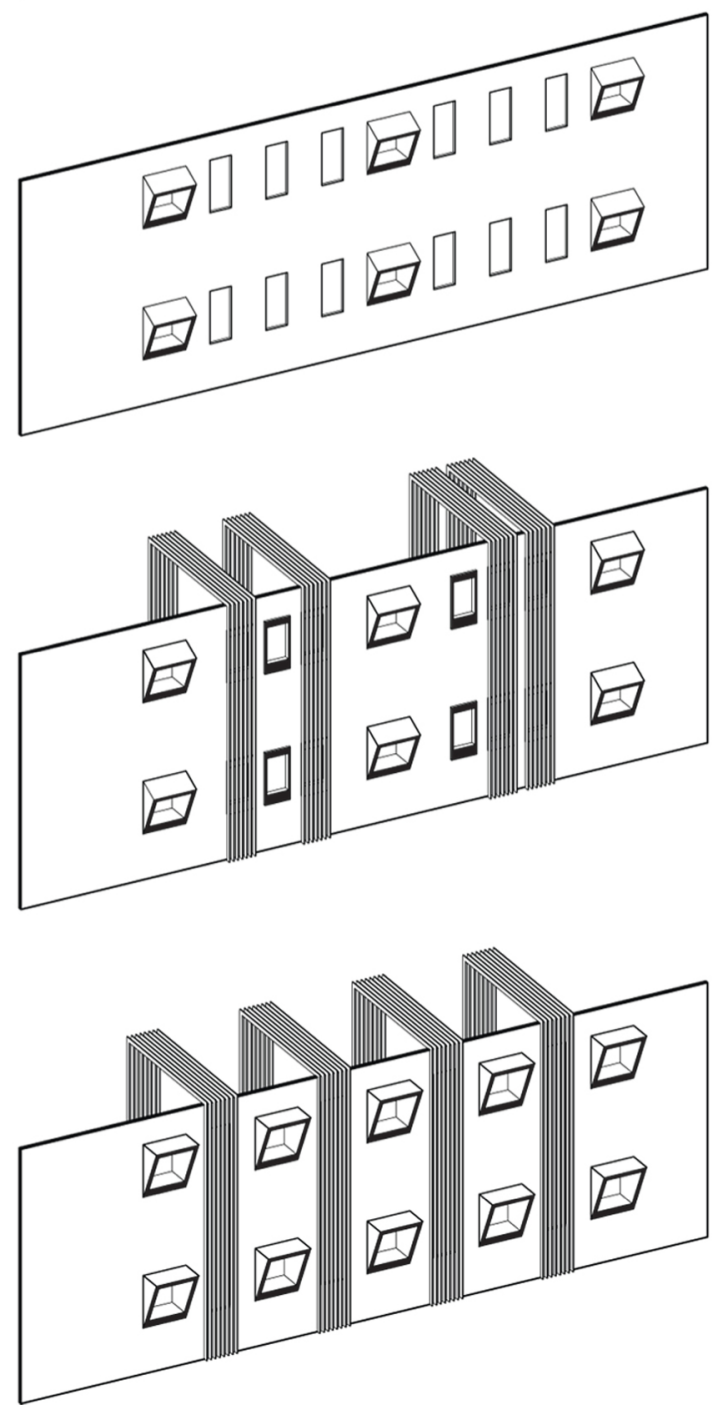

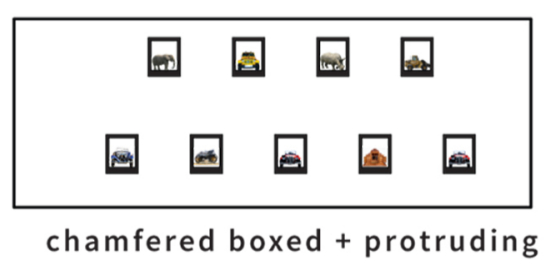

国田田国田田国 国田田国目田国

chamfered boxed + opening

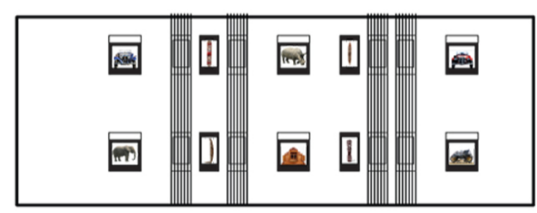

chamfered boxed + opening + screens

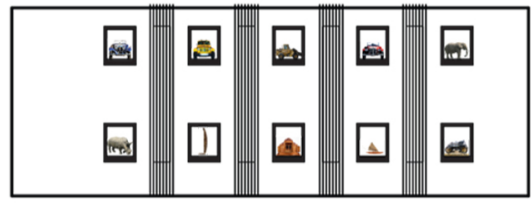

chamfered boxed + screens 


\section{SOUTHERN FACADE SKETCH EXPERIMENTS}

maiximising curation opportunities of the archives in the public scope
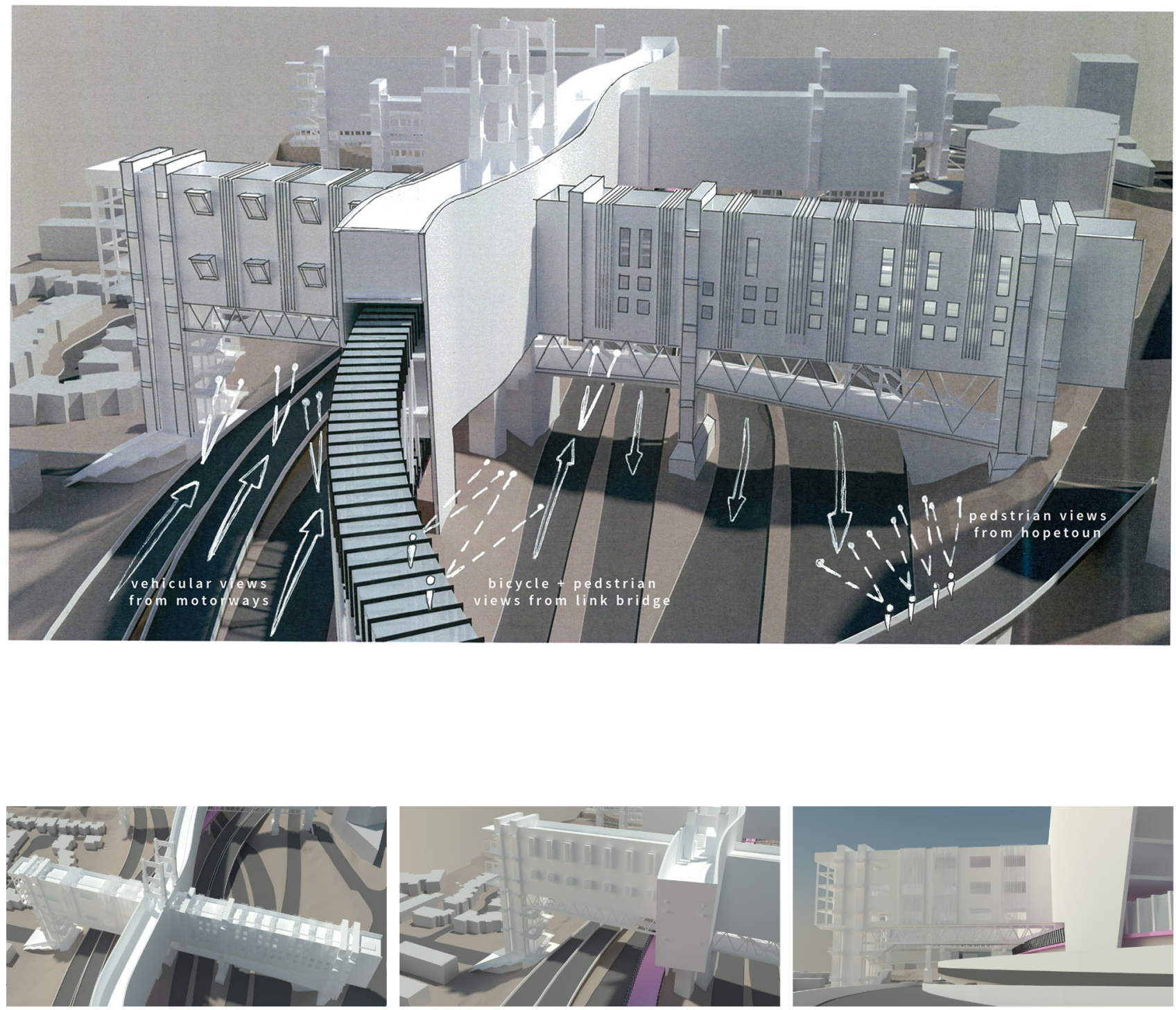

The velocity of the users and the position from which they engage the wing facades changes at different points in the CMJ. The facade design and objects curated in them must change accordingly. Areas in the design where motor vehicles move past at rapid velocities require larger apertures and larger items on display. Elements of the design that engage the slower pedestrian movement can have smaller displays of more intimate items. 

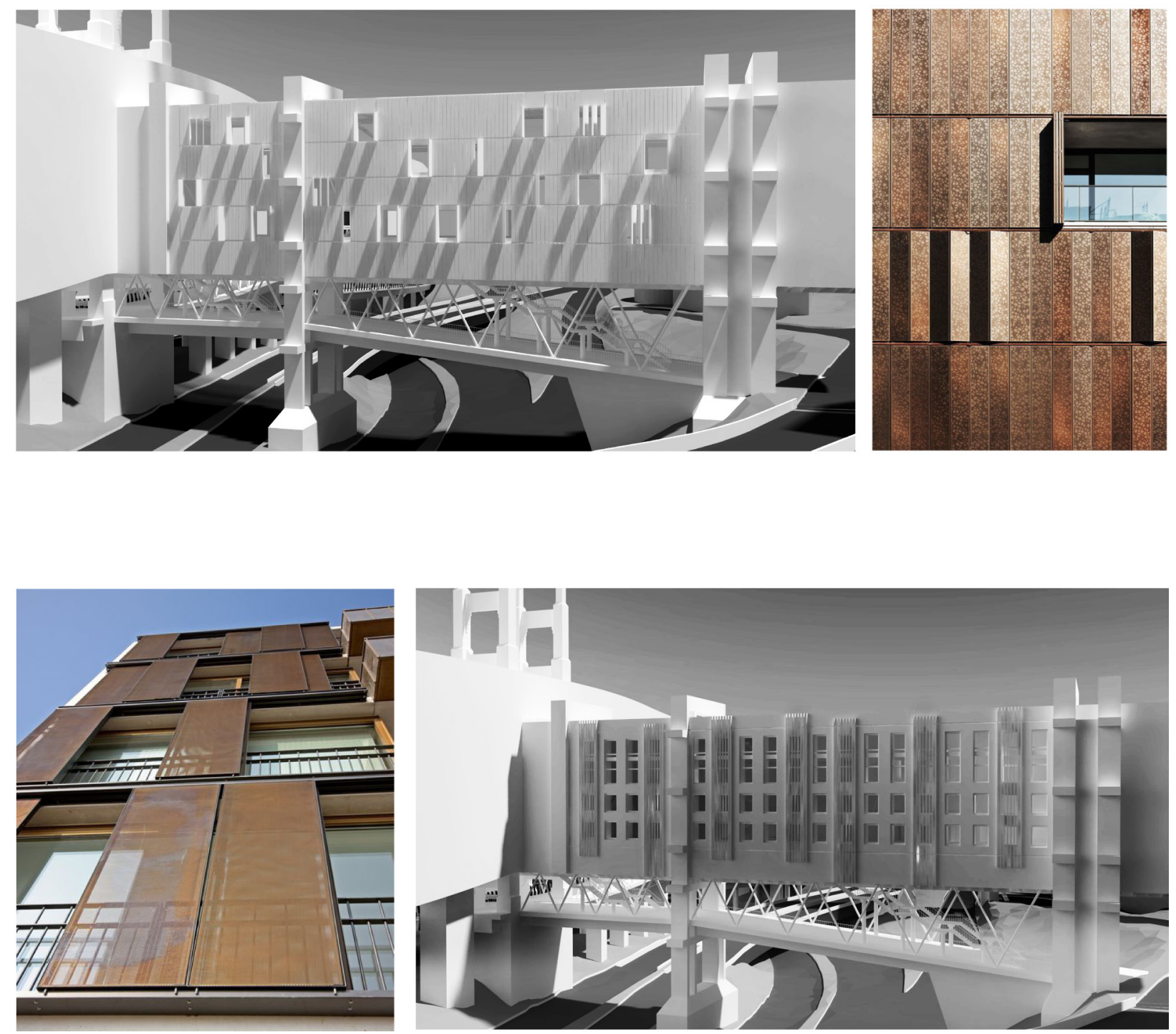

Moveable elements would allow for an enhanced level of curation in the facades. Certain archives could be displayed at different times and in different combinations to the public. By having the exterior elements moveable it allows these different combinations of collections to be curated without having to physically move the fragile collections themselves. 

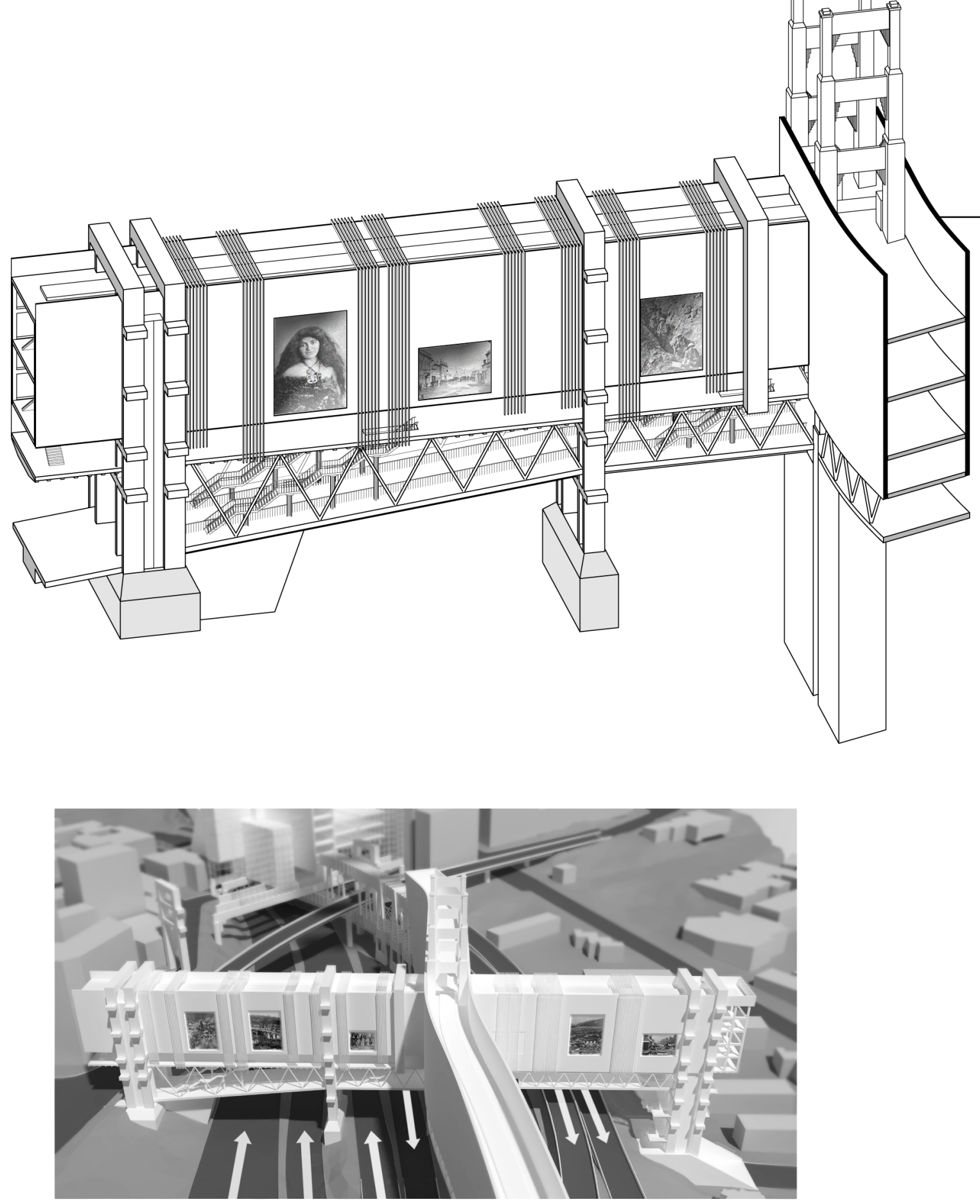

Figure 6.20 (above spread): Sunlight issues on the northern facades make them unsuitable for the storage of physical archives. To engage with these northern facades the displayed 'archives' need to be non-light sensitive. It is on these north facing facades where the film archive and seed bank will be situated. 


\section{[digital display ]}

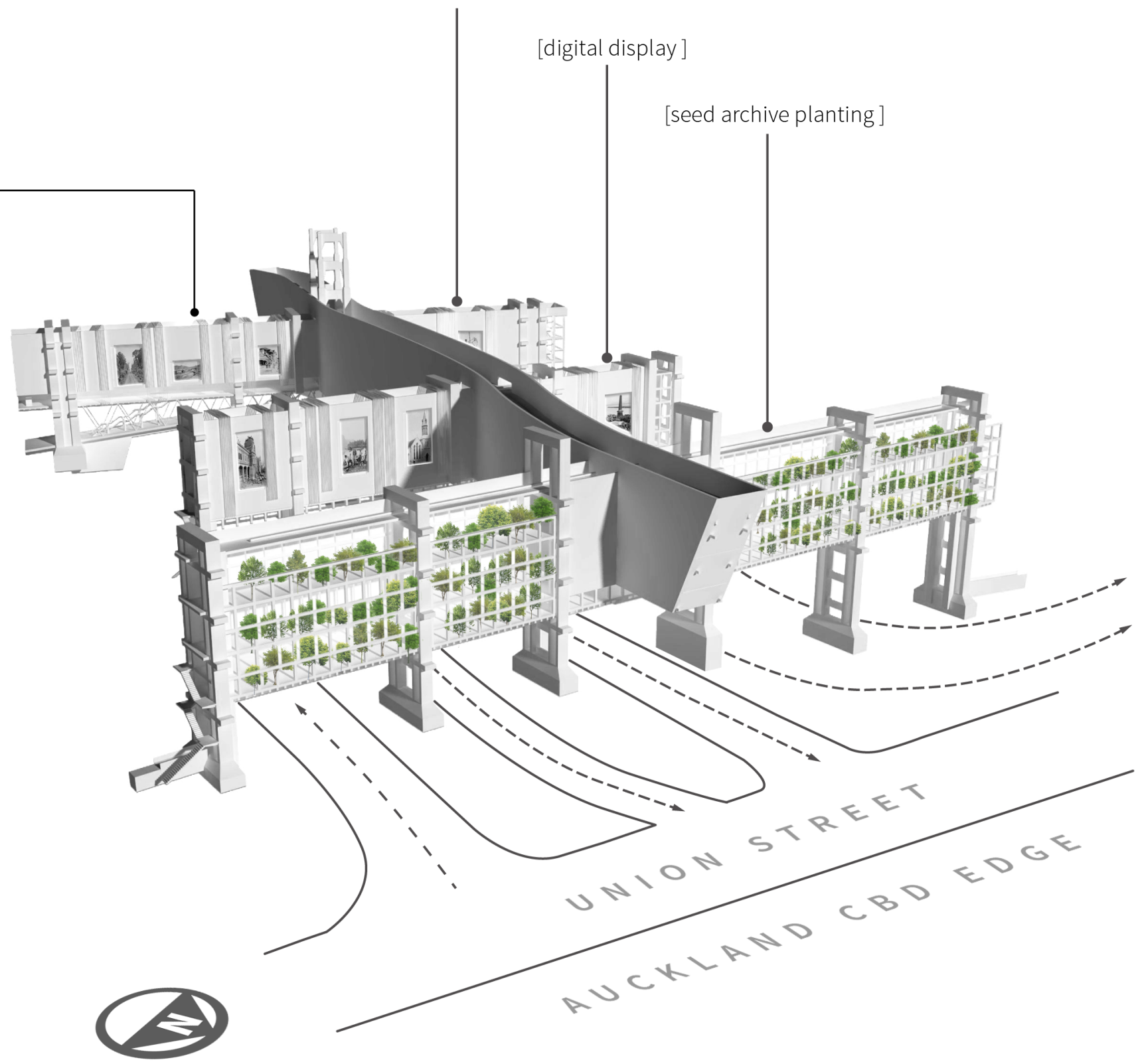

The northernmost wing of the architecture sits right up to the edge of the CBD and receives the most sunlight of all the wing facades. This logically leads to this wing being the seed archive space. Inclusion of a vertical park can offer space to test the viability of the seeds in storage, is a suitable programme to maximise the available sunlight, and creates a softer edge between the architecture and the edge of the central city. 


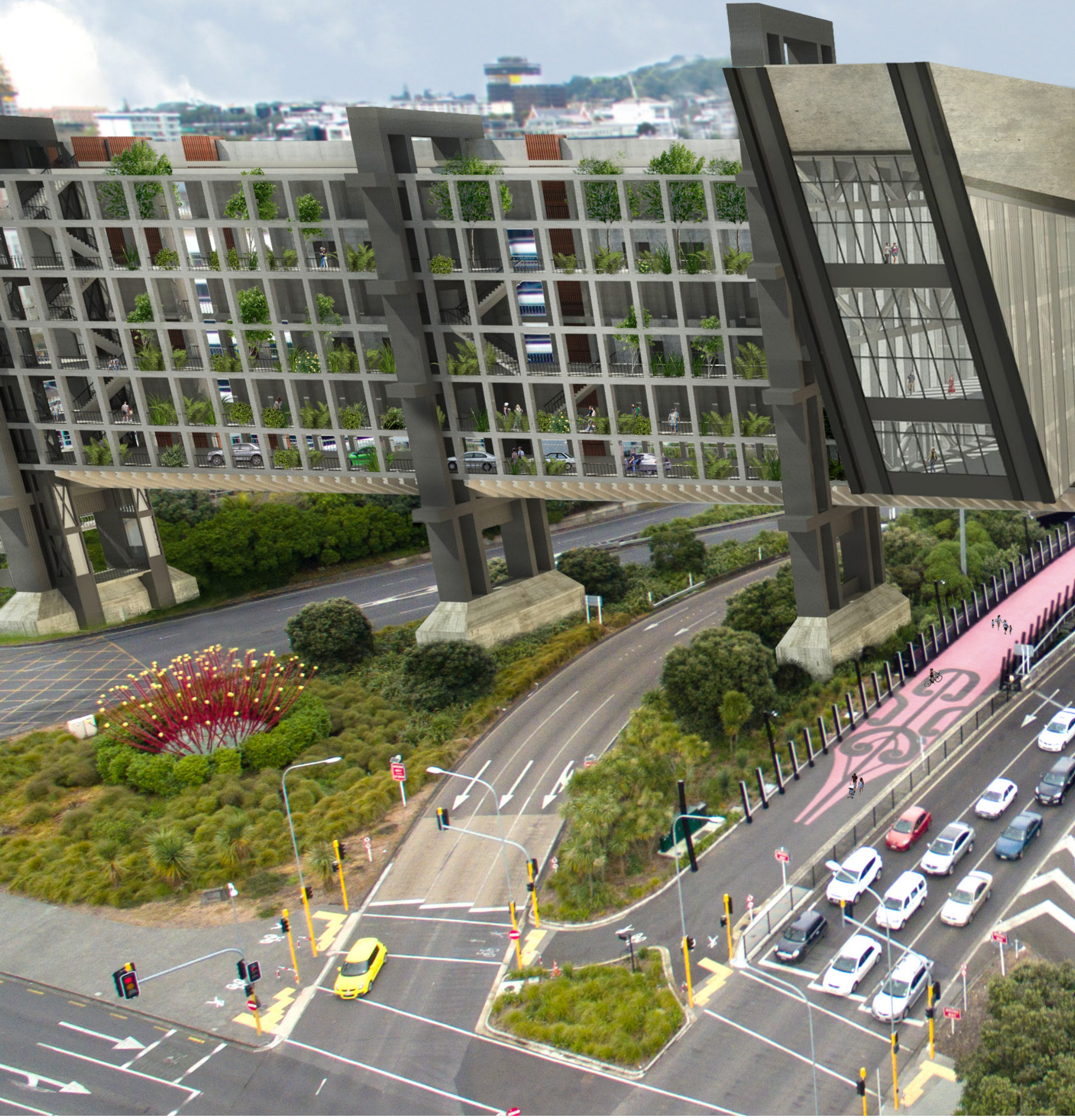

Figure 6.21: The northern most wing becomes a green pedestrian link across the CMJ site. 


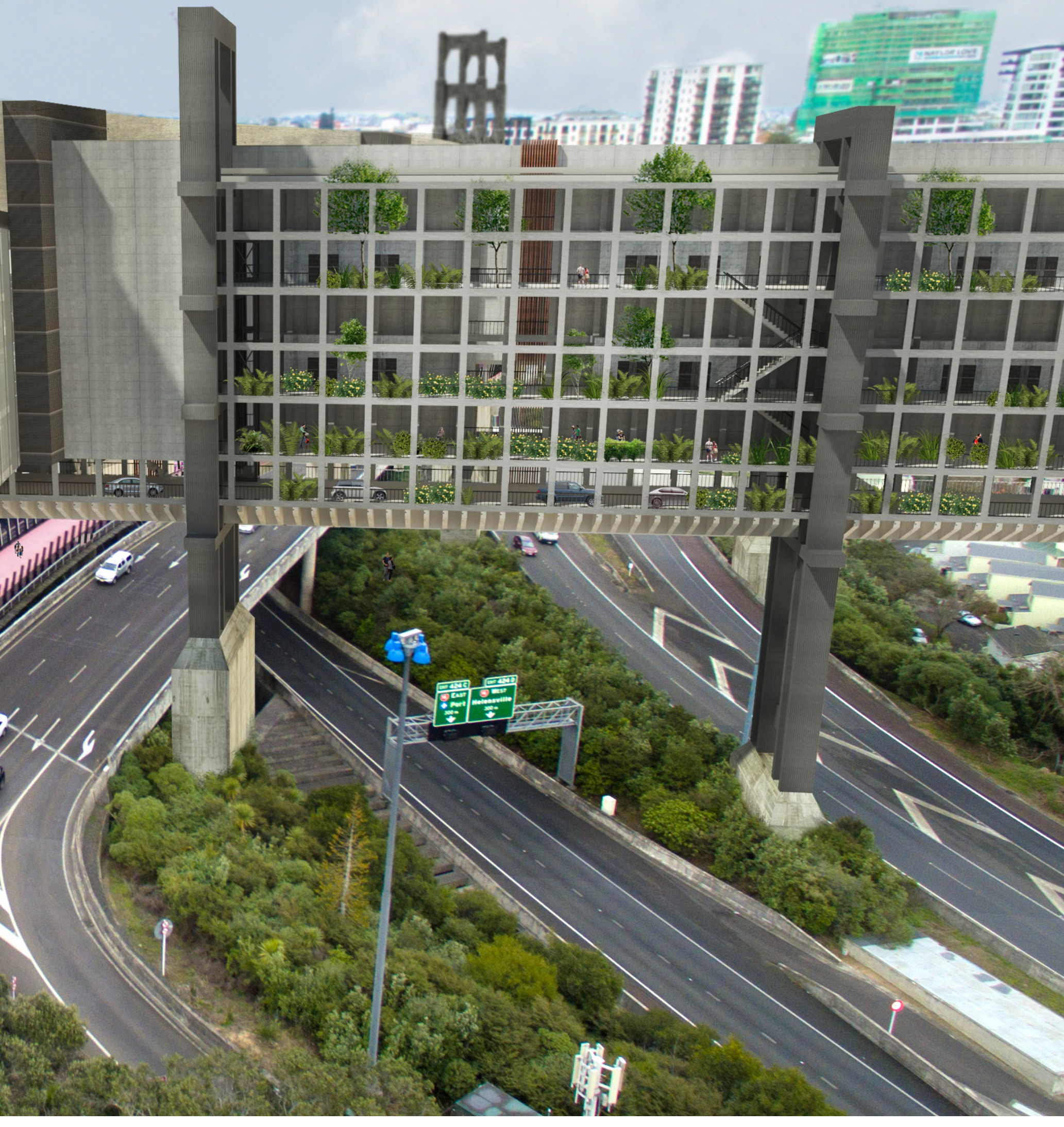




\section{SPINE FACADE SKETCHING}

developing the spine facade as a contributor to the fluid motorway typology
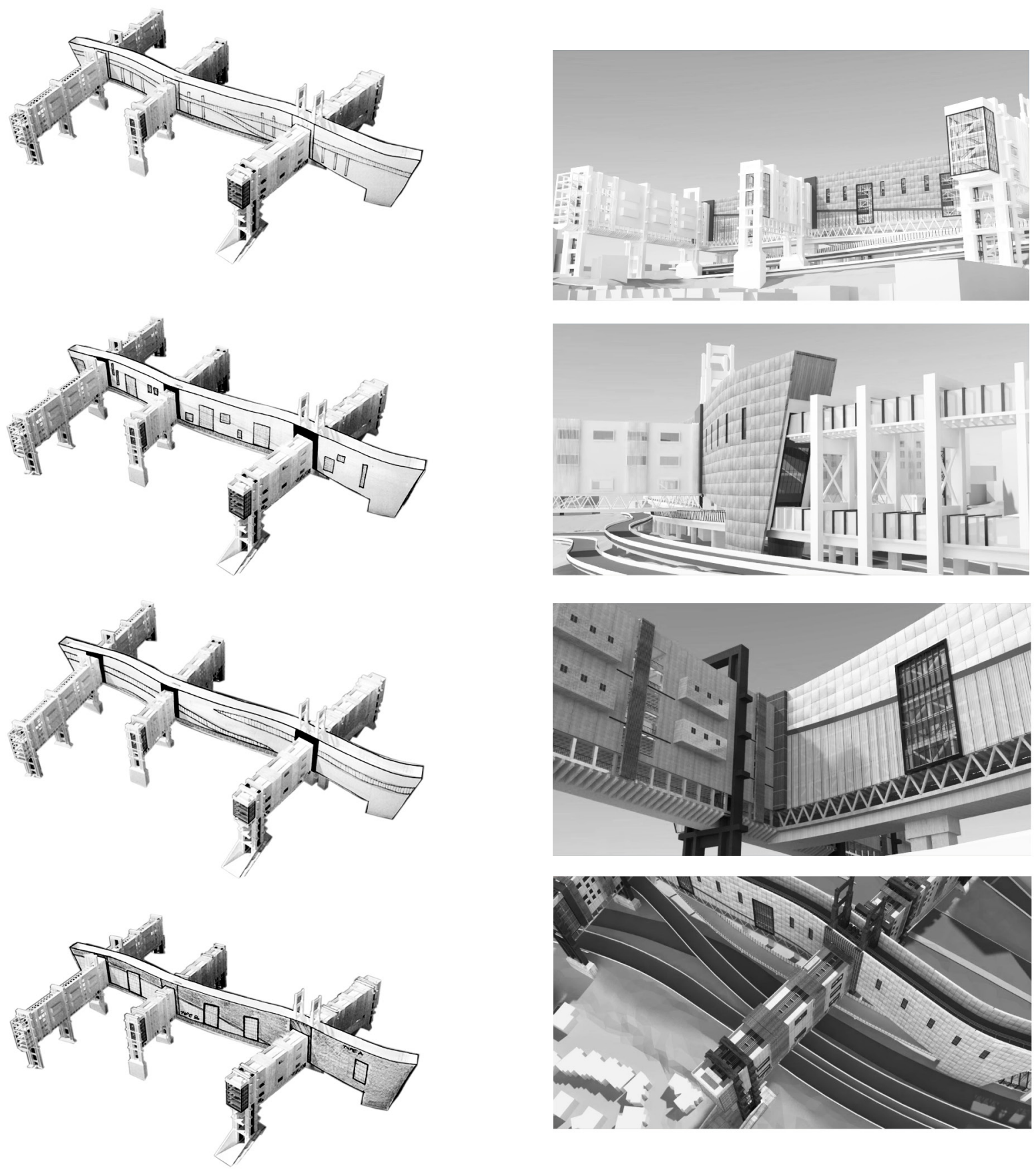


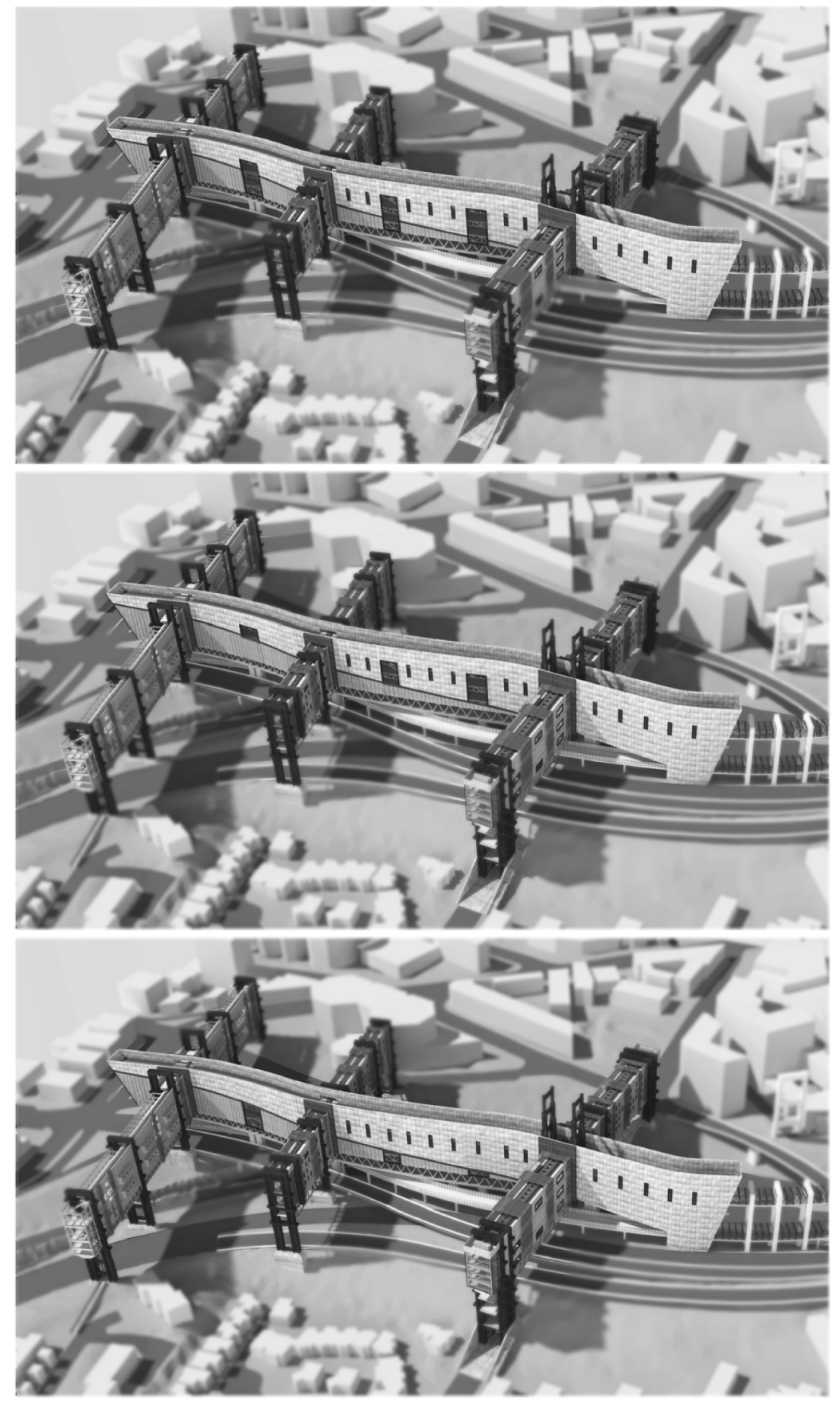

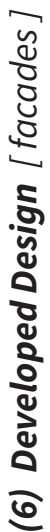




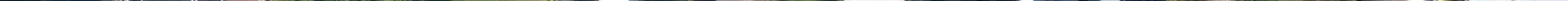




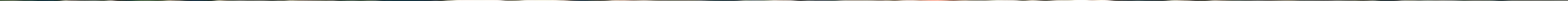




\section{vehicles}

[1] Service entry level through motorway berm to loading dock

[2] Pedestrian entry off Beresford Street Central (elevators + stairs).

[3] Parking space for bicycles and motorcycles.

[4] Pedestrian + bicyclist entry off Nelson Street Cycleway (stairs).

[5] Pedestrian access off Nelson Street Cycleway (elevators).

[6] Freight elevator from loading dock to top floor.

[7] Main entry off Hopetoun Street/ Beresford Square for vehicles + pedestrians + bicyclists (stairs + elevators).

[8] Parking spaces along length of spine building.

[9] Pedestrian entry off St James Street (elevators + stairs).

Covered walkway to Karangahape Road building.

[10] Pedestrian entry off Hayden Street (elevator).

[11] Entry to Nelson Street Cycleway off Union Street.

[12] Parking spaces in wing on south side with planter boxes on north side.

[13] Pedestrian entry at Pitt Street / Hobson Street (stairs + elevators). 
pedestrian
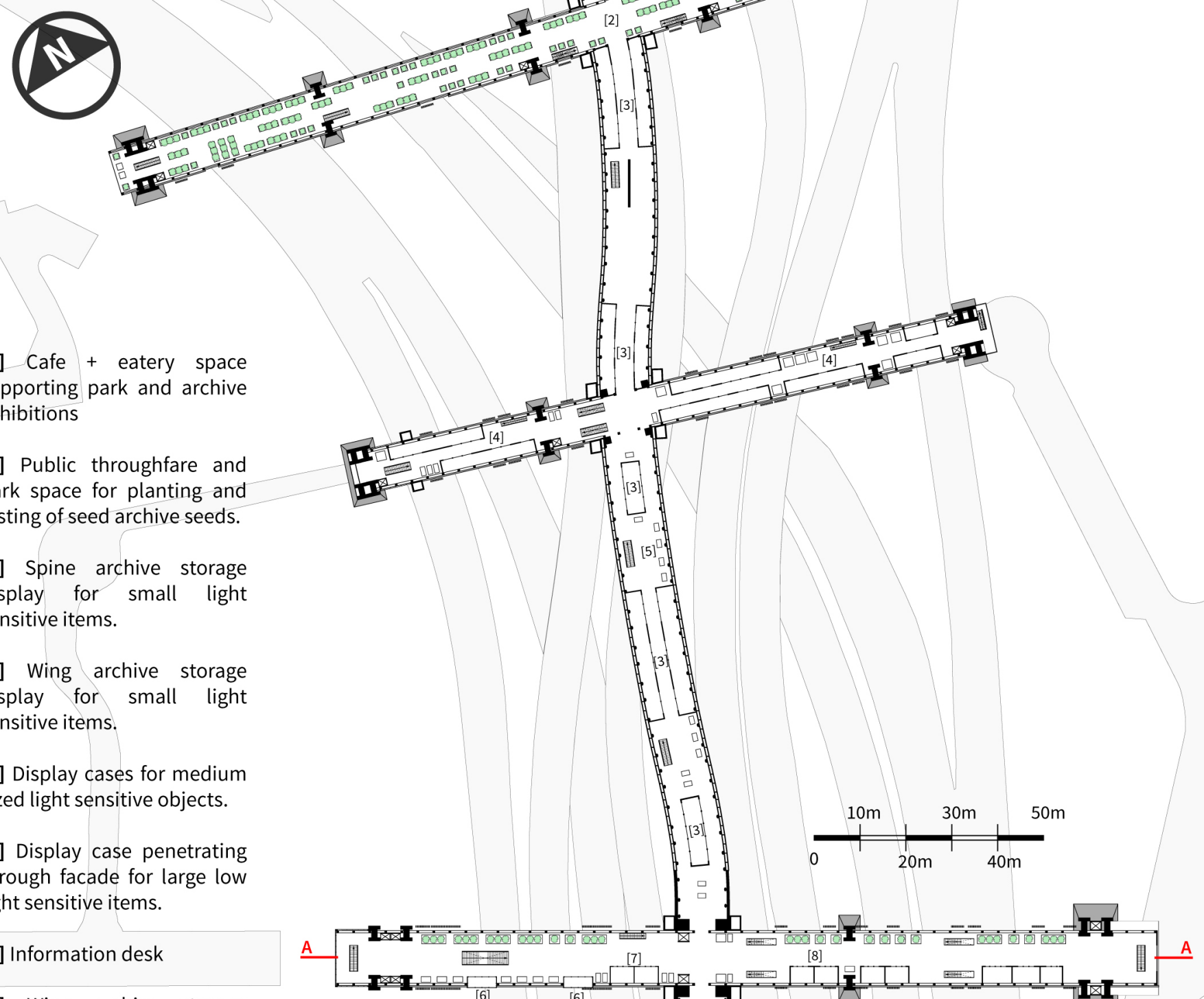

[1] Cafe + eatery space supporting park and archive exhibitions

[2] Public throughfare and park space for planting and testing of seed archive seeds.

[3] Spine archive storage display for small light sensitive items.

[4] Wing archive storage display for small light sensitive items.

[5] Display cases for medium sized light sensitive objects.

[6] Display case penetrating through facade for large low light sensitive items.

[7] Information desk

[8] Wing archive storage display for small light sensitive items.

[9] Freight elevator.

[10] Office + administration space.

*all spaces on this level apart from the office + admin space are accessible to the public. 


\section{4}
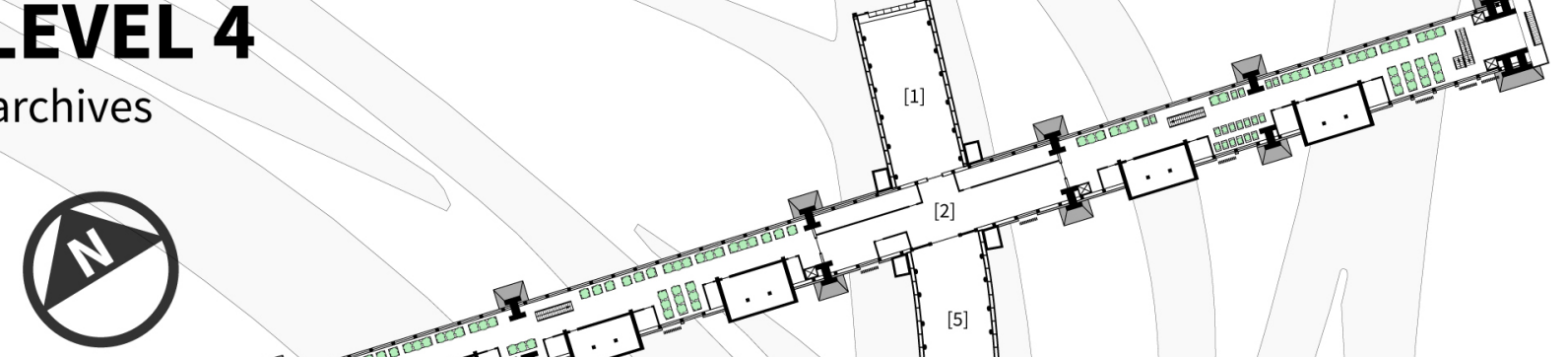

[1] Seed archive lab spaces.

[2] Seed archive support spaces

[3] Public throughfare of seed archive planting spaces.

[4] Seed bank for frozen seed storage + adjacent work stations.

[5] Admin + support spaces for archives.

[6] Storage for sensitive archive items.

[7] Elevated mezzanine for public access + viewing through archive space.

[8] Sensitive archives stored on northern side of archive wing.

[9] Display cases penetrating through facade for medium sized, low light sensitive items.

[10] Offices + work stations.

[11] Archive support spaces.

[12] Elevated mezzanine for public access + viewing through archive space.

[13] Digital archive screen on north facade.

[14] Display cases penetrating through facade for large, low light sensitive items.

[15] Freight elevator.

[16] Workshop + archive support spaces.

[17] Elevated sky bridge to karangahape road building

* all wing elements have public access elements across their length.
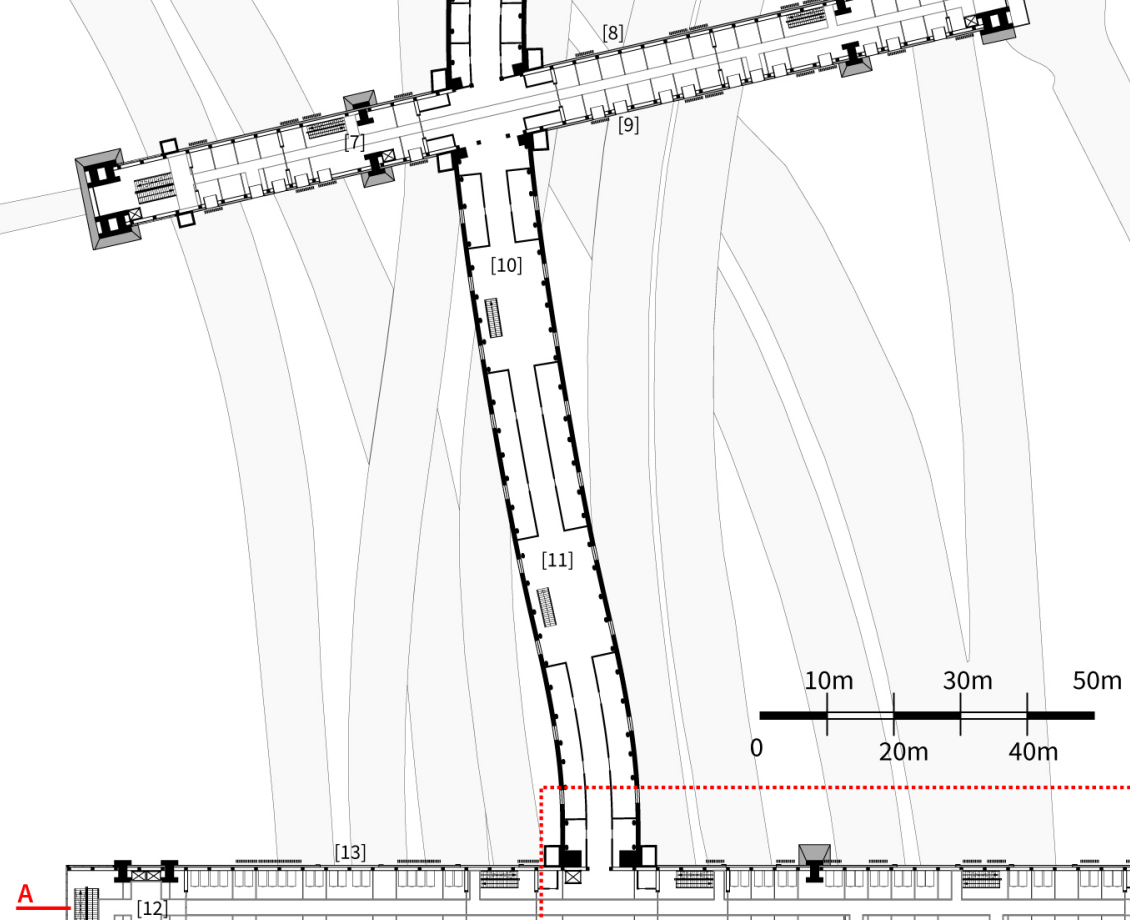


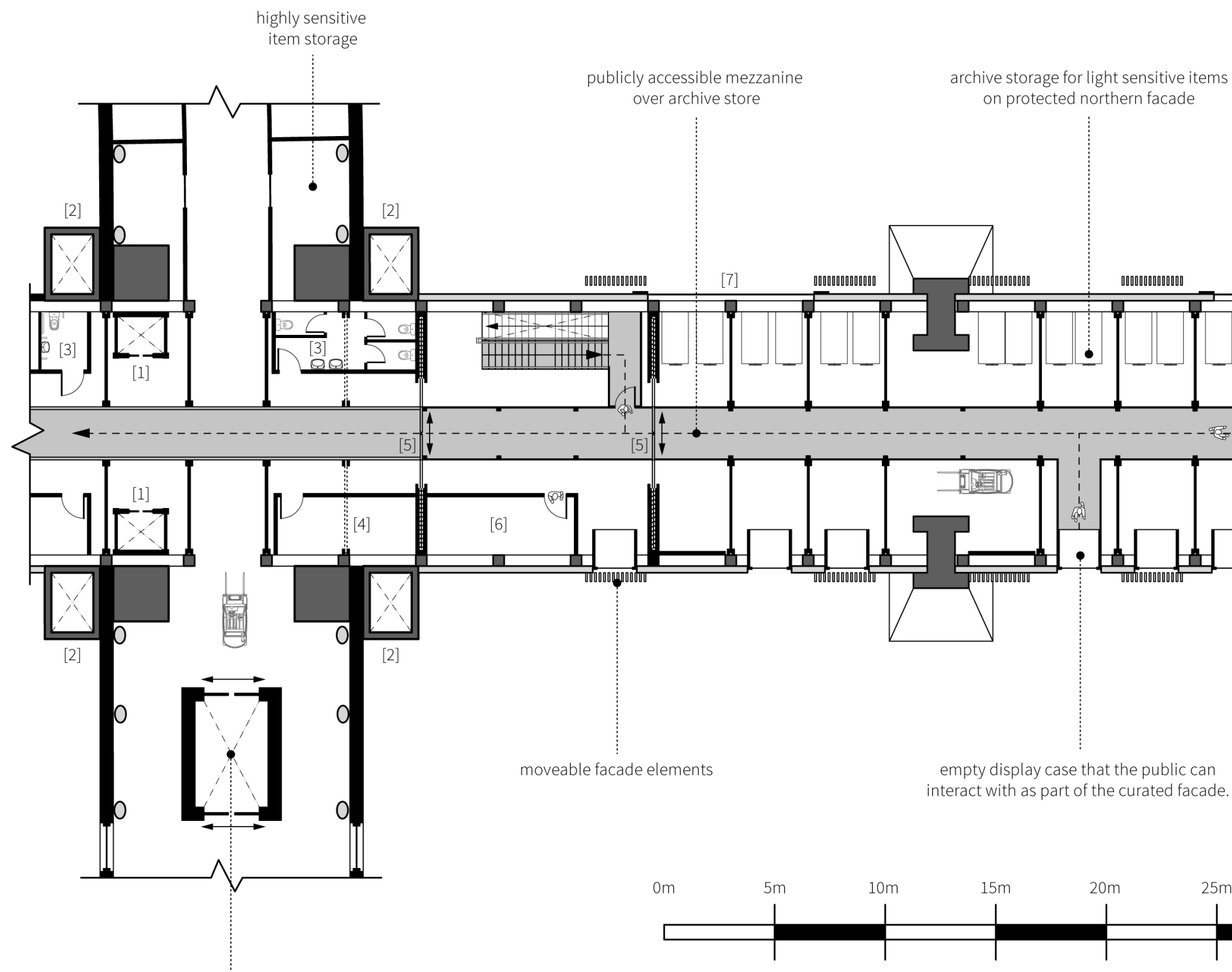

freight elevator

[1] elevator access

[2] service core
[3] restrooms

[4] administration areas 


\section{SOUTH WING PLAN}

level 4 archives
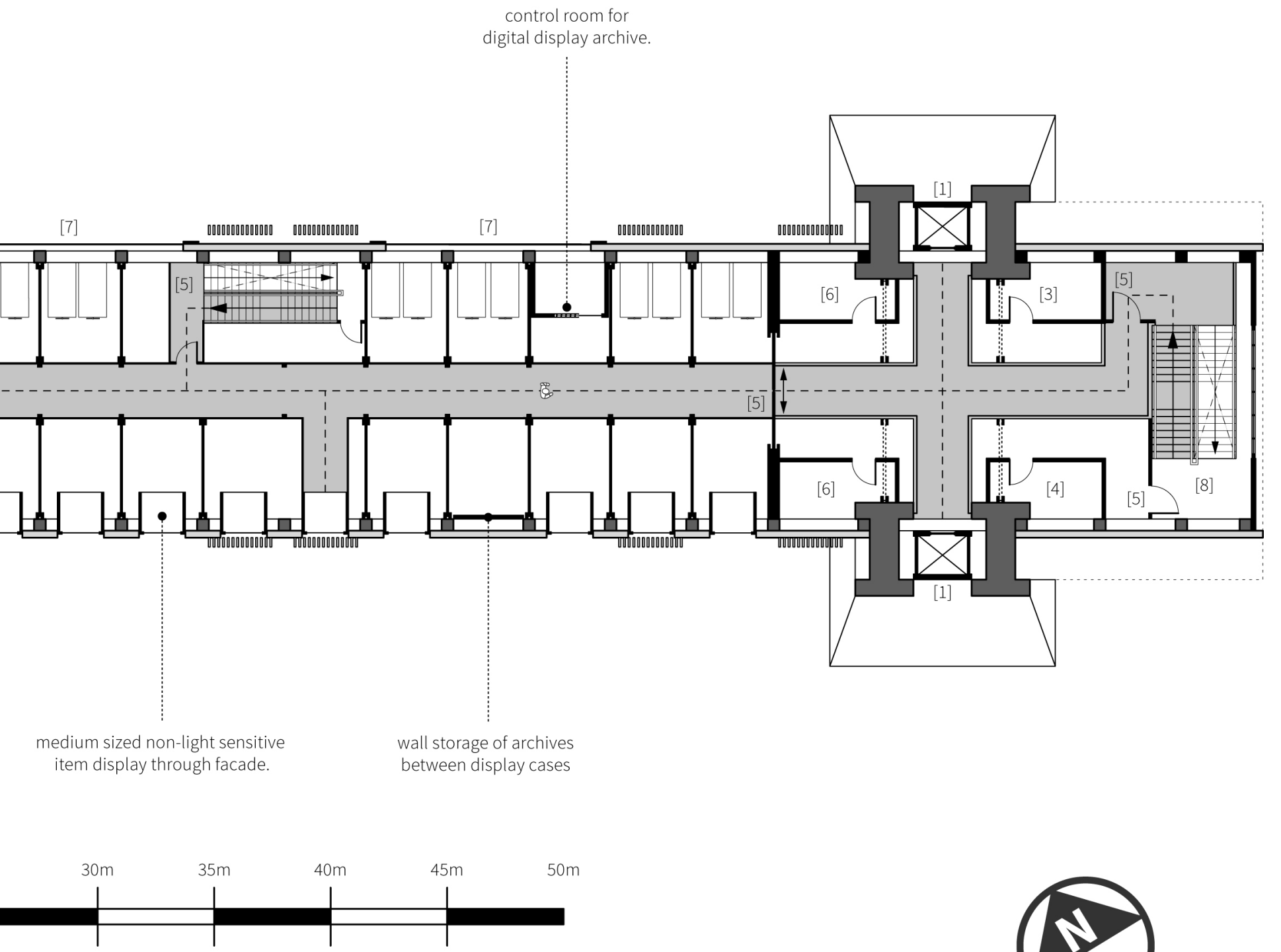

[5] airlock and fire rated door

[7] Film archive display screen

[6] workspace / labspace

[8] Fire Exit stairwell

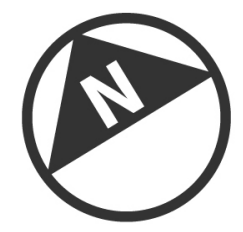



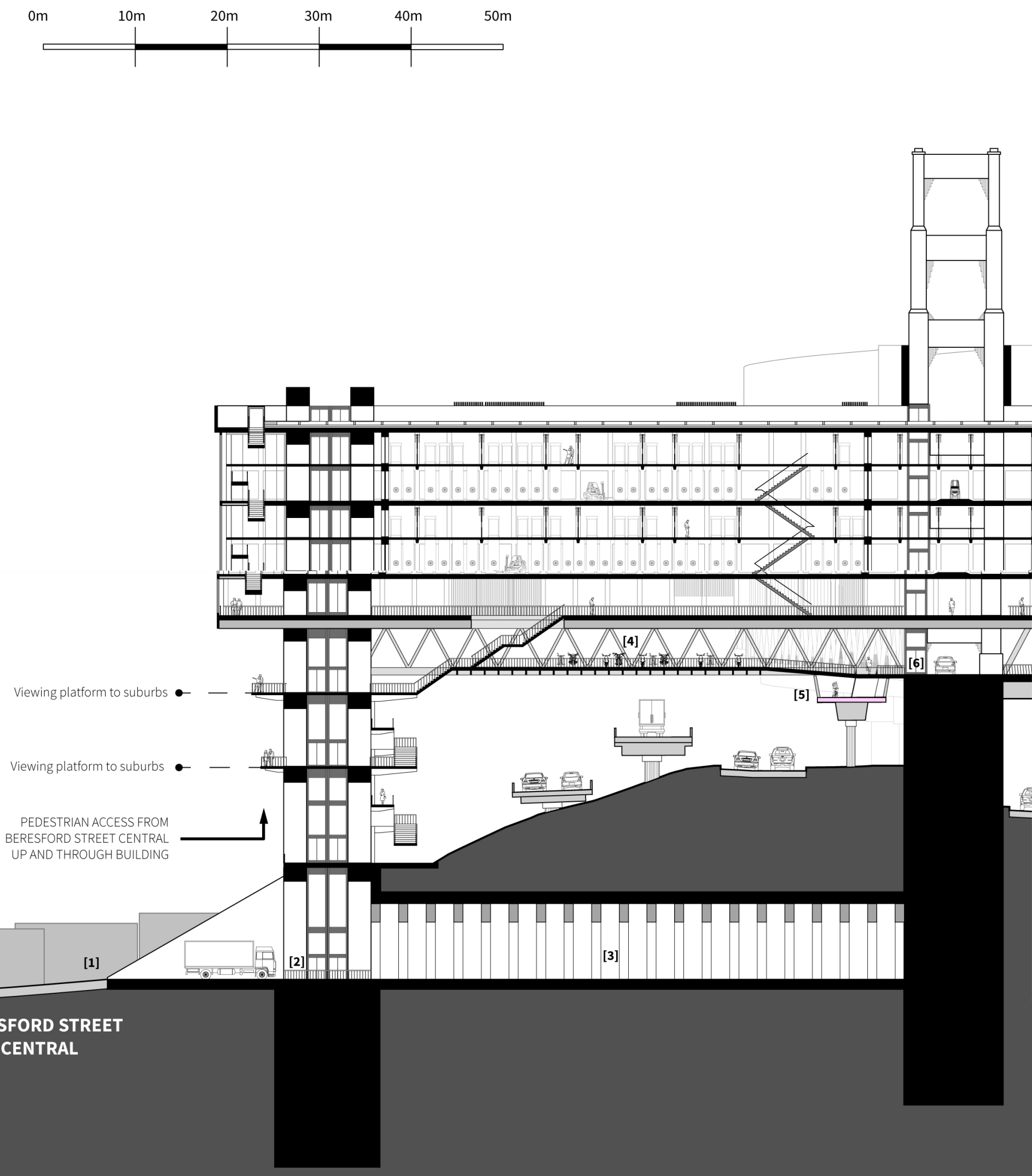


\section{SECTION AA}

through south wing

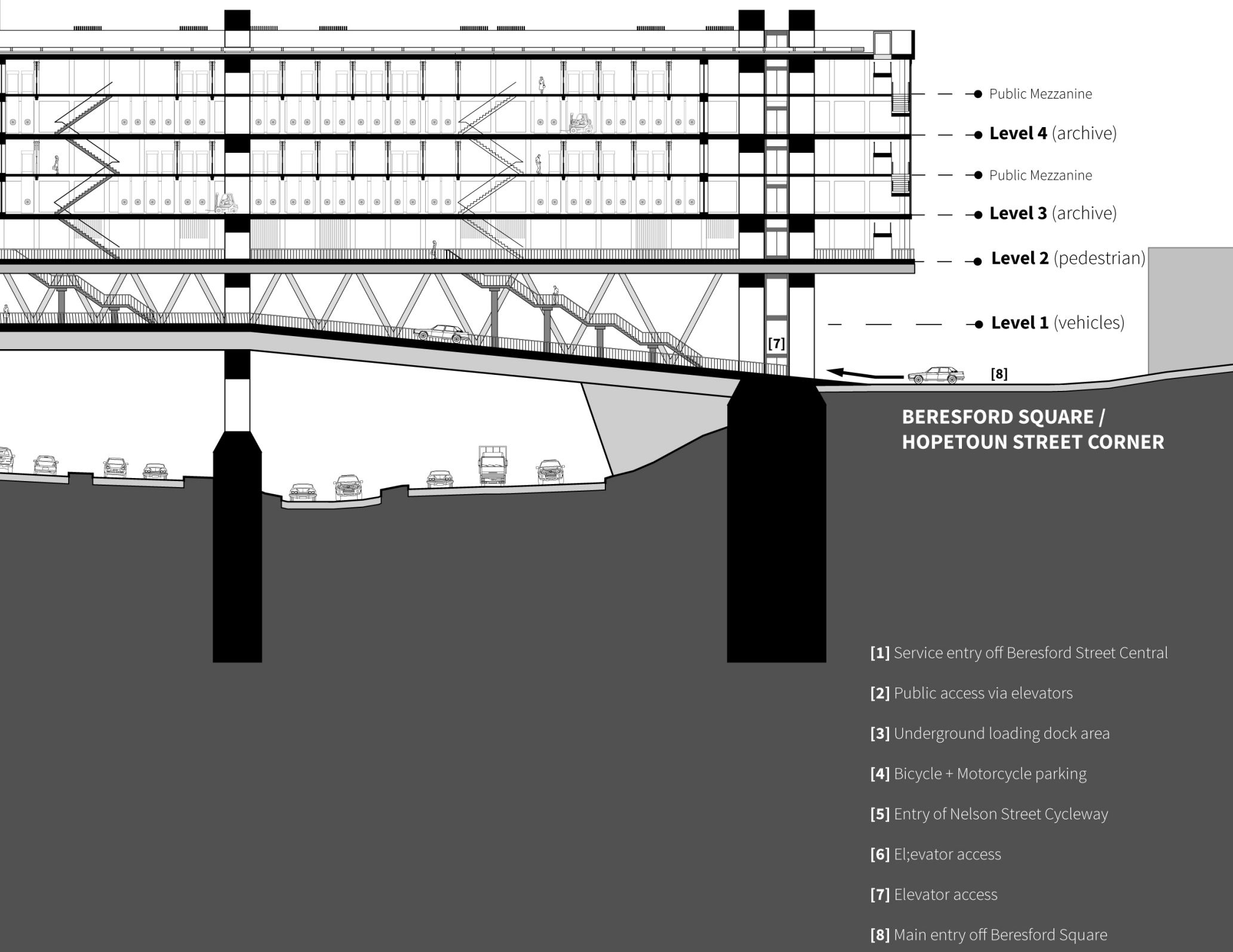




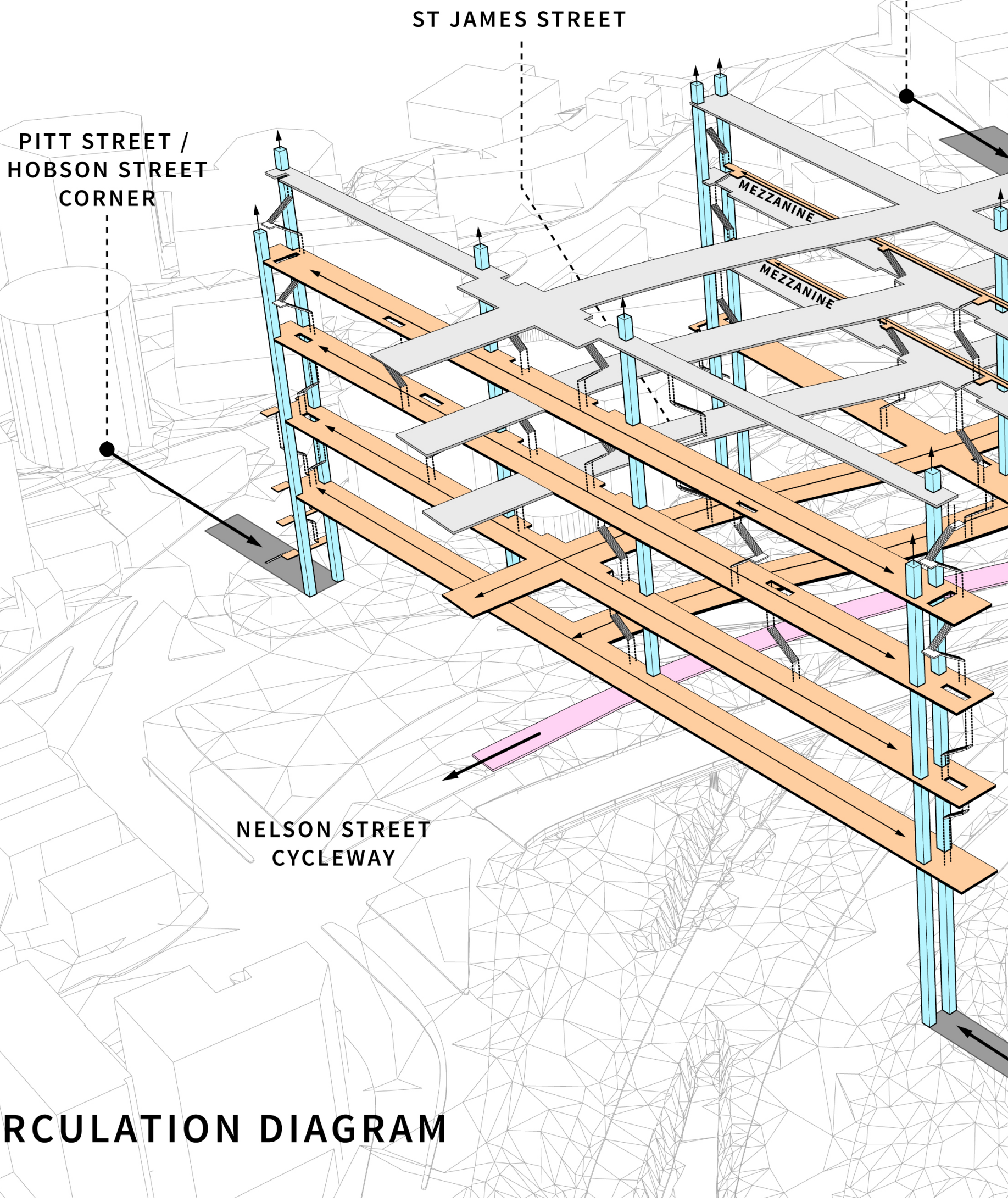




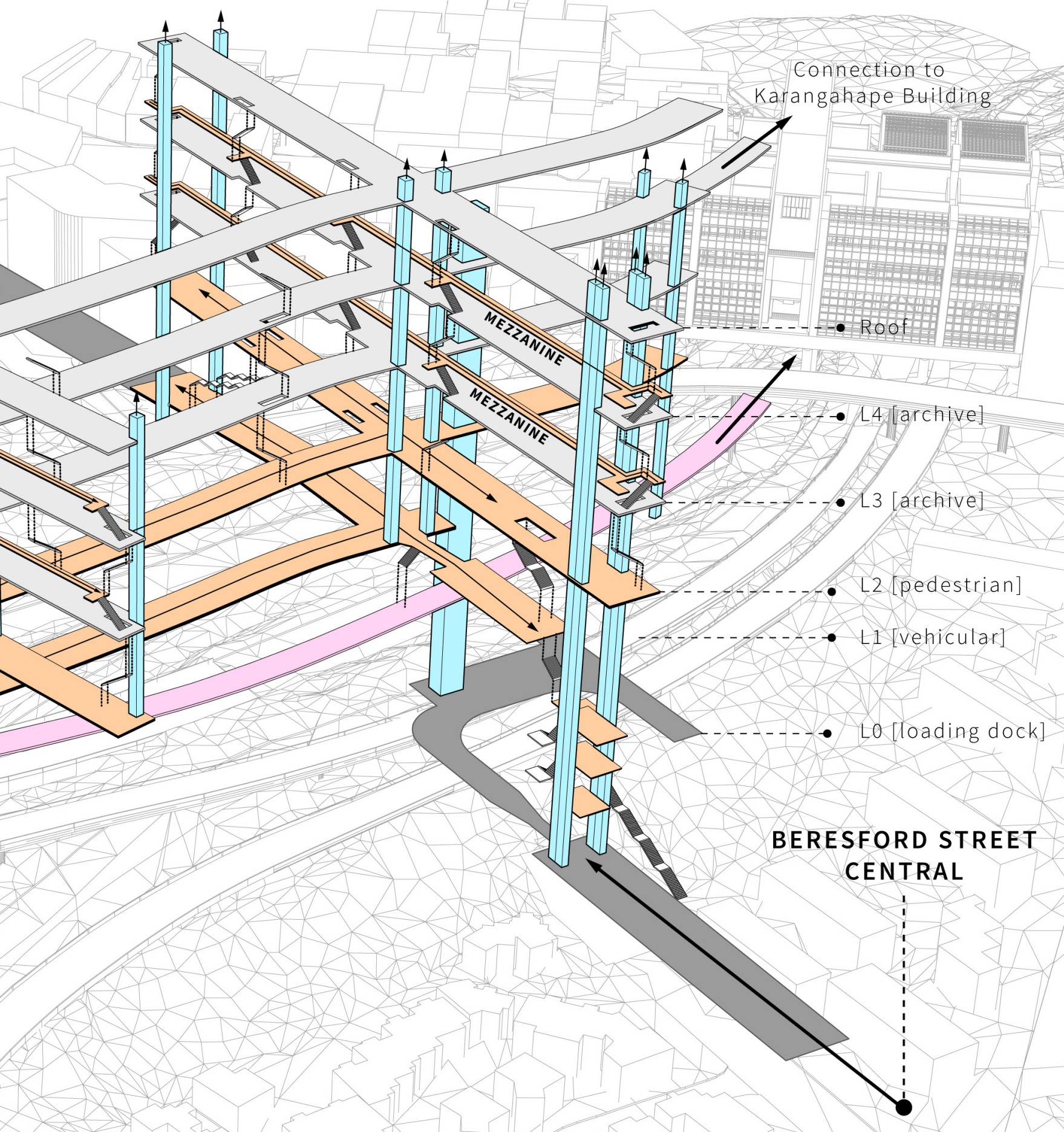

HAYDEN STREET

publicly acessible areas

elevator access

restricted access areas 



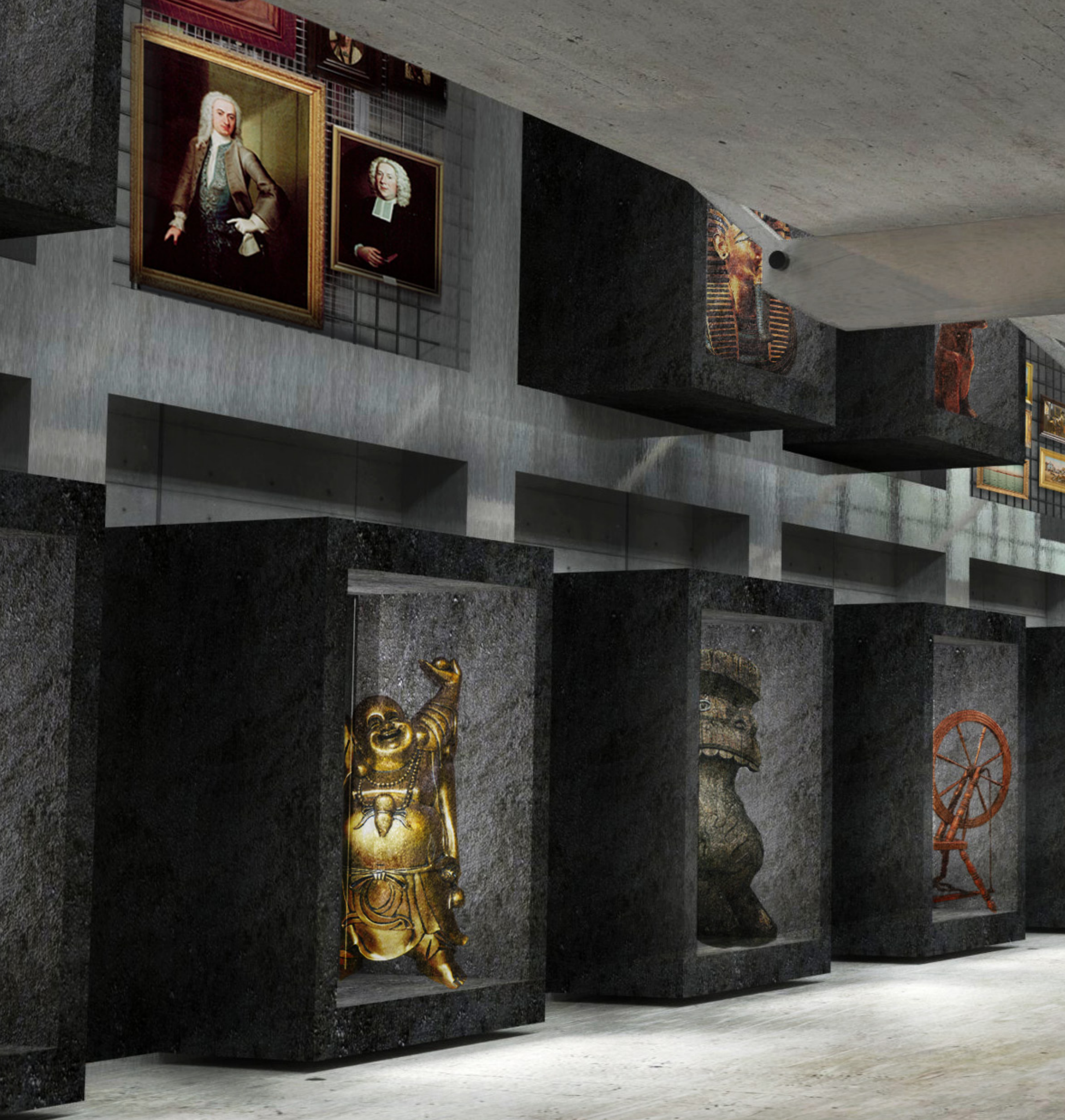

Figure 6.31: A view from the archive storage space on the staff level. The public mezzanine can be seen above. 


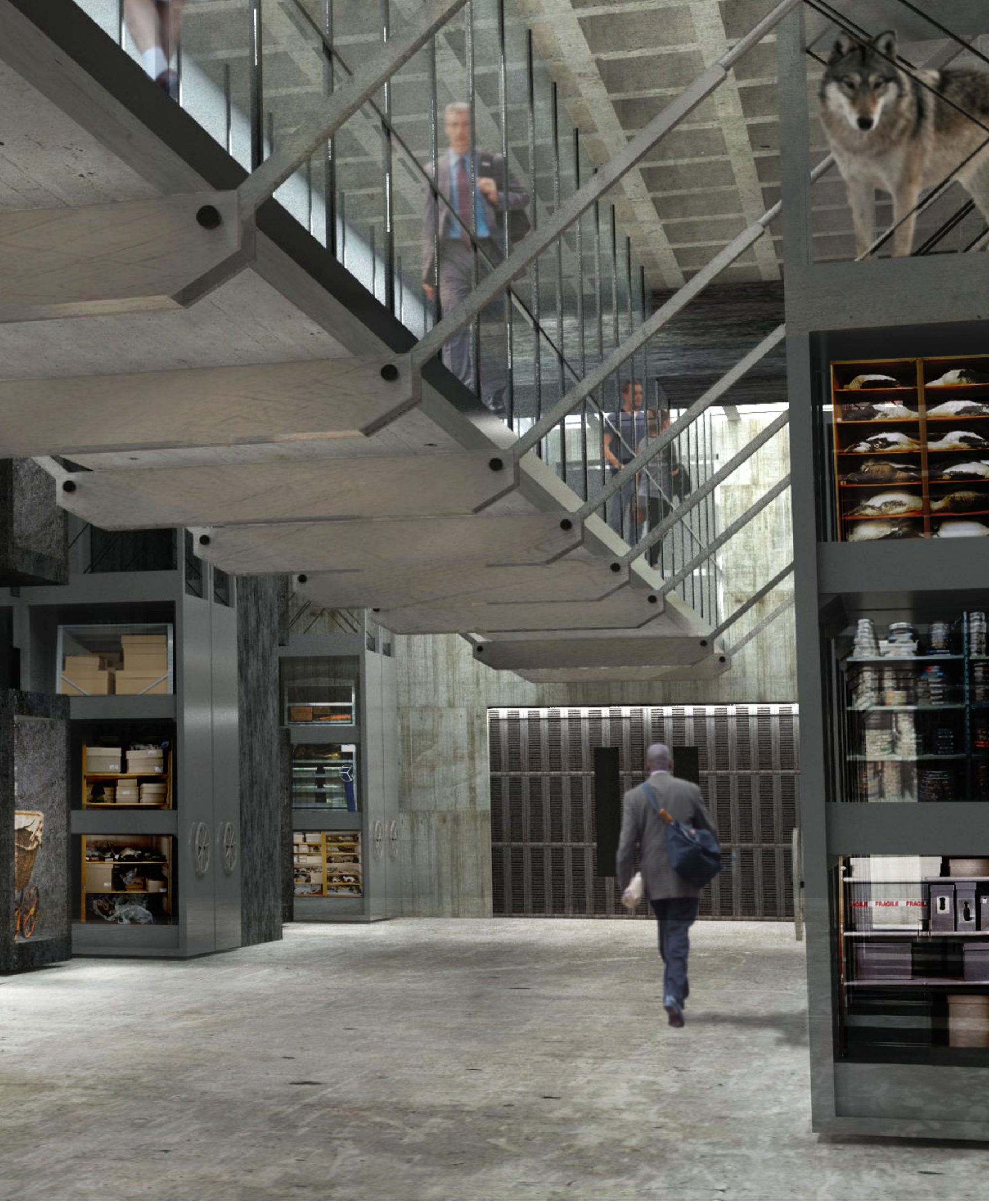






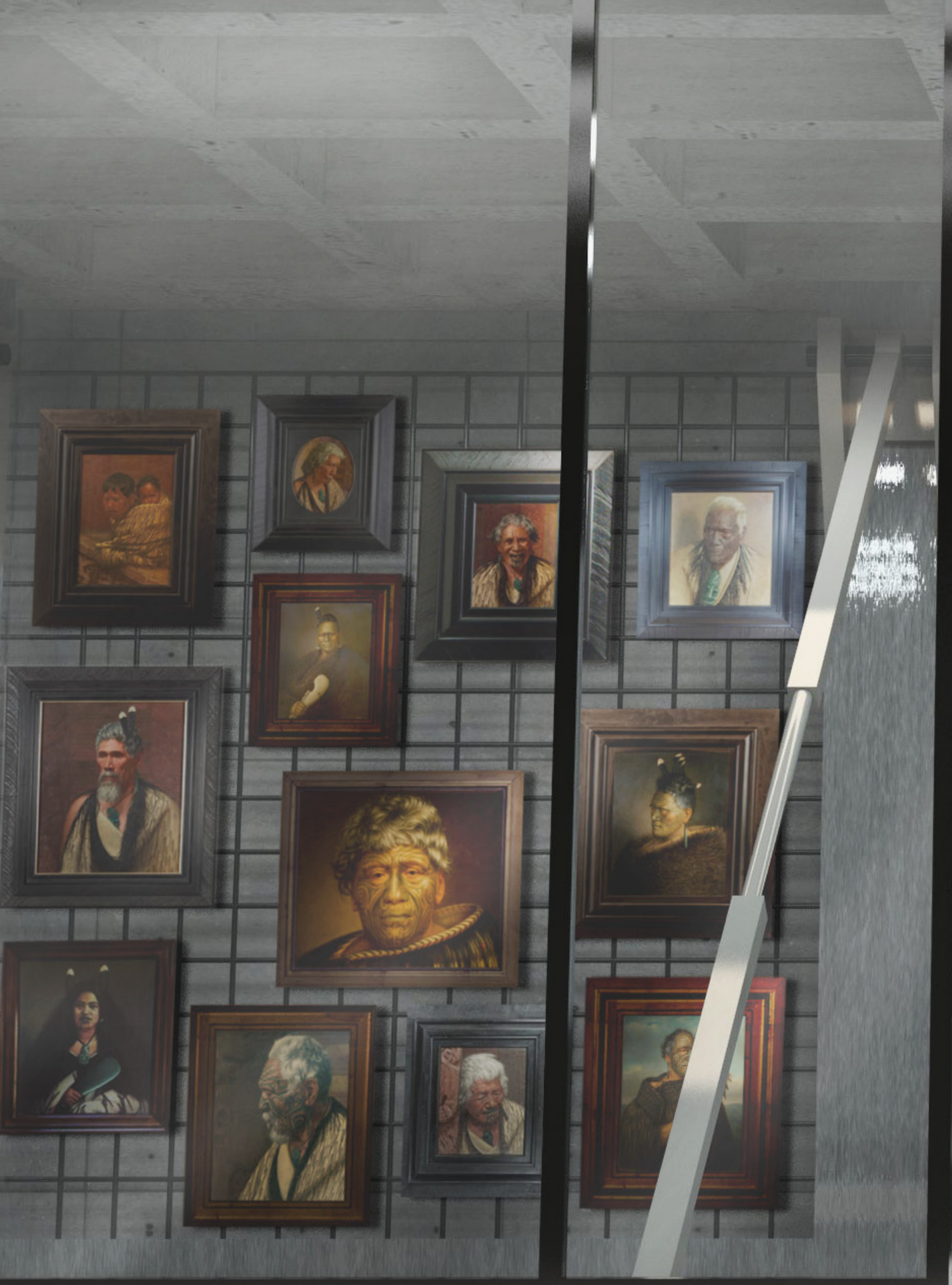
making themselves part of the national heritage display to the outside public. 


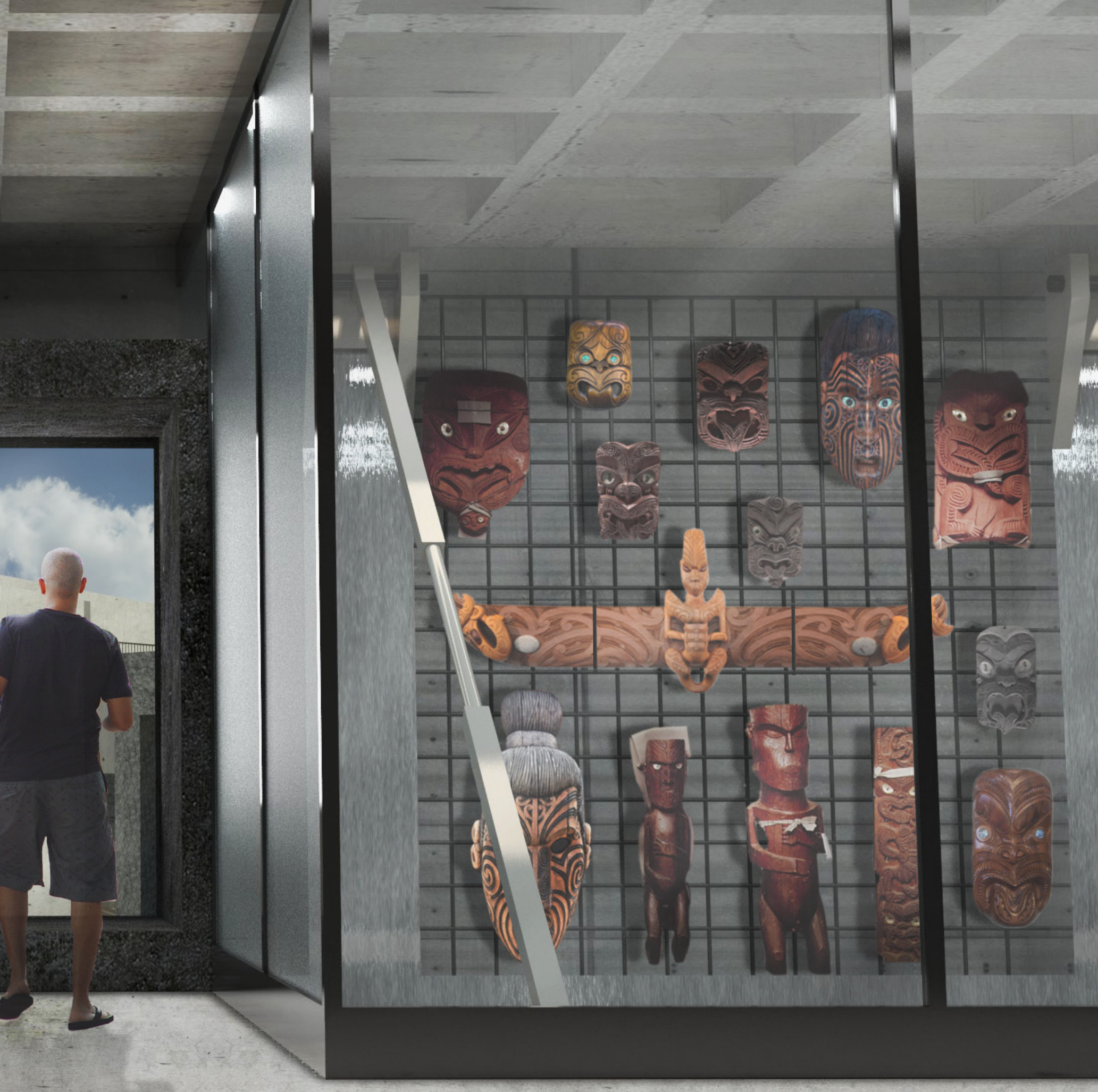




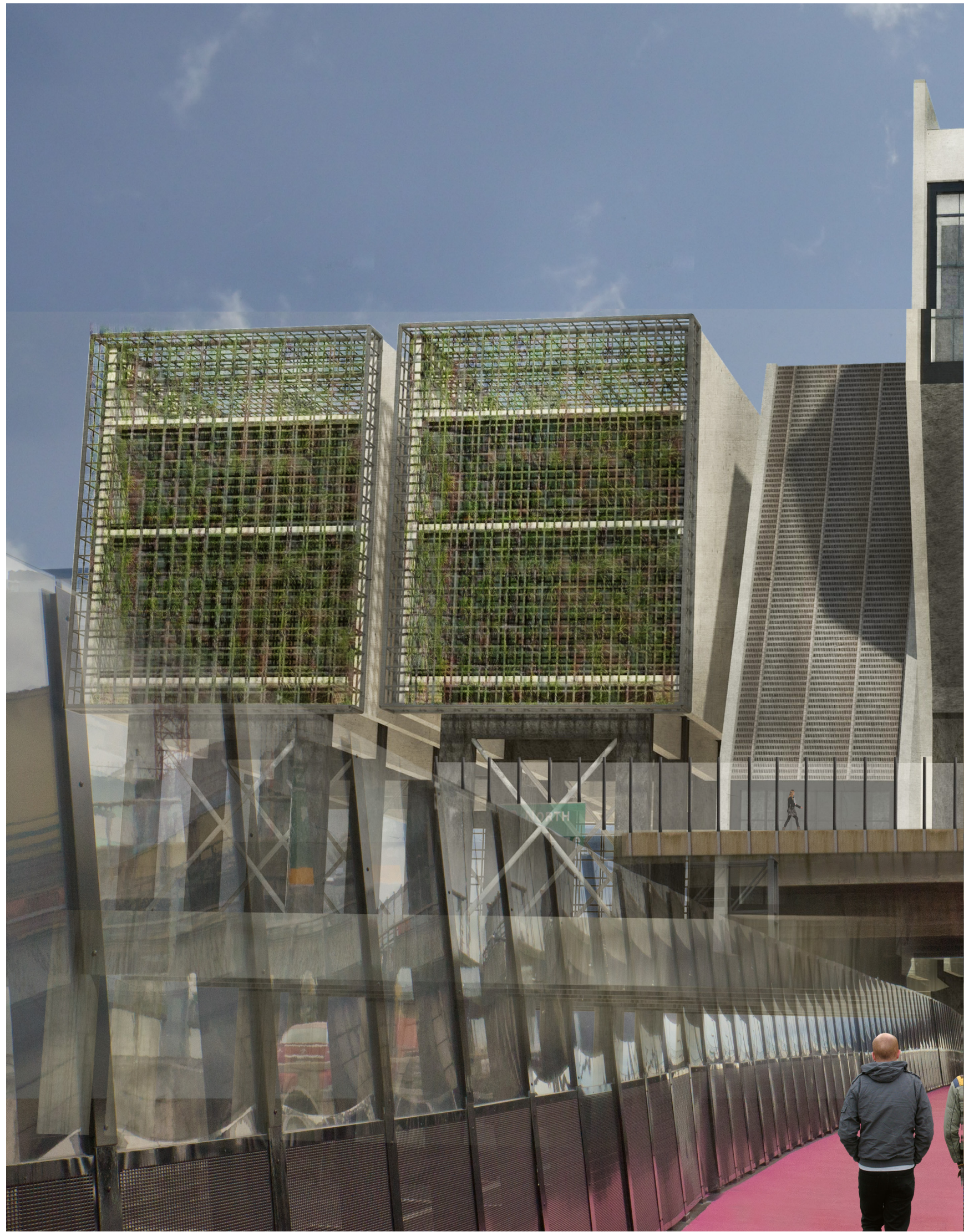

Figure 6.34: A view of the south side of the Karangahape building from the Nelson Street Cycleway. The Karangahape building holds the alcohol stored items that require specific environmental systems and extensive lab spaces. It will also have spaces where the smallest and most sensitive items from the collections can be viewed by the public in a gallery-like setting. 


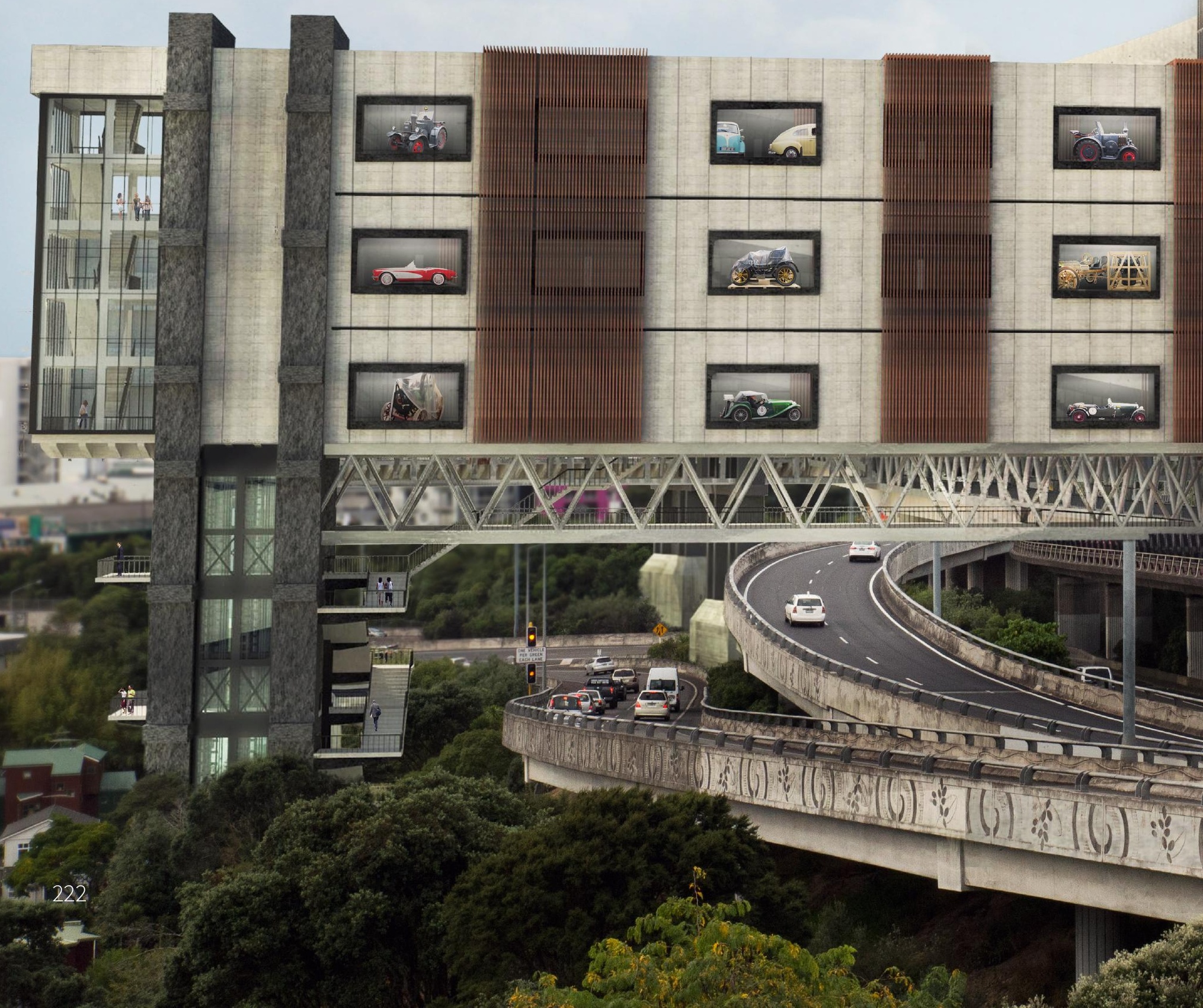




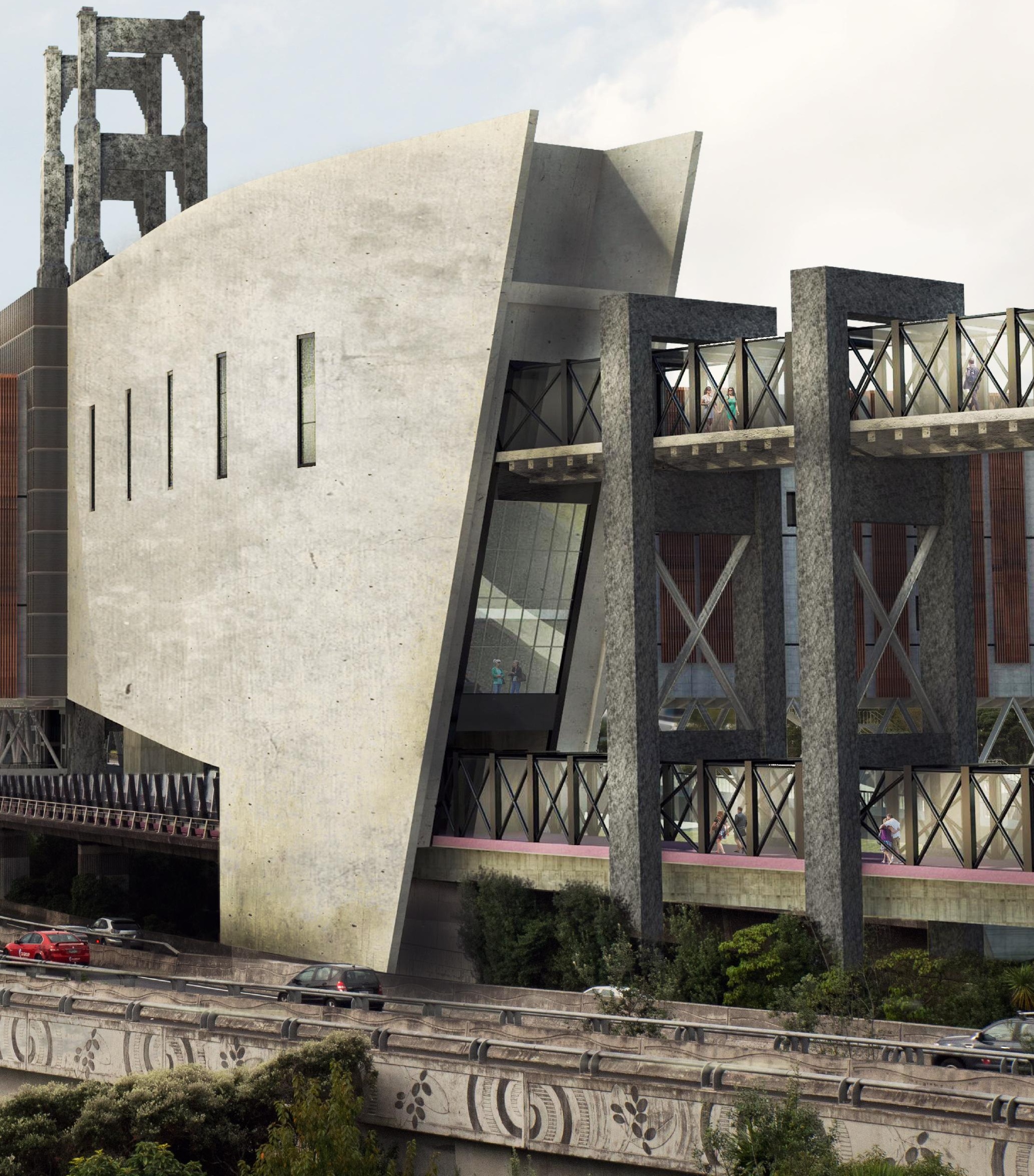




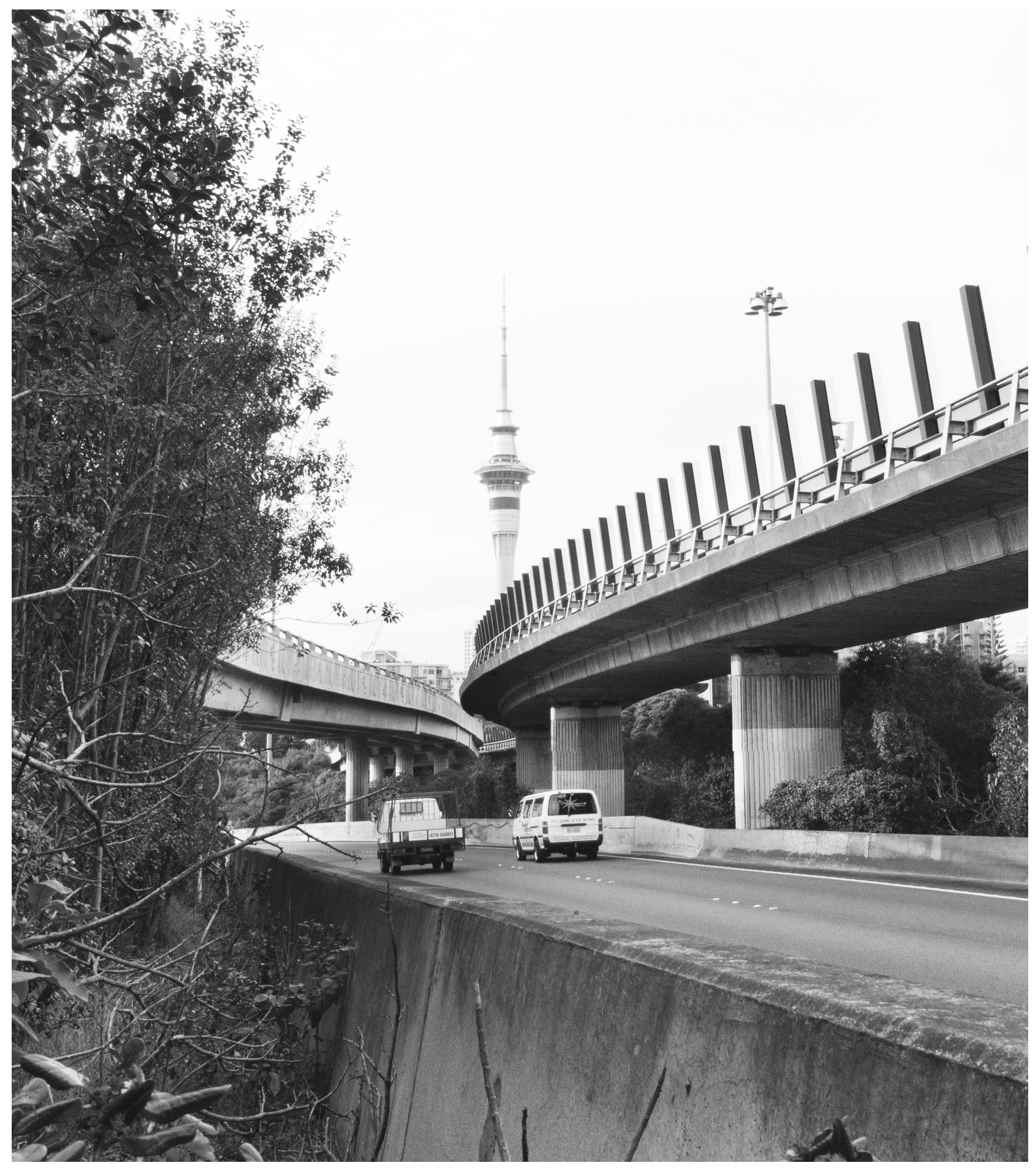

224 Figure 6.35 (previous spread): View driving south on the motorway or walking across the Hopetoun Bridge Figure 6.36 (above): Two vehicles passing through the CMJ (photo by author). 


\section{[ CRITICAL REFLECTION ] - Developed Design Solution}

\section{NOVEMBER DESIGN REVIEW ( 3 . 11 . 2016)}

Design and project critique based on feedback from Brian McGrath, Zelia Alves, and Jacqueline Mcintosh.

\section{- [STRENGTH ]}

The formal changes in the spine to reflect the fluid nature of the motorway were highly successful from Preliminary Design to Developed Design. The developed element fits more elegantly in its surrounding context and now embraces the typology of motorway heritage (RO3). This in combination with the wing elements provides much stronger historic links across the CMJ making the architecture almost a palimpsest of the site's history (RO6).

\section{- [ STRENGTH ]}

Positioning the seed archive to the northern-most wing has maximised the potential of the site environment. It allows for a softer transition from CBD to archive storage and creates a clear green link in the architecture that connects the existing city green spaces back together.

\section{- [ STRENGTH ]}

The development of the public mezzanine through the internal spaces of the archive was a move that really enforced the research objectives around 'hidden heritage' - bringing the private archive space into the public scope (RO4). This allowed opportunities for public education and awareness of these important heritage collections whilst still keeping the archives in a safe and controlled environment.

\section{- [DEVELOPMENT OPPORTUNITIES]}

Although the shift to the dynamic facade offers a greater opportunity in the design to curate the archive objects, it could be explored further if the scope of the project expanded and allowed more time. This idea for the facade has the greatest potential to properly curate the interior archives to the public, but has only had an opportunity to be investigated as broad concepts for opening apertures and sliding screens.

\section{- [DEVELOPMENT OPPORTUNITIES]}

The design successfully engages with two of the city's iconic landmarks and the suburbs to the west, framing a dynamic landscape that will change as the city grows (RO6). If the scope of the project were to expand, it could further explore how the heritage elements of the city to the east or the CBD skyline could be framed by the architecture.

\section{- [DEVELOPMENT OPPORTUNITIES]}

The topography of the site has meant that there are massive height changes between the urban side and the suburban side. Currently the intervention accentuates this height difference. Although this does lead to a degree of monumentality and sense of importance through the architectural scale, the building does not address the change from urban density to suburban density as well as it might. This could be achieved by looking at the underside of the motorway, if the scope of the project expanded. 


\section{[ CRITICAL REFLECTION ]}

\section{Lost Sites}

[RO1] to diversify the utilitarian nature of the elevated urban motorway by incorporating a suitable architectural programme capable of productivelyengaging with the monumentality of such a site.

The intervention has diversified the utilitarian motorway site by incorporating an architectural programme that displays the nation's 'hidden heritage' to the public. This architectural storage space is a particularly suitable programme for the harsh environmental conditions of the CMJ. The monumental scale of the motorway infrastructure has been embraced in the design with the elements of archive storage spread throughout the CMJ to create threshold spaces with which the vehicles on the motorway, pedestrians, and bicyclists around the site can engage. Pedestrian links and public space elements have been integrated into the design to increase the diversity of users in this 'lost space' and transform it into a productive inner city place.

[RO2] to reduce the 'urban barrier' characteristics of an inner city motorway by enhancing its permeability, incorporating green space, and establishing place identity; and to utilise these elements to shift the site from dystopian to heterotopian.

The urban barrier of the CMJ has been permeated by reestablishing historic links through the site as well as introducing new pedestrian links in a variety of places that bridge the current separation between CBD and suburbs. The seed archive and attached green spaces that surround these links enable the established green space / cultural belt of the city to continue from the CBD across the
CMJ and into Western Park and the western suburbs. Opportunities for developing place identity have been achieved in the design through its engagement with site heritage, city heritage, and enhanced public engagement with the didactic archive programme that promotes cultural awareness and a greater understanding of New Zealand's history and identity. This development of place and cultural identity, in combination with the time capsule of heritage that the architecture curates, imposed on this unusual and iconic urban motorway infrastructure enables the design to become an alternative and 'other space' in the city. The design outcome has resulted in a highly unusual architecture that provides not only its inhabitants, but also the people around it, and travelling past it, a completely new and unique perspective on the city, the motorway, and New Zealand's national heritage, shifting the site from the dystopian into the realm of heterotopia.

[RO3] to embrace and celebrate the 'motorway typology' by establishing an architectural intervention that embraces the iconic nature of the elevated motorway, rather than trying to hide it.

The form of the architecture itself reflects and celebrates the fluid nature and dimensional widths of motorway lanes and cross roads. The design also embraces the motorway as a viable urban experience, curating the collections to enable engagement with the motor vehicles passing by, and using the architecture to denote the CMJ as an iconic threshold space into and out of the Auckland $\mathrm{CBD}$. The design has been careful not to disrupt the existing format of the motorway system and has instead worked around, and through it to take it from the simply functional to the rich and experiential. 


\section{Hidden Heritage}

[RO4] to enhance engagement with stored national heritage artefacts by placing them into the public realm to encourage public engagement in diverse ways;

The design has two main features it utilises to enhance the engagement of the archives in the public realm. The first is the facade treatments which allow public interaction from all forms of transport that move through the site. Motor vehicles, bicyclists, and pedestrians are all provided visual connections to parts of the archives from the exterior environment. The placement of these items of national cultural significance into the heart of the public realm in the centre of the CBD means they are interacted with by an extensive portion of the population - some of whom would never visit an musuem or archive space otherwise. The second feature of the design allows an even more intensive engagement with the archive collections. The elevated mezzanines not only provide pedestrian linkages across the CMJ but also allow the public a close look inside these typically private back-of-house spaces so they can fully appreciate and understand the significance and the wealth of items in the Te Papa archives.

[RO5] to 'curate' stored national heritage artefacts in ways that maximise the didactic potential of the archive collection and increase cultural awareness about these items for the general public.

Curation of the archive objects is achieved in the design through a proposed new typology of cataloguing the items. This new format where items are stored based on their light sensitivity and scale allows them to be placed in the architecture where the public engagement would be the greatest and their didactic potential can be realised. The dynamic facade treatments in the design also allow a heightened level of curation of these items to the public. The architecture's ability to hide or display different items and different combinations of items to the exterior environment allows for curation of these often fragile items without having to physically shift them.

[RO6] to explore the 'non-archived' elements of the city and the site's 'hidden heritage', inviting these alternative elements of heritage to also actively contribute to cultural and place identity.

This research has argued that it is not only the Te Papa, Film, and Seed archive programmes that contribute to cultural heritage but that elements of the city and the urban environment play an equally large role. The architecture utilises curated view shafts that frame iconic elements of the city's heritage to create moments of pause and appreciation. The 'lost' heritage of the site is also embraced in the design through the reestablishment of historical links such as Beresford Street and Hayden Street across the CMJ and the inclusion of the seed bank and green spaces in the programme that pay homage to the original typology of the site as a green gully space. Making the inhabitants of the architecture aware of the historical heritage of the site as well as the city around them helps actively contribute to their sense of place and cultural identity. 


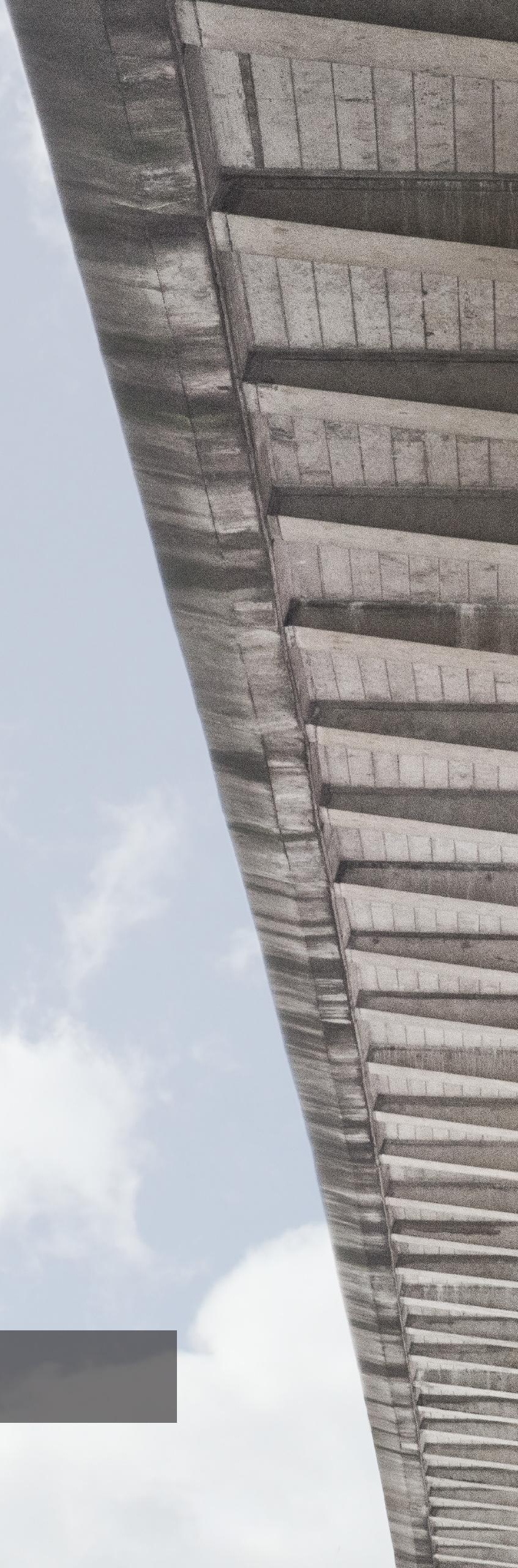




\section{7 | Conclusion}

\section{[ Critical Reflection ]}

This thesis investigation represents an important issue to resolve through design, as it has examined an urban condition common in almost every large city in the world how large amounts of 'lost' space caused by elevated urban motorway infrastructure can be embraced as positive contributors to their surrounding environments rather than as negative ones.

This research has shown that through an architectural intervention that aims to develop place and cultural identity, sites such as the Auckland Central Motorway Junction can become vital elements of a city's identity.

The Te Papa archive programme has had heavy influence on this research as a catalyst for creating cultural and place awareness, by tapping into its rich potential which iscurrently underutilised. The research has argued that programmes not requiring significant outdoor environmental interaction such as this - in combination with fully engaging with both historic and contemporary conditions of a site - provides an opportunity to make an inhospitable non-space into a place. This has application to many other so called 'lost sites'.

\section{[ Limitations of the Findings ]}

The archive storage space area requirement was made using plan drawings and visits by the author to both the Cable Street and Tory Street buildings where the Te Papa archives are currently stored. An absolute defining catalogue of all the items in the Te Papa collection along with their sizes, specific storage requirements, and light sensitivity was not available and is outside the scope of this project.

To further develop this new typology of storage more information would be necessary on the specific types and quantities of space required. It is acknowledged that the cost implications of constructing architecture within the constraints of a functioning elevated motorway would be significant. Determining these costs was also outside the scope of this project. 


\section{[ Conclusions Drawn ]}

A strong understanding of site is required - both in terms of its dynamic place in the landscape and its social and cultural history - for a 'lost' site to re-establish itself with some form of identity.

A robust programme capable of withstanding significant adverse environmental conditions is required to transform these nonspaces. These urban infrastructures are often vast and have harsh environmental conditions that limit the potentials of certain programmes. Establishing programmes that can appropriately and confidently fill these spaces is crucial.

All elements of the site should be embraced. Unusual sites provide unusual opportunities for architectural design (such as how a building is perceived at different velocities or when passing through it rather than around it), and the design can embrace these opportunities in new ways.

Every element of a site, even those traditionally perceived as negative, can provide significant new design opportunities. Every aspect in the history of a site has contributed to its story, and an architectural intervention has the capacity to bring that story to life.

\section{[ Going Forward ]}

Further research could explore such sites in relation to a speculative future, such as how the architecture would change if the motorway systems become obsolete, or in contrast, if more and more motorway infrastructure had to be developed.

Future research could also consider opportunities for embedding architectural foundations whenever developing new motorways, to facilitate architectural interventions that may be added later.

Further programmatic opportunity lies in exploration into the way the archive space could expand as more and more storage is required. Further study would look at how a framework would be set up in the building that would give the potential for growth on the site as the research potential derived from collecting and storing items never ceases. 


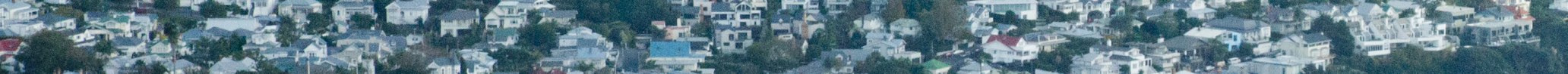

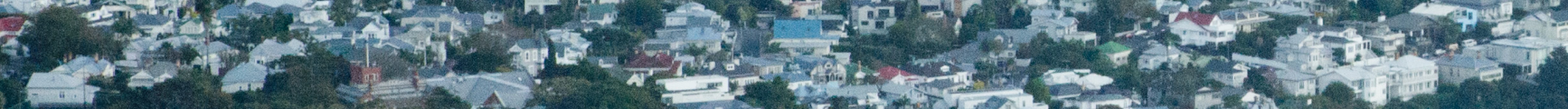

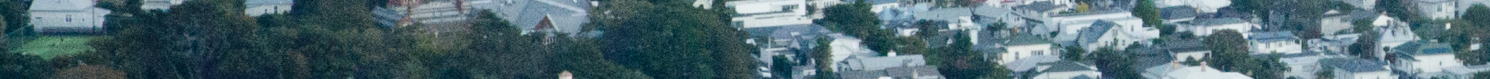

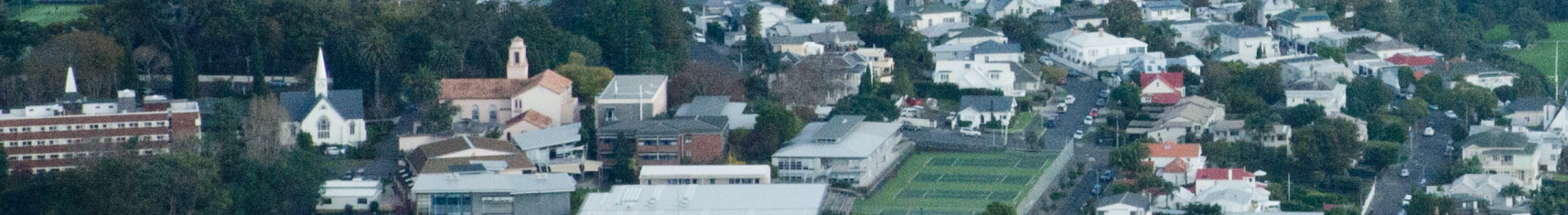

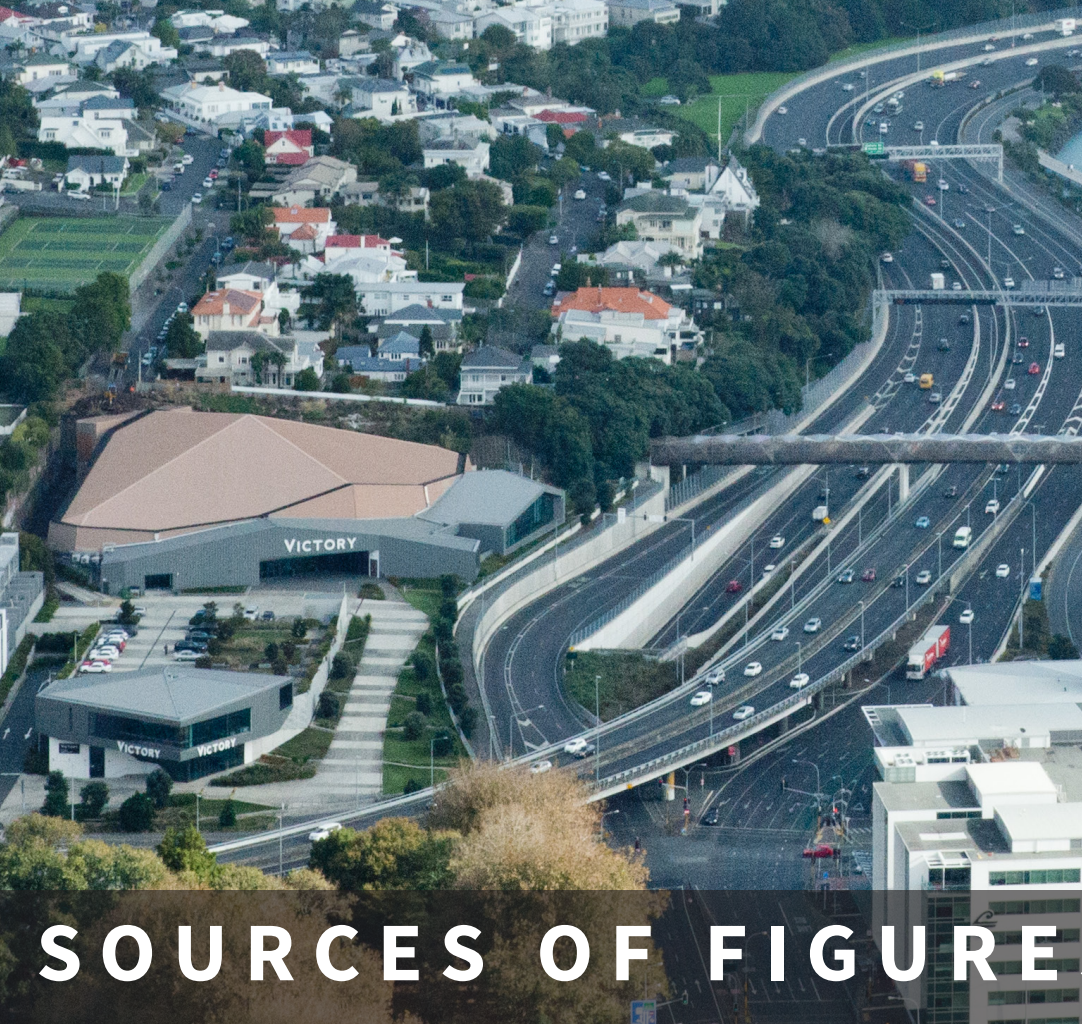

\section{BIBLIOGRAPHY + SOURCES OF FIGURE}

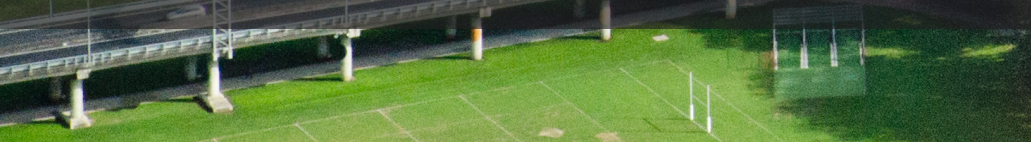

in: $\rightarrow=0$

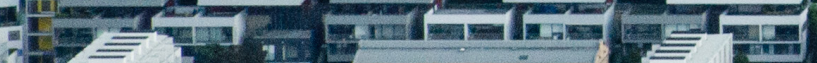

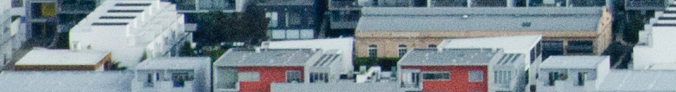

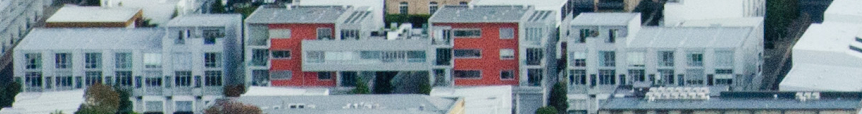
1. $4=2$ Tा $=1-3152$ 


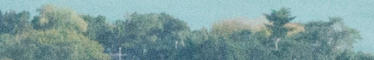

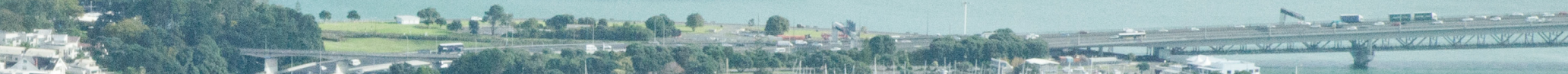

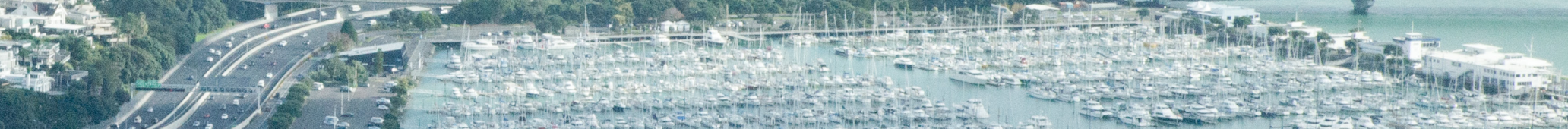
$-5$ 


\section{|| Bibliography}

Auckland and Council Regional. A Vision for Managing Growth in the Auckland Region : Auckland Regional Growth Strategy, 2050. Auckland: Auckland Regional Council, 1999. Print.

Auckland, et al. A Brief History of Auckland's Urban Form. Auckland, N.Z.: Auckland Regional Council, 2010. Print.

Augé, Marc. Non-Places : Introduction to an Anthropology of Supermodernity. London; New York: Verso, 1995. Print.

Ballard, J. G. Concrete Island. New York: Farrar Straus and Giroux, 1974. Print.

Blake, Peter. God's Own Junkyard; the Planned Deterioration of America's Landscape. New York: Holt, Rinehart and Winston, 1964. Print.

Borden, Iain, and Jane Rendell. Intersections : Architectural Histories and Critical Theories. London; New York: Routledge, 2000. Print.

Crisman, Phoebe. "Inhabiting the Edge: Architecture and Transport Infrastructure Intertwined." Peripheries : Edge Conditions in Architecture. Eds. Morrow, Ruth and M. Gamal Abdelmonem. London; New York: Routledge, 2013. 115-28. Print.

Cromarty, A. S., et al. Design of Seed Storage Facilities for Genetic Conservation. Rome: IBPGR, 1990. Print.

D'Hooghe, Alexander. "The Objectification of Infrastructure: The Cultural Project of Suburban Infrastructure Design." Infrastructure as Architecture : Designing Composite Networks. Eds. Stoll, Katrina, Scott Lloyd and Stan Allen. Berlin: Jovis, 2010. 78-87. Print.

Dehaene, Michiel, and Lieven de Cauter. Heterotopia and the City : Public Space in a Postcivil Society. London; New York: Routledge, 2008. Print.

Dominion Post, The. "The Art Treasures Hidden in Te Papa's Attic." Dominion Post (2010). Web. 28 November 2016.

Dooney, Laura. "Curiouscity: A Glimpse at What's Stored by Te Papa." Dominion Post (2016). Web. 28 August 2016. 
E.A.S.T, Bureau, Takako Tajima, and Aziza Chaouni. "Cultured Infrastructures." Infrastructure as Architecture : Designing Composite Networks. Eds. Stoll, Katrina, Scott Lloyd and Stan Allen. Berlin: Jovis, 2010. 78-87. Print.

Elkins, James. The Object Stares Back: On the Nature of Seeing. San Diego; London: Harcourt Brace, 1997. Print.

Fitzwater-Hyde, Chirstina., and Kimberley McCombie. "Te Papa Entry Fee Won't Deter Overseas Tourists.” (2012). Web. 15 June 2016.

Foucault, Michel, and Jay Miskowiec. "Of Other Spaces." Diacritics 16.1 (1986): 22-27. Print.

Frances, Helen. "Pukeahu National War Memorial Park." Architecture Now. AGM Publishing 2015. Web. 16 November 2016.

Franch, Marti. "Peculiar Ecosystems." NZIA City Talks: Marti Franch with Martin Bryant and Penny Allan. City Gallery Wellington, Civic Square, Wellington 2015. Lecture.

Francis, Clio. "Overflowing Te Papa Looks for Display Space " Dominion Post (2012). Web. 28 August 2016.

Friedman, Avi. A Place in Mind: The Search for Authenticity. Montreal: Véhicule Press, 2010. Print.

Gallardo-Torrano, Pere. "From Mindscapes to Landscapes: J.G. Ballard's SelfSought Utopia in Concrete Island." Spaces of Utopia: An Electronic Journal 2. Summer 2006 (2006): 15-27. Print.

Gastil, Ray. "Prospect Parks: Walking the Promenade Planteé and the High Line." Studies in the History of Gardens \& Designed Landscapes 33 (2013): 28089. Print.

Gehl, Jan. Cities for People. Washington (DC); Covelo; London: Island Press, 2010. Print.

Ghamkar, Dr. Kioumars. “Margot Forde Germplasm Centre.” 2016. Web. 14 March 2016. 
Hall, Ken. "From Hidden Places." The Vault. Christchurch, N.Z.: Christchurch Art Gallery in partnership with Eyework Art Production., 2009. Print.

Harnack, Maren, and Martin Kohler. "As Found. Use, Meaning and ReAppropriation of Contentious Urban Spaces." Infrastructural Urbanism : Addressing the in-Between. Eds. Hauck, Thomas, Regine Keller and Volker Kleinekort. Berlin: DOM Publishers, 2011. 131-44. Print.

Hauck, Thomas, and Regine Keller. "Extending the Public Realm." Infrastructural Urbanism : Addressing the in-Between. Eds. Hauck, Thomas, Regine Keller and Volker Kleinekort. Berlin: DOM Publishers, 2011. 303-16. Print.

Hauck, Thomas, and Volker Kleinekort. "Infrastructural Urbanism." Infrastructural Urbanism : Addressing the in-Between. Eds. Hauck, Thomas, Regine Keller and Volker Kleinekort. Berlin: DOM Publishers, 2011. 9-18. Print.

Heritage, European Route of International. "North Duisburg Landscape Park." 2016. Web. 8/6/2016 2016.

Hodgson, Terence E. R. The Heart of Colonial Auckland, 1865-1910. Auckland, N.Z.: Random Century, 1992. Print.

Hornstein, Shelley. Losing Site : Architecture, Memory and Place. Farnham: Ashgate, 2013. Print.

Ingels, Bjarke. A Moment in Vancouver's Skyline. Westbank Projects Corporation 2014.

---. Structural Design - Walking the Column. Westbank Projects Corporation 2014.

Ingersoll, Richard. Sprawltown : Looking for the City on Its Edges. New York: Princeton Architectural Press, 2006. Print.

Kameswara Rao, N. Manual of Seed Handling in Genebanks. Rome: Bioversity International, 2006. Print. 
Knightbridge, Phil. Proposal for a Seed Bank for New Zealand's Threatened Seed Plants: New Zealand Plant Conservation Network, 2006. Print.

Linington, Simon, Keith Manger, and Partnership Millennium Seed Bank. Seed Bank Design : Cold Rooms for Seed Storage. 2014. Print.

---. Seed Bank Design : Seed Drying Rooms. 2014. Print.

Lopate, Phillip. “Above Grade: On the High Line.” Places Journal (2011). Web. $8 / 6 / 2016$.

Lynch, Kevin. The Image of the City. Cambridge, Mass.: MIT Press, 1960. Print.

Macdonald, Nikki. "Te Papa's Planned Auckland Offshoot Is Put on Ice " Dominion Post (2015). Web. 28 August 2016.

---. "Te Papa Taonga on the Move North" Dominion Post (2014). Web. 28 August 2016.

Maidment, Simon. "When the Journey Becomes the Destination: Freeway Art in Melbourne." Public Art Review 21.42 Spring/Summer 2010 (2010): 2427. Print.

Manaugh, Geoff. “Concrete Island.” BLDGBLOG 2006. Web. 28 August 2016.

Mead, Walter Russell. "Trains, Planes, and Automobiles: The End of the Postmodern Moment." World policy journal. 12.4 (1995): 13. Print.

Meyboom, Annalisa. "Infrastructure asPractice." JOAE Journal of Architectural Education 62.4 (2009): 72-81. Print.

Nijhuis, Steffen, Daniel Jauslin, and Frank van der Hoeven. Flowscapes : Designing Infrastructure as Landscape. 2015. Print.

NZ, Stuff. “Auckland's Te Papa Plans” Dominion Post (2013). Web. 28 August 2016.

Ostwald, Michael J., Chris Tucker, and Michael Chapman. Residue : Architecture as a Condition of Loss. Melbourne, Victoria: RMIT University Press, 2007. Print. 
Pardington, Neil. The Vault. Christchurch, N.Z.: Christchurch Art Gallery in partnership with Eyework Art Production., 2009. Print.

Paul, Rahul. "From Object Line to Vector Field - the Social Instrument." Infrastructural Urbanism : Addressing the in-Between. Eds. Hauck, Thomas, Regine Keller and Volker Kleinekort. Berlin: DOM Publishers, 2011. 49-62. Print.

Potteiger, Matthew, and Jamie Purinton. Landscape Narratives : Design Practices for Telling Stories. New York: J. Wiley, 1998. Print.

Robertson, Susan. "Urban Mobilities of the Westway in London." Infrastructural Urbanism : Addressing the in-Between. Eds. Hauck, Thomas, Regine Keller and Volker Kleinekort. Berlin: DOM Publishers, 2011. 109-16. Print.

Schalk, Meike, and Apolonija Sustersic. "Taking Care of Public Space." Architectural Research Quarterly 13.2 (2009): 141-50. Print.

Schoen, Daniel J., and Anthony H. D. Brown. "The Conservation of Wild Plant Species in Seed Banks." BioScience 51.11 (2001): 960-66. Print.

Shopes, Linda. "Popular Consciousness of Local History: The Evidence of Oral History Interviews." International Oral History Conference. 1994. Print.

Stone, R. C. J. Logan Campbell's Auckland: Tales from the Early Years. Auckland, N.Z.: Auckland University Press, 2007. Print.

Trancik, Roger. Finding Lost Space : Theories of Urban Design. New York: Van Nostrand Reinhold, 1986. Print.

Wesselman, Daan. "The High Line, "the Balloon," and Heterotopia." Space and Culture 16 (2013): 16-27. Print.

White, Anna-Marie. "Whose Logic? Different Cultural Perspectives at Work in the Vault." The Vault. Christchurch, N.Z.: Christchurch Art Gallery in partnership with Eyework Art Production., 2009. Print.

Zapatka, Christian, and Mary Miss. Mary Miss : Making Place. New York, NY: Whitney Library of Design, 1997. Print. 


\section{|| Sources of Figures}

NOTE: All figures and photos, unless stated here, are by the author.

Figure 0.1: http://67.media.tumblr.com/tumblr_me1kzmvviv1qke84501_1280.jpg

Figure 1.2: http://arastiralim.net/com/wp-content/uploads/2013/03/American-Freeway.jpg

Figure 2.2: http://images.adsttc.com/media/images/5779/d02b/e58e/ce2f/8800/022b/large_jpg/LightPathAKL___5_ of_6.jpg?1467600925

Figure 2.3: Aerial image sourced from: https://data.linz.govt.nz/layers/category/aerial-photos/

Figures 2.9 2.10: http://www.aucklandcity.govt.nz/dbtw-wpd/exec/dbtwpub.dll?AC=PREV_RECORD\&XC=/dbtw-wpd/ exec/dbtwpub.dll\&BU=http\%3A\%2F\%2Fwww.aucklandcity.govt.nz\%2Fdbtw-wpd\%2FCityArchives $\% 2$ F1908Map\%2Fsearch1908map.htm\&TN=1908Map\&SN=AUTO3867\&SE=1879\&RN=1\&MR=20\&TR=0 $\& T X=1000 \& E S=0 \& C S=1 \& X P=\& R F=M a p+$ Results \&EF=\&DF=Map + Description $\& R L=0 \& E L=0 \& D L=0 \& N P$ $=2 \&|D=\& M F=W P E n g M s g . i n i \& M=\& T I=0 \& D T=\& S T=0 \&| R=0 \& N R=0 \& N B=0 \& S V=0 \& S S=0 \& B G=\& F G=\& Q S=\& O$ EX=ISO-8859-1\&OEH=ISO-8859-1

Figure 2.11: Aerial image sourced from: https://data.linz.govt.nz/layers/category/aerial-photos/ Figure 2.12: Aerial image sourced from: https://data.linz.govt.nz/layers/category/aerial-photos/ Figure 2.19: Aerial image sourced from: https://data.linz.govt.nz/layers/category/aerial-photos/ Figure 2.20: Aerial image sourced from: https:/data.linz.govt.nz/layers/category/aerial-photos/ Figure 2.23: Aerial image sourced from: https://data.linz.govt.nz/layers/category/aerial-photos/

Figure 2.24: http://images.adsttc.com/media/images/55af/ffb9/e58e/ce6c/0700/0172/large_jpg/F__Sean_Munson. jpg?1437597610

Figure 2.25: https://s-media-cache-ak0.pinimg.com/originals/8e/2c/5e/8e2c5e7050497e6d0cd38105fa4df878.jpg Figure 2.26: http://www.sanahujapartners.com/sites/default/files/styles/blog_big/public/bspmal7.jpg?itok=xrhjiekj

Figure 2.31: Background image sourced from: http://transportblog.co.nz/wp-content/uploads/2015/12/LightPathVaughn-Davis.jpg

Figure 2.36: Aerial image sourced from: https://data.linz.govt.nz/layers/category/aerial-photos/

Figure 3.5: Background Aerial Image sourced from: https://data.linz.govt.nz/layers/category/aerial-photos/

Figure 3.6: http://www.neilpardington.com/work/_details/id_223/art_store_6.html

Figure 3.7: http://www.neilpardington.com/work/_details/id_40/taonga_maori_store_2.html

Figure 3.8: http://www.neilpardington.com/work/_details/id_35/pacific_store_2_samoan_clubs.html

Figure 3.9: http://www.neilpardington.com/work/_details/id_34/pacific_store_1_samoan_clubs.html

Figure 3.10a: Aerial photographs of building sourced from: https://data.linz.govt.nz/layers/category/aerial-photos/

Figure 3.12: Truck turning circle sourced from: http://www.nzta.govt.nz/assets/resources/road-traffic-standards/ img/2007-sh-09-large-truck-25m-radius.jpg

Figure 3.13: All images sourced from: http://collections.tepapa.govt.nz/Topic

Figure 3.14: All images sourced from: http://collections.tepapa.govt.nz/Topic

Figure 3.15: All images sourced from: http://collections.tepapa.govt.nz/object

Figure 3.16: Alcohol jar store images sourced from: http://www.neilpardington.com/work/_details/id_196/wet_room_1.html http://www.neilpardington.com/work/_details/id_278/asteroidea__patangaroa_otago_museum_dunedin_ new_zealand_1_2014.html http://www.paemanu.org.nz/resources/publications/neil-pardington 
Figure 3.17: Top images sourced from:

https://s-media-cache-ak0.pinimg.com/originals/b8/e4/76/b8e4765cd640c0b67b5da4b3b8f5ede6.jpg

http://channel.tepapa.govt.nz/wp-content/uploads/2014/06/MA_I006711.6049x2016-400x133.jpg

http://booknotes-unbound.org.nz/wp-content/uploads/2014/03/Phar-Lap-web.jpg

http://immediateentourage.com/ie/wp-content/uploads/OceanBird-375x375.png

https://immediateentourage.com/gull/

https://cdn.avopix.com/photos/detail/d_31039_penguin-five.png

http://collections.tepapa.govt.nz/object/207370

https://immediateentourage.com/couple-of-ducks/

https://immediateentourage.com/ocean-bird/

Figure 3.18: All images sourced from: http://collections.tepapa.govt.nz/object

Figure 3.19: All images sourced from: http://collections.tepapa.govt.nz/object

Figure 3.27: Images sourced from:

http://www.freepngimg.com/

http://collections.tepapa.govt.nz/Topic

http://collections.tepapa.govt.nz/object

Figures 3.28 - 3.30: http://www.archdaily.com/789207/yingliang-stone-archive-atelier-alter

Figure 3.31: https://c.o0bg.com/rf/image_960w/Boston/2011-2020/2014/10/29/BostonGlobe.com/Arts/Images/arts front2.jpg

Figure 3.32: https://static1.squarespace.com/static/557ad483e4b05d594de0640a/t/5624bf4de4b006ea8cf50acd/144524 $8855891 /$ ?format $=750 \mathrm{~W}$

Figure 3.33: http://www.wessexpictures.com/hres/c2ag_550x324_3_TruVue\%200ptium.jpg

Figure 3.34: London : The Society of British Theatre Designers, 2002. p. 74

Figure 3.35: Background aerial image sourced from: https://data.linz.govt.nz/layers/category/aerial-photos/

Figure 3.37: Background aerial image sourced from: https://data.linz.govt.nz/layers/category/aerial-photos/

Figure 3.38: http://www.abc.net.au/news/2016-03-28/seedbank-the-living-library-releasing-plants-in-emergen cies/7263122

Figure 3.39: Components of image sourced from: https://bostonnewsgroupblog.files.wordpress.com/2013/12/20131220080225.jpg

Figure 3.40: http://images.adsttc.com/media/images/53aa/2ceb/c07a/8033/bd00/005d/large_jpg/S1012007_N151_me dium.jpg?1403661530

Figure 3.41: https://www.stantonwilliams.com/assets/lib/2015/08/18/img0b\%2047.jpg

Figure 3.43: https://www.stantonwilliams.com/assets/lib/2015/10/18/img3\%2038.jpg

Figure 3.44: https://media.npr.org/assets/img/2015/09/24/ap_080226076821_custom-bd1d2550957b7c69807d6a746db 1fc811037d549.jpg

Figure 3.45: https://images.ehive.com/accounts/3292/profiles/images/1c3co97_8q8a_l.jpg

Figure 4.5: http://www.discoverynetworks.nl/wp-content/themes/DNB/img/pers_dnb.jpg

Figure 4.6: http://tervlap.hu/uploads/large/2501_12637.jpg

Figure 4.7: http://www.jeroenfortgens.nl/cms/wp-content/uploads/2015/03/amsterd.jpg

Figure 4.8: http://4.bp.blogspot.com/-1c3Fzwp8Ur8/UgOfastEfHI/AAAAAAAAAUk/oCoJd8WrUTw/s1600/duisburg+old.jpg

Figure 4.9: http://storage.edmontonsun.com/v1/dynamic_resize/sws_path/suns-prod-images/1297439650099_ORIGI NAL.jpg?quality $=80 \&$ size $=650 \mathrm{x}$

Figure 4.10: http://www.arcmep.com/r/data/attachment/forum/201504/19/181433a100eloeu0s0x51z.png

Figure 4.11: http://assets.latzundpartner.de/media/cache/16/f5/16f592f4daf3edadf2fd92bc38868023.jpg

Figure 4.12: http://www.landezine.com/wp-content/uploads/2011/08/29-Ore-Bunker-Gallery-M\%C3\%B6llerbunker.jpg 
Figure 4.13: https://s-media-cache-ak0.pinimg.com/originals/e2/cf/f3/e2cff30fde8622a1ce5e42d6482ab21c.jpg

Figure 4.15: http://www.vancitybuzz.com/wp-content/uploads/2013/02/BIG-Tower-Vancouver.png

Figure 4.16: Images sourced from:

http://adbr001cdn.archdaily.net/wp-content/uploads/2012/04/1335541169_beach_and_howe_mixed_use_ tower_big_1334376190_van_image_by_big_02.jpg

http://2.bp.blogspot.com/-oXSXie-PaBY/T4wKOdeGTnI/AAAAAAAAH_o/h1laQeO4EL8/s1600/BIG-Vancouver6.

jpg

http://d2ciprw05cjhos.cloudfront.net/files/v3/styles/gs_large/public/2013/10/granvilletower3_131025.

jpg?itok=lYcxJKbu

Figure 4.17: http://www.architravel.com/pointofview/pointofview_wp/wp-content/uploads/2013/01/ph_1358379870.

jpg

Figure 4.18: http://1.bp.blogspot.com/-FpGUUexa_o/USfSMwwCmQI/AAAAAAAAARs/YbzMCoPqGs0/s640/Bjark5.png

Figure 4.19: http://images3.arq.com.mx/noticias/articulos/7/med-20817-07.jpg

Figure 4.20: http://c1038.r38.cf3.rackcdn.com/group4/building38963/media/mzha_08emflandscapearchitecturebestia ri3.jpg

Figure 4.21: http://images3.arq.com.mx/noticias/articulos/med-20816-05.jpg

Figure 4.22: https://static1.squarespace.com/static/54c3828be4b0e37688141099/t/55773156e4b0165265b ce137/1433874775681/THE+HIGHLINE+NEW+YORK

Figure 4.23: http://nyrealestatebuzz.com/wp-content/uploads/2015/09/High-Line-Featured-Photo.jpg

Figure 5.2: Background image sourced from: http://transportblog.co.nz/wp-content/uploads/2015/12/LightPathVaughn-Davis.jpg

Figure 5.3: Background aerial image sourced from: https://data.linz.govt.nz/layers/category/aerial-photos/

Figure 5.12: Background aerial image sourced from: https://data.linz.govt.nz/layers/category/aerial-photos/

Figure 5.13: http://archidose.blogspot.co.nz/2004_03_01_archidose_archive.html

Figure 5.21: Background image sourced from: https://www.google.co.nz/maps/search/googleima/@$36.8540077,174.7607085,527 a, 20 y, 237.37 \mathrm{~h}, 39.57 \mathrm{t} / \mathrm{data}=! 3 \mathrm{~m} 1 ! 1 \mathrm{e} 3$

Figure 5.31: Background aerial image sourced from: https://data.linz.govt.nz/layers/category/aerial-photos/

Figure 5.46: Background aerial image sourced from: https://data.linz.govt.nz/layers/category/aerial-photos/

Figure 6.2: Background image sourced from: http://transportblog.co.nz/wp-content/uploads/2015/12/LightPath-V aughn-Davis.jpg

Figure 6.3: Background aerial image sourced from: https://data.linz.govt.nz/layers/category/aerial-photos/

Figure 6.4: Background aerial image sourced from: https://data.linz.govt.nz/layers/category/aerial-photos/

Figure 6.12: Images sourced from:

http://www.deborahlozier.com/uploads/1/3/9/0/13901361/4960420_orig.jpg

https://s-media-cache-ak0.pinimg.com/736x/95/a3/65/95a365ae78dfd236f938391e0af13df3.jpg

http://gonyctourism.com/wp-content/uploads/nyc-metropolitan-museum-exhibit.jpg

http://www.spacesaver.com/wp-content/uploads/2015/11/compact-art-rack-storage.jpg

https://suitcasemag.com/wp-content/uploads/2016/01/picture-room-recess-displaying-nymph-credit-

derry-moore.jpg

http://dienerdiener.ch/media/PUB_727-3_HUB/Diener_0727-3-HUB_New-East-Wing-Expansion-Museum-ofNatural-History_Berlin_P5919-0658.jpg

https://s-media-cache-ak0.pinimg.com/564x/e1/b0/68/e1b06867a40907e52e69fdc200561355.jpg 
Figure 6.15: Images sourced from:

http://design.rootiers.it/lab1/sites/default/files/4126/12746042_10208836724986391_128514662_n.jpg https://s-media-cache-ak0.pinimg.com/736x/d9/7a/e7/d97ae716373b845a5b0d15649662366f.jpg https://b0.burst.zone/wp-content/uploads/2013/12/urban-lines-3.jpg

Figure 6.19: Images sourced from:

https://s-media-cache-ak0.pinimg.com/originals/9d/fe/8c/9dfe8c2c4a5a3713a03586b22606c8ea.jpg https://s-media-cache-ak0.pinimg.com/originals/5d/85/2f/5d852f317cab4c1751e6e3df11451ebd.jpg

Figure 6.24: Background aerial image sourced from: https://data.linz.govt.nz/layers/category/aerial-photos/ 
